\title{
Treatment of Passive Component Reliability in Risk-Informed Safety Margin Characterization
}

FY 2010 Report

Karl N. Fleming

Stephen D. Unwin

Dana Kelly

Peter P. Lowry

Mychailo B. Toloczko

Robert F. Layton

Robert Youngblood

David. Collins

Aparna V. Huzurbazar

Brian Williams

Patrick G. Heasler

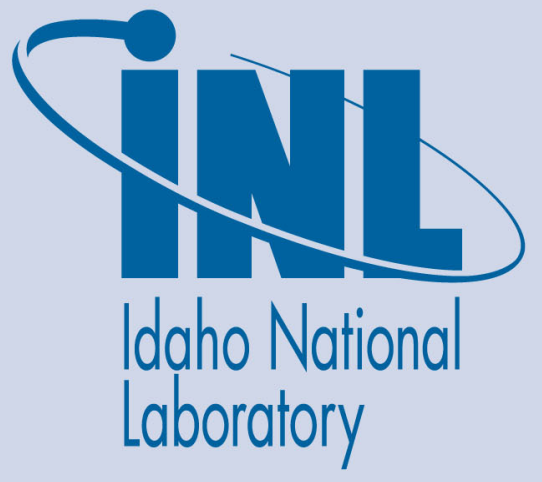

September 2010

The INL is a U.S. Department of Energy National Laboratory operated by Battelle Energy Alliance 
INL/EXT-10-20013

\title{
Treatment of Passive Component Reliability in Risk- Informed Safety Margin Characterization
}

\section{FY 2010 Report}

\author{
Karl N. Fleming \\ Stephen D. Unwin ${ }^{1}$ \\ Dana Kelly \\ Peter P. Lowry ${ }^{1}$ \\ Mychailo B. Toloczko ${ }^{1}$ \\ Robert F. Layton ${ }^{1}$ \\ Robert Youngblood \\ David. Collins ${ }^{2}$ \\ Aparna V. Huzurbazar ${ }^{2}$ \\ Brian Williams ${ }^{2}$ \\ Patrick G. Heasler ${ }^{1}$
}

${ }^{1}$ Pacific Northwest National Laboratory

${ }^{2}$ Los Alamos National Laboratory

September 2010

Idaho National Laboratory

Idaho Falls, Idaho 83415

http://www.inl.gov

Prepared for the

U.S. Department of Energy

Office of Nuclear Energy

Under DOE Idaho Operations Office

Contract DE-AC07-05ID14517 


\section{Executive Summary}

\section{Background}

The Risk-Informed Safety Margin Characterization (RISMC) pathway is a set of activities defined under the U.S. Department of Energy (DOE) Light Water Reactor Sustainability Program. The overarching objective of RISMC is to support plant life-extension decision-making by providing a state-of-knowledge characterization of safety margins in key systems, structures, and components (SSCs). A technical challenge at the core of this effort is to establish the conceptual and technical feasibility of analyzing safety margin in a risk-informed way, which, unlike conventionally defined deterministic margin analysis, is founded on probabilistic characterizations of SSC performance.

The anticipation is that probabilistic safety margins will in general entail the uncertainty characterization both of the prospective challenge to the performance of an SSC ("load") and of its "capacity" to withstand that challenge. In the context of long-term asset management and reactor life extension, those characterizations might be expected to depend on the age of the SSC, accounting for degrading SSC capacity, and potentially on increasing loads due to, say, power uprates. Therefore, in the establishment of safety margins intended to protect public safety in the long term, account of the effects of system aging will be essential.

Adverse effects of aging would be particularly significant in those SSCs for which management options are limited; that is, components for which replacement, refurbishment, or other means of rejuvenation are least practical. These include various passive SSCs, such as piping components. In probabilistic risk assessment (PRA) models, passive SSCs appear as significant risk-contributors in the form of initiating events such as loss of coolant accidents and internal floods, and they are also the focus of plant fragility evaluation for seismic events. Furthermore, because of limited options for rejuvenation, passives may be expected to play an increasing role in long-term risk. Therefore, in the establishment of safety margins intended to ensure long-term safety, the effects and implications of SSC aging and degradation must be addressed.

This is an interim report describing progress made in FY10 under one task defined within the RISMC pathway. This task had the objective of establishing technical models, and their mathematical means of implementation, to predict the reliability behavior of passive components, including the ability to account for aging. Furthermore, these models are to be developed in a way that allows them to integrate with tools being created under a parallel set of RISMC activities; particularly, development of the RELAP 7 (R7) software. Specifically, the goal is to establish reliability models of passive SSCs that are sensitive to the thermal hydraulic loading conditions predicted in an R7 environment. If this can be achieved then, in principle, the impact of a reactor system's thermal hydraulic history on SSC performance could be accommodated in the formulation of safety margins. The mechanism for this integration of thermal hydraulic analyses with reliability models to infer accident conditions and sequences is yet to be established, but it is clear that the reliability models will need to incorporate sufficient "physics" to accommodate the boundary conditions established in the R7 environment. Therefore, the use of physics models of the specific mechanisms of component aging degradation will be essential in establishing this reliability/R7 
modeling interface. Examples of such physics models are among the areas of progress reported here.

\section{Scope}

One problematic aspect of the statistical modeling of passive SSC reliability has been the relative sparseness of supporting data (compared to data available for active components). Among the more successful approaches to meeting that challenge has been the development of Markov models of component reliability, with particular application to metallic piping components. These models consider the progressive degradation of a component through a series of discrete states, from success, through detectable (using conventional NDE technology) flaw, to leak and rupture. The transition rates between these states are traditionally quantified using degradation rates inferred from service data and flaw/leak discovery/repair rates based on detection reliability assessment. Among the advantages of such models is that they can utilize component degradation service data in addition to the sparser component failure data. Figure ES-1 shows the diagrammatic representation of a pipe failure Markov model.

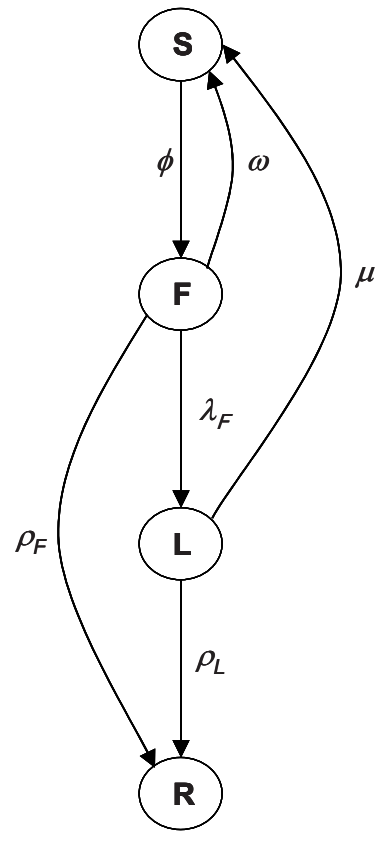

\section{Pipe Element States}

S - success, no detectable damage

$\mathrm{F}$ - flaw detectable via NDE

$\mathrm{L}$ - detectable leak

$\mathrm{R}$ - rupture

State Transition Rates

$\phi$ - flaw occurrence rate

$\lambda_{F}$ - leak failure rate given flaw

$\rho_{F}-$ rupture failure rate given flaw

$\rho_{L}$ - rupture failure rate given leak

$\omega$ - repair rate via NDE

$\mu$ - repair rate via leak detection

\section{Figure ES-1 \\ Structure of Pipe Component Markov Model}

Even though Markov models themselves are probably too limited to serve well in the long run, the state transition diagrams serve to structure the analysis in a useful way. Accordingly, Markov modeling has been adopted as a starting point for the current RISMC task.

To provide focus in the current FY, a set of component types and associated degradation mechanisms was selected. Given the potential risk-significance of pipe failures (LOCAs, internal flooding, high-energy line breaks outside containment), in conjunction with the relatively substantial 
experience of pipe ruptures (in non-safety related systems); this was the general class of components selected for analysis. Specifically, the components identified for study were:

1. Fire protection system piping: A source of risk-significant accident sequences involving internal flooding, difficult to replace, and several large ruptures have occurred.

2. PWR feedwater, condensate and steam system piping: A source of significant accident sequences associated with high energy line breaks, and a substantial number of ruptures associated with flow accelerated corrosion have occurred.

3. ASME Class 1piping dissimilar metal weld (Westinghouse PWR surge line nozzle weld): LOCA-sensitive piping that is subject to a dominant degradation mechanism - stress corrosion cracking.

The principal activities undertaken in FY10 and reported here are:

1. A review of the service data for the selected passive components to determine if there is broad empirical evidence of increasing failure rates with component age.

2. Use of existing Markov models in conjunction with current service data to determine predicted component failure rates. The existing Markov methodology is based on analysis of service data and associated models of component degradation and repair. These models have been updated in light of present operational data for the selected component classes.

3. Identification and use of improved statistical methodologies to implement the models. The existing Markov models are largely 4-state (see Figure ES-1), and exact analytical solutions to the ordinary differential equations (ODEs) represented by these models had already been developed. However, for models of increased size (such as those that might delineate rupture sizes by individual Markov states), or where the state transition rates are no longer time-independent, it is anticipated that exact analytical solutions will not be practical. Therefore, alternative numerical methods for solving Markov models need to be identified and evaluated. Three numerical solution algorithms were assessed:

(a) The OpenBUGS software used to solve the Markov ODEs.

(b) Bayesian Flowgraph Methodology to solve the ODEs.

(c) The Proportional Hazards Methodology.

A benchmark problem focused on stress corrosion cracking and design defects in ASME Class 1 dissimilar metal welds was defined to allow comparison of the original analytical implementing methodology with numerical approaches (a) and (b). Approach (c) was developed to solve the physics-based models identified in the next item.

4. Development of a preliminary physics-based model of component reliability performance. In this model, the state transition rates were based on models of the physical phenomena of component degradation. By taking steps towards the incorporation of physics models into the reliability analysis, the intent was to pre-empt the basis for addressing component degradation in an R7 modeling environment. This model focused on stress corrosion 
cracking in ASME Class 1 dissimilar metal welds. Figure ES-2 shows the general form of the model, in which a micro-crack initiation state has now been introduced (compare to Figure ES-1) to accommodate the distinctive physical models that address crack initiation and crack growth. Distinctions in crack morphology were also introduced to support the differences in leak/rupture characteristics. Since in this model the transition rates were determined to be time-dependent random variables (and thus, strictly, the model is not longer Markovian), the Proportional Hazards Methodology was used to solve the model, which involves the generation of an equivalent Markov model.

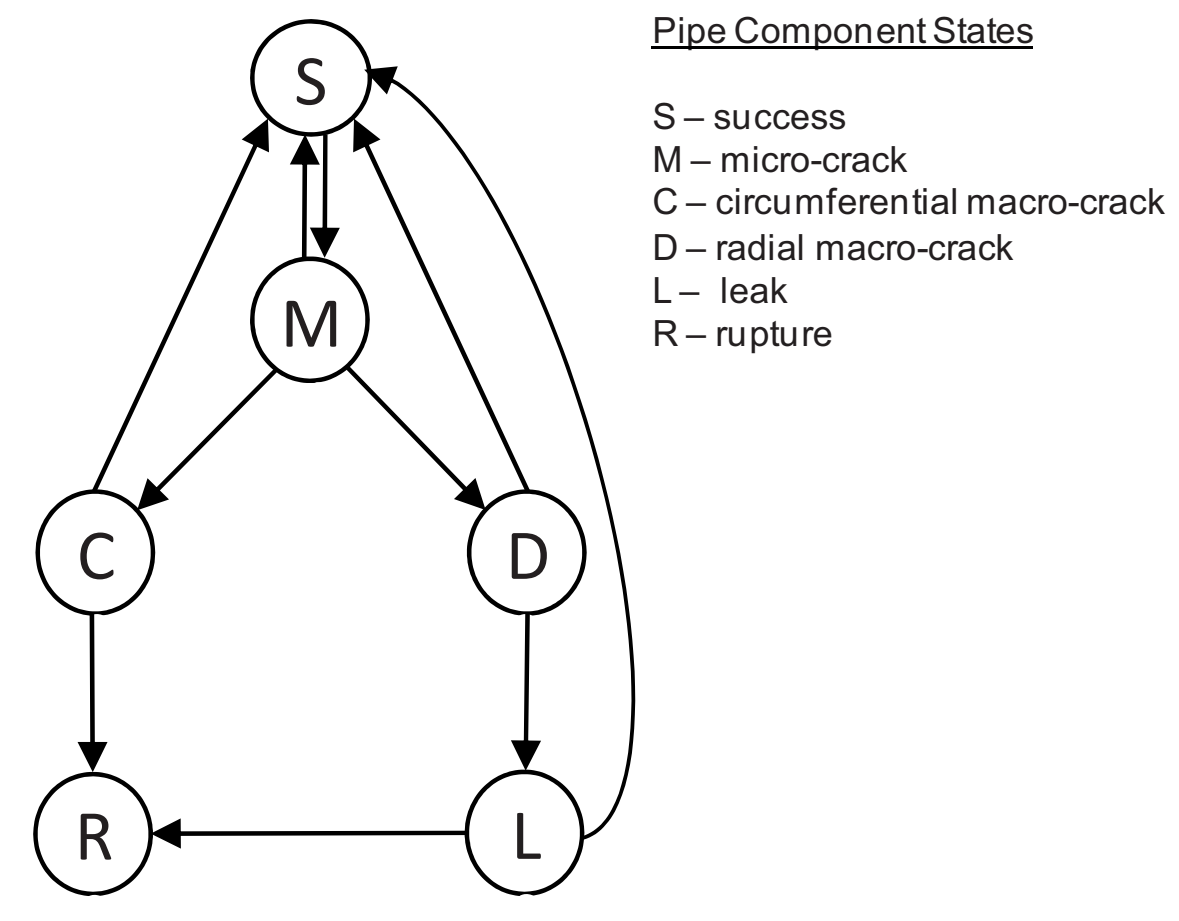

Figure ES-2

Structure of Preliminary Physics-Based Model of Dissimilar Metal Weld Stress Corrosion Cracking

\section{Interim Results}

The results generated during this first year of the Passives RISMC task are considered to be interim and tentative. Some of the key results are summarized here. (See the main report for greater detail.) 


\section{Service Data Review}

Empirical pipe failure rates associated with fire protection systems for the period 1970 to 2005 are summarized in Figure ES-3. It can be seen that these failure rates appear to have increased substantially over the past five years. This trend suggests component aging as an explanation. These insights are discussed in detail in Section 4 of the main report along with similar, although more modest, trends in PWR feedwater and condensate piping performance.

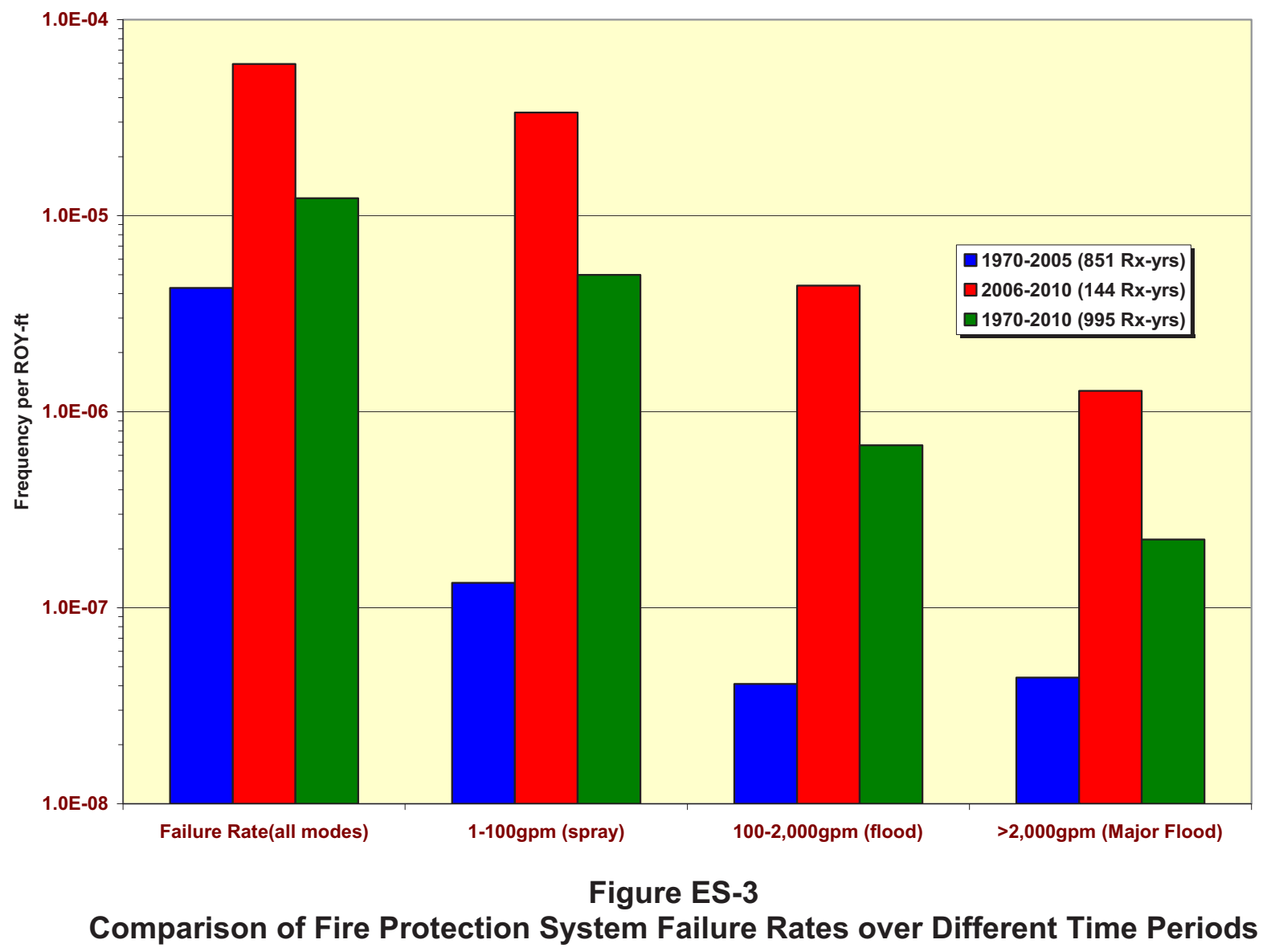

Service Data-Based Markov Models and the Benchmark Exercise

Markov models of all three of the selected component types were developed and quantified (see Sections 4 and 5 of the main report) using the existing Markov methodology. For the benchmark 
exercise, Class 1 piping dissimilar metal welds provided the basis for comparison of the existing analytical methodology with the OpenBUGS and Flowgraph numerical methods. This comparison incorporated a Bayesian uncertainty analysis in which state transition rate prior distributions were updated by operational data (provided by the PIPExp-2005 database). Details of the methodologies are contained in Section 5 and Appendix $\mathrm{C}$ of the main report.

Figure ES-4 shows an example of the results (rupture hazard rate for a 10-inch break) using the original methodology, while Figure ES-5 compares the original methodology results with those produced by the numerical methods for several cases.

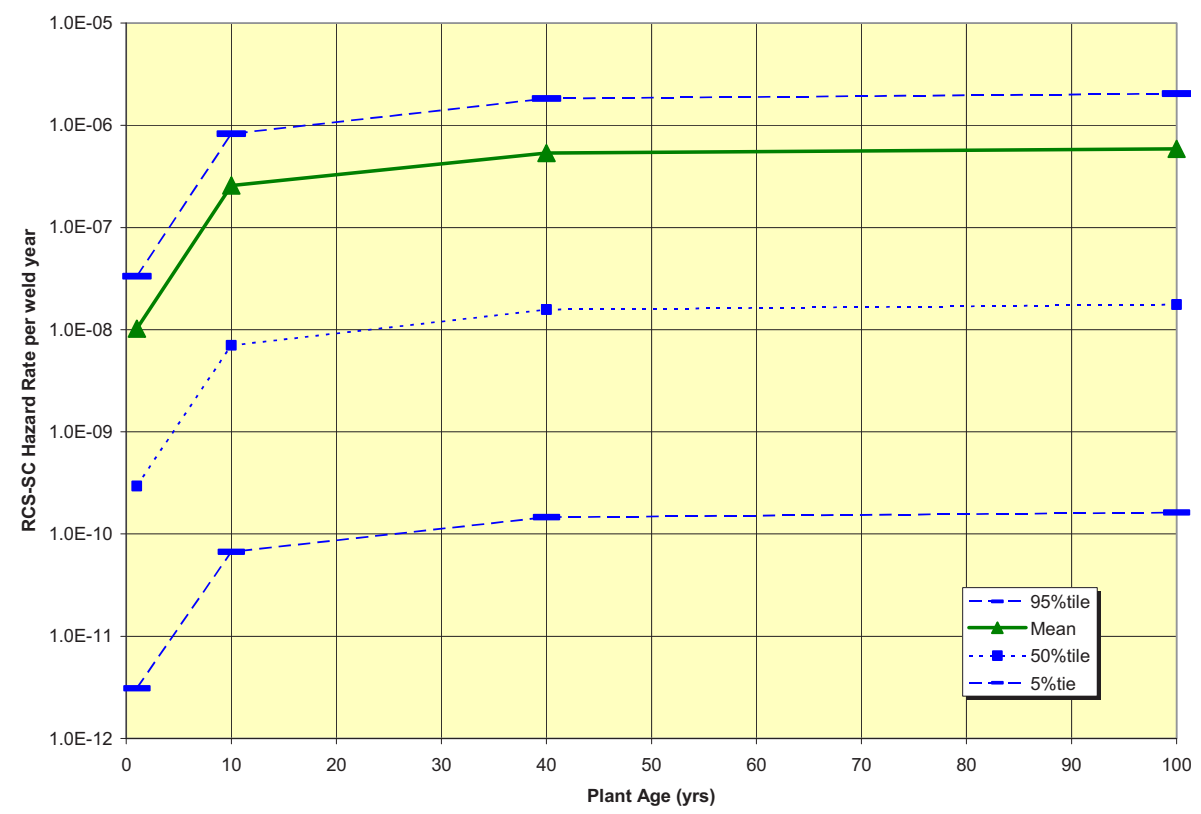

Figure ES-4

Original Analytical Solution: Uncertainty in Hazard Rates for ASME Class 1 Pipe 10-inch Line Break 


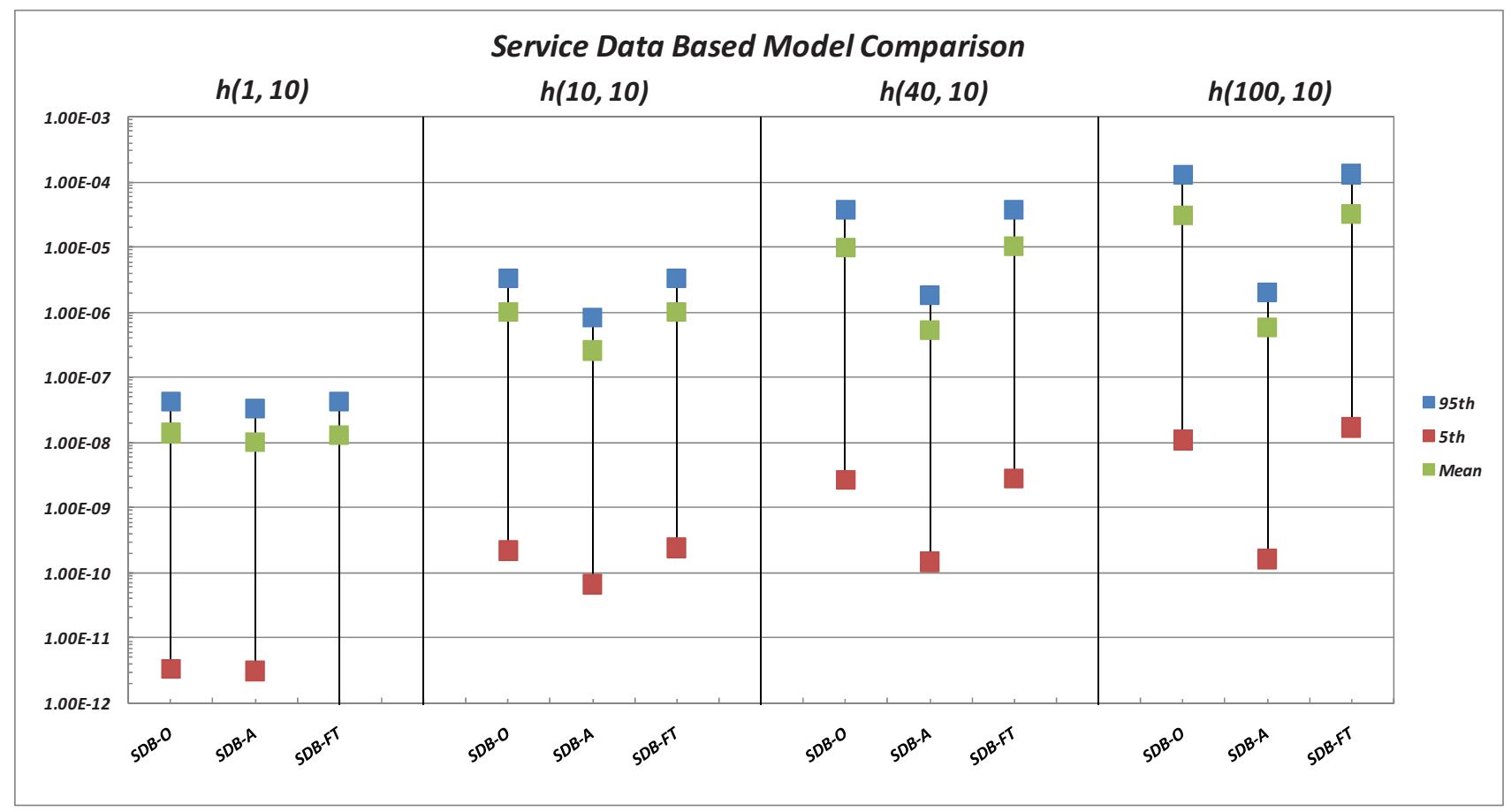

Figure ES-5

\section{Comparison of Original Analytical Solution (SDB-A) of the Service Data-Based Model to Numerical Methodology Solutions: SDB-O (OpenBUGS) and SDB-FT (Flowgraph). $h(x, y)$ is the rupture hazard rate at $x$ years for a $y$-inch line break}

Resolution of the discrepancies reflected in Figure ES-5 is ongoing; however, the close agreement between numerical methods indicates that they are likely to provide a feasible alternative to the existing analytical approach, thus enabling larger and more complex Markov models of passive component performance to be solved.

\section{Physics Models of Passive Component Reliability}

A preliminary model was developed that incorporates the physics of stress corrosion cracking micro-crack initiation and crack growth for various crack morphologies, to the point of leak or rupture. The details of this analysis are contained in Section 6 of the main report. The state transition rates in this model, unlike the benchmark model, are random variables since, for example, the time to micro-crack formation is randomly distributed and the subsequent transition rate to macro-crack formation depends on the time from micro-crack initiation. Therefore, the model represented in Figure ES-2 is not, strictly, Markovian. Proportional Hazards Methodology, described in Appendix D, was the basis for solving the model. Figure ES-6 shows the rupture hazard rate predicted by this preliminary physics model based on best estimate quantifications of the input physical parameters. (Note, these are preliminary best estimates - the principle purpose of this analysis was to demonstrate the computational feasibility of the model.) Figure ES-6 shows the predicted point-estimate rupture hazard rates for two values of the parameter $\mathrm{T}$ which appears in the Weibull model of crack initiation:

$$
P(t)=1-\exp \left[-(t / T)^{b}\right]
$$


where the probability of micro-crack initiation by time $t$ is $P(t)$. An interesting aspect of the resulting hazard curves is that they do not monotonically increase with component age but, rather, display a maximum. This might not be expected of component aging behavior.

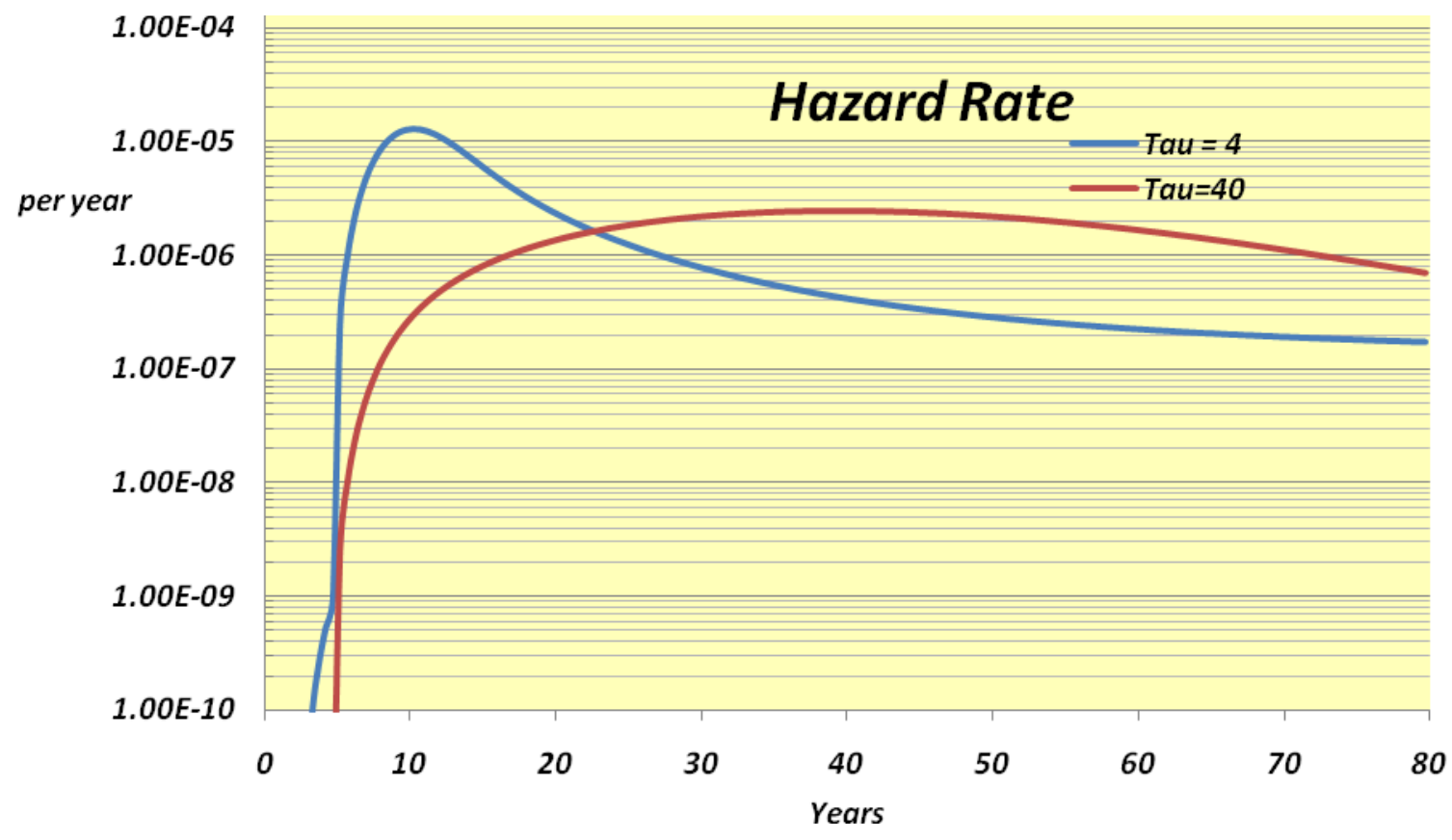

\section{Preliminary Physics-Based Model: Point Estimates of Rupture Hazard Rates}

\section{Interim Conclusions}

First, the availability of several options for the computational implementation of Markov and Markovtype models eliminates any practical impediments to solving these problem classes. While there remain some residual discrepancies in reconciliation of the benchmark methodologies, these are not expected to represent significant issues of feasibility. It is clear, however, that the original analytical approach to solving Markov models is unlikely to be feasible for more complex models with additional states and time dependent transition rates.

Second, while direct analysis of service data for the fire protection and feedwater/ condensate piping clearly indicates the existence of reliability degradation, it is unclear to what extent we are currently capturing the sources and mechanisms for aging in the context of the service data-based and the physics-based Markov models. For instance, the service data-based model of Class 1 weld degradation (Figure ES-4) displays an initial increase in hazard rate over a short period of about 10 years before approaching an asymptote. This rapid, initial hazard rate increase followed by a relatively flat performance is not the behavior that might be expected of aging degradation. Note that the state transition rates in this model are constant in time, and a relevant question is whether 
state transition rates (at least those characterizing component degradation) should instead be expected to increase with component age.

In the physics-based model, the state transition rates are time-dependent; however, the hazard rate predictions raise their own questions, particularly in light of the hazard rate maxima. Again, one question is whether this current version of the model, in which micro-cracks form in accordance with a Weibull process and then grow at a constant rate, is capturing the phenomena (associated with stress corrosion cracking) that define component aging. What needs to be considered is whether certain simplifying assumptions made for the purposes of this demonstration model (such as constant crack growth rates) have served to eliminate effects that are relevant to component aging. Nevertheless, the demonstration analysis has established that the computational framework is available to implement time-inhomogeneous models with randomly distributed transition rates.

Issues associated with both the service data-based and the physics-data based models point to the need to establish a deeper understanding of phenomena critical to the modeling of component aging. Also there is the need to develop a better understanding of the role of hazard rate metrics in predicting aging effects. For example, how would the hazard rate prediction compare to actual statistical trends in service data if aging effects were present?

\section{Path Forward}

Several areas of research are identified to advance this task in FY11:

1. Continued development of the physics-based model to address additional phenomena of relevance to component aging along with collection of associated physical data resources.

2. Development of the means to integrate service data-based and physics-based Markov analyses to allow both materials degradation models and operational data to be incorporated into aging-based hazard rate prediction. Here, there will be the need to address multiple failure mechanisms that may apply to a component, including both degradation phenomena and loading conditions.

3. Establishment of the conceptual and analytical interfaces between the passives reliability methodology and the RISMC framework, with emphasis on integration of the passives models into the R7 environment and development of a margins-based characterization of passives performance. 


\section{TABLE OF CONTENTS}

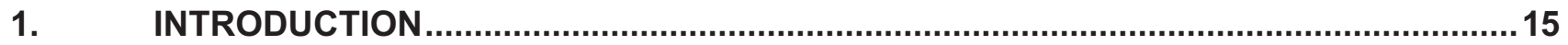

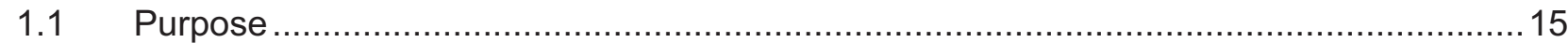

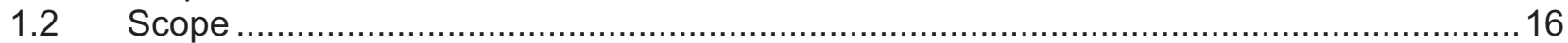

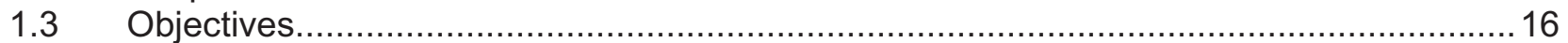

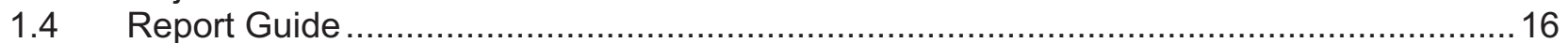

2. TECHNICAL APPROACH FOR PASSIVE COMPONENT RELIABILITY .......................17

2.1 Role of Safety Margins as Contributing to Passive Component Reliability .......................17

2.2 Technical Approach to Passive Component Reliability Used in Current PRAs..................17

2.2.1 Uncertainty Treatment.................................................................................. 17

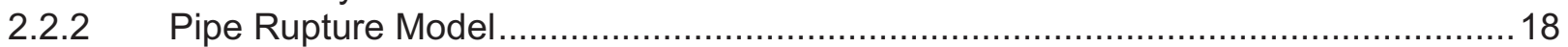

2.2.3 Markov Model for Evaluation of Integrity Management Strategies ............................21

2.2.4 How the Markov Model is Used in PRA Applications ........................................2.25

2.2.5 Use of the Hazard Rate to Define Time Dependent Hazard Rates .........................2.28

2.2.6 Limitations and Open Issues with Piping System Reliability Models .......................29

2.3 Enhancements to Reliability Models Evaluated in This Study .........................................30

3. SELECTION OF PASSIVE COMPONENTS FOR EVALUATION ................................32

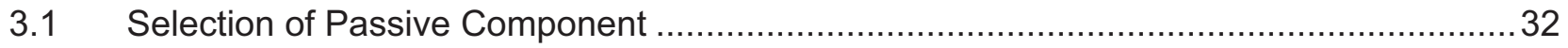

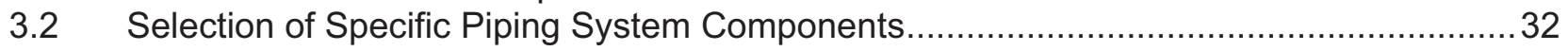

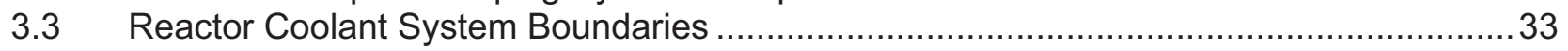

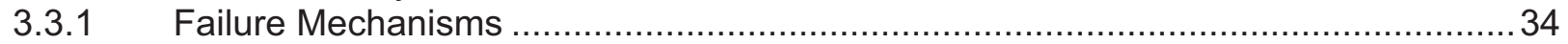

3.3.1.1 Reactor Coolant System Vessels and Pumps ...............................................35

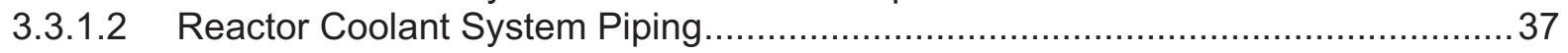

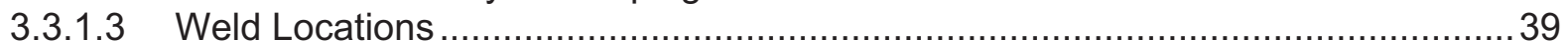

3.3.2 High Susceptibility RCS Degradation Mechanisms ............................................. 40

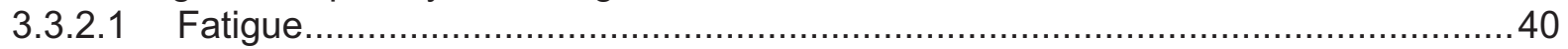

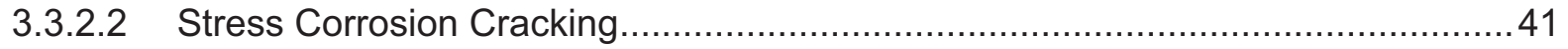

3.3.2.3 Boric Acid Corrosion .................................................................................. 41

3.3.2.4 Comparison of Applicable Degradation Mechanisms ...................................... 42

4. EVALUATION OF PIPE FAILURE RATES IN SELECTED PASSIVE COMPONENTS ... 43

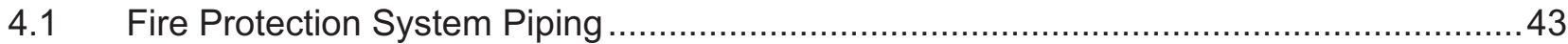

4.1.1 Data Collection for Fire Protection System...................................................4 43

4.1.2 Estimates of Failure Rates and Rupture Frequencies.........................................4 44

4.1.3 Impact of Alternative Inspection and Surveillance Strategies for FP System ............47

4.1.4 Impact of Plant Age on Estimated Failure Rates for FP System .............................51

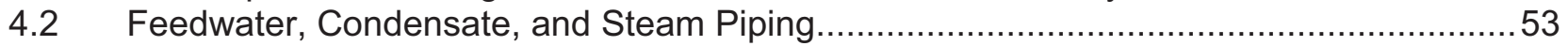

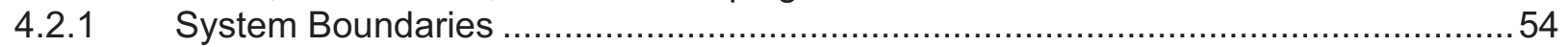

4.2.2 Failure Data Collection for Feedwater, Condensate and Steam Piping ....................54

4.2.3 Conditional Probability of Pipe Rupture Given Failure ...........................................59

4.2.4 Failure Rates and Cumulative Rupture Frequencies for FWC System .....................63

4.2.5 Evaluation of Temporal Trends in Failure Rates for FAC Susceptible Systems .......65 
4.2.6 Impact of Alternative Inspection and Surveillance Strategies on FWC Piping .........66

4.2.7 Impact of Plant Age on Estimated Failure Rates for FAC Susceptible Systems .......69

4.3 Investigation of Aging via Direct Estimation of Failure Rates and Rupture Frequencies ..69

4.4 ASME Class 1 PWR Pressurizer Surge Line Nozzle .................................................72

5. EVALUATION OF ALTERNATIVE MARKOV MODEL SOLUTION APPROACHES .......74

5.1 Definition of Selected Component........................................................................ 74

$5.2 \quad$ Baseline Assessment Using Current Reliability Methods......................................... 74

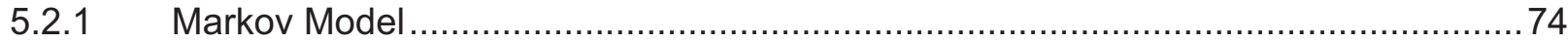

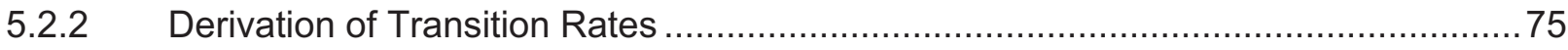

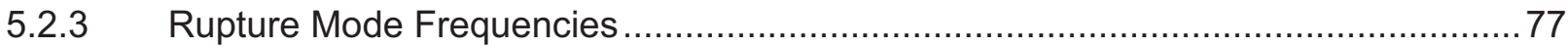

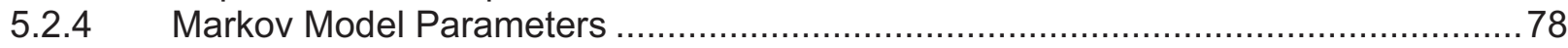

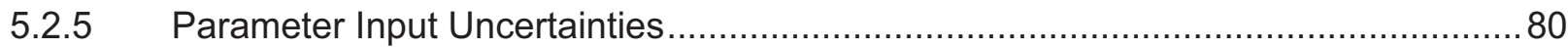

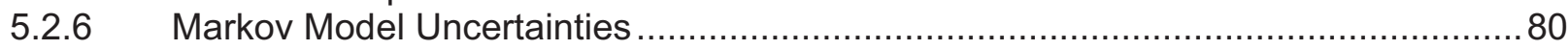

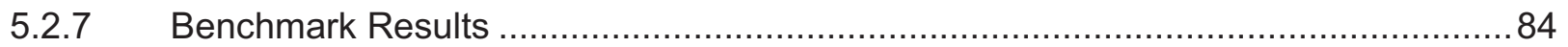

5.3 Benchmark Problem 1 Using Numerically Based Computational Approaches ................86

5.3.1 Comparison of the Service Data Based Analytical Solution and the Service Data

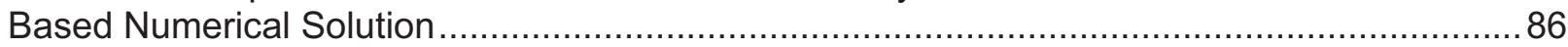

6. ENHANCED MARKOV MODEL BASED ON PHYSICS OF FAILURE............................99

6.1 Physics of Failure Enhancements to Markov Model ............................................. 90

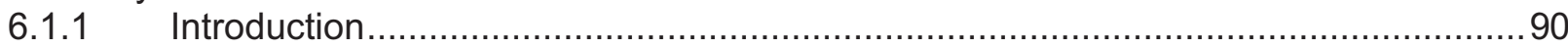

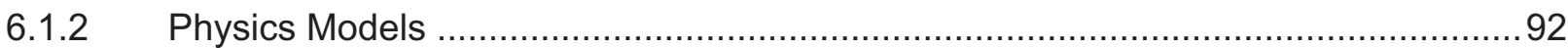

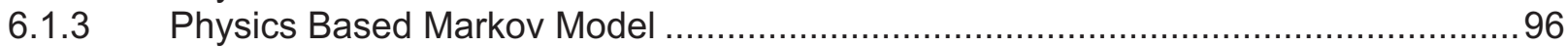

6.1.4 Association of Physics and Markov Models .................................................... 97

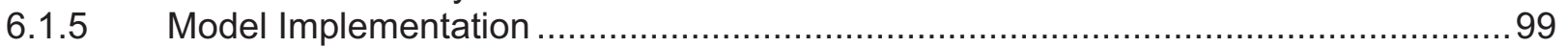

6.2 Bases for Preliminary Model Implementation ................................................... 100

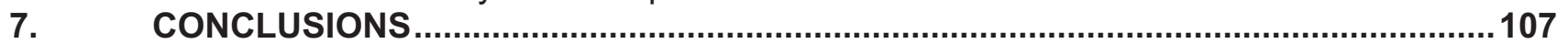

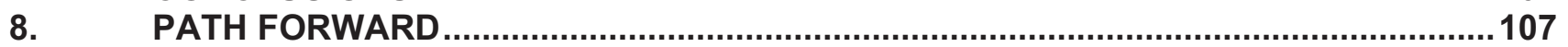

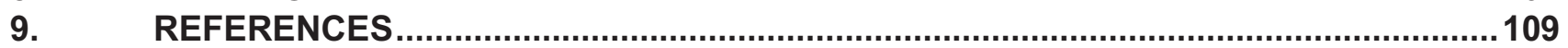

Appendix A PIPExp Database Description

Appendix B Evaluation of Pipe Failure Rates and Rupture Frequencies in Non-Safety Piping Systems

Appendix C Numerical Methods for Solving Benchmark Problem

Appendix D Implementation of Proportional Hazards Solution of Physics Model 


\section{TABLE OF FIGURES}

Title

Page

Figure 2-1 Flow Chart for Bayes' Estimates of System, Size, and Damage Mechanism Specific Pipe

Failure Rates $(\lambda)$ and Rupture Frequencies $(\rho)$.... .21

Figure 2-2 Markov Model for Predicting the Influences of Leak Detection and Pipe Inspections on

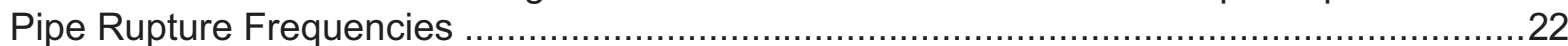

Figure 2-3 Typical Integrity Management Factor for ASME Class 3 Component Cooling Water Pipe

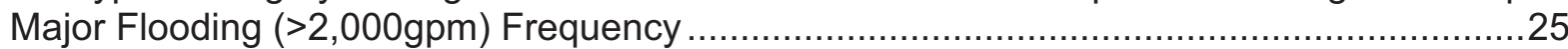

Figure 3-1 Location of High SCC Alloy 82/182 Welds in RCS ...............................................40

Figure 4-1 Results for Rupture Frequency vs. Break Size for NPS 24" FP Header.......................46

Figure 4-2 Cumulative Pipe Rupture Frequency for FP NPS 24" .........................................4

Figure 4-3 Impact of Design and Inspection Strategies to Reduce the Frequency of Fire Protection

Header Pipe Ruptures............................................................................................. 51

Figure 4-4 Plant Age Dependent Hazard Rates for Selected Break Sizes in 24" FP Pipe .............53

Figure 4-5 Hazard Rate Sensitivity Study - Vary Flaw to Leak Ratio .......................................53

Figure 4-6 PWR Worldwide Experience with non-Code FWC Piping 1970-2004 .......................56

Figure 4-7 PWR Worldwide Experience with non-Code Steam Piping 1970-2004 [1] ...................57

Figure 4-8 Cumulative Rupture Frequency vs. Break Size for NPS > 10" FWC Pipe.....................64

Figure 4-9 Comparison of Pipe Failure Rates in Large (>6") FAC Susceptible Piping Based on

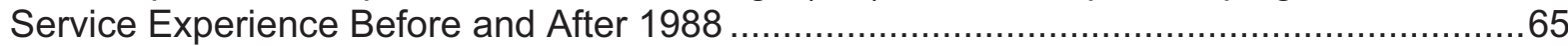

Figure 4-10 Temporal Trends in the Frequency of Large Pipe Breaks in FAC Susceptible Systems

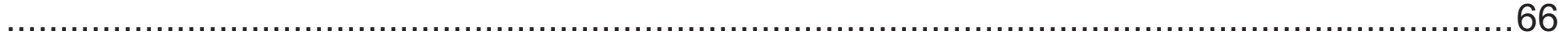

Figure 4-11 Comparison of Fire Protection System Failure Rates Over Different Time Periods ......70

Figure 4-12 Comparison of PWR FWC Failure Rate Estimates for Different Time Periods .............71

Figure 4-13 Cumulative Rupture Frequency vs. Break Size for PWR Nozzle Weld .......................72

Figure 5-1 Layout of a Westinghouse PWR surge line nozzle connection to the pressurizer

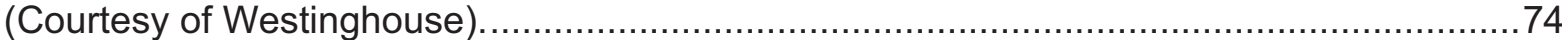

Figure 5-2 Markov Model for PWR RCS Weld Susceptible to Stress Corrosion Cracking ...............75

Figure 5-3 Discrete Distribution Model for Service Data Exposure Uncertainty ...........................77

Figure 5-4 Uncertainty Distribution for Hazard Rate for 0.1 inch Breaks .....................................85

Figure 5-5 Uncertainty Distribution for Hazard Rate for 10.0 inch break ..................................85

Figure 5-6 Comparison of Analytical and Numerical Solutions for Service Data-Based Model - 10.0

inch break.............................................................................................................. 89

Figure 6-1 Layout of a Westinghouse PWR surge line nozzle connection to the pressurizer

(Courtesy of Westinghouse)...................................................................................

Figure 6-2 Two basic cross-flow crack morphologies: radial and circumferential........................91

Figure 6-3 Example Weibull cumulative probability plot for crack initiation- The horizontal axis is a

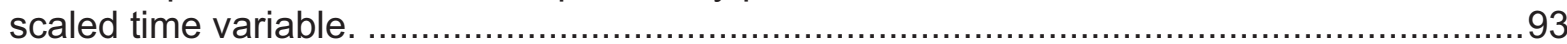

Figure 6-4 Screen data set assembled by EPRI for the MRP-115 crack growth rate equation for alloy 182 (From EPRI MRP-115) .........................................................................94

Figure 6-5 Screen data set assembled by EPRI for the MRP-115 crack growth rate equation for alloy 82 (From EPRI MRP-115) ............................................................................. 95

Figure 6-6 Form of the Phase 0 Physics Based Markov Model ..............................................96

Figure 6-7 State Probabilities for tau $=4$ years............................................................... 103

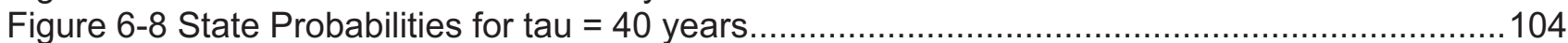

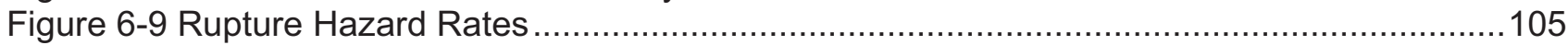

Figure 6-10 Comparison of Rupture Hazard Rates to Service Data Based Benchmark .........106 


\section{LIST OF TABLES}

Title

Page

Table 2-1 Markov Model Parameters that Vary with RIM Strategy ..........................................27

Table 3-1 PWR Reactor Coolant System Vessel Degradation Mechanisms .................................35

Table 3-2 PWR Reactor Coolant System Piping Degradation Mechanisms .................................38

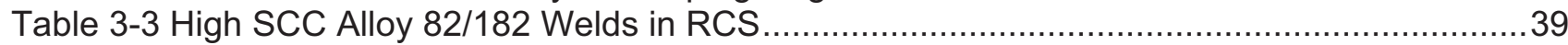

Table 4-1 Pipe Lengths Used to Establish Fire Protection System Exposure ..............................43

Table 4-2 Fire Protection System Failure Counts by Failure Mode, Pipe Size and Failure Mechanism

Table 4-3 Failure Rates and Cumulative Rupture Frequencies for FP NPS 24" and No Water Hammer Protection

Table 4-4 Impact of Alternative Leak Detection Strategies to Reduce Fire Protection System Pipe Rupture Frequencies

Table 4-5 Impact of NDE and Alternative Leak Detection Strategies to Reduce Fire Protection System Pipe Rupture Frequencies

Table 4-6 Integrity Management Factors for Various Combinations of NDE and Leak Inspections for

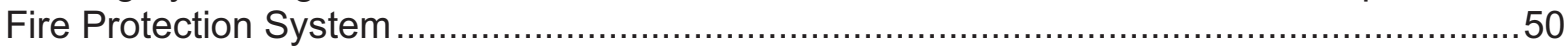

Table 4-7 Factors To Account for Aging Effects on NPS 24" FP Header ..................................52

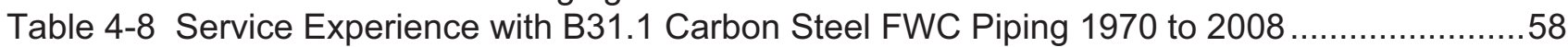

Table 4-9 Service Experience with B31.1 Carbon Steel Steam Piping 1970 to $2008 \ldots \ldots \ldots \ldots \ldots \ldots \ldots . . . . . .58$

Table 4-10 Estimated Pipe Lengths for PWR Steam, Feedwater, and Condensate Systems..........59

Table 4-11 Pipe Ruptures in BWR and PWR Feedwater, Condensate, and Steam Systems ..........60

Table 4-12 Failure Rates and Cumulative Rupture Frequencies for NPS > 10" FWC System .........64

Table 4-13 Impact of Alternative Leak Detection Strategies to Reduce Feedwater-Condensate

System Pipe Rupture Frequencies

Table 4-14 Impact of NDE and Alternative Leak Detection Strategies to Reduce Fire Feedwater-

Condensate System Pipe Rupture Frequencies

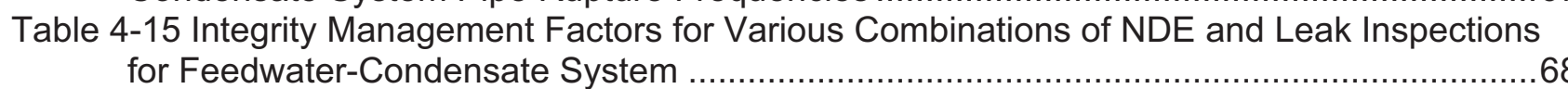

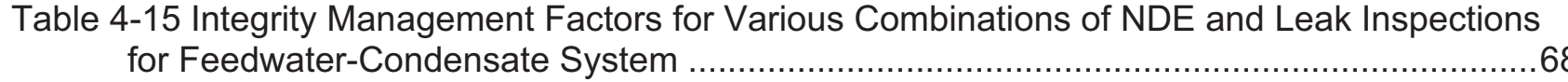

Table 4-16 Factors to Account for Aging Effects on NPS 24" FWC Pipe....................................69

Table 4-17 Failure Rates and Cumulative Rupture Frequencies for PWR Nozzle Weld .................73

Table 5-1 Uncertainty Distribution Assumption for Benchmark Problem Input Parameters.............81

Table 5-2 Uncertainty Treatment for Conditional Pipe Rupture Probabilities Given Pipe Failure .....84

Table 5-3 Uncertainty Distribution Results for Selected Benchmark Parameters...........................84

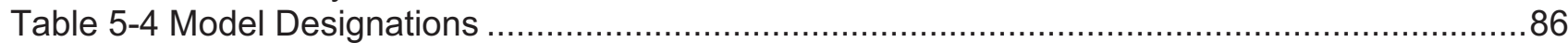

Table 5-5 Comparison of Current Benchmark Results ....................................................... 88

Table 6-1 Preliminary Implementation: Model Input Parameters .............................................. 102 


\section{INTRODUCTION}

\subsection{Purpose}

The Risk-Informed Safety Margin Characterization (RISMC) pathway is a set of activities defined under the U.S. Department of Energy (DOE) Light Water Reactor Sustainability Program. The overarching objective of RISMC is to support plant life-extension decision-making by providing a state-of-knowledge characterization of safety margins in key systems, structures, and components (SSCs). A technical challenge at the core of this effort is to establish the conceptual and technical feasibility of analyzing safety margin in a risk-informed way, which, unlike conventionally defined deterministic margin analysis, is founded on probabilistic characterizations of SSC performance.

The anticipation is that probabilistic safety margins will in general entail the uncertainty characterization both of the prospective challenge to the performance of an SSC ("load") and of its "capacity" to withstand that challenge. In the context of long-term asset management and reactor life extension, those characterizations might be expected to depend on the age of the SSC, accounting for degrading SSC capacity, and potentially on increasing loads due to, say, power uprates. Therefore, in the establishment of safety margins intended to protect public safety in the long term, account of the effects of system aging will be essential.

Adverse effects of aging would be particularly significant in those SSCs for which management options are limited; that is, components for which replacement, refurbishment, or other means of rejuvenation are least practical. These include various passive SSCs, such as piping components. In probabilistic risk assessment (PRA) models, passive SSCs appear as significant risk-contributors in the form of initiating events such as loss of coolant accidents and internal floods, and they are also the focus of plant fragility evaluation for seismic events. Furthermore, because of limited options for rejuvenation, passives may be expected to play an increasing role in long-term risk. Therefore, in the establishment of safety margins intended to ensure long-term safety, the effects and implications of SSC aging and degradation must be addressed.

This is an interim report describing progress made in FY10 under one task defined within the RISMC pathway. This task had the objective of establishing technical models, and their mathematical means of implementation, to predict the reliability behavior of passive components, including the ability to account for aging. Furthermore, these models are to be developed in a way that allows them to integrate with tools being created under a parallel set of RISMC activities; particularly, development of the RELAP 7 (R7) software. Specifically, the goal is to establish reliability models of passive SSCs that are sensitive to the thermal hydraulic loading conditions predicted in an R7 environment. If this can be achieved then, in principle, the impact of a reactor system's thermal hydraulic history on SSC performance could be accommodated in the formulation of safety margins. The mechanism for this integration of thermal hydraulic analyses with reliability models to infer accident conditions and sequences is yet to be established, but it is clear that the reliability models will need to incorporate sufficient "physics" to accommodate the boundary conditions established in the R7 environment. Therefore, the use of physics models of the specific mechanisms of component aging degradation will be essential in establishing this reliability/R7 modeling interface. Examples of such physics models are among the areas of progress reported here. 


\subsection{Scope}

The scope of work covered in this report includes the characterization of the current state of the art in the assessment of passive component reliability and the development of new methods that are needed to assess the links between safety margins associated with passive components in nuclear power plants and the reliability performance of these components. The methods under development in this project are expected to be useful in the risk informed evaluation of safety margins in light of potential aging effects as plants approach their original design and extended lifetime.

\subsection{Objectives}

This task had the objective of establishing technical models, and their mathematical means of implementation, to predict the reliability behavior of aging passive components.

The specific objectives of this task are to:

- Evaluate impact of aging and life extension on selected passive components

- Characterize uncertainties important for risk-informed decision making regarding passive component reliability.

- Develop methods for evaluating possible reduction in safety margins due to passive component aging and life extension

- Establish bases for reliability models that are compatible with and potentially interface with the anticipated RISMC modeling environment.

- Demonstrate methods on selected passive components to support risk-informed decision making

- Determine the feasibility of developing a physics-based model to estimate aging impacts on reliability performance. Identify technical issues that need to be addressed to evaluate passive components in light of RISMC objectives

\subsection{Report Guide}

The current technical approach to the treatment of passive component reliability is summarized in Section 2. In Section 3, the selection of passive components for the investigation of methods for risk informed safety margin characterization is described. The development of baseline failure rates and rupture frequencies for this model using the methodology of Section 2 is documented in Section 4. Enhanced methods for passive component reliability that address some open issues and uncertainty are presented in Sections 5 and 6 . Section 5 focuses on computation approaches to assess passive component reliability, whereas Section 6 explores the use of degradation-specific physics model to evaluate the age-dependent reliability performance of passive components in nuclear power plants. In Section 7 the interim conclusions of this project based on progress made in FY10 are presented. Section 8 identifies a path forward for firming the basis for incorporation of passive component reliability models into the RISMC framework. Details on the pipe experience databases and mathematical methodologies are found in the supporting appendices. 


\section{TECHNICAL APPROACH FOR PASSIVE COMPONENT RELIABILITY}

\subsection{Role of Safety Margins as Contributing to Passive Component Reliability}

The safety design approach of currently licensed nuclear power plant utilizes a defense-in-depth philosophy that involves the use of multiple barriers to fission product release and robust engineered safety systems that serve to prevent core damage and mitigate the consequences of accidents. There are critical passive components, whose reliability is key to the safety design approach. Examples of these passive components include pressure vessels and piping components that comprise the reactor coolant system pressure boundary, concrete structures and supports, and piping systems inside and outside the containment whose failure poses challenges to the capability to perform safety functions. Passive component failures are responsible for several major classes of risk significant accidents identified in Probabilistic Risk Assessments including Loss of Coolant Accidents (LOCAs), steam generator tube failures, internal flooding, and high energy line breaks. The fact that reactor pressure vessel failures have not been found to be risk significant is highly dependent on the achievement and maintenance of a high degree of pressure vessel reliability.

The reliability performance of passive components is due to many factors including the use of appropriate design codes and standards that control the selection of materials, fabrication and construction techniques, welding, inspections, and surveillance programs. One of the defensein-depth principles incorporated into these design codes is the prudent use of safety margins which provide a high degree of confidence that the components can withstand the loading conditions imposed by normal operation, upset conditions, and accidents. Hence, on a qualitative basis, it is clear that there are direct links between the adequacy of safety margins and the reliability of the passive components. One of the goals of this project is to obtain a more quantitative understanding of these links so that the adequacy of safety margins can be maintained as reactors approach their design and extended lifetimes.

\subsection{Technical Approach to Passive Component Reliability Used in Current PRAs}

The search for links between safety margins and reliability begins with a review of the current state of knowledge in assessing the reliability of selected passive components. The focus of this review is with selected nuclear plant piping systems.

The preliminary model used to estimate pipe break frequencies for the initiating event models in this report is the same as that used in a recent Electric Power Research Institute (EPRI) report on internal flooding initiating event frequencies [1], a study on high energy line break (HELB) initiating event frequencies for Kewaunee [3], and the evaluation for piping systems for Columbia Generating Station [4]. The approach is similar to that used in recent NRC studies regarding loss of coolant accident (LOCA) initiating event frequencies [8] [9]. The source of pipe failure and exposure data used to quantify the failure rates used in these models is known as "PIPExp-2009" [10]. A summary of this database is provided in Appendix A.

\subsubsection{Uncertainty Treatment}

Uncertainties in these pipe failure rates were quantified using a Bayes' methodology that was developed in the EPRI Risk-Informed-In Service Inspection (RI-ISI) program [11] and approved by the NRC for use in applied RI-ISI evaluations [12]. An independent review of this pipe failure rate uncertainty treatment was performed to support the Nuclear Regulatory Commission (NRC) 
Safety Evaluation and results of this favorable review are provided in Reference [13]. An earlier EPRI report [16] developed a set of pipe failure rates for use in the EPRI RI-ISI applications which was also approved and independently reviewed in References [12] and [13]. These earlier failure rate estimates were derived from a pipe failure database that had been developed in Reference [18]. During subsequent work in applying these estimates in applied RI-ISI evaluation, a significant number of data classification errors in the original data source [18] were identified and improved estimates of the exposure population became available. These factors, as discussed more fully in Reference [17], were the prime motivation to switch to the more comprehensive and validated "PIPExp-2009" database when Reference [1], was developed. Recent NRC sponsored work on piping reliability analysis has utilized input data extracted from the PIPExp database; e.g., References [5], [13] and [14].

\subsubsection{Pipe Rupture Model}

The service data based model used for relating failure rates and rupture frequencies uses the following simple model that is widely used in piping reliability assessment and was used in recent updates of recommended Loss of Coolant Accident (LOCA) frequencies [9]. The failure modes included in the estimation of failure rates include all failures requiring repair or replacement including wall thinning, cracks, leaks and ruptures of various sizes up to and including complete severance of the pipe. The model is expressed in the following equation:

$$
\rho_{i x}=\sum_{k=1}^{M_{i}} \rho_{i k x}=\sum_{k=1}^{M_{i}} \lambda_{i k} P_{i k}\left\{R_{x} \mid F\right\} I_{i k}
$$

Where:

$$
\begin{aligned}
& \rho_{\text {ix }}={ }_{x} \quad \text { total rupture frequency for pipe component } i \text { for rupture mode } \\
& \rho_{i k x} \quad=\quad \text { rupture frequency of pipe component } i \text { due to damage } \\
& \text { mechanism } \mathrm{k} \text { for rupture mode } x \\
& \lambda_{i k}=\text { failure rate of pipe component } i \text { due to damage mechanism } k \\
& P_{i k}\left\{R_{x} \mid F\right\}=\text { conditional probability of rupture mode } x \text { given failure for } \\
& \text { pipe component } i \text { and damage mechanism } k \\
& M_{i} \quad=\quad \text { Number of different damage mechanisms for component } i \\
& I_{i k} \quad=\quad \text { Integrity management factor for component } i \text { and damage } \\
& \text { mechanism } k \text {, this factor adjusts the rupture frequency to } \\
& \text { account for variable reliability and integrity management } \\
& \text { (RIM) strategies such as leak detection, volumetric NDE, in- } \\
& \text { service testing, etc. that might be different than the } \\
& \text { components in the service data. This parameter is } \\
& \text { determined using the Markov Model as explained more fully } \\
& \text { in Section 2.2.4 }
\end{aligned}
$$

In general, a point estimate of the frequency of pipe failures, $\lambda_{i j k}$, is given by the following expression:

Where

$$
\lambda_{i j k}=\frac{n_{i j k}}{f_{i j k} N_{i j} T_{i j}}
$$




$$
\begin{aligned}
& n_{i j k}=\text { the number of failures (cracks, wall thinning, leaks and ruptures) } \\
& \text { events for pipe size } \mathrm{i} \text { in system } \mathrm{j} \text { due to damage mechanism } \mathrm{k} \\
& T_{i j} \quad=\quad \text { the total time over which failure events were collected for pipe } \\
& \text { size } \mathrm{i} \text { in system } \mathrm{j} \\
& N_{i j}=\text { the number of components that provided the observed pipe } \\
& \text { failures for size } i \text { in system } \mathrm{j} \text {, components may be defined in } \\
& \text { terms of pipe welds, linear feet of pipe, or sections of pipe } \\
& \text { susceptible to a given damage mechanism depending on the } \\
& \text { application } \\
& f_{i j k}=\quad \text { the fraction of number of components of size } \mathrm{i} \text { in system } \mathrm{j} \text { that are } \\
& \text { susceptible to failure from damage mechanism } \mathrm{k} \text { for conditional } \\
& \text { failure rates given susceptibility to damage mechanism } \mathrm{k}, 1 \text { for } \\
& \text { unconditional failure rates }
\end{aligned}
$$

Based on a comprehensive review of LWR piping system service experience, all known pipe failures in nuclear power plant piping systems were the result of the following damage or degradation mechanisms [15]:

\begin{tabular}{ll} 
Code & Damage Mechanism \\
\hline CF & Corrosion-fatigue \\
COR & Corrosion attack, Microbiologically Induced Corrosion (MIC), Pitting \\
D\&C & Design and construction flaws and defects \\
E/C & Erosion Corrosion. Also referred to as flow-accelerated corrosion (FAC) \\
E-C & Erosion-cavitation \\
FP & Frozen pipe \\
HE & Human error \\
OVP & Overload \\
SC & Stress corrosion cracking \\
TF & Thermal fatigue \\
UNR & Unreported Cause \\
VF & Vibration-fatigue \\
WH & Water hammer
\end{tabular}

Note that all failure modes that result in pipe repair are included in the failure rate and that all failures thus defined are regarded as precursors to rupture. The events counted as ruptures are based on a specific definition of rupture which is application specific. For internal flooding and HELB applications, we seek unconditional failure rates and hence we can combine these equations under the condition: $f_{i j k}=1$ to obtain the following expression for the point estimate of the rupture frequency.

$$
\rho_{i x}=\sum_{k=1}^{M_{i}} \rho_{i k x}=\sum_{k=1}^{M_{i}} \lambda_{i k} P_{i k}\left\{R_{x} \mid F\right\} I_{i k}=\sum_{k=1}^{M_{i}} \frac{n_{i k}}{N_{i} T_{i}} P_{i k}\left\{R_{x} \mid F\right\} I_{i k}
$$

In the development of Bayes' uncertainty distributions for these parameters, prior distributions are developed for the parameters $\lambda_{i j k}$ and $P_{i k}\{R / F\}$ and these prior distributions are updated using the evidence from the failure and exposure data as in standard Bayes' updating. The original prior distributions for the pipe failure rates developed in Section 3 are the same as those 
documented in the EPRI Report 1013141[1]. The exposure terms (denominator of the fractions on the right hand side of Equation (2.3) also have uncertainty as these terms must be estimated for the entire nuclear industry that provides the number of failures for the failure rate estimation. This uncertainty is treated in this process by adopting three hypotheses about the values of the exposure terms which requires three Bayes updates for each failure rate. The resulting posterior distributions for each parameter on the right hand side of Equation (2.3) are then combined using Monte Carlo sampling to obtain uncertainty distributions for the pipe rupture frequencies. A picture of this process is shown in Figure 2-1. This flow chart shows the full treatment of uncertainty needed for the risk-informed in-service inspection (RI-SI) formulation in Equation (2.2). For the internal flooding and HELB formulation of Equation (2.3) the damage mechanism susceptibility fractions $\left(f_{i j k}\right)$ do not come into play. The specific way in which this flow chart is applied is discussed in Section 4 for each system and failure mode.

In Reference [1] rupture frequencies were developed for three rupture sizes that were selected to support internal flooding analysis. These sizes include water sprays with flood rates of up to $100 \mathrm{gpm}$, flooding with flood rates of 100 to $2000 \mathrm{gpm}$, and major flooding with flood rates greater than $2000 \mathrm{gpm}$. For the Kewaunee HELB-initiated internal flooding models [2], a somewhat different rupture size model had to be developed as the criteria for producing the consequences of interest are based on specific rupture sizes in steam and feedwater piping that were determined in a deterministic calculation, to provide sufficient release of thermal energy to activate fire protection system sprinklers located in the turbine building. In that study. rupture modes greater than $2 \mathrm{in}$. and those greater than $6 \mathrm{in}$. in equivalent break size were calculated as these break sizes were found to have different consequences in terms of fire sprinkler actuation.

In an evaluation performed in 2009 for Prairie Island [3], the rupture model developed for Kewaunee was extended to consider whether the rupture was complete and thus presenting the potential for pipe whip. The methodology for treatment of pipe rupture in the evaluation of internal flooding and HELB effects was further refined in a study performed for Columbia Generating Station and this is the methodology that is applied in this study. In this refinement, the conditional probability of pipe rupture is quantified as a continuous function of break size ranging for very small size failures that produce through wall leaks up to and including complete offset rupture of the pipe, and hence the potential for pipe whip. This approach is applied not only for HELBs in feedwater and steam systems, but also in key systems of interest to internal flooding PRA such as service water and fire protection system piping. 


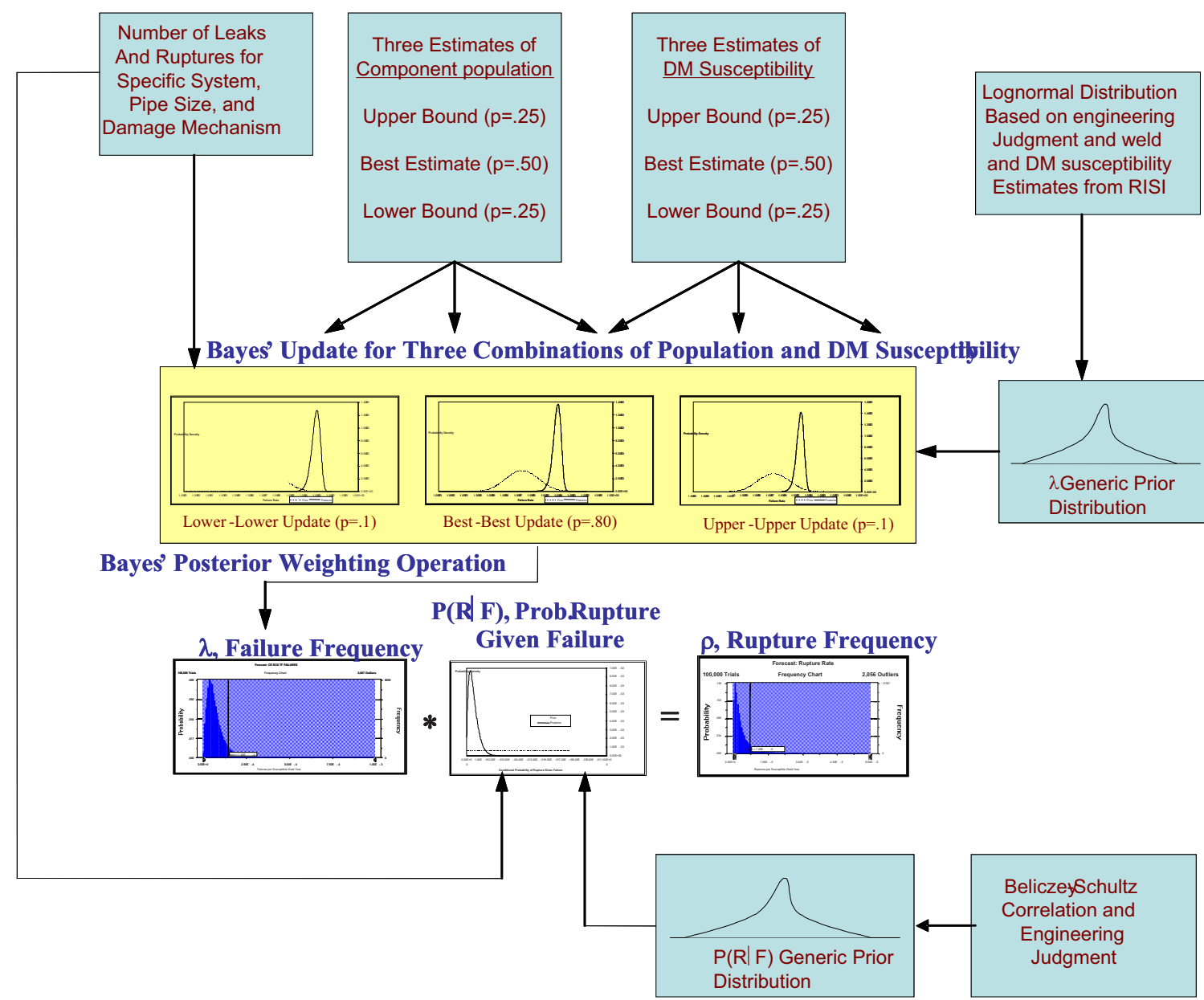

Figure 2-1 Flow Chart for Bayes' Estimates of System, Size, and Damage Mechanism Specific Pipe Failure Rates $(\lambda)$ and Rupture Frequencies $(\rho)$

\subsubsection{Markov Model for Evaluation of Integrity Management Strategies}

The reliability characteristics of piping systems are potentially influenced by various piping reliability and integrity management (RIM) programs. These include leak detection systems and surveillance programs, system leak and pressure tests, and in-service inspections involving visual and volumetric non-destructive examinations of the piping system components. When service data from industry data is applied, the resulting estimated failure rates reflect the RIM programs that were implemented on the systems in the database. A given plant that applies this generic data may have RIM programs that are different than those reflected in the generic data. Even if the plant using the data has a typical RIM program, there may be an interest in improving the piping system reliability if, for example, the calculated risks from pipe failures is too high.

Referring back to Section 2.1, the influence of the RIM programs on the pipe failure rates and rupture frequencies is accounted by the Integrity Management Factor $I_{i k}$ shown in Equations 
(2.1) and (2.3). Changes in the pipe reliability due to changes in the RIM program, i.e. changes in the way pipe inspections and leak surveillances are done, are quantified by changes in this factor. The Integrity Management Factor $l_{i k}$ is quantified using a Markov model as described below. As was the case with the Bayes' uncertainty treatment described in the previous section, the Markov model was originally developed for RI-ISI evaluations for LWR piping systems [5] and was approved by the NRC for use in these applications (see References [12] and [13]. In that application, changes in the RIM program included removing and adding inspection locations to the ISI program and improving some of the inspections by implementing the inspection for cause principle, i.e. optimizing the NDE procedure to focus on pre-determined damage mechanisms.

The Markov model for this application is described in Figure 2-2. This model is applied to each component in a piping system, including the areas of the pipe around welds and in other locations that may be subject to a degradation mechanism and the target of an RIM program to detect leaks, perform non-destructive examination (NDE) for flaws, or a combination of these. Each location is assigned four possible states to represent no degradation, degradation with detectable flaws, leak, and rupture. Transition rates between states are assigned to model the damage mechanisms producing each failure mode and two opportunities to detect damage and repair the pipe prior to its rupture. One of these represents the ISI process of detecting flaws through NDE and subsequent repair if damage is found, and the other the leak detection and repair process. The model provides the capability of modeling degradation that obeys a "leak before break" failure process as well as mechanisms that produce pipe rupture without a prior leak warning. The purpose of this model is to predict the influence of ISI exams and leak detection strategies in reducing the pipe rupture frequency.

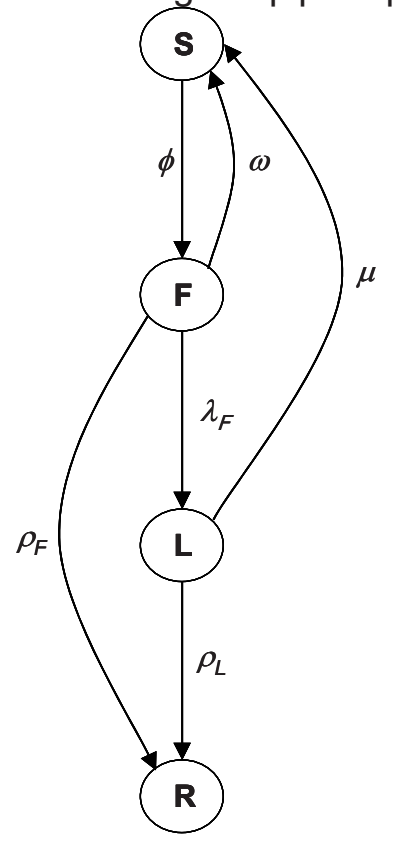

Pipe Element States

S - success, no detectable damage

$\mathrm{F}$ - flaw detectable via NDE

$\mathrm{L}$ - detectable leak

$R$ - rupture

$\underline{\text { State Transition Rates }}$

$\phi$ - flaw occurrence rate

$\lambda_{F}$ - leak failure rate given flaw

$\rho_{F}-$ rupture failure rate given flaw

$\rho_{L}$ - rupture failure rate given leak

$\omega$ - repair rate via NDE

$\mu$ - repair rate via leak detection

Figure 2-2 Markov Model for Predicting the Influences of Leak Detection and Pipe Inspections on Pipe Rupture Frequencies

The repair rates $\mu$ and $\omega$ are estimated with the help of two simple models described as follows. For the flaw repair rate $\omega$, the model of Equation (2.4) is used: 


$$
\omega=\frac{P_{I} P_{F D}}{\left(T_{F I}+T_{R}\right)}
$$

where:

$P_{l}=$ probability that a piping element with a flaw will be inspected per inspection interval. In the case where inspection locations are inspected at random, this parameter is related to the fraction of the pipe segment that is inspected during each interval and the capability of the inspection strategy to pinpoint the location of possible flaws in the pipe. When locations for the inspection are fixed, this term is either 0 or 1 depending whether it is inspected or not. When applying the model to a population of plants that produce the service data, this parameter corresponds to the fraction of the locations in the population that are subjected to ISI. For example according to ASME Section XI rules $25 \%$ of Class 1 and $7.5 \%$ of Class 2 pipe welds are subjected to inservice inspection. Other exam locations may be subject to some kind of augmented examination. There are specific augmented inspection programs for such damage mechanisms as microbiologically induced corrosion (MIC) which is important for some raw water systems, flow accelerated corrosion (FAC) which is important for steam, feedwater, and condensate systems, and stress corrosion cracking which is important for some systems with stainless steel piping and pipe locations which employed certain alloys. Most of the service data that has been generated thus far from safety related piping systems has been subjected to the ASME Section XI examination requirements as RI-ISI programs have only been in existence for the last few years.

The probability of inspection term is conditioned on, i.e. assumes the occurrence of one or more flaws in the piping element being modeled, usually a weld or piping segment with similar damage mechanism potential. This is true since this Markov model transition rate, $\omega$, is only applied to the initial state of a flaw. The model assumes that the flaw is severe enough to cause a need for repair or replacement if the NDE is successful in identifying it.

$P_{F D}=$ probability that a flaw will be detected given this segment is inspected. This parameter is related to the reliability of non destructive examination (NDE) inspection and is a conditional probability given that the location being inspected has a flaw that meets the criteria for repair according to the ASME code. This term is often referred to as the "probability of detection" or POD by NDE specialists.

$T_{F I}=$ mean time between inspections for flaws, (inspection interval)

$T_{R}=$ mean time to repair once detected. There is an assumption in this model that any significant flaw that is detected will be repaired.

Similarly, estimates of the repair rate for leaks can be estimated according to Equation (2.5):

$$
\mu=\frac{P_{L D}}{\left(T_{L I}+T_{R}\right)}
$$

where: 
$P_{L D}=$ probability that the leak in the segment will be detected per inspection

$T_{L I}=$ mean time between inspections for leaks

$T_{R}=$ as defined above but for full power applications, this time should be the minimum of the actual repair time and the time associated with any technical specification limiting condition for operation (LCO) if the leak rate exceeds technical specification requirements.

Opportunities for leak detection are highly dependent on the system in which the leak occurs as well as the specific location and size of the leak. For example, in the reactor coolant system (RCS) of an LWR, leaks of a significant magnitude would create an immediate high containment radiation alarm in the control room. In these cases, the time to inspection and repair is limited by technical specifications on RCS leakage and the time to shutdown the plant and begin the process of repair. Other leaks may not cause an alarm but would be subject to possible detection during operator walk visual inspections every shift or other opportunity for leak detection. There are some leaks that may only be detected upon periodic leak testing which may occur less often as required to meet ASME rules for different classes of pipe per ASME Section $\mathrm{XI}$ and other requirements for leak testing.

An important observation about this leak repair term $\mu$ in comparison to the flaw repair term $\omega$ is that for most leaks the detection possibilities are not normally limited to some predetermined population of welds that are inspected, however leak testing often provides an opportunity to inspect all locations system wide. Hence, given a leak of significant magnitude anywhere in the system, the probability of leak detection tends to be high. By contrast, most of the locations that could produce a non-leaking flaw are never inspected according to ASME rules, in which case the repair rate term, the flaw repair term $\omega$ is zero. Also, the time between successive inspections for leaks tends to be much shorter than for volumetric examination of welds with virtually instantaneous detection in cases when the leak would trigger an alarm in the control room. Hence, the Markov model provides the capability to take into account for the "leak before break" principle. The extent to which this principle contributes to reducing the probability of a rupture is only a function of the relative values of the Markov model transition rates as will be demonstrated in the examples that are provided in Section 3.

Typical Integrity Management factors that have been derived for a safety grade component cooling water system using ASME Class 3 pipe are illustrated in Figure 2-3 for the frequency of major flooding (flood rates $>2,000 \mathrm{gpm}$ ). These Integrity Management factors are normalized to 1 for the case with no leak detection and no NDE being applied. Two sets of bars are indicated, one for the assumption of no NDE and another with an assumption that periodic NDE is performed every 12 years at a probability of successful flaw detection of $90 \%$. These bars show the variability in the Integrity Management factor for different leak surveillance frequencies at $90 \%$ probability of successful leak detection. As seen in this example, which is typical of Markov Model applications, introduction of annual leak surveillance is responsible for an order of magnitude reduction in the major flood rupture frequency. Leak surveillance at greater frequencies is seen to obey a law of diminishing returns effect. Addition of a 12 year NDE program at $90 \%$ POD is seen to provide about a factor of 2 to 3 reduction in major flooding rupture frequency at a given leak surveillance frequency. 
In Section 3, Integrity Management Factors for service water and fire protection system piping systems are evaluated for Prairie Island Nuclear Plant. Inspection Factors for the steam, feedwater and condensate systems are not developed because these systems are already within the scope of the plant's augment FAC program.

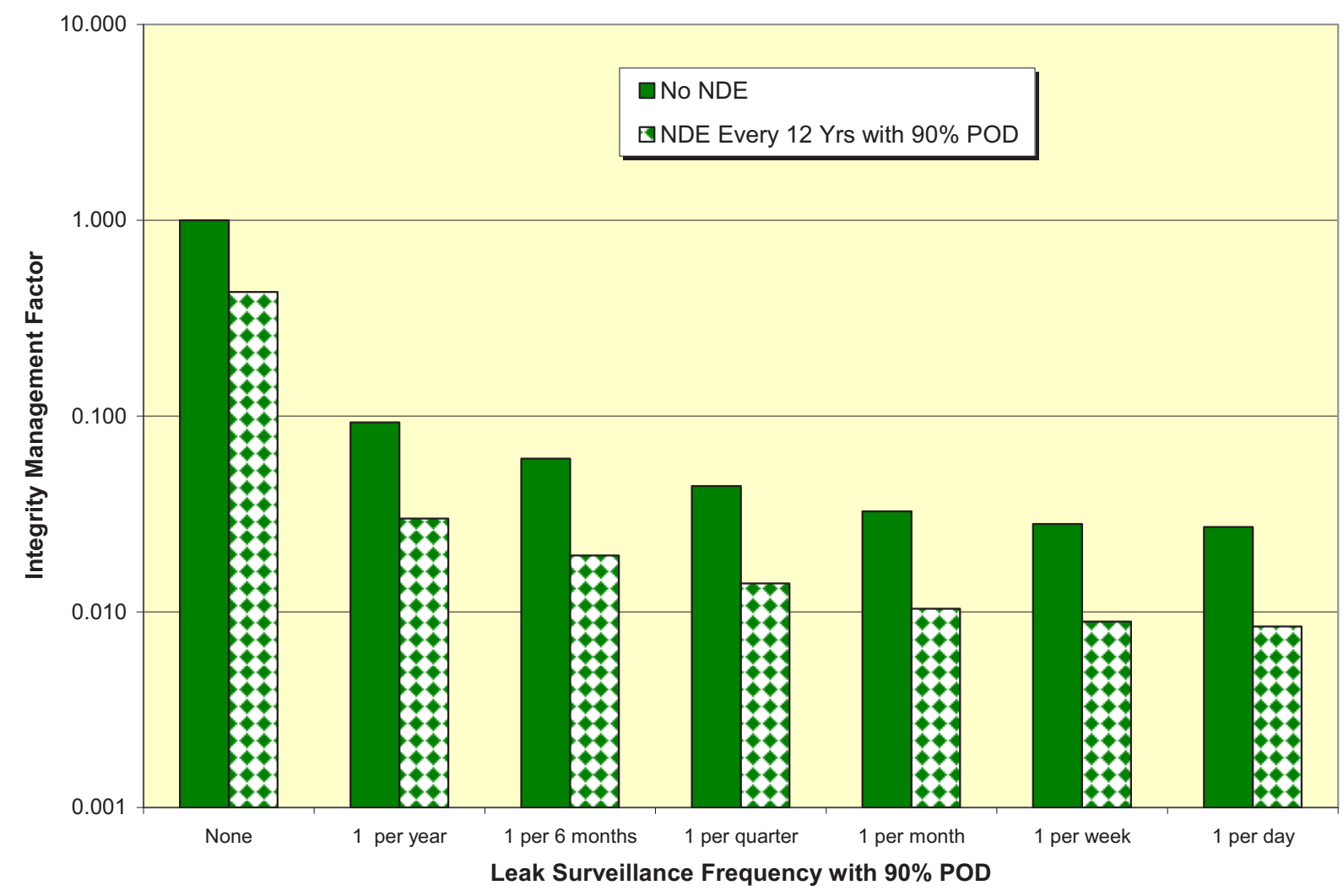

Figure 2-3 Typical Integrity Management Factor for ASME Class 3 Component Cooling Water Pipe Major Flooding (>2,000gpm) Frequency

\subsubsection{How the Markov Model is Used in PRA Applications}

The Markov model is used to set up a set of linear coupled differential equations whose solution provides the time dependent probabilities of occupying each of the four states of the model. That solution is used to derive time dependent hazard rates for the model. The time dependent hazard rates correspond with the plant age dependent rupture frequencies for each mode of failure considered in Equation (2.1). A different solution is obtained for each failure mode. As described more fully in Reference [29], a closed form analytical solution for the time dependent rupture frequencies as a function of all the input parameters is obtained and these solutions are entered into a Microsoft Excel spreadsheet. The input parameters to quantify the model include failure rates and rupture frequencies derived from service data and parameters that describe the reliability and integrity management (RIM) program. These parameters and the way they are applied in this report are defined in Table 2-1. The application of the Markov model to the evaluation of selected passive components is described in the next section. 
There is a "chicken and egg" loop that must be broken to perform this application. The failure rates and rupture frequencies that are derived from service experience assume that the Prairie Island Nuclear Plant components will be subjected to a RIM program that is the same or similar to that which the piping in the LWR service data has been historically subjected to. These rates are also derived from a population of reactors that has experienced on the average around 32 years of commercial operation. In the LWR service data, the RIM program is primarily dictated by ASME Section XI requirements for inservice inspection as well as related requirements for leak testing or pressure testing as well as augmented or owner defined inspection programs for specific damage mechanisms not addressed in Section XI. This "chicken and egg" loop is broken using the following logic.

The integrity management factor in Equation (2.1) is derived from the Markov model using the following equation:

$$
I\{t, x\}=\frac{h_{x}(t)}{h_{B A S E}(32)}=I_{x} I_{t}=\frac{h_{B A S E}(t)}{h_{B A S E}(32)} \frac{h_{x}(t)}{h_{\text {Base }}(t)}
$$

Where:

$I\{t, x\}=$ Age and Integrity management factor for RIM strategy $\mathrm{x}$ at plant age $\mathrm{t}$. As shown in this equation, this factor can be expressed as a product of separate integrity management and plant age factors. The RIM strategy includes a specification of how often and how effective leak tests and inspections and NDE exams are performed on the piping system component.

$h_{x}(t)=$ Hazard rate (time dependent rupture mode frequency) at plant age $t$ and RIM strategy $\mathrm{x}$

$h_{B A S E}(32)=$ Hazard rate (time dependent rupture mode frequency) at plant age of 32 years and RIM strategy corresponding to an "average" component in the service data. For example for ASME Class 1 components the average component is determined by $25 \%$ of the components being subjected to NDE exams every 10 years, the remain $75 \%$ not being subjected to NDE and $100 \%$ of the components being subjected to a system leak test once every refueling outage which occurs about once every 18 months on the average.

$I_{t}=$ ratio of the hazard rate at time $t$ to the hazard rate at 32 years using the base RIM strategy

$I_{x}=$ ratio of the hazard rate using RIM strategy $x$ to the hazard rate using the base RIM strategy both at time $t$. In this study time $t$ is taken to be 32 years for the base failure rates and rupture frequencies, which corresponds with the average age of the US plant population reflected in the piping service data. As a sensitivity study it is also evaluated at 40 years and 60 years to investigate the impact of aging effects at the end of the plant design life and an extended life, respectively. Evaluation of aging was not in the scope 
of this study but is provided anyway because the results are very easy to generate once the base calculations are performed.

The hazard rates are derived from the solution of the Markov model ordinary differential equations, which yields the time dependent probabilities of occupying each of the four states: $S\{t\}$ for the success state, $F\{t\}$ for the flaw state, $L\{t\}$ for the leak state, and $R\{t\}$ for the rupture state. Since we are primarily interested in the pipe rupture state, The "reliability" of the Markov model, $r\{t\}$ is simply the sum of the non-rupture state probabilities:

$$
r\{t\}=S\{t\}+F\{t\}+L\{t\}
$$

The hazard rate for the model is then obtained using the equation:

$$
h\{t\}=-\frac{\frac{d r\{t\}}{d t}}{r\{t\}}
$$

\begin{tabular}{|c|c|c|}
\hline Symbol & Definition & How Quantified in This Study \\
\hline$P_{I}$ & $\begin{array}{l}\text { Probability per inspection interval that the } \\
\text { pipe element will be inspected }\end{array}$ & $\begin{array}{l}\text { This parameter is set to } 1 \text { for components } \\
\text { assumed to be part of an NDE ISI program } \\
\text { and set to } 0 \text { if no inspections are performed. }\end{array}$ \\
\hline$P_{F D}$ & $\begin{array}{l}\text { Probability per inspection that an existing } \\
\text { flaw will be detected }\end{array}$ & $\begin{array}{l}\text { This is the "probability of detection" } \\
\text { parameter known by NDE specialists. In this } \\
\text { study a sensitivity study is performed by } \\
\text { setting this parameter to } 0 \text { for no NDE, } 0.5 \\
\text { for "Secondary NDE" and } 0.9 \text { for "Primary } \\
\text { NDE". In practice this is established from } \\
\text { programs to qualify NDE specialists. }\end{array}$ \\
\hline$P_{L D}$ & $\begin{array}{l}\text { Probability per detection interval that an } \\
\text { existing leak will be detected }\end{array}$ & $\begin{array}{l}\text { This is a function of the reliability of the test } \\
\text { being performed for leak detection. For LWR } \\
\text { applications a value of } 0.9 \text { has been } \\
\text { accepted when the leak test meets the } \\
\text { requirements of ASME Section XI }\end{array}$ \\
\hline$T_{F I}$ & $\begin{array}{l}\text { Flaw inspection interval, mean time between } \\
\text { in-service inspections }\end{array}$ & $\begin{array}{l}\text { For LWR piping subject to ASME Section XI } \\
\text { requirements this is } 10 \text { years for locations } \\
\text { that are inspected and infinity for those that } \\
\text { are not inspected. For augmented exams } \\
\text { are more frequent inspection may be } \\
\text { required. }\end{array}$ \\
\hline$T_{L D}$ & $\begin{array}{l}\text { Leak detection interval, mean time between } \\
\text { leak inspections }\end{array}$ & $\begin{array}{l}\text { This is a parameter of the test and is } \\
\text { determined by ISI requirements such as } \\
\text { ASME Section XI. In this study alternative } \\
\text { hypotheses are considered including no leak } \\
\text { test, annual, semi-annual, quarterly, monthly, } \\
\text { weekly, and 8-hour shift test intervals }\end{array}$ \\
\hline
\end{tabular}

Table 2-1 Markov Model Parameters that Vary with RIM Strategy 


\begin{tabular}{|l|l|l|}
\hline Symbol & \multicolumn{1}{|c|}{ Definition } & \multicolumn{1}{c|}{ How Quantified in This Study } \\
\hline$T_{R}$ & $\begin{array}{l}\text { Mean time to repair the piping element given } \\
\text { detection of a critical flaw or leak }\end{array}$ & $\begin{array}{l}\text { This parameter is set to } 200 \text { hours in this } \\
\text { study and the results are not sensitive to this } \\
\text { assumption }\end{array}$ \\
\hline$\lambda_{F}$ & Failure rate for Leaks given a flaw & $\begin{array}{l}\text { Taken as the failure rate for the smallest EBS } \\
\text { evaluated in this study }-0.32 \text { in.; note that } \\
\text { this } \lambda_{F} \text { is somewhat different than the } \lambda \text { used } \\
\text { in Eq. (2.3). This version includes only those } \\
\text { failures involving leaks and is conditioned on } \\
\text { the existence of a flaw, whereas the Eq. }(2.3) \\
\text { version is an unconditional failure rate that } \\
\text { includes all failure modes involving repair } \\
\text { and replacement which includes leaks and } \\
\text { non-leak events. }\end{array}$ \\
\hline$\phi$ & Occurrence Rate for detectable flaws & $\begin{array}{l}\text { Taken as a multiple ( 4) of the total failure } \\
\text { rate for the component; established in LWR } \\
\text { RI-ISI evaluations }\end{array}$ \\
\hline$\rho_{F}$ & Rupture frequency given a flaw & $\begin{array}{l}\text { Taken as the rupture frequency for each EBS } \\
\text { evaluated in this study }\end{array}$ \\
\hline$\rho_{L}$ & Rupture frequency given a leak & $\begin{array}{l}\text { Taken as the rupture frequency given a } \\
\text { severe loading condition (e.g., water } \\
\text { hammer) derived from service data. ( } 2 \times 10^{-2} \\
\text { per year); established in LWR RI-ISI } \\
\text { evaluations }\end{array}$ \\
\hline
\end{tabular}

\subsubsection{Use of the Hazard Rate to Define Time Dependent Hazard Rates}

When the Markov model transition rates are assumed to be constant in time, as has been the case in previous applications of the model, the time dependent hazard rate starts at 0 at $t=0$ and then increases according to a mixed exponential function to an asymptotic value. In practical applications of the model that have been done to support PRAs and risk informed inservice inspection evaluations, the time to reach the asymptotic hazard rate is typically much longer than the design lifetime of a nuclear power plant. In order for the model to produce ruptures, the flaw state must first be populated in order to produce any ruptures given flaws, and then the leak state must be populated to produce ruptures given leaks. These transitions are associated with pipe degradation mechanism which take significant time produce pipe failures. As the flaw and leak states become populated, opportunities to repair the pipe to the success state via NDE and leak detection aspects of the RIM strategies. Because the time to reach the steady state hazard rate is long, this formulation of the Markov model predicts a certain type of aging in the sense that the hazard rate grows with time over the practical plant lifetime. This observation then leads to a certain limited capability of the model to investigate aging, i.e. increasing pipe rupture frequencies over the plant lifetime. It is noted however, that this was not the original intent of the development of the Markov model. The original intent was to investigate how changes to the piping system RIM program, e.g. removing locations from the NDE program, may influence the pipe rupture frequencies. 


\subsubsection{Limitations and Open Issues with Piping System Reliability Models}

There are some key assumptions that are made in the current PRA treatment of piping system reliability as described in the previous sections that give rise to uncertainties and limitations in the investigation of risk informed safety margins. Some of the key assumptions in the estimation of the failure rates and rupture frequencies include the following.

- Statistical data from which to estimate pipe rupture frequencies, especially for ASME Class 1 piping systems, are sparse, making it difficult for direct estimation

- The current model assumes that all pipe failures that involve repair or replacement are precursors to more severe pipe ruptures. The advantage of this model, to the extent it can be shown to be valid, is that there are significant data involving pipe failures from which to derive statistically significant pipe failure rates. However, to be able to estimate the conditional probability of pipe rupture, it is necessary to utilize other types of models such as probabilistic fracture mechanics. This is also an area that has been addressed via expert elicitation in which results of both fracture mechanics and statistical analysis of data have been utilized as in NUREG-1829 for estimation of loss of coolant accident frequencies.

- To facilitate the treatment of uncertainties associated with the above issues, the Bayes' framework for parameter estimation described in the previous section was adopted. This leads to the important need to document the basis for the assumed prior distributions as well as the data parameters for the pipe failures and component exposure estimates.

- The current solution approach allows for the incorporation of fracture mechanics or physics of failure models for the pipe failure degradations but to date this has been primarily accomplished by using such information to develop the prior distributions. For example, information from the expert elicitation of NUREG-1829 partly based on fracture mechanics has been used to form a basis for the priors for the conditional pipe rupture probabilities.

In the original development of the Markov model in 1998 [11] the following strategy was followed to develop the model and solve the ordinary differential equations (ODEs).

- The ODEs were solved via closed form analytical solutions using the eigenvalue/eigenvector method. The motivation for this strategy was to support the ability to perform Monte Carlo uncertainty analysis using the tools available then. The analytical solutions were applied to Microsoft Excel equations and then Crystal Ball was used to propagate uncertainties in the parameters used to calculate the transition rates through the solutions. This limited the size of the model to 4 states. The polynomial that needed to be solved for this solution approach was order 3 (actually order 4 which factors down to order 3 ) which is the highest order with a closed form solution. Hence, adding a 5th state would have led to a 4th order polynomial equation which does not have a general closed form solution. Hence this model was at the limit of the calculational strategy that was selected and the tools available to the model author.

- The analytical strategy described above also forced the assumption of constant transition rates. Time dependent transition rates could have been accommodate if a numerical solution scheme were used, however this would not have enabled the Monte Carlo capability that was selected. It should also be noted that even if the tools had 
been available to use time dependent transition rates and uncertainties, there was no basis available then to estimate the time dependent behavior of these rates.

- The current model for the repair rate transitions assume that these transitions are done at a constant rate over time. However, it is typical for RIM strategies to perform NDE and some types of leak inspections on a periodic basis. This issue was investigated in the independent review carried out by the University of Maryland which compared the current model to alternative models that treat one or both of the repair transitions as periodic rather than continuous [11]. While the periodic models showed a characteristic "sawtooth" shape of the time dependent hazard rate, the envelope of the sawtooth tracked closely to the continuous model solution.

- The 4-state model only has room for one rupture state. However, in PRA applications the consequences of the pipe rupture are strongly influenced by the degree of severity of the pipe rupture. In Class 1 piping systems breaks up to about 2" in diameter are classified as "Small LOCAs" and those above 6" are regarded as "Large LOCAs". Small, medium and large LOCAs have different success criteria to prevent core damage. In internal flooding PRAs a small leak up to $100 \mathrm{gpm}$ can be effectively mitigated by room drains and sumps, where as larger breaks must be differentiated in size to characterize the time available for operator actions. When applying this Markov model to situations where there are several rupture states to be investigated, the model has been solved separately for each rupture state. An improved model would be to have multiple rupture states so the competing aspects of these states could be determined in a more integrated fashion.

- Due to the limitations with the available tools, the steps of the uncertainty analysis associated with Bayes' updating and Monte Carlo uncertainty propagation were not fully integrated. To address uncertainties in the component population exposure, Bayes updates were performed over a discrete set of hypotheses about exposure and then combined via posterior weighting. The Bayes' updating and the remaining steps of the uncertainty propagation were thus performed separately.

\subsection{Enhancements to Reliability Models Evaluated in This Study}

In light of the limitations discussed above the following enhancements to the Markov model are evaluated in this study. These enhancements, which are discussed in greater detail in Section 5 of this report, include:

- Enhanced computational tools

- A more powerful set of computational tools operated under the OpenBugs platform was used to first benchmark and then extend the original computational approach that was based on analytical solutions to the ODEs. These tools provide the capabilities to handle much larger Markov models, time dependent transition rates, and fully integrated Bayesian uncertainty analysis.

- A second set of tools (Flowgraph methodology) using a Laplace transform method of solving the ODE and an integrated uncertainty analysis capability.

- Additional states;

- Given the availability of more powerful and capable computational tools, this study investigates the addition of states to accommodate a physics of failure approach to estimation of some of the transition rates.

- The new tools also offer the capability to model several distinct rupture states which are needed to address PRA applications.

- Physics of failure models for transition rates 
- Rather than rely on statistical service data to estimate for the transition rates associated with degradation, this study investigates the development of physics of failure models for deriving these rates for selected components and degradation mechanisms. Since the incorporation of physics-based state transition models are found to violate Markov conditions (involving, for example, randomly distributed time-inhomogeneous transition rates), alternative methods for solving the transition model are explored and applied. 


\section{Selection of Passive Components for Evaluation}

\subsection{Selection of Passive Component}

The candidate systems, structures, and components (SSCs) that were considered for further evaluation under the Risk Informed Safety Margin Characterization (RISMC) were any components that may be subject to aging phenomena or safety margin reduction and are not normally replaced or are too costly to replace during the lifetime of a nuclear power plant as modified via life-extension. Such SSCs include:

- Reactor pressure vessel (RPV)

- Other piping system components

- Concrete structures

- Major structural supports

- Non-replaceable instrumentation and controls

Piping system components were considered for several reasons. These include:

- Pipe failures have a high degree of risk significance in PRA results. This risk significance includes the following elements:

- LOCA induced accident sequences, particularly those involving small LOCAs resulting from pipe ruptures up to about 2" in diameter, are significant risk contributors at essentially all U.S. plants

- Accident sequences resulting from internal flooding from pipe breaks in systems located outside the containment are risk significant, and even risk dominant contributors at some U.S. plants

- Accident sequences resulting from high energy line breaks outside the containment and inside the containment are significant risk contributors at some plants

- There have been a significant number of pipe ruptures in non-safety related systems due to degradation mechanisms such as flow accelerated corrosion (FAC) and microbiologically induced corrosion (MIC) as well as due to severe loading conditions such as water hammer. In addition there is some evidence of aging in these piping systems.

- Piping systems are comprised of passive components and are normally not planned to be replaced unless significant degradation is encountered. Extensive replacement of piping systems would be very costly and in some cases prohibitive.

\subsection{Selection of Specific Piping System Components}

The specific piping systems and components selected for further investigation under RISMC include:

- Selected ASME non-safety class piping outside the containment including:

- Fire protection system piping

○ PWR feedwater, condensate, and steam system piping 
- A selected ASME Class 1 piping system component subject to stress corrosion cracking. The particular component selected is a Westinghouse PWR surge line nozzle weld which is an example of an Alloy 82/182 dissimilar metal weld

The fire protection (FP) system was selected for several reasons. First it is the source of risk significant and risk dominant accident sequences associated with internal flooding. Due to its widespread routing throughout nuclear power plant buildings and rooms full of electrical, mechanical and control equipment it would be extremely difficult to replace. Finally it has been subject to several large pipe ruptures in the service data that involved damage to safety related SSCs.

The PWR Feed-water \& Condensate (FWC) and steam systems were selected for several reasons. First is the source of risk significant accident sequences associated with high energy line breaks and internal flooding (via actuation of the FP sprinklers). It is also the source of a significant number of pipe ruptures associated with FAC.

The reliability assessment of the non-safety related piping systems is discussed in Section 4 based on the technical approach described in Section 2. This includes a review of the service data, estimation of pipe failure rates and rupture frequencies, temporal trends in failure rates including possible aging effects, and typical applications of the Markov model to investigate alternative RIM strategies and time dependent hazard rates.

The ASME Class 1 component (Westinghouse PWR surge line nozzle weld) was selected based on rationale described in section 3.3 below. In summary, it is an example of LOCA sensitive piping that is subject to a single, dominant degradation mechanism - stress corrosion cracking. The reliability assessment of this component using the current Markov methods of Section 2 is also provided in Section 4 which includes comparisons to the non-safety related piping described above.

\subsection{Reactor Coolant System Boundaries}

This evaluation addresses passive components in the PWR Reactor Cooling System (RCS) including vessels, piping (straight pipes, fittings, safe ends, nozzles and thermal sleeves), and their degradation mechanisms. The intent is to identify a component and associated degradation mechanism as the basis for methodology development.

RCS component classes in the following vessel and piping systems are addressed:

- pressurizer

- reactor pressure vessel

- reactor coolant pump (pressure boundary)

- steam generator (pressure vessel)

- cold leg piping

- crossover leg piping

- hot leg piping

- pressurizer spray piping

- $\quad$ pressurizer surge piping

- pressurizer piping to PORVs

- pressurizer piping to SRVs and

- $\quad$ stop valve loop bypass piping. 
RCS piping systems and major components identified in NUREG/CR-6923 [30] not addressed in this Section include the internals (non-Class 1 Components) the reactor and reactor coolant pump, and steam generator internals and tubes.

During power operation, most of these components are exposed to primary water at temperatures in the range $288-327^{\circ} \mathrm{C}\left(550-620^{\circ} \mathrm{F}\right)$ but some of the pressurizer and pressurizerpiping components are exposed to saturated steam/condensate at about $343^{\circ} \mathrm{C}\left(650^{\circ} \mathrm{F}\right)$. Where pertinent, the external environment for the RCS components is containment air, which is expected to contain both moisture and chloride aerosols during outages. External surfaces are generally hot $->121^{\circ} \mathrm{C}\left(250^{\circ} \mathrm{F}\right)$ - and dry during power operation.

The materials used for the RCS include carbon steel piping clad with austenitic stainless steel, austenitic stainless steel piping, both cast and wrought form, Alloy 600, and weld filler and buttering materials. The austenitic stainless steel used for cladding and piping is either stabilized or non-stabilized [21].

\subsubsection{Failure Mechanisms}

An expert elicitation exercise was conducted for LOCA frequencies in 2008, and there were several technical insights that were consistently identified in "Estimating Loss-of-Coolant Accident (LOCA) Frequencies through the Elicitation Process," (NUREG 1829 [9]). Many participants believed that the rate of crack and leak occurrence is a precursor measure of the LOCA susceptibility for the associated degradation mechanism. Welds are almost universally recognized as likely failure locations because:

- they can have relatively high residual stress,

- are preferentially-attacked by many degradation mechanisms, and

- are most likely to have preexisting fabrication defects.

For screening components in this current study, NUREG/CR-6923 was queried to identify areas subject to specific degradation mechanisms. NUREG/CR-6923 documents a structured elicitation drawing on the knowledge of a panel of eight international experts and the use of a Phenomena Identification and Ranking Table (PIRT) process to identify and rank aging mechanisms for BWR and PWR systems.

The panel was elicited relative to a metric defining the susceptibility of a given component type to a specific degradation mechanism. NUREG/CR-6923 documents the results of the expert elicitation describing the assessed degrees of susceptibility of representative components to the identified degradation mechanisms under specified system operating conditions.

Susceptibilities were assessed on a range of $0-3$ and then averaged over the experts (with some minor caveats). Susceptibility in the range 2-3 for a component indicated that there was strong basis, possibly including service data from multiple plants, to indicate that the mechanism affects that component. A susceptibility in the range 1-2 indicated a significant basis for concluding that the mechanism affects the component, possibly with supporting service data from a single plant. Lower susceptibilities indicated that there was some conceptual basis for believing that the mechanism might affect the component, but with no verifying service data.

Components were assessed against each of the following degradation mechanisms: 


$\begin{array}{ll}\text { BAC } & \text { Boric Acid Corrosion } \\ \text { CREEP } & \text { Thermal Creep } \\ \text { CREV } & \text { Crevice Corrosion (including denting) } \\ \text { DEBOND } & \text { De-bonding } \\ \text { EC } & \text { Erosion Corrosion Including Steam Cutting and Cavitation } \\ \text { FAC } & \text { Flow-accelerated Corrosion } \\ \text { FAT } & \text { Fatigue (corrosion/thermal/mechanical) } \\ \text { FR } & \text { Reduction of Fracture Resistance } \\ \text { GALV } & \text { Galvanic Corrosion } \\ \text { GC } & \text { General Corrosion } \\ \text { IC } & \text { Irradiation Creep } \\ \text { MIC } & \text { Microbially Induced Corrosion } \\ \text { PIT } & \text { Pitting Corrosion } \\ \text { SCC } & \text { Stress Corrosion Cracking (intergranular, transgranular, irradiation-assisted, } \\ & \text { strain-induced, hydrogen-embrittlement) and Intergranular Attack } \\ \text { SW } & \text { Swelling } \\ \text { WEAR } & \text { Fretting/Wear. }\end{array}$

\subsubsection{Reactor Coolant System Vessels and Pumps}

For reactor coolant system vessels and pumps, Table 3-1 shows the significant degradation mechanisms identified in NUREG/CR-6923; that is, those for which the susceptibility level exceeds 1 . The following aging mechanisms were identified as having the potential for impacting the RCS Vessels: boric acid corrosion (BAC), crevice corrosion (CREV), debonding (DEBOND), erosion corrosion (EC), fatigue (FAT), reduction in fracture resistance (FR), pitting corrosion (PIT), and stress corrosion cracking (SCC).

Table 3-1 PWR Reactor Coolant System Vessel Degradation Mechanisms

\begin{tabular}{|c|c|c|c|c|}
\hline 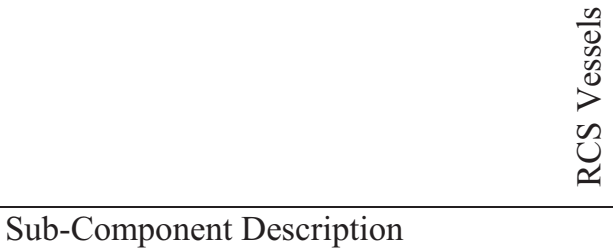 & 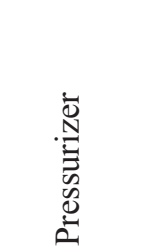 & 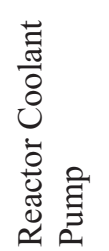 & 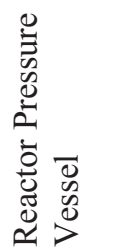 & 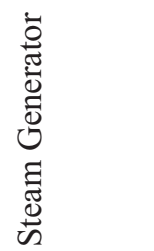 \\
\hline $\begin{array}{l}\text { Carbon and Low-Alloy Steel Components, } \\
\text { including shell/plates, forgings and welds }\end{array}$ & $\begin{array}{c}\text { BAC } \\
\text { FAT } \\
\text { FR }\end{array}$ & & $\begin{array}{c}\text { BAC } \\
\text { FAT } \\
\text { FR }\end{array}$ & $\begin{array}{l}\text { BAC } \\
\text { FAC } \\
\text { PIT } \\
\text { SCC }\end{array}$ \\
\hline $\begin{array}{l}\text { Type 308/309 Stainless Steel Clad } \\
\text { Components }\end{array}$ & $\begin{array}{l}\text { DEBOND } \\
\text { SCC }\end{array}$ & & FR & $\begin{array}{c}\text { DEBOND } \\
\text { FAT } \\
\text { FR } \\
\text { SCC }\end{array}$ \\
\hline $\begin{array}{l}\text { Wrought and Forged Type 304/316- } \\
\text { SS Components }\end{array}$ & FAT & & $\begin{array}{l}\text { FAT } \\
\text { SCC }\end{array}$ & FAT \\
\hline $\begin{array}{l}\text { Type 308/309 SS Dissimilar Welds - } \\
\text { Internal }\end{array}$ & $\begin{array}{l}\text { FAT } \\
\text { SCC }\end{array}$ & & $\begin{array}{l}\text { FAT } \\
\text { SCC }\end{array}$ & $\begin{array}{c}\text { FAT } \\
\text { FR } \\
\text { SCC }\end{array}$ \\
\hline High Strength Bolts, Studs & $\begin{array}{l}\text { BAC } \\
\text { SCC }\end{array}$ & & $\mathrm{EC}$ & \\
\hline Cast Stainless Components & & $\begin{array}{c}\text { FAT } \\
\text { FR }\end{array}$ & $\begin{array}{l}\text { FAT } \\
\text { SCC }\end{array}$ & \\
\hline
\end{tabular}




\begin{tabular}{|c|c|c|c|c|}
\hline Sub-Component Description & 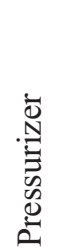 & 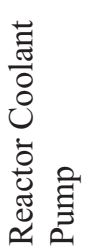 & 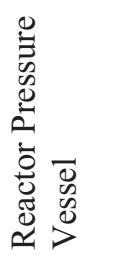 & 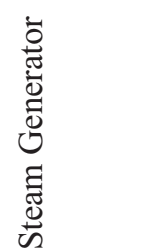 \\
\hline & & SCC & & \\
\hline Alloy 82/182 Dissimilar Welds -Internal & $\begin{array}{l}\text { FAT } \\
\text { FR } \\
\text { SCC }\end{array}$ & & $\begin{array}{l}\text { FAT } \\
\text { FR } \\
\text { SCC }\end{array}$ & $\begin{array}{l}\text { FAT } \\
\text { FR } \\
\text { SCC }\end{array}$ \\
\hline Type 308 SS Welds & $\begin{array}{l}\text { FAT } \\
\text { SCC }\end{array}$ & $\begin{array}{l}\text { FAT } \\
\text { FR } \\
\text { SCC }\end{array}$ & & \\
\hline $\begin{array}{l}\text { Inconel Alloy } 600 \text { Components } \\
\text { Nozzles, Heater and Channel Clad/Welds, }\end{array}$ & $\begin{array}{l}\text { FAT } \\
\text { SCC }\end{array}$ & & $\begin{array}{l}\text { FAT } \\
\text { SCC }\end{array}$ & $\begin{array}{c}\text { DEBOND } \\
\text { FAT } \\
\text { FR } \\
\text { SCC }\end{array}$ \\
\hline Type 304/316/308 SS Components & & & $\begin{array}{c}\text { CREV } \\
\text { FAT } \\
\text { SCC }\end{array}$ & \\
\hline Type 304/316 SS HAZ & $\begin{array}{l}\text { FAT } \\
\text { SCC }\end{array}$ & & & \\
\hline Type 308/309 Dissimilar Weld -External & SCC & & SCC & SCC \\
\hline Alloy 82/182 Dissimilar Welds -External & SCC & & SCC & \\
\hline
\end{tabular}

For the RCS Vessels, the high susceptibility ( $>2$ ) degradation mechanisms were assessed to be boric acid corrosion, fatigue and stress corrosion cracking. Fatigue and Stress Corrosion Cracking primarily impacted component classes with Alloy 600 and Alloy 82/182 makeup, although SCC was identified as an issue for the Control Rod Drive Mechanism Housing also. Boric Acid corrosion was limited to the Reactor Pressure Vessel (Low Alloy Steel).

\section{Carbon and Low-Alloy Steel Components -Shell/Plates, Forgings, Welds}

Components made of carbon steel or low-alloy steel include reactor pressure vessel shell/plates, forgings, welds, pressurizer shell/plates, forging, steam generator shell/plates, forging and LAS nozzles. Only components associated with the reactor pressure vessel shell/plates, forgings, and welds were considered to have significant susceptibility to any identified degradation mechanism. For the RPV, external boric acid corrosion of low-alloy steel is a known problem. This is most likely to occur on the upper or lower heads of the RPV due to leaking nickel-alloy welds.

The degradation mechanisms identified for the Type 304/316/308 Stainless Steel Components welds were stress corrosion cracking, fatigue and crevice corrosion, and of these only SCC was considered to have high (>2) susceptibility. Both the base metal and the weld metal were considered together with respect to these mechanisms. The components are in contact with PWR primary water normally under stagnant conditions in the temperature range of 93-316 C (200-600 F). These mechanisms were applicable to the Control Rod Drive Mechanism Housing.

The CRDM were considered susceptible to stress corrosion cracking because of the possibility of non-standard water chemistry including the presence of corrosive species and oxygen trapped after shutdowns in such dead legs although operational practices today have largely 
eliminated the risk of trapping oxygen. Cases of both transgranular and intergranular stress corrosion cracking have been reported in these components. Other aggravating factors noted were high residual stresses and cold work.

\section{Dissimilar Inconel Alloy Welds}

For components manufactured with alloys 182 and 82, SCC was identified as a generic issue which is expected to occur after exposure to PWR primary water for long periods of time $(130,000$ effective full-power hours). The PIRT panel also held the view that there is insufficient understanding of the problem to mitigate the cracking. Some panel members also indicated a need for development of inspection and prediction tools, not least because of the long and very variable crack initiation times and large dispersion in propagation rates. Sensitization in the dilution zone near the low alloy interface, cracking in the dilution zone with low alloy steels and the possibility of low temperature aging were also listed as contributing factors.

The Inconel alloy 82/182 dissimilar metal welds which fall into the highest susceptibility category $(>2)$ were found in the pressurizer, reactor pressure vessel, and steam generator. It was not always possible to distinguish between stainless steel (SS 308/309) and nickel base alloy (Alloys 182/82) weldments. The assumption used was that the welds were Alloy $182 / 82$ since these materials are considered to be much more susceptible to stress corrosion cracking than Type 308/309 stainless steels. Stress corrosion cracking was identified as high susceptibility $(>2)$ in all of the components, while fatigue was identified as high only for the RPV Dissimilar welds.

\section{Inconel Alloy 600 Components}

Alloy 600 components (other than steam generator tubes) identified as having high (>2) susceptibility for stress corrosion cracking are pressurizer alloy 600 forged austenitic nozzles on the pressurizer at $345^{\circ} \mathrm{C}\left(653^{\circ} \mathrm{F}\right)$, Alloy 600 forged austenitic nozzles on the reactor pressure vessel at $327^{\circ} \mathrm{C}\left(620^{\circ} \mathrm{F}\right)$ maximum, and pressurizer cold-worked Alloy 600 heater cladding and attachment pads in CE plants.

The panel noted that Alloy 600, in particular forged or cold-worked material, is vulnerable to stress corrosion cracking in PWR primary water and that this is considered to be a generic problem. The mechanism is not fully understood and the initiation times are long and unpredictable.

\subsubsection{Reactor Coolant System Piping}

For reactor coolant piping components Table 6-2 shows the degradation mechanisms identified in NUREG/CR-6923 to be significant (susceptibility >1). The following aging mechanisms were identified as having a significant impact on the life of the MCL piping components: fatigue (thermal, vibrational), reduction in fracture resistance (thermal aging), primary water stress corrosion cracking, and boric acid corrosion, pitting (atmospheric corrosion) and swelling.

For the RCS piping systems and components the high susceptibility (>2) degradation mechanisms were fatigue and stress corrosion cracking. Fatigue was identified as high for Stainless Steel 304/308/316 Socket Welds in the Cold Leg, Crossover Leg, Hot Leg, Pressurizer Spray, Pressurizer Surge and Pressurizer Piping to the PORVs. SCC was identified as high susceptibility in 308/309 Dissimilar metal welds (exterior) in the Cold Leg, Crossover Leg, and Hot Leg Piping. 


\section{Socket Welds}

Socket welds are known to fail in service. The mode of failure may be a combination of high frequency vibration fatigue, corrosion fatigue and stress corrosion cracking. However, the only high susceptibility mechanism identified in NUREG/CR-6923 was fatigue. The geometry of socket welds makes them prone to low and high cycle fatigue owing to the fact that they are a relatively flexible attachment to a more robust component. The loading will depend on the design details and flow induced vibrations, and there will also be residual welding stresses and possibly other stresses introduced by, for example, excessive grinding during manufacture. The condition of the stainless steel is unknown and may be sufficiently sensitized to be prone to stress corrosion cracking in the hydrogenated environment together with the probable presence of cold work and ripple loading.

Fatigue of the Stainless Steel 304/308/316 Socket Welds was identified in the Cold Leg Piping, Crossover Leg Piping, Hot Leg Piping, Pressurizer Spray Piping, Pressurizer Surge Piping, and Pressurizer Piping to the PORVs.

\section{Type 308/309 Dissimilar Weld -External}

External stress corrosion cracking is an issue identified in 308/309 stainless steel dissimilar metal welds in the Cold Leg Piping, Crossover Leg Piping, and Hot Leg Piping. This issue affects components which are insulated and therefore are at or near the operating temperature $293-327^{\circ} \mathrm{C}\left(559-620^{\circ} \mathrm{F}\right)$. However, cracking may even occur before the component is placed into service. For the external surfaces of these welds, stress corrosion cracking was considered the only significant degradation mechanism.

Table 3-2 PWR Reactor Coolant System Piping Degradation Mechanisms

\begin{tabular}{|c|c|c|c|c|c|c|c|c|}
\hline 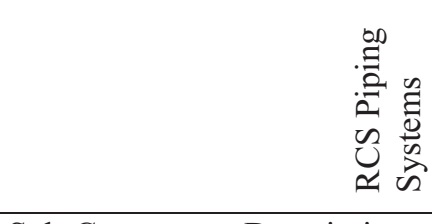 & 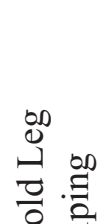 & 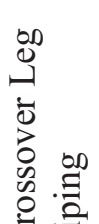 & $\begin{array}{l}.0 \\
.0 \\
\stackrel{0}{0} \\
0 \\
0 \\
0 \\
0 \\
0 \\
0\end{array}$ & 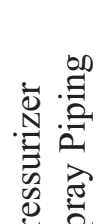 & 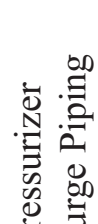 & 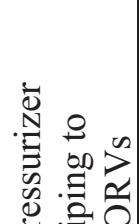 & 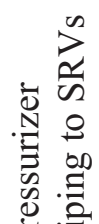 & 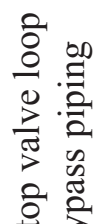 \\
\hline Sub-Component Description & & & & & & $=\overline{0}$ & $\equiv \bar{E}$ & \\
\hline SS 304/316 Piping & FAT & FAT & FAT & & FAT & FAT & FAT & $\begin{array}{l}\text { FAT } \\
\text { SCC }\end{array}$ \\
\hline SS 304 Piping HAZ & $\begin{array}{l}\text { FAT } \\
\text { SCC }\end{array}$ & $\begin{array}{l}\text { FAT } \\
\text { SCC }\end{array}$ & $\begin{array}{l}\text { FAT } \\
\text { SCC }\end{array}$ & $\begin{array}{l}\text { FAT } \\
\text { SCC }\end{array}$ & $\begin{array}{l}\text { FAT, } \\
\text { SCC }\end{array}$ & $\begin{array}{l}\text { FAT } \\
\text { SCC }\end{array}$ & $\begin{array}{l}\text { FAT } \\
\text { SCC }\end{array}$ & $\begin{array}{l}\text { FAT } \\
\text { SCC }\end{array}$ \\
\hline SS 316 Piping HAZ & $\begin{array}{l}\text { FAT } \\
\text { SCC }\end{array}$ & $\begin{array}{l}\text { FAT } \\
\text { SCC }\end{array}$ & $\begin{array}{l}\text { FAT } \\
\text { SCC }\end{array}$ & $\begin{array}{l}\text { FAT } \\
\text { SCC }\end{array}$ & $\begin{array}{l}\text { FAT } \\
\text { SCC }\end{array}$ & $\begin{array}{l}\text { FAT } \\
\text { SCC }\end{array}$ & $\begin{array}{l}\text { FAT } \\
\text { SCC }\end{array}$ & $\begin{array}{l}\text { FAT } \\
\text { SCC }\end{array}$ \\
\hline Type 308 SS Weld & $\begin{array}{l}\text { FAT } \\
\text { FR } \\
\text { SCC }\end{array}$ & $\begin{array}{l}\text { FAT } \\
\text { FR } \\
\text { SCC }\end{array}$ & $\begin{array}{c}\text { FAT } \\
\text { FR } \\
\text { SCC }\end{array}$ & $\begin{array}{l}\text { FAT } \\
\text { FR } \\
\text { SCC }\end{array}$ & $\begin{array}{c}\text { FAT } \\
\text { FR } \\
\text { SCC }\end{array}$ & $\begin{array}{c}\text { FAT } \\
\text { FR } \\
\text { SCC }\end{array}$ & $\begin{array}{c}\text { FAT } \\
\text { FR } \\
\text { SCC }\end{array}$ & $\begin{array}{c}\text { FAT } \\
\text { FR } \\
\text { SCC }\end{array}$ \\
\hline $\begin{array}{l}\text { Type } 308 / 309 \text { Dissimilar } \\
\text { Weld -Internal }\end{array}$ & $\begin{array}{c}\text { FAT } \\
\text { FR } \\
\text { SCC }\end{array}$ & $\begin{array}{l}\text { FAT } \\
\text { FR } \\
\text { SCC } \\
\end{array}$ & $\begin{array}{c}\text { FAT } \\
\text { FR } \\
\text { SCC } \\
\end{array}$ & & & & & \\
\hline $\begin{array}{l}\text { CASS CF8/CF8M } \\
\text { Components }\end{array}$ & $\begin{array}{l}\text { FAT } \\
\text { FR }\end{array}$ & $\begin{array}{l}\text { FAT } \\
\text { FR }\end{array}$ & $\begin{array}{l}\text { FAT } \\
\text { FR }\end{array}$ & & & & & $\begin{array}{c}\text { FAT } \\
\text { FR }\end{array}$ \\
\hline
\end{tabular}




\begin{tabular}{|c|c|c|c|c|c|c|c|c|}
\hline Sub-Component Description & 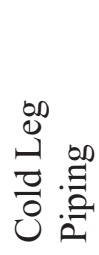 & 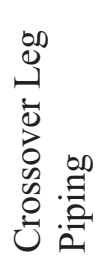 & 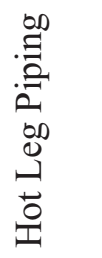 & 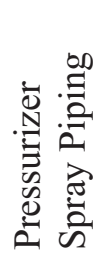 & 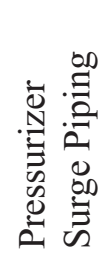 & 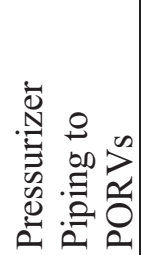 & 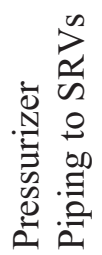 & 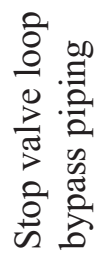 \\
\hline & SCC & SCC & SCC & & & & & SCC \\
\hline SS 304/308/316 Socket & FAT & FAT & FAT & FAT & FAT & FAT & & \\
\hline Welds & $\mathrm{SCC}$ & $\mathrm{SCC}$ & $\mathrm{SCC}$ & $\mathrm{SCC}$ & $\mathrm{SCC}$ & $\mathrm{SCC}$ & & \\
\hline $\begin{array}{l}\text { Forged } 304 / 308 / 316 \mathrm{SS} \\
\text { Nozzles }\end{array}$ & FAT & FAT & FAT & FAT & FAT & FAT & FAT & FAT \\
\hline $\begin{array}{l}\text { Type 308/309 Dissimilar } \\
\text { Weld -External }\end{array}$ & $\mathrm{SCC}$ & $\mathrm{SCC}$ & $\mathrm{SCC}$ & & & & & \\
\hline CASS CF8/CF8M Piping & $\begin{array}{c}\text { FAT } \\
\text { FR } \\
\text { SCC }\end{array}$ & $\begin{array}{c}\text { FAT } \\
\text { FR } \\
\text { SCC }\end{array}$ & $\begin{array}{c}\text { FAT } \\
\text { FR } \\
\text { SCC } \\
\end{array}$ & & & & & \\
\hline SS Clad Ferritic Piping & $\begin{array}{l}\text { BAC } \\
\text { SCC }\end{array}$ & $\begin{array}{l}\text { BAC } \\
\text { SCC }\end{array}$ & & & & & & \\
\hline
\end{tabular}

\subsubsection{Weld Locations}

This section addresses the high susceptibility 82/182 weld locations in the RCS (based on a Westinghouse Pressurized Water Reactor). Alloy 82/182 butt welds in a typical Westinghouse 3 - loop design plant are summarized in Table 4.3-3 and shown in Figure 4.3-1. Westinghouse plants have stainless steel primary coolant piping. As a result, there are large diameter (DM) butt welds between the stainless steel piping and the low-alloy steel reactor pressure vessel and steam generators.

Other Alloy 82/182 pipe butt welds greater than or equal to 1" NPS, and operating at cold leg temperature and above, are between the low-alloy steel pressurizer and the stainless steel surge, spray, and safety/relief valve lines.

Table 6-3 reflects typical location and types of Class 1 Alloy 82/182 welds in the Reactor Coolant System based on a Westinghouse PWR (EPRI MRP 139NP).

Table 3-3 High SCC Alloy 82/182 Welds in RCS

\begin{tabular}{|l|c|c|c|l|}
\hline Application & $\begin{array}{l}\text { Reference } \\
\text { Number in } \\
\text { Figure 4.3-1 }\end{array}$ & $\begin{array}{l}\text { Typical } \\
\text { Temperature } \\
\left({ }^{\circ} \text { F) }\right.\end{array}$ & $\begin{array}{l}\text { Typical } \\
\text { ID } \\
\text { (inches) }\end{array}$ & $\begin{array}{l}\text { 3 Loop } \\
\text { Typical } \\
\text { Quantity }\end{array}$ \\
\hline $\begin{array}{l}\text { Reactor Pressure Vessel (PMMD 10) } \\
\text { - Reactor Vessel Outlet - Hot Leg } \\
\text { - Reactor Vessel Inlet - Cold leg }\end{array}$ & 4 & $600-620$ & 29 & 1 \\
\hline Steam Generator (PMMD 11) & 7 & $550-560$ & 27.5 & \\
- S/G Outlet Nozzle & 6 & $550-560$ & -- & \\
- S/G Inlet Nozzle & 5 & $600-620$ & & \\
\hline Pressurizer (PMMD 4) & 1 & 653 & 10 & 1 \\
- Surge Line Nozzle & 2 & & 4 & 1 \\
- Spray line Nozzle & 3 & & 5 & 4 \\
- Safety / Relief Nozzles & & & \\
\hline
\end{tabular}




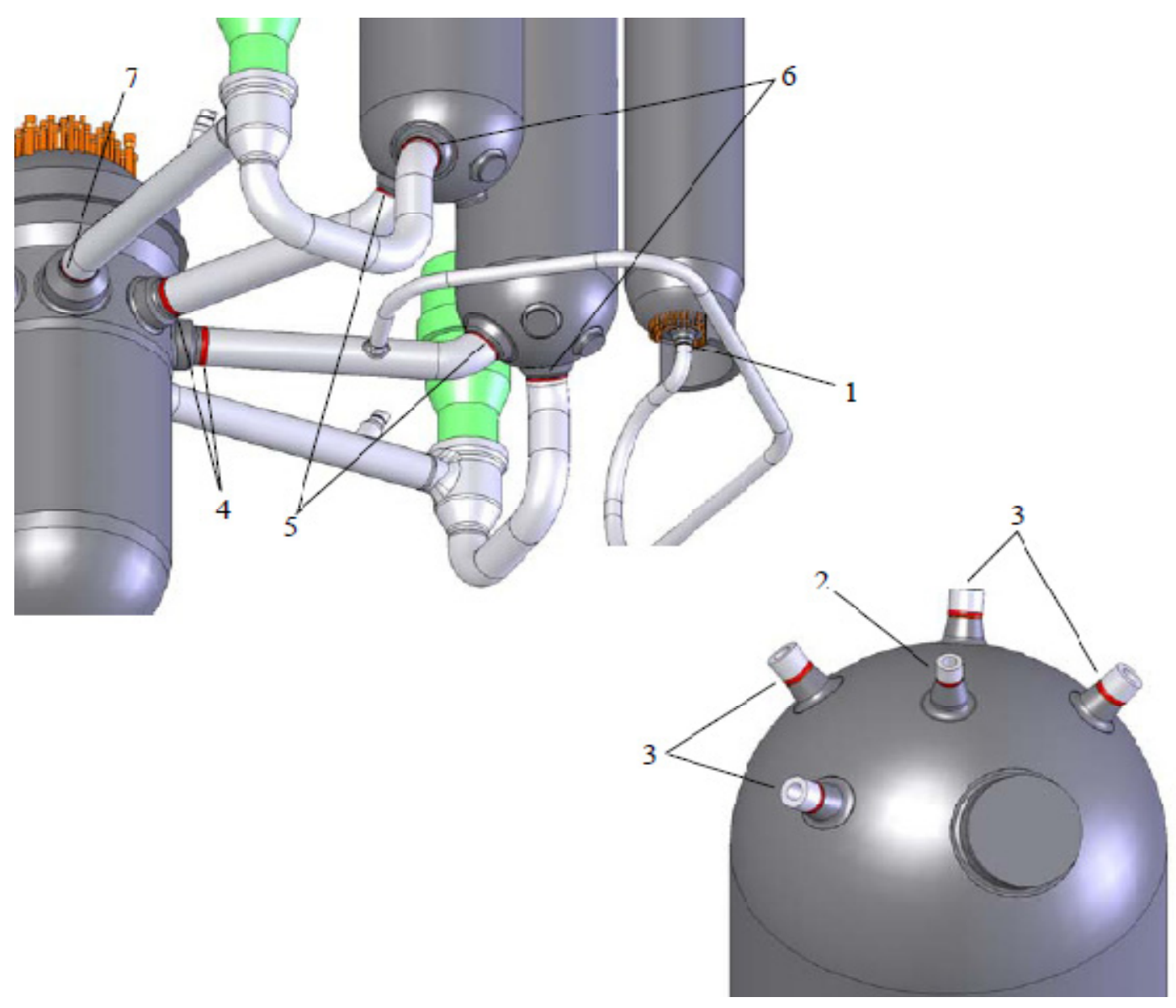

Figure 3-1 Location of High SCC Alloy 82/182 Welds in RCS

\subsubsection{High Susceptibility RCS Degradation Mechanisms}

Insights from NUREG/CR-6923 and NUREG-1829 on the susceptibility of RCS components to various degradation mechanisms were summarized in Section 3.1.2. This section provides supplementary technical description of the leading degradation mechanisms.

\subsubsection{Fatigue}

Fatigue encompasses the formation and propagation of cracks caused by stress and strain cycling of a material. Mechanical load, water pressure, and temperature variations in the reactor can all contribute to stress and strain cycling. Environment can be a contributing factor to the fatigue cracking process, and this type of fatigue is often referred to as environmental fatigue. The phenomenon of fatigue cracking is normally considered as a two step process; crack initiation that is followed by crack growth.

Fatigue crack growth is further differentiated by whether it is high cycle fatigue or low cycle fatigue. High cycle fatigue is characterized by a relatively high load cycling frequency with stresses that are below the yield stress of the material. High cycle fatigue is typical driven by mechanically induced stresses such as vibrations due to pumps, variations in water pressure, or 
flow induced vibration. In some instances, such as locations in a reactor where hot and cold water mix, high cycle fatigue can be driven by temperature variations on a component. For high cycle fatigue, crack initiation times are very long while fatigue crack growth rates are relatively fast.

Low cycle fatigue is characterized by high stresses typically exceeding the yield stress of the material, and large stress variations. The actual driving force for cracking is large strain cycling of the material. This type of loading is often driven by processes that occur over longer periods of time and is usually driven by a combination of loading factors, e.g. temperature change, water pressure change, and mechanical loading change. The classic example of this is reactor startup and shutdown. Crack initiation occurs readily during low cycle fatigue, and thus it is the fatigue crack rate that characterizes component life time for this degradation process. Both types of fatigue take place in class I piping. High cycle mechanical vibration plays a role in the lifetime of small pipe attachments to larger components (e.g. socket welds), while low cycle fatigue contributes during reactor startup and shutdown.

\subsubsection{Stress Corrosion Cracking}

Stress corrosion cracking (SCC) in light water reactor environments is driven by stress, oxidation, and passive film formation. The overall SCC phenomenon is often broken up into two processes - crack initiation and crack growth. The phenomenon of crack initiation is relatively simple in concept; pitting or an existing defect act as a site for a stress riser, and more importantly, water chemistry changes (driven by stagnation) that promotes the formation of an SCC crack. Initiation time, however, has been difficult to characterize due to difficulty in observing the formation of a crack. Only in the last few years have new methods been developed that have the promise to identify cracks at much earlier stages that what was previously possible. The sensitivity of initiation to the presence of preexisting defects and microstructural features in the near surface complicates the application of any initiation data to engineering structures.

Crack growth after the formation of a crack has been studied in much greater detail. As mentioned above, SCC requires the formation of a passive film on the material. SCC is driven by strong chemistry changes at the crack tip caused by water stagnation and material stress that cause preferential breakup of the passive film at the crack tip over other locations on the surface of the material. SCC mechanisms can be broken up into two basic categories, anodic and cathodic reactions. An anodic reaction is one where dissolution of the material at the crack tip occurs while an example of a cathodic reaction would be hydrogen evolution, absorption, and diffusion that leads to a hydrogen embrittlement type cracking response.

\subsubsection{Boric Acid Corrosion}

BAC is a degradation process that affects only carbon and low alloy steel components. Under normal reactor operating conditions, boric acid concentration in the reactor coolant water is below any value that could induce significant corrosion in these materials, and stainless steel cladding is used to shield low alloy steel from the coolant water. However, when a crack forms that leads to carbon or low allow steel material, the boric acid concentration in the crack can become quite high, especially for a through wall crack where boric acid is left behind as water escapes from the component. 


\subsubsection{Comparison of Applicable Degradation Mechanisms}

Fatigue has historically been considered to be the primary degradation mechanism that would allow a through wall crack to form and possibly lead to pipe rupture, either axially or circumferentially (guillotine break), and the leak before break (LBB) assessment concept was developed with fatigue cracking as the dominant mechanism. LBB existed in this state for many years. In more recent years, it has become clear that SCC is the dominant mechanism that can lead to through wall crack formation. Studies are now underway, via the NRC Extremely Low Probability of Rupture (xLPR) program [43], to determine whether the LBB assessment method can be adapted to stress corrosion cracks. Thus, it is clear that there is currently a strong interest in understanding how stress corrosion cracks will affect reactor component lifetime, providing a strong rationale for addressing SCC in a Markov setting.

BAC plays a minor and well understood role in the degradation of class 1 piping and will not be considered further. Both fatigue and SCC are accelerated by temperature, and this temperature dependence is manifested in a growing number of issues and concern with class I piping components at high temperature such as the hot leg and pressurizer components, including parts of the surge line.

Because of the LOCA-significant location, dissimilar weld materials, high susceptibility to stress corrosion cracking, and significant non-detection probability, the selected component for further analysis was a PWR pressurizer surge line nozzle alloy 182/82 dissimilar butt weld. This component provided an excellent selection to investigate enhanced computational approaches to solve the Markov model ordinary differential equations (ODEs) as well as to explore the use of physics of failure models to enhance the capabilities of the current passive component reliability models used in PRAs. Benchmarks to evaluate advanced computational approaches to solve the Markov model are presented in Section 5. Section 6 documents progress made in developing physics of failure models. 


\section{EVALUATION OF PIPE FAILURE RATES IN SELECTED PASSIVE COMPONENTS}

The purpose of this section is to summarize the results of the reliability assessment of the passive components selected in Section 3 using the methods and service data described in Section 2 and Appendix A, respectively. The non-safety related passive components that were selected include: piping in the fire protection system of currently operating nuclear power plants, piping in the feedwater, condensate, and steam systems of PWRs that are susceptible to flow accelerated corrosion. This section provides a summary of the results of the reliability assessment, a limited analysis of temporal trends in the service data including possible aging effects, and some information on how the rupture frequencies are expected to change as a result of changes in the piping system Reliability and Integrity Management Program. Details in the development of this information for the fire protection and feedwater and condensate system are found in Appendix B. Some of the details in the development of the reliability assessments for the ASME Class 1 nozzles are outlined in this section, and expanded in Section 5 in the context of the Benchmark problem.

\subsection{Fire Protection System Piping}

\subsubsection{Data Collection for Fire Protection System}

The data analysis for fire protection system piping is presented in this section. The approach taken for this system is to update the service data developed in Reference [1], which was based on service experience at 34 plants and 851 reactor years from 1970 to 12-31-2005. The results presented here are for the same 34 plants and service experience through 3-31-2009 which adds 144.4 reactor years of service data for a total of 965.5 reactor years. While this is somewhat less than that used to develop the estimates for the service water systems, it is more than adequate to establish a valid statistical basis. The pipe lengths for 3 categories of fire protection system pipe sizes are the same as those from Reference [1] and are listed in Table 4-1.

Table 4-1 Pipe Lengths Used to Establish Fire Protection System Exposure

\begin{tabular}{|c|c|}
\hline Nominal Pipe Size (NPS) & $\begin{array}{c}\text { Pipe Length per Reactor } \\
{[\mathrm{ft}]}\end{array}$ \\
\hline NPS $\leq 4 "$ (sprinkler supply, hose stations) & 3,012 \\
\hline 4" $<$ NPS $\leq 6$ " (risers) & 1,920 \\
\hline NPS $>$ 6" (header piping) & 1,390 \\
\hline Totals: & 6,322 \\
\hline
\end{tabular}

The service data with pipe failures in the Fire Protection System is summarized in Table B-25 in terms of failure mode, pipe size category and failure mechanism. In comparison with the service data reported in Reference [1], this data exhibits a somewhat higher frequency in pipe failures and the number of significant rupture events has increased from 1 (Columbia water hammer event) to 3 . A total of 20 of the 138 observed piping system failures, including the Columbia event were due to water hammer. 
Table 4-2 Fire Protection System Failure Counts by Failure Mode, Pipe Size and Failure Mechanism

\begin{tabular}{|c|c|c|c|c|c|c|}
\hline \multirow{2}{*}{$\begin{array}{c}\text { Pipe } \\
\text { Diameter } \\
\text { [inch] }\end{array}$} & \multirow{2}{*}{$\begin{array}{c}\text { Failure / Degradation } \\
\text { Mechanism }\end{array}$} & \multicolumn{5}{|c|}{ Number of Failure Records (1970-2009) } \\
\hline & & All & $\begin{array}{l}\text { Wall } \\
\text { Thinning }\end{array}$ & $\begin{array}{l}\text { Pinhole } \\
\text { Leak }\end{array}$ & Leak & Rupture \\
\hline \multirow{7}{*}{ NPS $\leq 4 "$} & Corrosion & 24 & 0 & 23 & 1 & 0 \\
\hline & Design and Construction Errors & 6 & 0 & 3 & 2 & 1 \\
\hline & Erosion Corrosion & 1 & 0 & 1 & 0 & 0 \\
\hline & Erosion-Cavitation & 0 & 0 & 0 & 0 & 0 \\
\hline & Water Hammer & 0 & 0 & 0 & 0 & 0 \\
\hline & Vibration fatigue & 4 & 0 & 2 & 2 & 0 \\
\hline & NPS $\leq 4 "$ Totals: & 35 & 0 & 29 & 5 & 1 \\
\hline \multirow{7}{*}{$\begin{array}{c}4<\underset{\text { NPS }}{ } \leq \text { " } \\
6 "\end{array}$} & Corrosion & 19 & 3 & 12 & 3 & 1 \\
\hline & Design and Construction Errors & 3 & 0 & 2 & 1 & 0 \\
\hline & Erosion Corrosion & 2 & 0 & 2 & 0 & 0 \\
\hline & Erosion-Cavitation & 1 & 0 & 1 & 0 & 0 \\
\hline & Water Hammer & 3 & 0 & 0 & 3 & 0 \\
\hline & Vibration fatigue & 1 & 0 & 0 & 1 & 0 \\
\hline & $4<$ NPS $\leq 6 "$ Totals: & 29 & 3 & 17 & 8 & 1 \\
\hline \multirow{7}{*}{ NPS > 6" } & Corrosion & 49 & 11 & 33 & 5 & 0 \\
\hline & Design and Construction Errors & 5 & 0 & 3 & 2 & 0 \\
\hline & Erosion Corrosion & 3 & 0 & 3 & 0 & 0 \\
\hline & Erosion-Cavitation & 0 & 0 & 0 & 0 & 0 \\
\hline & Water Hammer & 17 & 0 & 2 & 14 & 1 \\
\hline & Vibration fatigue & 0 & 0 & 0 & 0 & 0 \\
\hline & NPS > 6" Totals: & 74 & 11 & 41 & 21 & 1 \\
\hline & System Totals: & 138 & 14 & 87 & 34 & 3 \\
\hline
\end{tabular}

\subsubsection{Estimates of Failure Rates and Rupture Frequencies}

The results were developed using the methodology presented in Section 2 which include the following steps. 
1. Failure rates and rupture frequencies are developed per linear foot of pipe and reactoroperating year. This form is useful for supporting internal flooding PRAs which must address many different flood areas in a nuclear power plant. Within the PRA the internal flood initiating event frequencies are developed in terms of events per reactor-calendar year so the accident sequence frequencies are in the proper units for PRA applications.

2. Different failure rates and rupture frequencies are developed for different pipe size categories selected to capture the range of pipe sizes used in this system in existing nuclear power plants.

3. Rupture frequencies are estimated as the product of the failure rate and the conditional probability of pipe rupture, which in turn is a function of the rupture break size. A range of pipe break sizes ranging from a small through wall leak up to and including complete severance of the pipe is considered.

4. Bayes' prior distributions are developed based on piping system reliability estimates that were available prior to the collection of service data

5. Uncertainty in the pipe component exposure that produced the failure counts was addressed by using different hypotheses about the variation of exposure about the point estimates derived from plant data. Separate Bayes' updates of the common prior are made for each hypothesis of component exposure.

6. Conditional probabilities as a function of break size are also estimated using a Bayes update procedure using prior distributions based on expert opinion and updated based on counts of failures in each discrete rupture size category.

7. Final results are obtained in terms of exceedance frequency, i.e. the frequency of a pipe rupture that exceeds an indicated break size from a small through wall leak up to and including complete severance of the pipe. The family of curves produced by Monte Carlo propagation of the Bayes' uncertainties in the failure rates, posterior weighting of the posterior distribution over the different hypotheses about exposure, and the conditional rupture mode probabilities express the epistemic uncertainty in the rupture frequency.

A summary of the results for the pipe rupture exceedance frequency, i.e. frequency of pipe ruptures equal to or greater than an equivalent break size (EBS), is shown in Figure 4-1 for a FP system header with assumed NPS of 24" for three cases: the results of the current study with and without the design features to protect against water hammer, and the results from the an EPRI study published in 2006 based on service data through 2004[1]. These results reflect several differences relative to the earlier EPRI study, including an increase in the rupture frequency for EBS up to several inches due to an observed increase in the frequency of FP failures and ruptures in the service data in last hundred reactor-years of experience since 2004, perhaps due to aging or improvements in the event reporting systems. There are significant reductions in pipe rupture frequency due to the design features to limit the contribution of water hammer, but since water hammer is only a significant but not a dominant failure mechanism, these improvements are not as dramatic as perhaps might be expected. (Note: The typical header size is NPS12 - i.e., the largest size FP pipe found in plants.) 


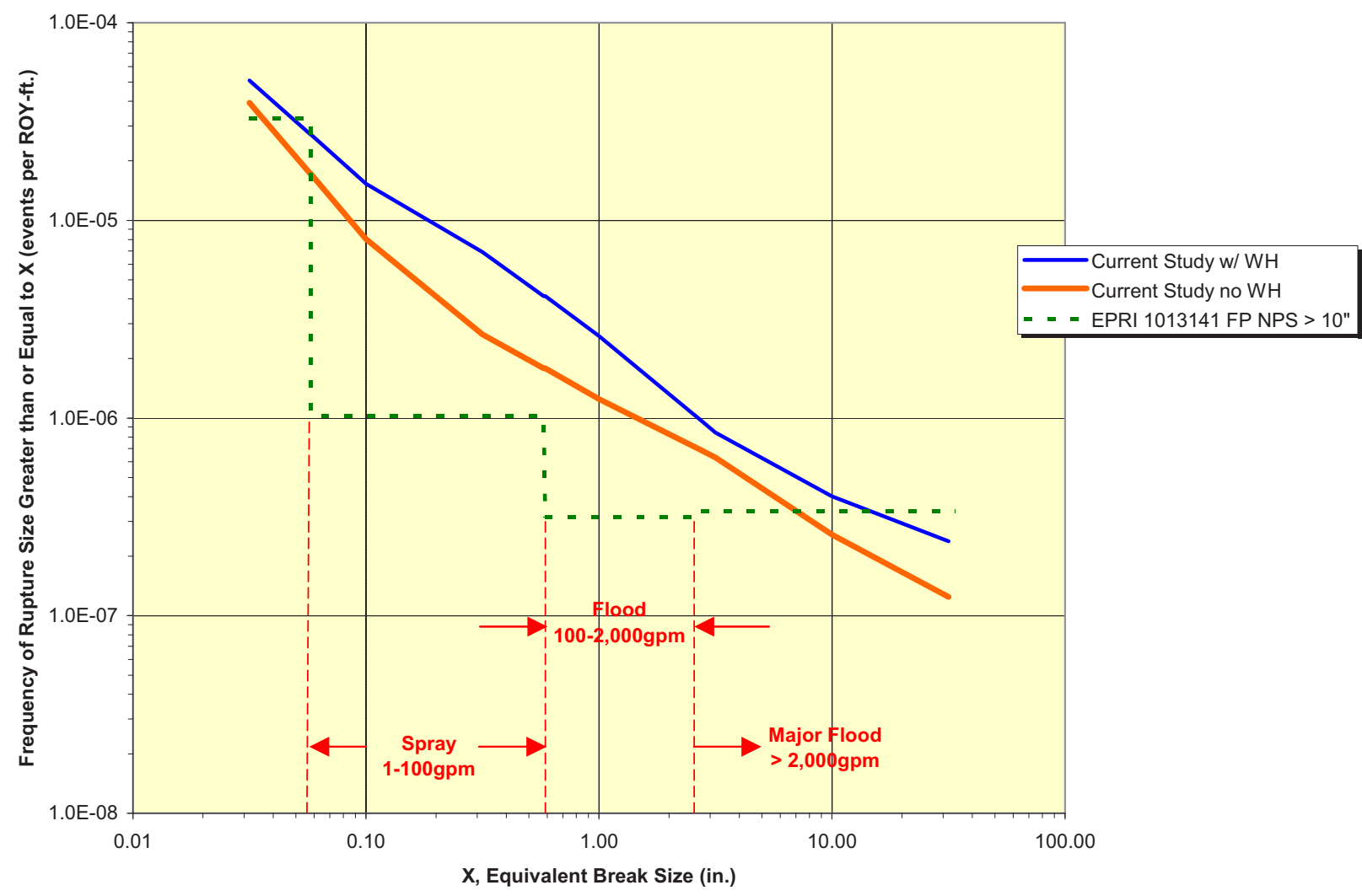

Figure 4-1 Results for Rupture Frequency vs. Break Size for NPS 24" FP Header

As will be shown in the next section, very significant additional improvements can be realized by adding some leak inspections and/or volumetric NDE to the RIM program for the FP system. If there are already RIM strategies in the Columbia FP system beyond those reflected in the service data, those are not credited in this figure.

Because few plants have design features to protect the FP system against water hammer, the remaining results presented for the FP system assume no such protection. The failure rates and cumulative rupture frequencies for FP system headers with nominal pipe size of 24" with no credit for water hammer protection are presented in Figure 4-2 and Table 4-3. Failure rate and cumulative rupture frequencies for other pipe sizes are found in Appendix B. 


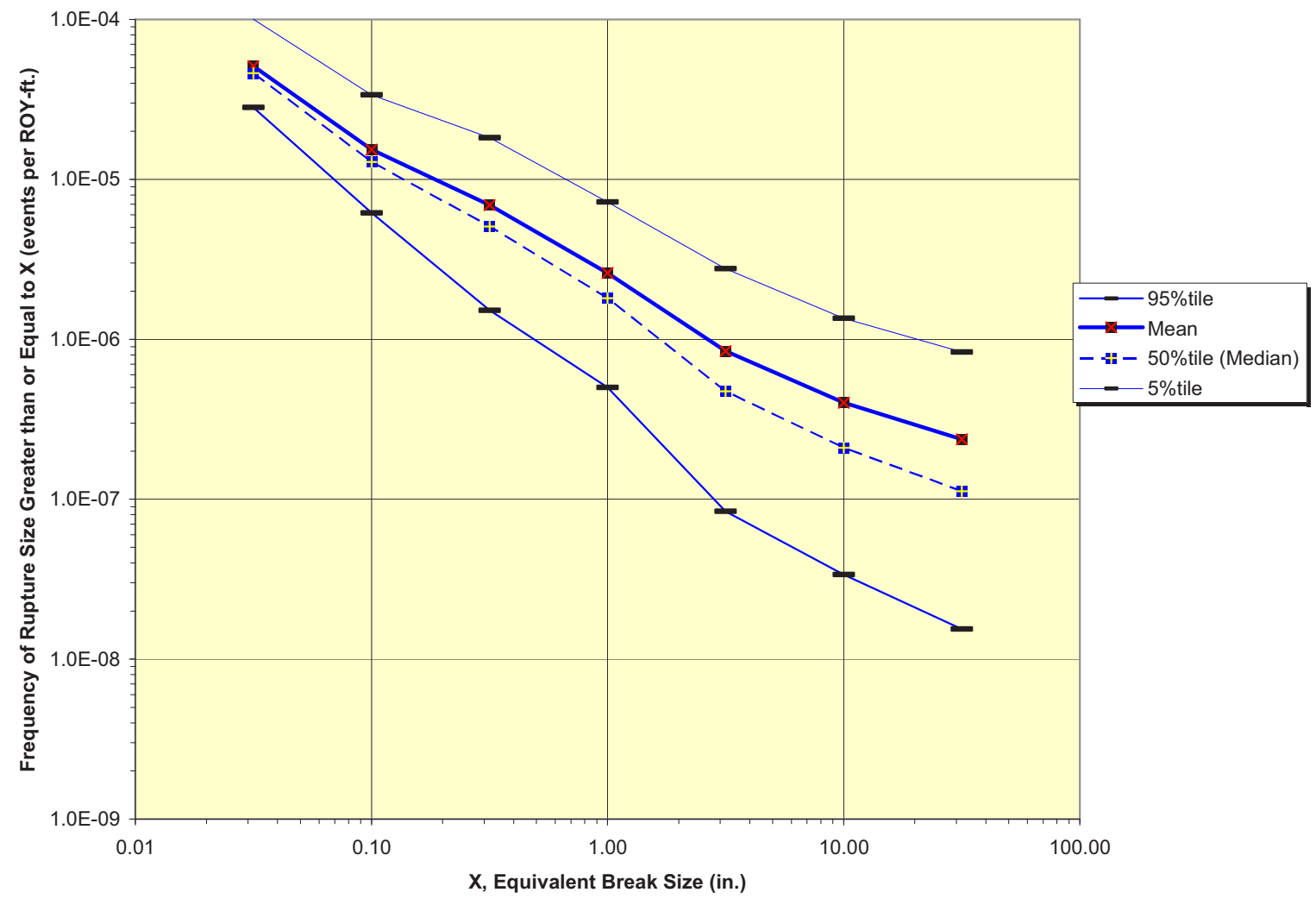

Figure 4-2 Cumulative Pipe Rupture Frequency for FP NPS 24"

\subsubsection{Impact of Alternative Inspection and Surveillance Strategies for FP System}

The impact of alternative inspection strategies to reduce the frequency of pipe rupture was evaluated using the Markov Model and selected results are shown in Table 4-4, and in Figure 4-3. Table 4-4 and show how varying the frequency of leak testing with and without additional NDE and a fixed $90 \%$ POD for both strategies change the Integrity Management factor. Table 4-6 shows how alternative POD with fixed frequencies of NDE (every 10 years) and leak testing (every quarter) impact the Integrity Management factor. These Integrity Management Factors are evaluated for the plant age of 32 years which corresponds to the average age of the plants in the service data. 
Table 4-3 Failure Rates and Cumulative Rupture Frequencies for FP NPS 24" and No Water Hammer Protection

\begin{tabular}{|c|c|c|c|c|c|c|}
\hline \multirow{2}{*}{\multicolumn{2}{|c|}{ Parameter }} & \multicolumn{5}{|c|}{ Frequency per ROY-ft. } \\
\hline & & Mean & $5 \%$ tile & $50 \%$ tile & $95 \%$ tile & $\mathrm{RF}^{[\text {Note 1] }}$ \\
\hline \multicolumn{2}{|c|}{ Failure Rate } & $5.66 \mathrm{E}-05$ & $3.50 \mathrm{E}-05$ & $5.27 \mathrm{E}-05$ & $1.06 \mathrm{E}-04$ & 1.74 \\
\hline \multirow{9}{*}{ 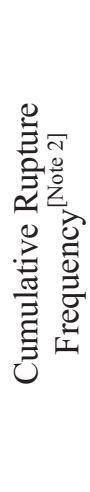 } & EBS (in.) & & & & & \\
\hline & 0.032 & $5.10 \mathrm{E}-05$ & $2.82 \mathrm{E}-05$ & 4.60E-05 & $1.00 \mathrm{E}-04$ & 1.89 \\
\hline & 0.10 & $1.53 \mathrm{E}-05$ & $6.18 \mathrm{E}-06$ & $1.28 \mathrm{E}-05$ & $3.38 \mathrm{E}-05$ & 2.34 \\
\hline & 0.316 & $6.90 \mathrm{E}-06$ & $1.52 \mathrm{E}-06$ & $5.08 \mathrm{E}-06$ & $1.82 \mathrm{E}-05$ & 3.47 \\
\hline & 1.00 & $2.60 \mathrm{E}-06$ & $5.01 \mathrm{E}-07$ & $1.81 \mathrm{E}-06$ & 7.23E-06 & 3.80 \\
\hline & 3.16 & $8.45 \mathrm{E}-07$ & $8.41 \mathrm{E}-08$ & 4.73E-07 & $2.76 \mathrm{E}-06$ & 5.73 \\
\hline & 10.00 & 4.02E-07 & 3.38E-08 & $2.10 \mathrm{E}-07$ & $1.35 \mathrm{E}-06$ & 6.32 \\
\hline & 31.62 & 2.37E-07 & $1.54 \mathrm{E}-08$ & $1.13 \mathrm{E}-07$ & 8.34E-07 & 7.36 \\
\hline & 33.94 & 7.73E-08 & 4.99E-09 & $3.66 \mathrm{E}-08$ & 2.69E-07 & 7.34 \\
\hline
\end{tabular}

Note $1 . \mathrm{RF}=(95 \% \text { tile/5\%tile })^{0.5}$; These distributions can be approximated as lognormal distributions with the indicated mean and the calculated range factor (RF)

Note 2. Frequency of pipe rupture with EBS equal to or greater than indicated EBS value

Table 4-4 Impact of Alternative Leak Detection Strategies to Reduce Fire Protection System Pipe Rupture Frequencies

\begin{tabular}{|c|c|c|c|c|}
\hline \multirow{3}{*}{$\begin{array}{c}\text { Equivalent } \\
\text { Break Size } \\
\quad \text { (in.) }\end{array}$} & \multicolumn{4}{|c|}{ No NDE with Variable Leak Testing Frequency } \\
\hline & \multirow[t]{2}{*}{$\begin{array}{l}\text { Base Rate } \\
\text { per ROY-ft. }\end{array}$} & \multicolumn{3}{|c|}{$\begin{array}{c}\text { Factor Reduction in Base Rate for } \\
\text { Periodic Leak Test @ 90\% POD }\end{array}$} \\
\hline & & Yearly & Quarterly & Weekly \\
\hline 0.032 & 3.57E-05 & 7.60E-01 & 7.34E-01 & 7.29E-01 \\
\hline 0.10 & 8.43E-06 & 4.60E-01 & 4.01E-01 & 3.89E-01 \\
\hline 0.32 & 4.30E-06 & 3.33E-01 & $2.61 \mathrm{E}-01$ & 2.46E-01 \\
\hline 1.0 & 1.76E-06 & 2.21E-01 & 1.36E-01 & 1.19E-01 \\
\hline 3.2 & 4.43E-07 & 1.47E-01 & $5.42 \mathrm{E}-02$ & 3.56E-02 \\
\hline 10 & 1.64E-07 & 1.29E-01 & 3.47E-02 & 1.56E-02 \\
\hline 31.6 & 1.60E-07 & 1.24E-01 & $3.44 \mathrm{E}-02$ & $9.30 \mathrm{E}-03$ \\
\hline 34 & 7.73E-08 & $1.24 \mathrm{E}-01$ & $2.84 \mathrm{E}-02$ & 9.30E-03 \\
\hline
\end{tabular}


Table 4-5 Impact of NDE and Alternative Leak Detection Strategies to Reduce Fire Protection System Pipe Rupture Frequencies

\begin{tabular}{|c|c|c|c|c|c|}
\hline \multirow{3}{*}{$\begin{array}{l}\text { Equivalent } \\
\text { Break Size } \\
\quad \text { (in.) }\end{array}$} & \multicolumn{5}{|c|}{$\begin{array}{c}\text { NDE every } 10 \text { years at } 90 \% \text { POD with Variable Leak Testing } \\
\text { Frequency }\end{array}$} \\
\hline & \multirow[t]{2}{*}{$\begin{array}{l}\text { Base Rate } \\
\text { per ROY-ft. }\end{array}$} & \multicolumn{4}{|c|}{$\begin{array}{c}\text { Factor Reduction in Base Rate for Periodic Leak } \\
\text { Test @ 90\% POD }\end{array}$} \\
\hline & & None & Yearly & Quarterly & Weekly \\
\hline 0.032 & 3.57E-05 & 3.62E-01 & 2.50E-01 & $2.41 \mathrm{E}-01$ & 2.40E-01 \\
\hline 0.10 & 8.43E-06 & 4.03E-01 & $1.52 \mathrm{E}-01$ & 1.32E-01 & $1.28 \mathrm{E}-01$ \\
\hline 0.32 & 4.30E-06 & $4.21 \mathrm{E}-01$ & $1.11 \mathrm{E}-01$ & 8.59E-02 & $8.10 \mathrm{E}-02$ \\
\hline 1.0 & 1.76E-06 & 4.36E-01 & 7.42E-02 & 4.49E-02 & 3.93E-02 \\
\hline 3.2 & 4.43E-07 & 4.46E-01 & 5.00E-02 & 1.79E-02 & 1.17E-02 \\
\hline 10 & 1.64E-07 & 4.49E-01 & 4.42E-02 & 1.15E-02 & $5.15 E-03$ \\
\hline 31.6 & $1.60 \mathrm{E}-07$ & 4.49E-01 & 4.41E-02 & 1.14E-02 & 5.06E-03 \\
\hline 34 & 7.73E-08 & 4.50E-01 & 4.24E-02 & 9.41E-03 & 3.06E-03 \\
\hline
\end{tabular}


Table 4-6 Integrity Management Factors for Various Combinations of NDE and Leak Inspections for Fire Protection System

\begin{tabular}{|c|c|c|c|c|c|c|c|}
\hline \multicolumn{8}{|c|}{ NO NDE with Quarterly Leak Testing and Variable Leak Testing POD } \\
\hline EBS & $\begin{array}{l}\text { No Leak } \\
\text { Test }\end{array}$ & $\mathrm{POD}=.50$ & $\mathrm{POD}=.60$ & $\mathrm{POD}=.70$ & $\mathrm{POD}=.80$ & $\mathrm{POD}=.90$ & $\mathrm{POD}=1.00$ \\
\hline 0.03 & $1.00 \mathrm{E}+00$ & 7.39E-01 & 7.37E-01 & 7.36E-01 & 7.35E-01 & 7.34E-01 & 7.33E-01 \\
\hline 0.10 & $1.00 \mathrm{E}+00$ & 4.12E-01 & 4.08E-01 & 4.05E-01 & 4.03E-01 & 4.01E-01 & 4.00E-01 \\
\hline 0.32 & $1.00 \mathrm{E}+00$ & 2.74E-01 & 2.69E-01 & 2.66E-01 & 2.63E-01 & 2.61E-01 & 2.59E-01 \\
\hline 1.00 & $1.00 \mathrm{E}+00$ & $1.52 \mathrm{E}-01$ & 1.46E-01 & 1.42E-01 & 1.39E-01 & 1.36E-01 & 1.34E-01 \\
\hline 3.20 & $1.00 \mathrm{E}+00$ & 7.14E-02 & $6.50 \mathrm{E}-02$ & 6.04E-02 & 5.69E-02 & 5.42E-02 & $5.20 \mathrm{E}-02$ \\
\hline 10.00 & $1.00 \mathrm{E}+00$ & 5.22E-02 & 4.57E-02 & 4.10E-02 & $3.74 \mathrm{E}-02$ & 3.47E-02 & $3.24 \mathrm{E}-02$ \\
\hline 31.60 & $1.00 \mathrm{E}+00$ & 5.19E-02 & 4.54E-02 & 4.07E-02 & 3.72E-02 & 3.44E-02 & 3.22E-02 \\
\hline 34.00 & $1.00 \mathrm{E}+00$ & 4.61E-02 & $3.95 \mathrm{E}-02$ & $3.48 \mathrm{E}-02$ & $3.12 \mathrm{E}-02$ & $2.84 \mathrm{E}-02$ & 2.62E-02 \\
\hline \multicolumn{8}{|c|}{ 10yr. NDE with $50 \%$ POD with Quarterly Leak Testing with Variable Leak Testing POD } \\
\hline EBS & $\begin{array}{l}\text { No Leak } \\
\text { Test }\end{array}$ & $\mathrm{POD}=.50$ & $\mathrm{POD}=.60$ & $\mathrm{POD}=.70$ & $\mathrm{POD}=.80$ & $\mathrm{POD}=.90$ & $\mathrm{POD}=1.00$ \\
\hline 0.03 & 5.31E-01 & 3.69E-01 & 3.69E-01 & 3.68E-01 & 3.67E-01 & 3.67E-01 & 3.67E-01 \\
\hline 0.10 & 5.69E-01 & 2.06E-01 & 2.04E-01 & 2.03E-01 & 2.01E-01 & 2.01E-01 & 2.00E-01 \\
\hline 0.32 & 5.85E-01 & 1.37E-01 & 1.35E-01 & 1.33E-01 & 1.32E-01 & $1.30 \mathrm{E}-01$ & 1.30E-01 \\
\hline 1.00 & 5.99E-01 & 7.63E-02 & 7.33E-02 & 7.12E-02 & 6.95E-02 & 6.83E-02 & 6.73E-02 \\
\hline 3.20 & 6.09E-01 & 3.59E-02 & 3.26E-02 & 3.03E-02 & 2.85E-02 & 2.72E-02 & 2.61E-02 \\
\hline 10.00 & 6.11E-01 & 2.63E-02 & $2.30 \mathrm{E}-02$ & 2.06E-02 & 1.88E-02 & 1.74E-02 & 1.63E-02 \\
\hline 31.60 & $6.11 \mathrm{E}-01$ & 2.62E-02 & $2.28 \mathrm{E}-02$ & $2.05 E-02$ & 1.87E-02 & 1.73E-02 & 1.61E-02 \\
\hline 34.00 & $6.12 \mathrm{E}-01$ & $2.32 \mathrm{E}-02$ & 1.99E-02 & $1.75 \mathrm{E}-02$ & 1.57E-02 & 1.43E-02 & 1.31E-02 \\
\hline \multicolumn{8}{|c|}{ 10yr. NDE with $90 \%$ POD with Quarterly Leak Testing with Variable Leak Testing POD } \\
\hline EBS & \begin{tabular}{|l|} 
No Leak \\
Test
\end{tabular} & $\mathrm{POD}=.50$ & $\mathrm{POD}=.60$ & $\mathrm{POD}=.70$ & $\mathrm{POD}=.80$ & $\mathrm{POD}=.90$ & $\mathrm{POD}=1.00$ \\
\hline 0.03 & $3.62 \mathrm{E}-01$ & 2.43E-01 & $2.42 \mathrm{E}-01$ & 2.42E-01 & 2.42E-01 & 2.41E-01 & $2.41 \mathrm{E}-01$ \\
\hline 0.10 & 4.03E-01 & 1.36E-01 & $1.34 \mathrm{E}-01$ & 1.33E-01 & $1.33 \mathrm{E}-01$ & 1.32E-01 & 1.31E-01 \\
\hline 0.32 & 4.21E-01 & 9.04E-02 & 8.87E-02 & 8.75E-02 & 8.66E-02 & 8.59E-02 & 8.53E-02 \\
\hline 1.00 & 4.36E-01 & 5.02E-02 & $4.82 \mathrm{E}-02$ & 4.68E-02 & 4.58E-02 & 4.49E-02 & 4.43E-02 \\
\hline 3.20 & 4.46E-01 & $2.37 \mathrm{E}-02$ & $2.15 \mathrm{E}-02$ & $2.00 \mathrm{E}-02$ & 1.88E-02 & 1.79E-02 & 1.72E-02 \\
\hline 10.00 & 4.49E-01 & 1.74E-02 & 1.52E-02 & 1.36E-02 & $1.24 \mathrm{E}-02$ & 1.15E-02 & 1.07E-02 \\
\hline 31.60 & 4.49E-01 & 1.73E-02 & $1.51 \mathrm{E}-02$ & 1.35E-02 & 1.23E-02 & 1.14E-02 & 1.06E-02 \\
\hline 34.00 & 4.50E-01 & 1.53E-02 & 1.31E-02 & $1.15 \mathrm{E}-02$ & 1.03E-02 & 9.41E-03 & 8.66E-03 \\
\hline
\end{tabular}

Depending on the break size pipe rupture frequency reductions of upwards of two orders of magnitude can be achieved in the pipe rupture frequency by periodic leak testing with a moderate to high probability of detection. As shown in Figure 4-3 it is seen that these strategies will more than offset the unexpected increases we found when updating the fire protection 
system failure rates to account for service data from 2004 to 2009 compared with the earlier EPRI report [1].

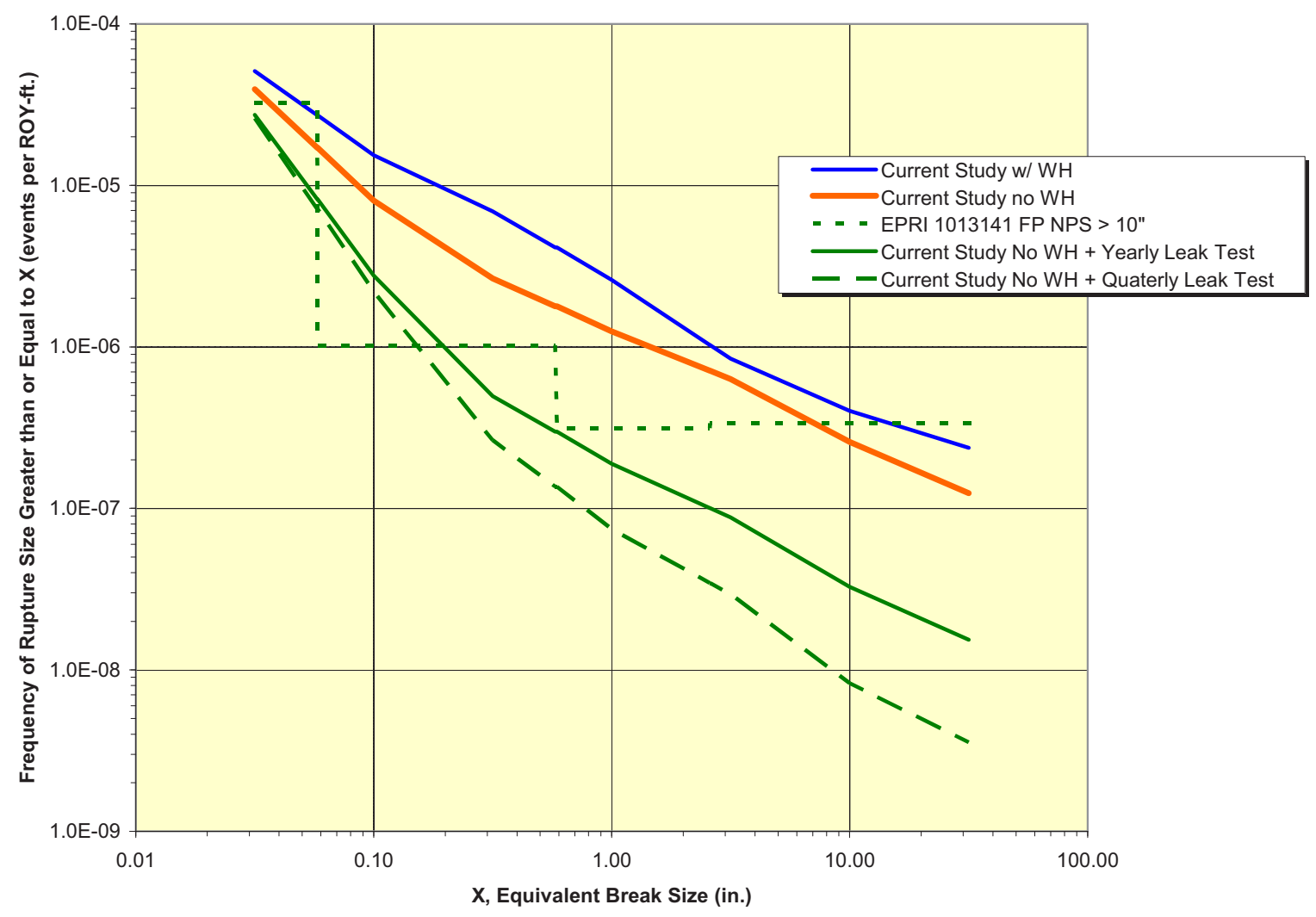

Figure 4-3 Impact of Design and Inspection Strategies to Reduce the Frequency of Fire Protection Header Pipe Ruptures

\subsubsection{Impact of Plant Age on Estimated Failure Rates for FP System}

The impact of plant age on FP system pipe failure rates vs. EBS can be evaluated by using the expression in Equation 2.2 in which the hazard rate at various plant ages is normalized against that for a plant age of 32 years which corresponds to the average plant age of the plants that produced the service data used to estimate the base failure rates. The factor increases with age and EBS. For the larger break sizes, the Markov model suggests that pipe rupture frequencies are expected to increase by a factor of 1.5 in the 8 years until $40 y$ rs, a factor of 3 increase to $60 \mathrm{yrs}$., and a factor of 5 increase at age $80 \mathrm{yrs}$. This information is presented in Table 4-7. 
Table 4-7 Factors To Account for Aging Effects on NPS 24" FP Header

\begin{tabular}{|c|c|c|c|c|c|}
\hline \multirow{2}{*}{\multicolumn{2}{|c|}{ Pipe Failure Mode }} & \multirow{2}{*}{$\begin{array}{l}\text { Base } \\
\text { Rates } \\
\text { (mean) }\end{array}$} & \multicolumn{3}{|c|}{$\begin{array}{l}I_{T} \text {, Factor Increase to Account } \\
\text { for Aging at Time } T\end{array}$} \\
\hline & & & $\begin{array}{l}40 \\
\text { Years }\end{array}$ & $\begin{array}{c}60 \\
\text { Years }\end{array}$ & 80 Years \\
\hline \multicolumn{2}{|c|}{ All Failure Modes } & 5.66E-05 & 1.3 & 2.2 & 3.1 \\
\hline \multirow{8}{*}{ EBS (in.) } & 0.032 & 5.10E-05 & 1.3 & 2.2 & 3.1 \\
\hline & 0.10 & 1.53E-05 & 1.4 & 2.6 & 3.9 \\
\hline & 0.32 & $6.90 \mathrm{E}-06$ & 1.4 & 2.7 & 4.2 \\
\hline & 1.0 & 2.60E-06 & 1.5 & 2.9 & 4.5 \\
\hline & 3.2 & 8.45E-07 & 1.5 & 3.0 & 4.7 \\
\hline & 10 & 4.02E-07 & 1.5 & 3.0 & 4.7 \\
\hline & 31.6 & 2.37E-07 & 1.5 & 3.0 & 4.7 \\
\hline & 34 & 7.73E-08 & 1.5 & 3.0 & 4.8 \\
\hline
\end{tabular}

These estimates of increases in rupture frequencies due to plant age arise from the time dependent behavior of the hazard rates as discussed more fully in Section 2. A plot of the hazard rates for selected break sizes for the 24" FP header is shown in Figure 4-4 which shows that the rate of growth of the hazard rate slows as the break size is increased. Eventually, each of the hazard rates reaches an asymptote that corresponds to one of the eigenvalues of the solution to the ordinary differential equations (ODEs) that are derived from the Markov Model. However, the time to reach these asymptotes is typically much longer than a reactor lifetime on the order of hundreds of years. The rate approach is dependent on the model transition rates. A sensitivity study was performed on the hazard rate for 3.2in breaks holding all the transition rates at their base case values except for the frequency of detectable flaws. The results are shown in Figure 4-5 which shows that the asymptote is approached more rapidly as the ratio of the flaw rate to the failure rate for leaks increases from its reference value of 4 to higher values. 


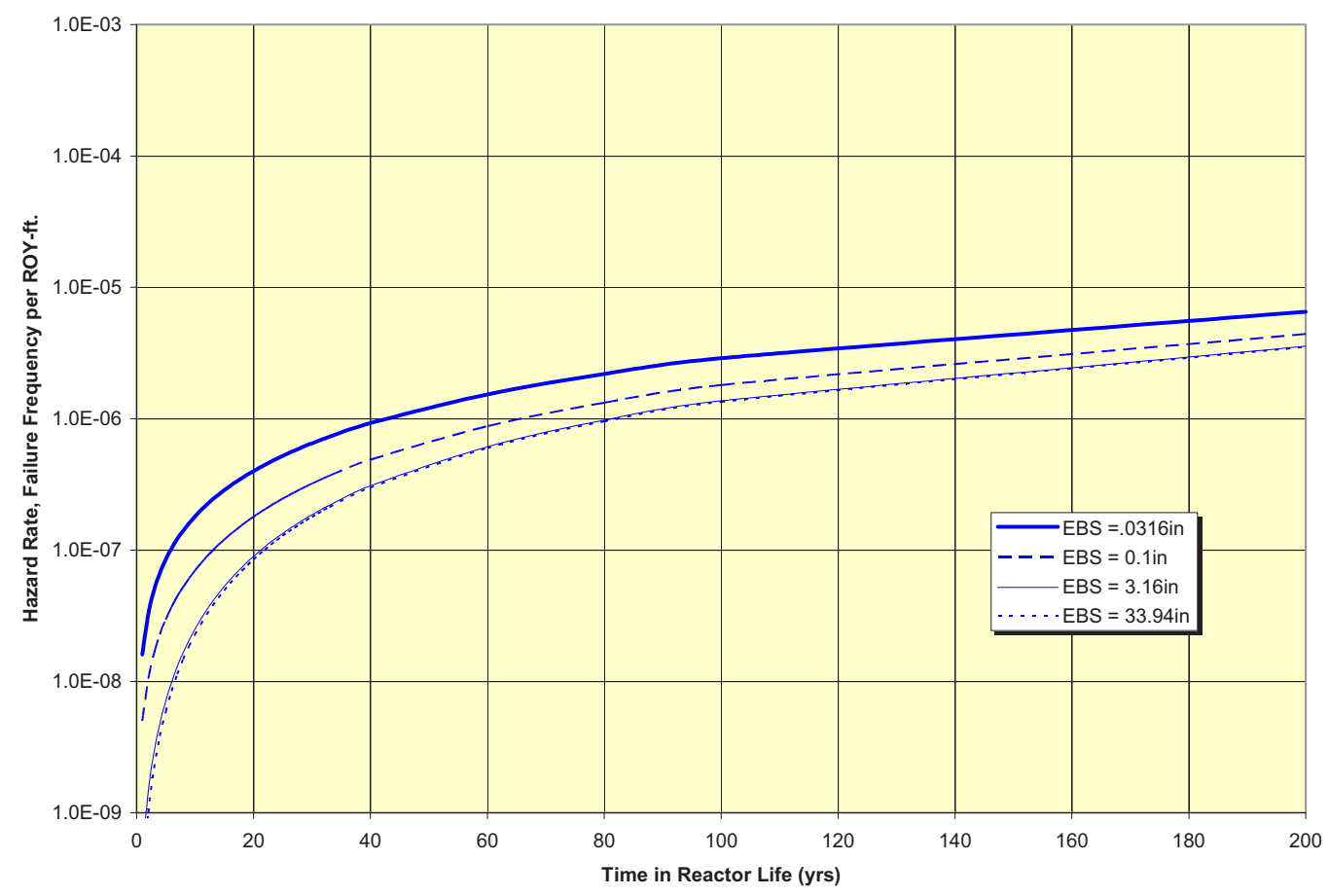

Figure 4-4 Plant Age Dependent Hazard Rates for Selected Break Sizes in 24" FP Pipe

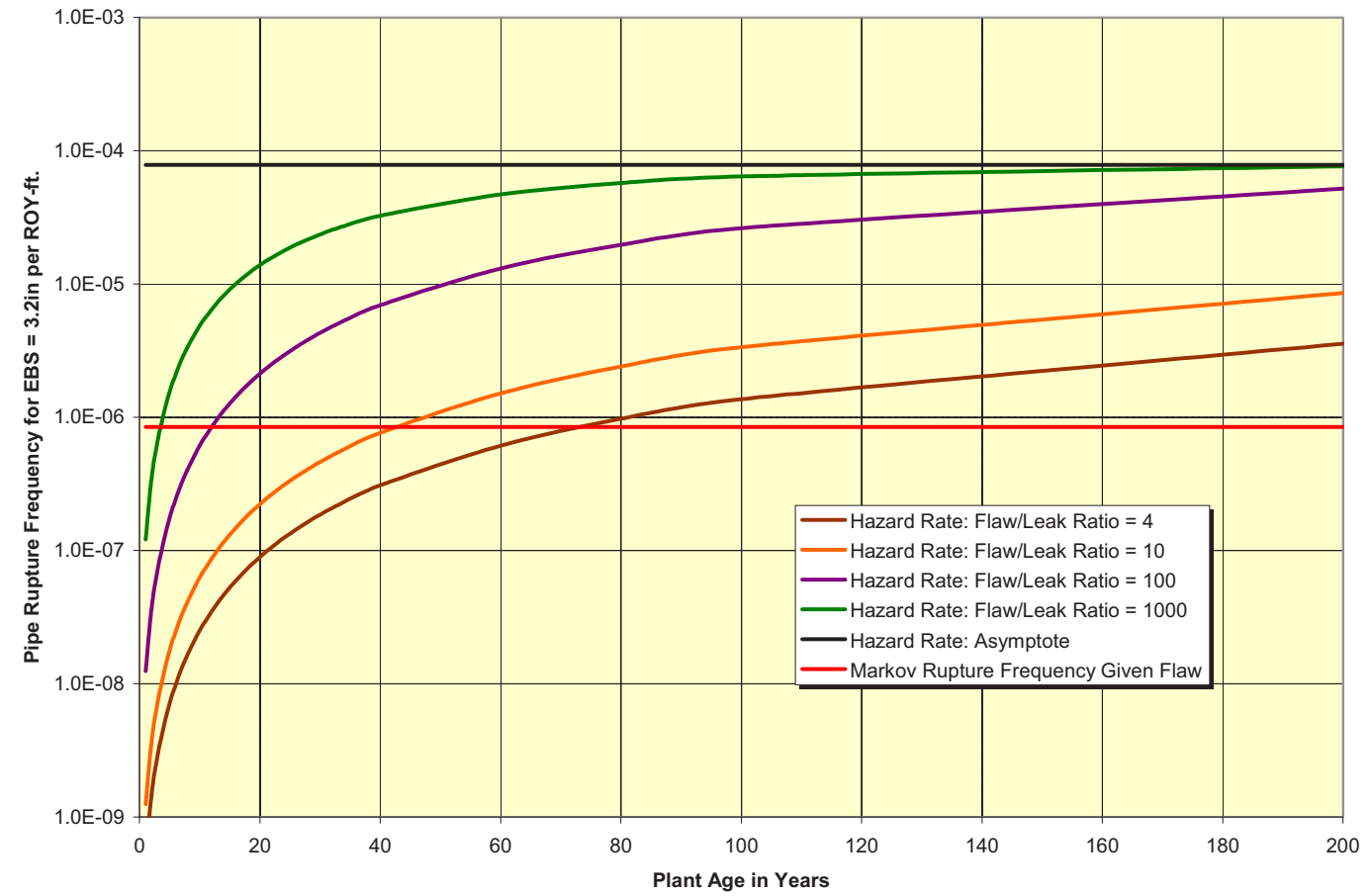

Figure 4-5 Hazard Rate Sensitivity Study - Vary Flaw to Leak Ratio

4.2 Feedwater, Condensate, and Steam Piping 


\subsubsection{System Boundaries}

This evaluation is concerned with non-ASME Code piping systems inside the Turbine Building of Pressurized Water Reactor (PWR) plants. The following systems are considered:

- Feed-water \& Condensate (FWC) piping: The Condensate piping system extends from the Condenser Hot-well up to and including the Low Pressure Heaters. It also includes the Drains and Vents System piping from the Low Pressure and High Pressure Heaters. The Feed-water piping system boundary considered in this evaluation consists of the piping from the Low Pressure Heaters, the Feed-water pump suction/discharge piping, High Pressure Heater inlet/outlet piping up to the outboard containment isolation valves. Due to comparable susceptibilities to flow accelerated corrosion (FAC) and plant to plant variability in how the boundaries between these systems are defined, a composite set of data parameters are developed for FWC piping.

- Steam Extraction (EXS) piping: In a typical PWR the high pressure portion of the turbine has extraction connections for two stages of feed-water heating. The low pressure portion of the turbine has extraction connections for four stages of feed-water heating.

- Low Pressure Steam (LPS) piping: In this evaluation, the low pressure steam piping includes piping between the high pressure (HP) and low pressure (LP) turbine stages, including steam cross-over and cross-under piping, and Moisture Separator Reheater (MSR) piping. The MSR piping is also located between the HP and LP turbines and it is used to extract moisture from the steam and reheat the steam to improve the turbine performance.

- HP Steam (HPS) piping: In this evaluation the HP steam piping is upstream of the HP turbine throttle valve and extends to the outboard containment isolation valves.

\subsubsection{Failure Data Collection for Feedwater, Condensate and Steam Piping}

The data processing considers the different FAC-susceptibilities of BWR and PWR piping [1]. In an "unmitigated" operating environment, the average pipe wall wear rate of piping in BWR plants is approximately half of that experienced by the corresponding FWC-piping in PWR plants. The term "unmitigated" refers to piping that is not subjected to any scheduled volumetric examination using ultrasonic testing techniques or radiography. Nor does it encompass any consideration of preemptive replacements using FAC-resistant materials. Under an assumption of near equal exposure terms, in unmitigated form a BWR-specific pipe failure rate should be expected to be at least half of a corresponding PWR-specific failure rate. Disregarding pre-1988 service data for PWR plants, the global service experience for the two plant types is largely similar. The higher failure occurrence rate pre-1988 is reflective of the major structural FWC piping failures experienced at Surry and Trojan nuclear power plants. In response to these events the industry began implementing FAC Program Plans that involved the replacement of large quantities of pipe. The same kind of information and subsections are provided as with the previous section with the exception that water hammer screening is not performed (not a significant contributor for these systems) and RIM strategies are not evaluated because changes to the FAC program are outside the scope of this study.

The pipe failure rates and rupture frequencies in this evaluation are derived from service data included in the PIPExp database (Appendix A). The full PIPExp includes on the order of 7,700 
data records covering ASME Code Class 1-3 and non-Code piping in commercial light water reactor plants. Input parameters to the pipe failure rate calculation in this evaluation are obtained through database queries that include filters for excluding any non-relevant service data:

- Initial screening on the basis of Code Class and PWR plant system. Retain failure data associated with non-Code piping in Turbine Building including the following systems:

- Condensate System

- Extraction steam piping

- Feedwater heater drain and vent piping

- Main Feedwater (from LP feedwater heaters to outboard containment isolation valves)

- Main Steam (from outboard containment isolation valve to High Pressure turbine steam admission valve, and turbine cross-over/cross-under piping)

- Moisture Separator Reheater piping

- Results of initial screening subjected to additional screening on the basis of nominal pipe size and through-wall flaw or break size:

- The evaluation considers piping of nominal pipe size (NPS) greater than 2-inch diameter as piping less than 2-inch is not within the scope of this evaluation. Two pipe size categories are used to define the different failure rate cases in Table 2-1: the small pipe size category covers pipes with NPS between 2in. and 6in., whereas the large pipe category covers pipe sizes greater than NPS 6in.

The service data involving through-wall flaws are reviewed in accordance with the Prairie Island pipe break analysis requirements. This means that the service data are screened further on the basis of flaw size ('EBS or equivalent break size'). The results of this screening step are input to the derivation of posterior Beta distribution parameters for calculation of conditional pipe failure probabilities for each of the systems, pipe size categories, and failure modes considered in this study

Consistent with recent studies completed for Prairie Island [2] and Kewaunee [3], the FAC susceptible systems are divided into four categories of systems, each of which has different susceptibilities to FAC. The first category is feedwater and condensate systems, the second is extraction steam (EXS), the third is low pressure steam (LPS), and the fourth is high pressure steam (HPS). HPS accounts for the piping between the reactor and the inlet of the HP turbine and given the dry steam conditions and relatively straight runs of pipe, has a relatively low susceptibility to FAC. EXS has the relatively poorest quality steam and relatively high susceptibility to FAC. The LPS accounts for the remaining elements of the steam system piping. FWC is not separated into FW and CND systems because insights from service data indicate a relatively uniform level of service induced failures and also plants do not use consistent definitions for establishing the boundaries between these systems. FWC is the most important FAC susceptible system for PWRs.

The results of the database queries for the development of system specific and pipe size specific failure rates are summarized in charts (Figure 4-6 and Figure 4-7) and tables (Tables 48 and table 4-9). Flow-accelerated corrosion (FAC) is a predominant degradation mechanism for the systems that are included in the study scope except for the high pressure steam system. Most if not all plant owners have implemented programs to mitigate FAC susceptibilities. These programs include implementing non-destructive examination (NDE) programs, pro-active monitoring of pipe wall wear rates, and replacing the original carbon steel piping with FAC- 
resistant piping material such as stainless steel, carbon steel clad on the inside diameter with stainless steel, or chrome-molybdenum alloy steel. The purpose of these initial data queries was to identify the appropriate data set to use that represents current industry practice for predicting the initiating event frequencies at Prairie Island. The use of time trend analysis is a requirement of the ASME PRA standard for Capability Category 3 analyses. In addition, evaluating the trending of events avoids important insights in the data that would be missed by simply averaging all the industry experience over the entire time span from 1970 to 2008.

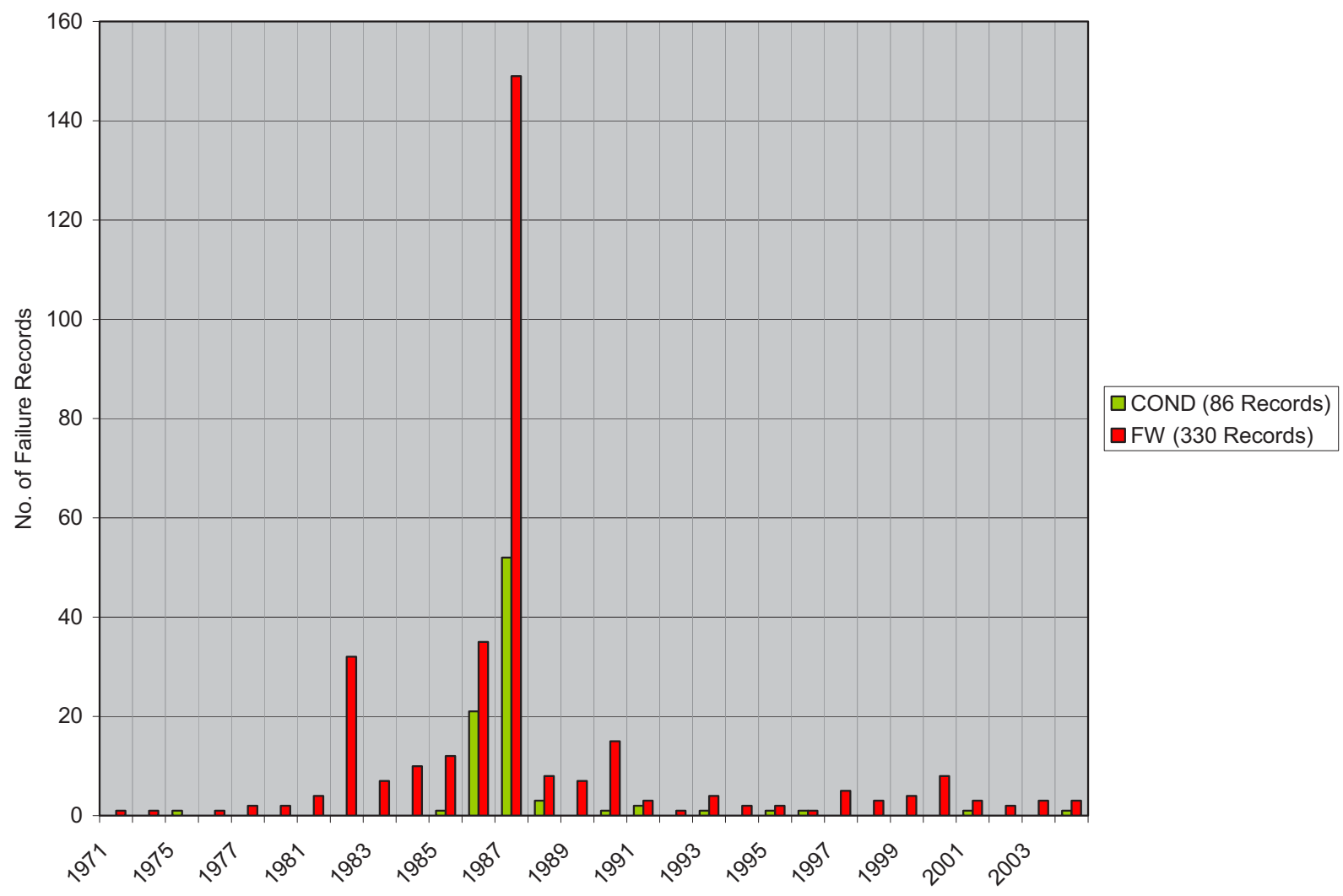

Figure 4-6 PWR Worldwide Experience with non-Code FWC Piping 1970-2004 


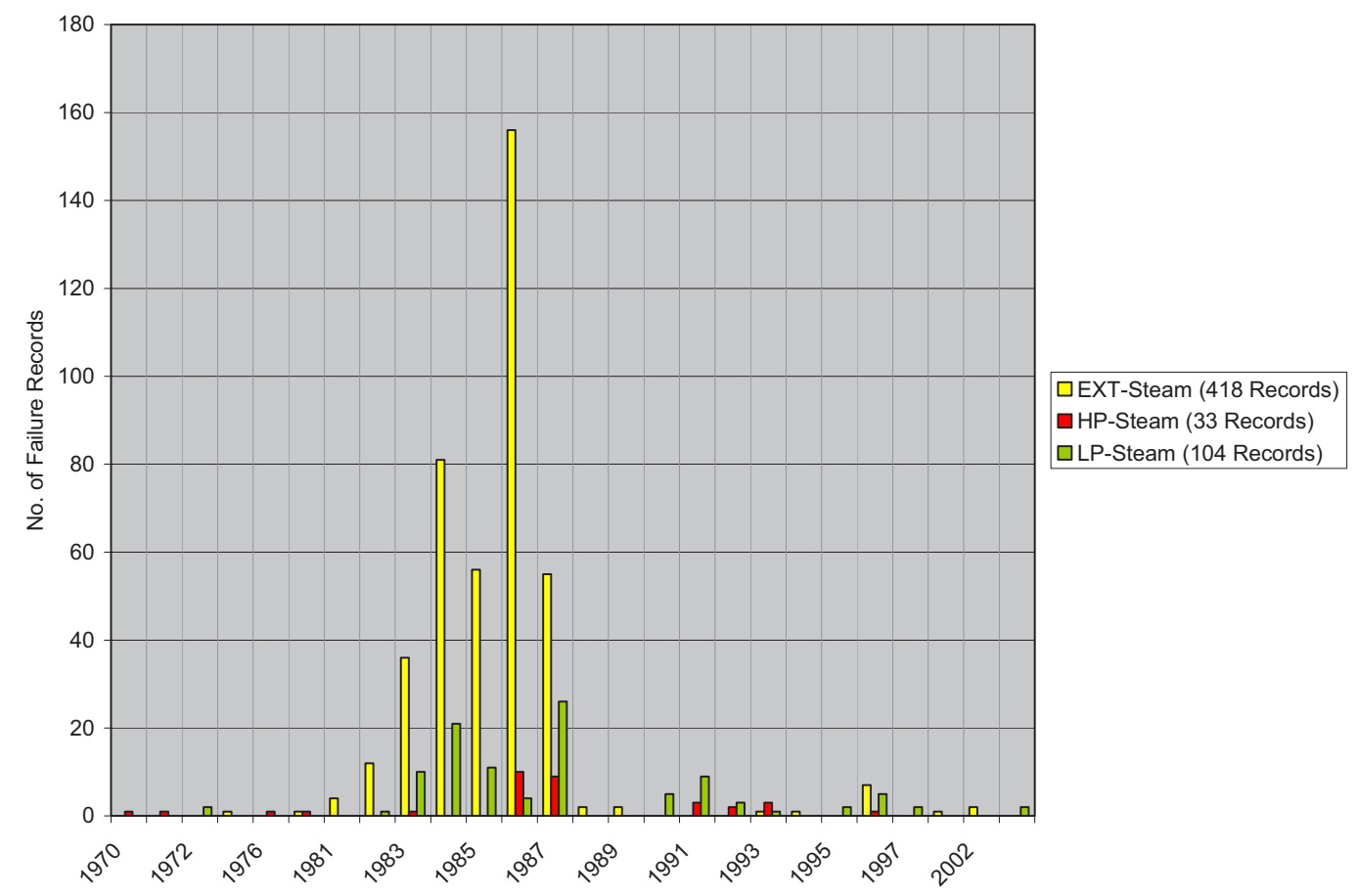

Figure 4-7 PWR Worldwide Experience with non-Code Steam Piping 1970-2004 [1]

The two charts above show a distinctly higher incident rate of pipe failures before 1988 . The before/after-1988 trends in Figure 4-6 and Figure 4-7 are accounted for in the following quantitative evaluation of the service-data. The service data coverage in PIPExp corresponds to 858 PWR reactor years for the period 1/01/1970 - 12/31/1987 and 2059 PWR reactor years for the period $01 / 01 / 1988-12 / 31 / 2008$. By the early- to mid-1980's the industry experienced several major failures of non-Code carbon steel piping (e.g., Trojan in March 1985 and Surry-2 in December 1986) (See References [23] through [26]). In response to these events as well as the industry-wide experience with pipe wall thinning and minor through-wall flaws attributed to FAC.

Table 4-8 and Table 4-9 show the same data sets as those included in Figure 4-6 and Figure 4-7 except that the data is organized by failure mode and pipe size to reflect the Prairie Island PRA HELB initiating event analysis requirements. The following failure mode definitions are used:

- Wall thinning; represents cases of severe wall thinning resulting in either weld overlay repair or preemptive replacement of affected piping section or fitting (e.g., elbow, tee).

- Leak; includes pinhole leak, leak or large leak resulting in isolation (where feasible) or manual reactor shutdown to effect repair or replacement.

- Rupture; significant through-wall flaw resulting in moderate or significant steam/water release and prompt manual shutdown or automatic turbine trip/reactor trip with estimated break size. 
Table 4-8 Service Experience with B31.1 Carbon Steel FWC Piping 1970 to 2008

\begin{tabular}{|c|c|c|c|c|c|c|c|c|}
\hline \multirow{2}{*}{$\begin{array}{c}\text { Nominal Pipe } \\
\text { Size } \\
\text { (NPS) } \\
\text { [Inch] }\end{array}$} & \multicolumn{4}{|c|}{$1970-1987$} & \multicolumn{4}{|c|}{ 1988-2008 } \\
\hline & Total & $\begin{array}{c}\text { Wall } \\
\text { Thinning }\end{array}$ & Leak & Rupture & Total & $\begin{array}{c}\text { Wall } \\
\text { Thinning }\end{array}$ & Leak & Rupture \\
\hline $2 "<\mathrm{NPS} \leq 6 "$ & 14 & 5 & 6 & 3 & 57 & 33 & 18 & 6 \\
\hline NPS > 6" & 300 & 275 & 17 & 8 & 155 & 126 & 23 & 6 \\
\hline Total: & 314 & 280 & 23 & 11 & 212 & 159 & 41 & 12 \\
\hline \multicolumn{9}{|c|}{$\begin{array}{l}\text { Notes: } \\
\text { - Service experience derived from } 2917 \text { reactor-years of PWR operation worldwide; } 858 \text { reactor-years pre-1988 and } 2059 \\
\text { reactor-years post-1987 and covers the period between Jan 1, } 1970 \text { and December 31, } 2008 \\
\text { - Failure data includes contributions from FAC (dominant degradation mechanism), vibration-fatigue and water hammer } \\
\text { - The root cause of post-1987 events in many cases is attributed to programmatic errors or weaknesses in the Owner's FAC } \\
\text { program } \\
\text { - }\end{array}$} \\
\hline
\end{tabular}

Table 4-9 Service Experience with B31.1 Carbon Steel Steam Piping 1970 to 2008

\begin{tabular}{|c|c|c|c|c|c|c|c|c|c|}
\hline \multirow[t]{2}{*}{ System } & \multirow{2}{*}{$\begin{array}{c}\text { Nominal Pipe } \\
\text { Size } \\
\text { (NPS) } \\
\text { [Inch] }\end{array}$} & \multicolumn{4}{|c|}{ 1970-1987 } & \multicolumn{4}{|c|}{ 1988-2004 } \\
\hline & & Total & $\begin{array}{c}\text { Wall } \\
\text { Thinning }\end{array}$ & Leak & Rupture & Total & $\begin{array}{c}\text { Wall } \\
\text { Thinning }\end{array}$ & Leak & Rupture \\
\hline \multirow[t]{2}{*}{ EXS } & $2 "<$ NPS $\leq 6 "$ & 10 & 0 & 8 & 2 & 11 & 1 & 9 & 1 \\
\hline & NPS > 6" & 392 & 385 & 4 & 3 & 37 & 20 & 10 & 7 \\
\hline \multirow[t]{2}{*}{ LPS } & $2 "<\mathrm{NPS} \leq 6 "$ & 14 & 0 & 11 & 3 & 29 & 10 & 18 & 1 \\
\hline & NPS > 6" & 61 & 60 & 1 & 0 & 15 & 2 & 9 & 4 \\
\hline \multirow[t]{2}{*}{ HPS } & NPS > 2" & 24 & 19 & 3 & 2 & 59 & 24 & 30 & 5 \\
\hline & Totals & 501 & 464 & 27 & 10 & 151 & 57 & 76 & 18 \\
\hline \multicolumn{10}{|c|}{$\begin{array}{l}\text { Notes: } \\
\text { - 'EXT-Steam' includes HP \& LP steam extraction piping. Most of this piping is > NPS6. } \\
\text { - } \quad \text { 'LP-Steam' includes piping between the HP and LP turbine stages, including cross-over/under piping and Moisture Separator } \\
\text { Reheater piping. } \\
\text { - } \quad \text { 'HP-Steam' includes piping upstream of the HP turbine throttle valve. } \\
\text { - Service experience derived from } 2917 \text { reactor-years of PWR operation worldwide; } 858 \text { reactor-years pre-1988 and } 2059 \\
\text { reactor-years January 1, } 1988 \text { through December 31, 2008. This experience was obtained by } 131 \text { U.S. and Foreign PWR } \\
\text { plants } \\
\text { Failure data includes contributions from FAC (dominant degradation mechanism for EXT-Steam and LP-Steam), vibration- } \\
\text { fatigue and water hammer } \\
\text { The root cause of post-1987 events in many cases is attributed to programmatic errors or weaknesses in the Owner's FAC } \\
\text { program. See Appendix A for more details on the PIPExp database. }\end{array}$} \\
\hline
\end{tabular}

The estimated pipe lengths presented in for PWR piping is based on pipe exposure information collected in Reference [13] and some assumptions about how the pipe is distributed between different systems and pipe length categories. The percentages assumed are consistent with actual counts from selected FAC programs as documented in Reference [2]. 
As discussed more fully in References [2] and [3], there has been a significant impact of augmented programs to address FAC in reducing the frequency of FAC induced pipe failures in both PWRs and BWRs since 1988. Hence only the service data since 1988 is accounted for in the query for pipe failures in these systems. From January 1, 1988 through March 31, 2009 the service data from both US and foreign PWR plants accounts for about 1,296 reactor operating years of service experience.

Table 4-10 Estimated Pipe Lengths for PWR Steam, Feedwater, and Condensate Systems

\begin{tabular}{|c|c|l|}
\hline System / System Group & Linear ft of Piping & \multicolumn{1}{|c|}{ Information Source / Comment ${ }^{\text {[Note 1] }}$} \\
\hline FWC & $14,037 \mathrm{ft}$ & $\begin{array}{l}\text { EPRI TR-111880, Table A-5; in the failure rate } \\
\text { calculation the given length is input as a median } \\
\text { value for pipes > 6in. diameter and upper } \\
\text { bound for pipes between 2" and 6" in diameter }\end{array}$ \\
\hline EXS & $1,500 \mathrm{ft}$ & $\begin{array}{l}\text { Entergy Nuclear Northeast (Indian Point-3 FAC } \\
\text { program information). In the failure rate } \\
\text { calculation the given length is input as a median } \\
\text { value for pipes between 2" and 6" in diameter } \\
\text { and the upper bound value for pipes > 6in. in } \\
\text { diameter }\end{array}$ \\
\hline LPS & $622 \mathrm{ft}$ & $\begin{array}{l}\text { Dominion Energy; the given length is for KNPP } \\
\text { and in the failure rate calculation it is input as a } \\
\text { lower bound value for pipes between 2" and 6" } \\
\text { in diameter: 2/3 of this length and the lower } \\
\text { bound value for pipes > 6in. in diameter }\end{array}$ \\
\hline HPS & $885 \mathrm{ft}$ & $\begin{array}{l}\text { Dominion Energy; the given length is for KNPP } \\
\text { and in the failure rate calculation it is input as a } \\
\text { lower bound value for all pipes > 2" in diameter }\end{array}$ \\
\hline
\end{tabular}

Note 1. For consistency with the approach used in References [1] and [2]; uncertainty in the exposure is modeled as a $10 \%$ probability of the lower bound, $80 \%$ probability of the median, and $10 \%$ probability of the upper bound. In all cases the upper and lower bounds are set at $50 \%$ of the exposure above and below the median value, respectively. The probability weights are used to combine Bayes' updates using each of the three hypotheses about exposure. See Section 2 for a more detailed explanation of this approach to treatment of pipe component exposure uncertainty.

\subsubsection{Conditional Probability of Pipe Rupture Given Failure}

The conditional probability of pipe rupture given pipe failure was developed using the same approach as used for the service water and FP systems. Details of this development are provided in Appendix B. The events in Table 4-8 and Table 4-9 involving leaks and ruptures were reviewed for flow rate and break size information. In addition a larger set of rupture events totaling 77 events that was collected and analyzed in References [2] and [3] was reviewed and incorporated into the model. These events include a mixture of PWR and BWR events and cover all the systems classified as susceptible to FAC. The events which had equivalent break sizes of at least 1" are listed in Table 4-16. The classification of these events for the purpose of 
updating the prior distributions for the conditional probabilities of rupture vs. break size is discussed in Appendix B.

Table 4-11 Pipe Ruptures in BWR and PWR Feedwater, Condensate, and Steam Systems

\begin{tabular}{|c|c|c|c|c|c|c|c|}
\hline Event Date & Plant Name & $\begin{array}{l}\text { Plant } \\
\text { Type }\end{array}$ & Country & $\begin{array}{c}\text { System } \\
\text { Group } \\
\text { [Note 1] }\end{array}$ & $\begin{array}{l}\text { Nominal } \\
\text { Pipe Size } \\
\text { (in.) }\end{array}$ & $\begin{array}{c}\text { Damage } \\
\text { Mechanism } \\
\text { [Note 2] }\end{array}$ & $\begin{array}{l}\text { Rupture } \\
\text { Category } \\
\text { [Note 3] }\end{array}$ \\
\hline $4 / 11 / 2004$ & Krsko & PWR & Slovenia & MSR & 2 & VF & A \\
\hline $2 / 25 / 2002$ & Krsko & PWR & Slovenia & EX-ST & 2 & FAC & $\mathrm{A}$ \\
\hline $7 / 23 / 1998$ & Calvert Cliffs-2 & PWR & US & MSR & 2 & FAC & A \\
\hline $3 / 10 / 1995$ & Paks-1 & PWR & Hungary & FW & 2 & VF & A \\
\hline $1 / 1 / 1995$ & Not disclosed & BWR & $\mathrm{XX}$ & FW & 2 & VF & A \\
\hline $1 / 11 / 1994$ & Catawba-1 & PWR & US & EXT-ST & 2 & FAC & A \\
\hline $12 / 9 / 1993$ & Indian Point-2 & PWR & US & MS & 2 & FAC & A \\
\hline 9/17/1993 & Zaporozhe-4 & PWR & Ukraine & MSR & 2 & FAC & A \\
\hline $5 / 24 / 1993$ & Koeberg-1 & PWR & $\begin{array}{l}\text { South } \\
\text { Africa }\end{array}$ & FW & 2 & $\mathrm{VF}$ & A \\
\hline $7 / 22 / 1992$ & Maine Yankee & PWR & US & MSR & 2 & FAC & A \\
\hline $1 / 6 / 1991$ & Duane Arnold & BWR & US & EXS & 2 & $\mathrm{VF}$ & A \\
\hline $8 / 8 / 1985$ & Kewaunee & PWR & US & MSR & 2 & FAC & A \\
\hline $6 / 24 / 1985$ & McGuire-2 & PWR & US & AFW & 2 & $\mathrm{TF}$ & A \\
\hline $1 / 9 / 1978$ & KWW Würgassen & BWR & Germany & FW & 2 & VF & $\mathrm{A}$ \\
\hline $7 / 1 / 1971$ & Haddam Neck & PWR & US & $\begin{array}{l}\text { Heater- } \\
\text { Drain }\end{array}$ & 2 & OVP & A \\
\hline $7 / 28 / 1991$ & Zion-2 & PWR & US & FW & 3 & FAC & A \\
\hline $3 / 19 / 1983$ & Oconee-2 & PWR & US & MSR & 3 & FAC & B \\
\hline $2 / 13 / 2001$ & Balakovo-2 & PWR & Russia & $\begin{array}{l}\text { Heater- } \\
\text { Drain }\end{array}$ & 3.2 & FAC & B \\
\hline $7 / 19 / 1988$ & Kola-2 & PWR & Russia & MS & 4 & VF & $\mathrm{D}$ \\
\hline $7 / 27 / 1972$ & Surry-1 & PWR & US & MSR & 4 & OVP & $\mathrm{D}$ \\
\hline 11/24/1993 & Kola-4 & PWR & Russia & MS & 4 & FAC & B \\
\hline $3 / 23 / 1990$ & Surry-1 & PWR & US & $\begin{array}{l}\text { Heater- } \\
\text { Drain }\end{array}$ & 4 & FAC & B \\
\hline 9/26/1989 & Indian Point-2 & PWR & US & MS & 4 & FAC & B \\
\hline $12 / 30 / 1973$ & Millstone-1 & BWR & US & COND & 4 & WH & B \\
\hline $1 / 1 / 1972$ & Millstone-1 & BWR & US & MS & 4 & OVP & B \\
\hline $8 / 10 / 1999$ & Callaway & PWR & US & $\begin{array}{l}\text { Heater- } \\
\text { Drain }\end{array}$ & 6 & FAC & $\mathrm{D}$ \\
\hline $12 / 31 / 1990$ & Millstone-3 & PWR & US & MSR & 6 & FAC & $\mathrm{D}$ \\
\hline
\end{tabular}




\begin{tabular}{|c|c|c|c|c|c|c|c|}
\hline Event Date & Plant Name & $\begin{array}{l}\text { Plant } \\
\text { Type }\end{array}$ & Country & $\begin{array}{c}\text { System } \\
\text { Group } \\
\text { [Note 1] }\end{array}$ & $\begin{array}{c}\text { Nominal } \\
\text { Pipe Size } \\
\text { (in.) }\end{array}$ & $\begin{array}{c}\text { Damage } \\
\text { Mechanism } \\
\text { [Note 2] }\end{array}$ & $\begin{array}{l}\text { Rupture } \\
\text { Category } \\
\text { [Note 3] }\end{array}$ \\
\hline $4 / 28 / 1970$ & H.B. Robinson-2 & PWR & US & MS & 6 & OVP & $\mathrm{D}$ \\
\hline $7 / 1 / 2005$ & South Ukraine-2 & PWR & Ukraine & $\begin{array}{l}\text { Heater- } \\
\text { Drain }\end{array}$ & 6 & VF & B \\
\hline $12 / 15 / 1996$ & Paks-3 & PWR & Hungary & $\begin{array}{c}\text { EXT- } \\
\text { STEAM }\end{array}$ & 6 & FAC & A \\
\hline $4 / 22 / 1995$ & Almaraz-1 & PWR & Spain & COND & 6 & FAC & B \\
\hline $7 / 27 / 1993$ & Bohunice-3 & PWR & Slovakia & MS & 6 & FAC & B \\
\hline $4 / 3 / 1987$ & Indian Point-2 & PWR & US & FW & 6 & FAC & B \\
\hline $7 / 29 / 1986$ & R.E. Ginna & PWR & US & MS & 6 & FAC & B \\
\hline $3 / 16 / 1985$ & Haddam Neck & PWR & US & FW & 6 & FAC & A \\
\hline $9 / 28 / 1983$ & Browns Ferry-1 & BWR & US & MSR & 6 & FAC & $\mathrm{B}$ \\
\hline 8/1/1983 & Zion-1 & PWR & US & EXS & 6 & FAC & A \\
\hline $1 / 9 / 1982$ & Trojan & PWR & US & EXS & 6 & FAC & B \\
\hline $11 / 18 / 1977$ & Ringhals-2 & PWR & Sweden & FW & 6 & FAC & $\mathrm{B}$ \\
\hline $11 / 1 / 1977$ & Browns Ferry-3 & BWR & US & EXS & 6 & FAC & B \\
\hline $5 / 9 / 1976$ & Oskarshamn-1 & BWR & Sweden & AFW & 6 & FAC & B \\
\hline $2 / 25 / 1993$ & Loviisa-2 & Finland & PWR & FW & 8 & FAC & $\mathrm{D}$ \\
\hline $12 / 5 / 2003$ & Bohunice-1 & Slovakia & PWR & $\begin{array}{c}\text { EXT- } \\
\text { STEAM }\end{array}$ & 8 & FAC & A \\
\hline $8 / 28 / 2002$ & Turkey Point-3 & US & PWR & $\begin{array}{l}\text { Heater- } \\
\text { Drain }\end{array}$ & 8 & FAC & B \\
\hline $8 / 8 / 1995$ & Millstone-2 & US & PWR & $\begin{array}{l}\text { Heater- } \\
\text { Drain }\end{array}$ & 8 & WH & B \\
\hline $4 / 10 / 1993$ & Fermi-2 & US & BWR & $\begin{array}{c}\text { EXT- } \\
\text { STEAM }\end{array}$ & 8 & FAC & B \\
\hline $12 / 18 / 1991$ & Almaraz-1 & Spain & PWR & MS & 8 & FAC & B \\
\hline $11 / 6 / 1991$ & Millstone-2 & US & PWR & MSR & 8 & FAC & B \\
\hline $1 / 15 / 1988$ & Catawba-1 & US & PWR & COND & 8 & OVP & $\mathrm{C}$ \\
\hline $9 / 25 / 1987$ & Doel-1 & Belgium & PWR & MSR & 8 & FAC & $\mathrm{C}$ \\
\hline $8 / 15 / 1983$ & Browns Ferry-1 & US & BWR & MS & 8 & FAC & B \\
\hline $9 / 29 / 1982$ & Browns Ferry-1 & US & BWR & MSR & 8 & FAC & B \\
\hline $6 / 24 / 1982$ & Browns Ferry-1 & US & BWR & MSR & 8 & FAC & B \\
\hline $3 / 1 / 1993$ & Sequoyah-2 & US & PWR & MS & 10 & FAC & B \\
\hline
\end{tabular}




\begin{tabular}{|c|c|c|c|c|c|c|c|}
\hline Event Date & Plant Name & $\begin{array}{l}\text { Plant } \\
\text { Type }\end{array}$ & Country & $\begin{array}{l}\text { System } \\
\text { Group } \\
\text { [Note 1] }\end{array}$ & $\begin{array}{l}\text { Nominal } \\
\text { Pipe Size } \\
\text { (in.) }\end{array}$ & $\begin{array}{c}\text { Damage } \\
\text { Mechanism } \\
\text { [Note 2] }\end{array}$ & $\begin{array}{l}\text { Rupture } \\
\text { Category } \\
\text { [Note 3] }\end{array}$ \\
\hline 9/17/1986 & Oconee-3 & US & PWR & MSR & 10 & FAC & $\mathrm{C}$ \\
\hline $5 / 28 / 1990$ & Loviisa-1 & Finland & PWR & FW & 12 & FAC & $\mathrm{D}$ \\
\hline $12 / 2 / 1971$ & Turkey Point-3 & US & PWR & MS & 12 & OVP + D\&C & $\mathrm{D}$ \\
\hline $4 / 21 / 1997$ & Fort Calhoun-1 & US & PWR & $\begin{array}{c}\text { EXT- } \\
\text { STEAM }\end{array}$ & 12 & FAC & $\mathrm{C}$ \\
\hline $5 / 6 / 1991$ & Kuosheng-2 & Taiwan & BWR & COND & 12 & FAC & B \\
\hline $4 / 18 / 1989$ & ANO-2 & US & PWR & $\begin{array}{l}\text { EXT- } \\
\text { STEAM }\end{array}$ & 14 & FAC & B \\
\hline $3 / 9 / 1985$ & Trojan & US & PWR & FW & 14 & FAC & $\mathrm{C}$ \\
\hline $12 / 29 / 1984$ & Krsko & Slovenia & PWR & FW & 14 & FAC & B \\
\hline $6 / 14 / 1996$ & Maanshan-2 & Taiwan & PWR & MS & 16 & FAC & B \\
\hline $12 / 1 / 1989$ & $\begin{array}{c}\text { Santa Maria de } \\
\text { Garona }\end{array}$ & Spain & BWR & FW & 16 & FAC & B \\
\hline $11 / 20 / 1984$ & Calvert Cliffs-1 & US & PWR & $\begin{array}{c}\text { EXT- } \\
\text { STEAM }\end{array}$ & 16 & FAC & $\mathrm{C}$ \\
\hline $9 / 10 / 1982$ & Maine Yankee & US & PWR & $\begin{array}{c}\text { EXT- } \\
\text { STEAM }\end{array}$ & 16 & FAC & A \\
\hline $2 / 9 / 1980$ & $\begin{array}{c}\text { Santa Maria de } \\
\text { Garona }\end{array}$ & Spain & BWR & $\begin{array}{l}\text { EXT- } \\
\text { STEAM }\end{array}$ & 16 & FAC & B \\
\hline 9/24/1996 & Oconee-2 & US & PWR & MSR & 18 & WH & $\mathrm{D}$ \\
\hline $6 / 10 / 1974$ & Quad Cities-2 & US & BWR & FW & 18 & OVP + D\&C & $\mathrm{D}$ \\
\hline $12 / 9 / 1986$ & Surry-2 & US & PWR & FW & 18 & FAC & $\mathrm{C}$ \\
\hline $6 / 27 / 1985$ & $\begin{array}{l}\text { KMK Mülheim- } \\
\text { Kärlich }\end{array}$ & Germany & PWR & FW & 18 & OVP & $\mathrm{C}$ \\
\hline $8 / 9 / 2004$ & Mihama-3 & Japan & PWR & FW & 20 & FAC & $\mathrm{C}$ \\
\hline $4 / 24 / 1986$ & Hatch-2 & US & BWR & FW & 20 & FAC & B \\
\hline $3 / 14 / 2007$ & Perry & US & BWR & $\begin{array}{c}\text { EXT- } \\
\text { STEAM }\end{array}$ & 24 & FAC & A \\
\hline $6 / 23 / 1982$ & Oconee-2 & US & PWR & $\begin{array}{c}\text { EXT- } \\
\text { STEAM }\end{array}$ & 24 & FAC & $\mathrm{C}$ \\
\hline $2 / 12 / 1982$ & Zion-1 & US & PWR & $\begin{array}{c}\text { EXT- } \\
\text { STEAM }\end{array}$ & 24 & FAC & B \\
\hline $10 / 15 / 1983$ & Surry-1 & US & PWR & $\begin{array}{l}\text { Heater- } \\
\text { Drain }\end{array}$ & 26 & OVP & $\mathrm{D}$ \\
\hline
\end{tabular}




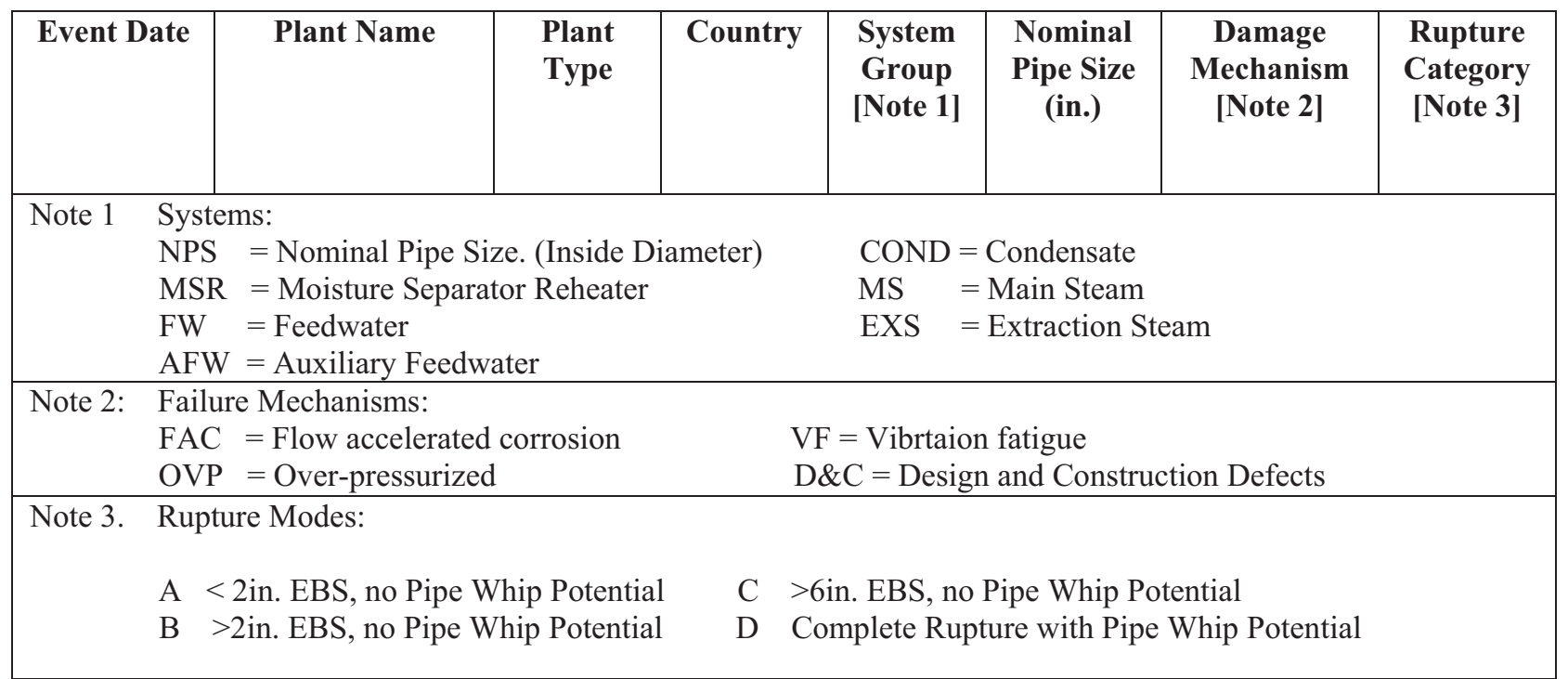

\subsubsection{Failure Rates and Cumulative Rupture Frequencies for FWC System}

The results for the failure rates and cumulative rupture frequencies for each of the four systems in the category of FAC susceptible systems and two categories of pipe sizes are presented in Appendix B. The results for the failure rates and cumulative rupture frequencies for feedwater and condensate (FWC) system piping are shown in Figure 4-8 and Table 4-12 for NPS > 10" pipe. 


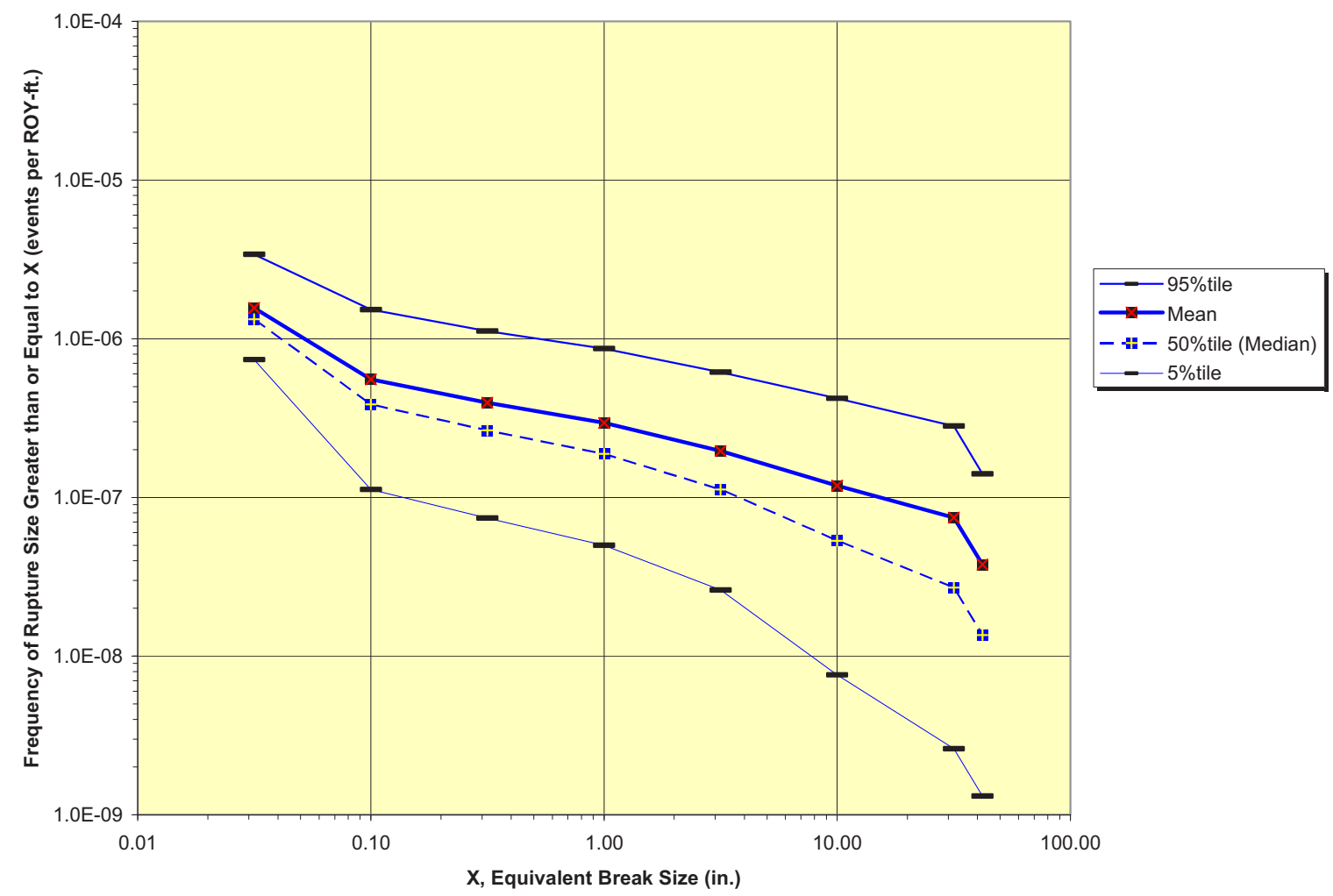

Figure 4-8 Cumulative Rupture Frequency vs. Break Size for NPS > 10" FWC Pipe Table 4-12 Failure Rates and Cumulative Rupture Frequencies for NPS > 10" FWC System

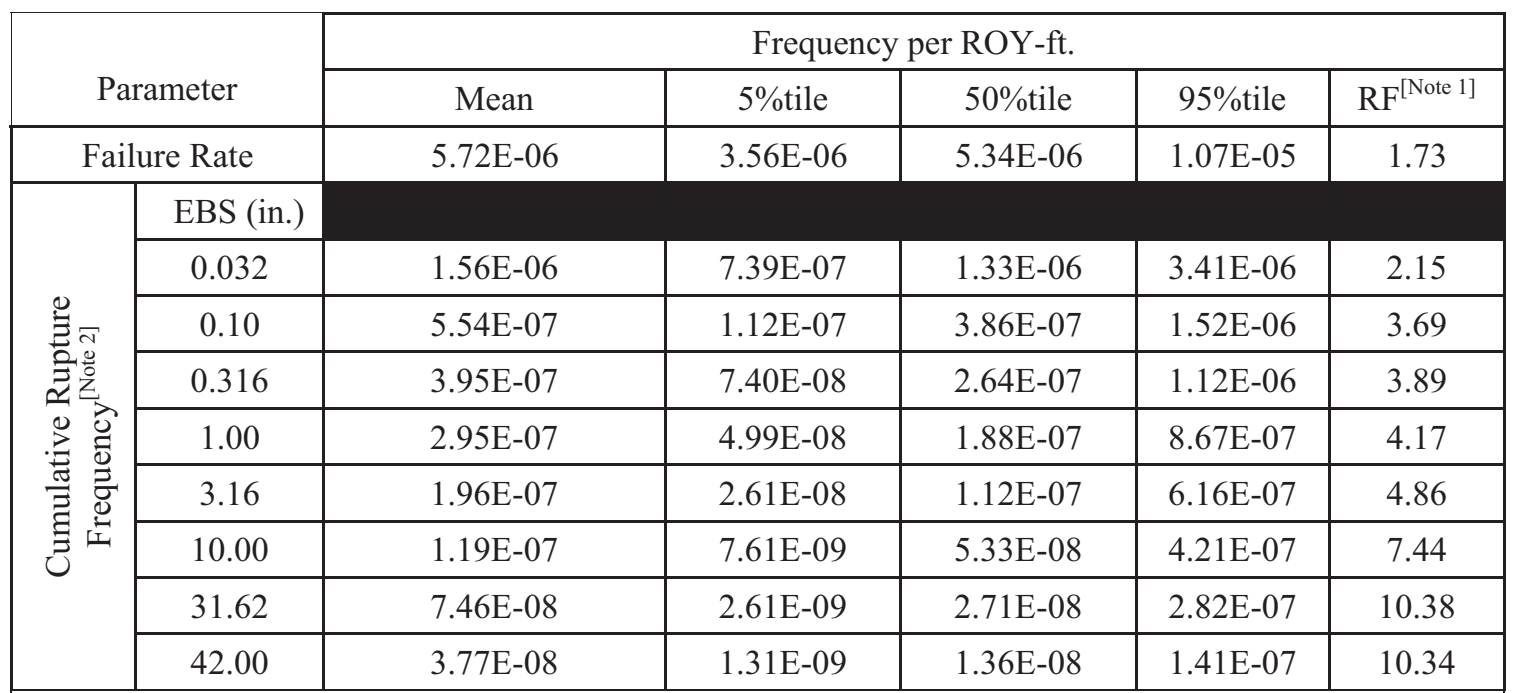

Note $1 . \mathrm{RF}=(95 \% \text { tile } / 5 \% \text { tile })^{0.5}$; These distributions can be approximated as lognormal distributions with the indicated mean and the calculated range factor (RF)

Note 2. Frequency of pipe rupture with EBS equal to or greater than indicated EBS value; use 42.0in. values for frequency of rupture with pipe whip potential. 


\subsubsection{Evaluation of Temporal Trends in Failure Rates for FAC Susceptible Systems}

To investigate the impact of industry efforts to address the FAC issue, a separate failure rate development was performed that considered only the service data prior to 1988. This was done by applying the failure rate history and the reactor years exposure data listed in Table 4-8 and Table 4-9 together with the same conditional rupture model as in the previous analysis to obtain a new set of failure rate parameters. This update showed that the failure rates for the smaller pipes did not change very much, but the failure rates for the larger pipes changed quite significantly. As seen in the bar chart in Figure 4-9 below, there were quite dramatic reductions in failure rates after 1988 in the Feedwater and Condensate, Extraction Steam, and Low Pressure Steam piping with no significant change in the HP Steam piping. These changes correlate well with what is known about the susceptibility of piping to this failure mechanism. HP steam is dry and is largely confined to large straight pipe runs upstream of the main turbine and hence these pipes have a relatively low susceptibility to FAC. Extraction Steam on the other hand has the highest susceptibility to FAC as evidenced in the pipe rupture data. It is also interesting to note that while the trend in the failure data did indeed show a rapid decline starting in 1988, where failures include all events involving repair and replacement, the trend in the large pipe rupture data as shown in Figure 4-10 does not show a significant decrease until about 1997 or 9 years later.

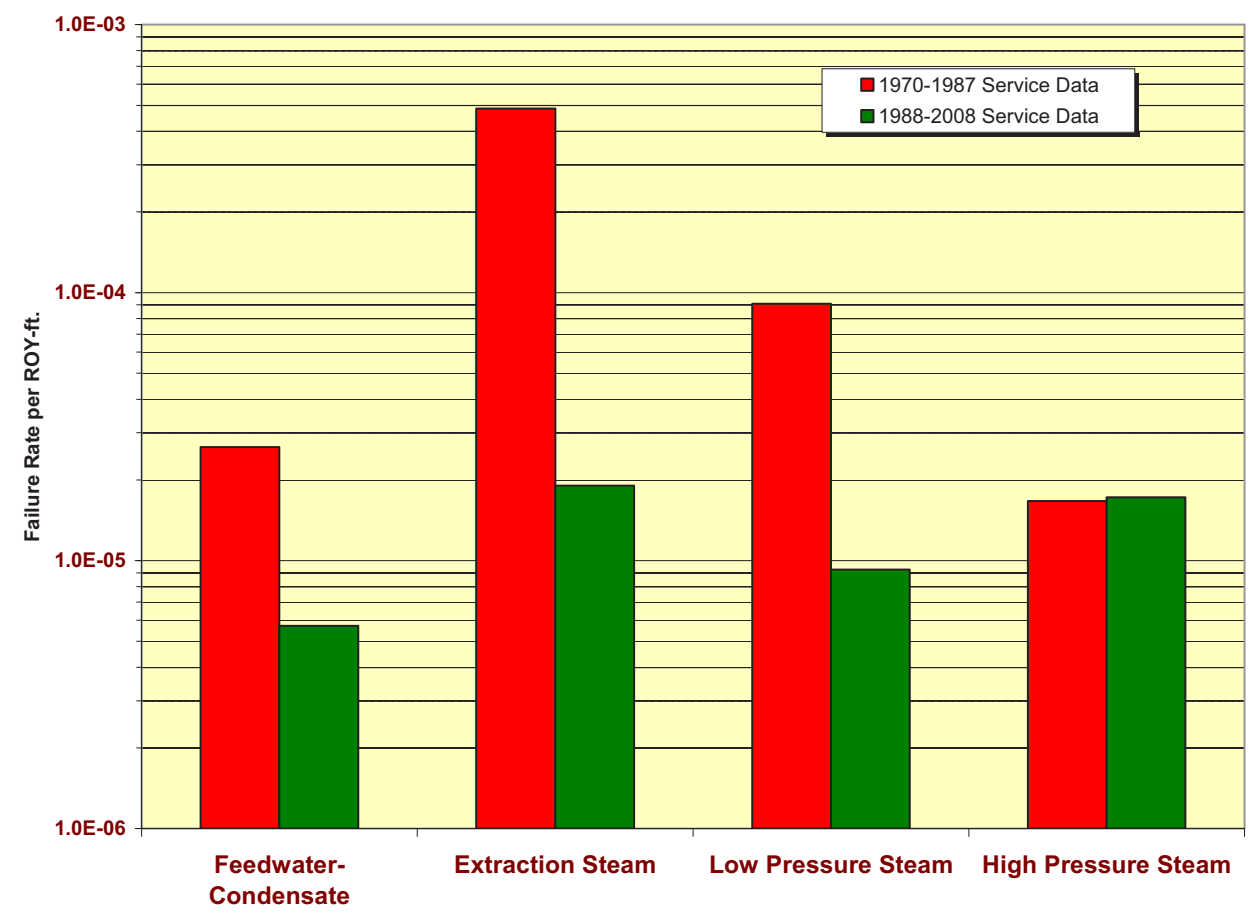

Figure 4-9 Comparison of Pipe Failure Rates in Large (>6") FAC Susceptible Piping Based on Service Experience Before and After 1988 


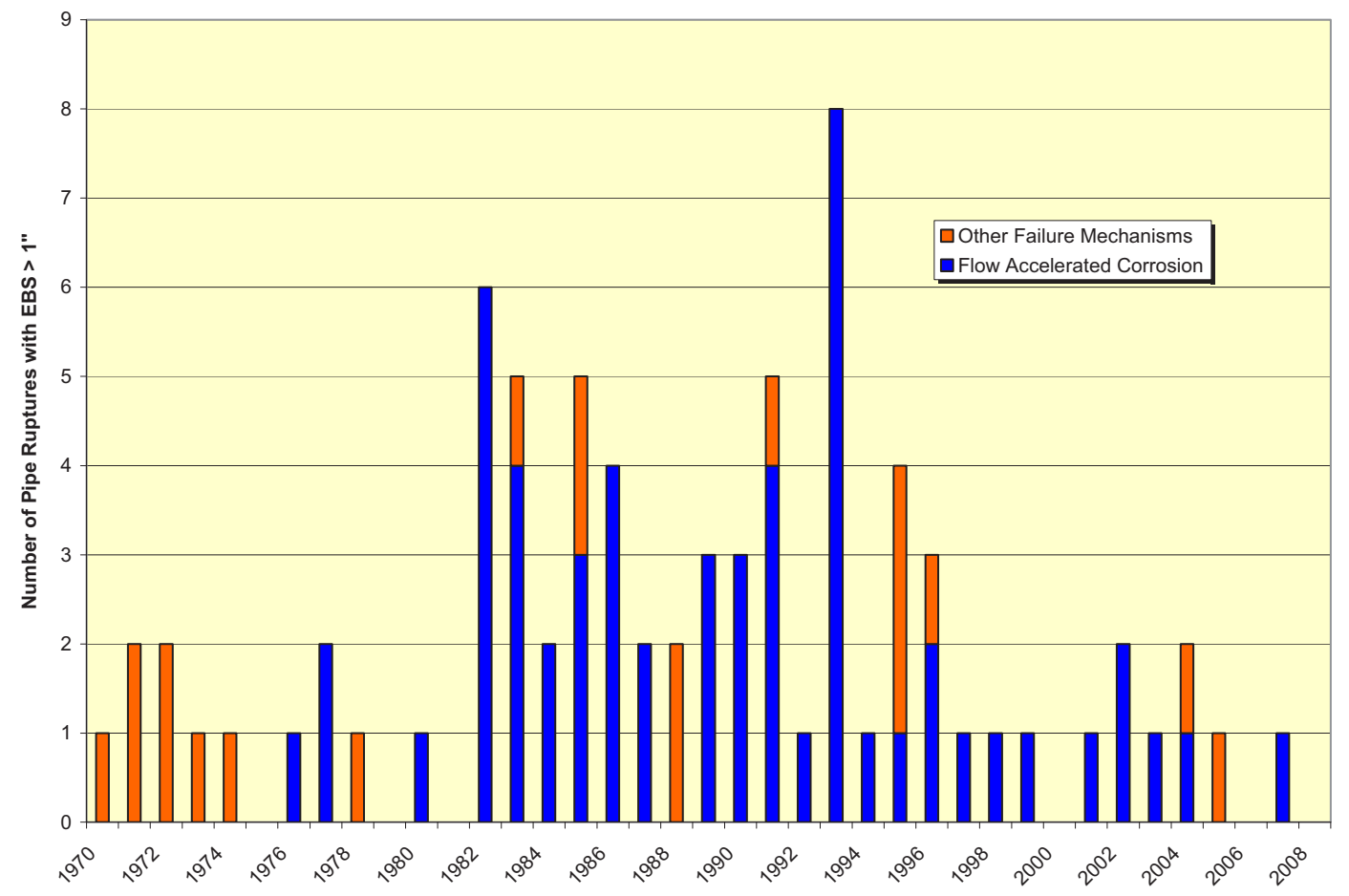

Figure 4-10 Temporal Trends in the Frequency of Large Pipe Breaks in FAC Susceptible Systems

\subsubsection{Impact of Alternative Inspection and Surveillance Strategies on FWC Piping}

The impact of alternative inspection strategies to reduce the frequency of pipe rupture was evaluated using the Markov Model and selected results are shown in Tables 4-13, 4-14, and 415. Table 4-13 shows how varying the frequency of leak testing with and without additional NDE and a fixed $90 \%$ POD for both strategies change the Integrity Management factor. Table 4-14 shows how alternative POD with fixed frequencies of NDE (every 10 years) and leak testing (every quarter) impact the Integrity Management factor. These Integrity Management Factors are evaluated for the plant age of 32 years which corresponds to the average age of the plants in the service data. The baseline integrity management program assumed in these calculations is based on $25 \%$ of the pipe being subjected to an augmented FAC inspection program with NDE @90\% every 3 years, 75\% not subjected to NDE and 100\% being subjected to a leak inspection @ $90 \%$ once every 1.5 years. Different combinations of NDE and leak testing strategies are investigated in Table 4-15. 
Table 4-13 Impact of Alternative Leak Detection Strategies to Reduce FeedwaterCondensate System Pipe Rupture Frequencies

\begin{tabular}{|c|c|c|c|c|}
\hline \multirow{3}{*}{$\begin{array}{l}\text { Equivalent } \\
\text { Break Size } \\
\text { (in.) }\end{array}$} & \multicolumn{4}{|c|}{ No NDE with Variable Leak Testing Frequency } \\
\hline & \multirow[t]{2}{*}{$\begin{array}{l}\text { Base Rate } \\
\text { per ROY-ft. }\end{array}$} & \multicolumn{3}{|c|}{$\begin{array}{l}\text { Factor Reduction in Base Rate for } \\
\text { Periodic Leak Test @ 90\% POD }\end{array}$} \\
\hline & & Yearly & Quarterly & Weekly \\
\hline 0.032 & $1.56 \mathrm{E}-06$ & $1.29 \mathrm{E}+00$ & $1.26 \mathrm{E}+00$ & $1.25 \mathrm{E}+00$ \\
\hline 0.10 & $5.54 \mathrm{E}-07$ & $1.29 \mathrm{E}+00$ & $1.20 \mathrm{E}+00$ & $1.19 \mathrm{E}+00$ \\
\hline 0.32 & 3.95E-07 & $1.29 \mathrm{E}+00$ & $1.17 \mathrm{E}+00$ & $1.15 \mathrm{E}+00$ \\
\hline 1.0 & 2.95E-07 & $1.29 \mathrm{E}+00$ & $1.14 \mathrm{E}+00$ & $1.12 \mathrm{E}+00$ \\
\hline 3.2 & 1.96E-07 & $1.29 \mathrm{E}+00$ & $1.08 \mathrm{E}+00$ & $1.03 E+00$ \\
\hline 10 & 1.19E-07 & $1.29 \mathrm{E}+00$ & 9.86E-01 & $9.31 \mathrm{E}-01$ \\
\hline 31.6 & 7.46E-08 & $1.29 \mathrm{E}+00$ & 8.77E-01 & $5.82 \mathrm{E}-01$ \\
\hline 34 & 3.77E-08 & $1.29 \mathrm{E}+00$ & 7.02E-01 & 5.82E-01 \\
\hline
\end{tabular}

Table 4-14 Impact of NDE and Alternative Leak Detection Strategies to Reduce Fire Feedwater-Condensate System Pipe Rupture Frequencies

\begin{tabular}{|c|c|c|c|c|c|}
\hline \multirow{2}{*}{$\begin{array}{c}\text { Equivalent } \\
\text { Break Size }\end{array}$} & \multicolumn{5}{|c|}{ NDE every 10 years at 90\% POD with Variable Leak Testing } \\
(in.) & $\begin{array}{c}\text { Brequency } \\
\text { per ROY-ft. }\end{array}$ & \multicolumn{4}{|c|}{$\begin{array}{c}\text { Factor Reduction in Base Rate for Periodic Leak } \\
\text { Test } 90 \% \text { POD }\end{array}$} \\
\cline { 3 - 6 } & & None & Yearly & Quarterly & Weekly \\
\hline 0.032 & $1.56 \mathrm{E}-06$ & $1.65 \mathrm{E}-01$ & $1.35 \mathrm{E}-01$ & $1.32 \mathrm{E}-01$ & $1.31 \mathrm{E}-01$ \\
\hline 0.10 & $5.54 \mathrm{E}-07$ & $2.13 \mathrm{E}-01$ & $1.36 \mathrm{E}-01$ & $1.26 \mathrm{E}-01$ & $1.25 \mathrm{E}-01$ \\
\hline 0.32 & $3.95 \mathrm{E}-07$ & $2.42 \mathrm{E}-01$ & $1.36 \mathrm{E}-01$ & $1.23 \mathrm{E}-01$ & $1.21 \mathrm{E}-01$ \\
\hline 1.0 & $2.95 \mathrm{E}-07$ & $3.01 \mathrm{E}-01$ & $1.36 \mathrm{E}-01$ & $1.20 \mathrm{E}-01$ & $1.17 \mathrm{E}-01$ \\
\hline 3.2 & $1.96 \mathrm{E}-07$ & $3.52 \mathrm{E}-01$ & $1.37 \mathrm{E}-01$ & $1.14 \mathrm{E}-01$ & $1.10 \mathrm{E}-01$ \\
\hline 10 & $1.19 \mathrm{E}-07$ & $4.09 \mathrm{E}-01$ & $1.37 \mathrm{E}-01$ & $1.04 \mathrm{E}-01$ & $9.71 \mathrm{E}-02$ \\
\hline 31.6 & $7.46 \mathrm{E}-08$ & $4.99 \mathrm{E}-01$ & $1.38 \mathrm{E}-01$ & $9.22 \mathrm{E}-02$ & $8.36 \mathrm{E}-02$ \\
\hline 34 & $3.77 \mathrm{E}-08$ & $7.65 \mathrm{E}-01$ & $1.39 \mathrm{E}-01$ & $7.38 \mathrm{E}-02$ & $6.14 \mathrm{E}-02$ \\
\hline
\end{tabular}


Table 4-15 Integrity Management Factors for Various Combinations of NDE and Leak Inspections for Feedwater-Condensate System

\begin{tabular}{|c|c|c|c|c|c|c|c|}
\hline \multicolumn{8}{|c|}{ NO NDE with Quarterly Leak Testing and Variable Leak Testing POD } \\
\hline EBS & $\begin{array}{l}\text { No Leak } \\
\text { Test }\end{array}$ & $\mathrm{POD}=.50$ & $\mathrm{POD}=.60$ & $\mathrm{POD}=.70$ & $\mathrm{POD}=.80$ & $\mathrm{POD}=.90$ & $\mathrm{POD}=1.00$ \\
\hline 0.03 & $1.57 \mathrm{E}+00$ & $1.26 \mathrm{E}+00$ & $1.26 \mathrm{E}+00$ & $1.26 \mathrm{E}+00$ & $1.26 \mathrm{E}+00$ & $1.26 \mathrm{E}+00$ & $1.26 \mathrm{E}+00$ \\
\hline 0.10 & $2.02 \mathrm{E}+00$ & $1.22 \mathrm{E}+00$ & $1.21 \mathrm{E}+00$ & $1.21 \mathrm{E}+00$ & $1.21 \mathrm{E}+00$ & $1.20 \mathrm{E}+00$ & $1.20 \mathrm{E}+00$ \\
\hline 0.32 & $2.29 \mathrm{E}+00$ & $1.20 \mathrm{E}+00$ & 1.19E+00 & $1.18 E+00$ & $1.18 E+00$ & $1.17 E+00$ & $1.17 E+00$ \\
\hline 1.00 & $2.85 \mathrm{E}+00$ & 1.17E+00 & $1.16 \mathrm{E}+00$ & $1.15 E+00$ & $1.15 E+00$ & $1.14 \mathrm{E}+00$ & $1.14 \mathrm{E}+00$ \\
\hline 3.20 & $3.32 \mathrm{E}+00$ & $1.12 \mathrm{E}+00$ & $1.11 \mathrm{E}+00$ & $1.09 E+00$ & $1.09 E+00$ & $1.08 E+00$ & $1.08 E+00$ \\
\hline 10.00 & $3.84 \mathrm{E}+00$ & $1.04 \mathrm{E}+00$ & $1.02 E+00$ & $1.01 \mathrm{E}+00$ & 9.95E-01 & 9.86E-01 & 9.79E-01 \\
\hline 31.60 & $4.65 \mathrm{E}+00$ & 9.53E-01 & 9.25E-01 & 9.05E-01 & 8.89E-01 & 8.77E-01 & 8.68E-01 \\
\hline 34.00 & $7.07 \mathrm{E}+00$ & 8.10E-01 & 7.70E-01 & 7.41E-01 & 7.19E-01 & 7.02E-01 & 6.88E-01 \\
\hline \multicolumn{8}{|c|}{ 10yr. NDE with $50 \%$ POD with Quarterly Leak Testing with Variable Leak Testing POD } \\
\hline EBS & \begin{tabular}{|l|} 
No Leak \\
Test
\end{tabular} & $\mathrm{POD}=.50$ & $\mathrm{POD}=.60$ & $\mathrm{POD}=.70$ & $\mathrm{POD}=.80$ & $\mathrm{POD}=.90$ & $\mathrm{POD}=1.00$ \\
\hline 0.03 & 2.96E-01 & 2.37E-01 & 2.37E-01 & 2.37E-01 & 2.36E-01 & 2.36E-01 & 2.36E-01 \\
\hline 0.10 & 3.80E-01 & 2.29E-01 & 2.28E-01 & 2.28E-01 & 2.27E-01 & 2.26E-01 & 2.26E-01 \\
\hline 0.32 & 4.31E-01 & $2.25 \mathrm{E}-01$ & $2.23 E-01$ & $2.22 \mathrm{E}-01$ & $2.21 \mathrm{E}-01$ & $2.21 \mathrm{E}-01$ & $2.20 \mathrm{E}-01$ \\
\hline 1.00 & 5.36E-01 & $2.20 \mathrm{E}-01$ & $2.18 \mathrm{E}-01$ & $2.16 \mathrm{E}-01$ & $2.15 \mathrm{E}-01$ & $2.15 \mathrm{E}-01$ & $2.14 \mathrm{E}-01$ \\
\hline 3.20 & $6.25 \mathrm{E}-01$ & 2.11E-01 & 2.08E-01 & 2.06E-01 & 2.04E-01 & 2.03E-01 & 2.02E-01 \\
\hline 10.00 & 7.23E-01 & 1.96E-01 & 1.92E-01 & 1.89E-01 & 1.87E-01 & 1.85E-01 & 1.84E-01 \\
\hline 31.60 & 8.78E-01 & 1.80E-01 & 1.74E-01 & $1.70 \mathrm{E}-01$ & 1.67E-01 & 1.65E-01 & 1.63E-01 \\
\hline 34.00 & $1.34 \mathrm{E}+00$ & $1.53 \mathrm{E}-01$ & 1.45E-01 & $1.40 \mathrm{E}-01$ & 1.35E-01 & 1.32E-01 & 1.30E-01 \\
\hline \multicolumn{8}{|c|}{ 10yr. NDE with $90 \%$ POD with Quarterly Leak Testing with Variable Leak Testing POD } \\
\hline EBS & $\begin{array}{l}\text { No Leak } \\
\text { Test }\end{array}$ & $\mathrm{POD}=.50$ & $\mathrm{POD}=.60$ & $\mathrm{POD}=.70$ & $\mathrm{POD}=.80$ & $\mathrm{POD}=.90$ & $\mathrm{POD}=1.00$ \\
\hline 0.03 & 1.65E-01 & 1.33E-01 & 1.32E-01 & 1.32E-01 & 1.32E-01 & 1.32E-01 & $1.32 \mathrm{E}-01$ \\
\hline 0.10 & 2.12E-01 & $1.28 \mathrm{E}-01$ & 1.27E-01 & 1.27E-01 & 1.27E-01 & $1.26 \mathrm{E}-01$ & 1.26E-01 \\
\hline 0.32 & 2.41E-01 & 1.26E-01 & $1.25 \mathrm{E}-01$ & $1.24 \mathrm{E}-01$ & $1.24 \mathrm{E}-01$ & 1.23E-01 & 1.23E-01 \\
\hline 1.00 & 2.99E-01 & 1.23E-01 & 1.22E-01 & 1.21E-01 & $1.20 \mathrm{E}-01$ & $1.20 \mathrm{E}-01$ & 1.19E-01 \\
\hline 3.20 & 3.49E-01 & 1.18E-01 & 1.16E-01 & 1.15E-01 & 1.14E-01 & 1.14E-01 & 1.13E-01 \\
\hline 10.00 & 4.04E-01 & 1.10E-01 & 1.07E-01 & 1.06E-01 & $1.05 \mathrm{E}-01$ & 1.04E-01 & 1.03E-01 \\
\hline 31.60 & 4.90E-01 & $1.00 \mathrm{E}-01$ & 9.73E-02 & 9.51E-02 & 9.35E-02 & 9.22E-02 & 9.12E-02 \\
\hline 34.00 & 7.46E-01 & 8.55E-02 & 8.11E-02 & 7.80E-02 & 7.57E-02 & 7.38E-02 & 7.24E-02 \\
\hline
\end{tabular}

In the above tables, factors above 1.0 indicate an assumed integrity management program less effective than what is assumed in the baseline, and factors less than 1 indicate a more effective RIM program. 


\subsubsection{Impact of Plant Age on Estimated Failure Rates for FAC Susceptible Systems}

As was done for the FP piping, the Markov model was used to calculate aging factors to adjust the baseline failure rates, derived from service data with average plant age of 32 years, to account for aging at 40yrs, 60yrs, and 80yrs. These results are shown in Table 4-16.

Table 4-16 Factors to Account for Aging Effects on NPS 24" FWC Pipe

\begin{tabular}{|c|c|c|c|c|c|}
\hline \multirow{2}{*}{\multicolumn{2}{|c|}{ Pipe Failure Mode }} & \multirow{2}{*}{$\begin{array}{l}\text { Base } \\
\text { Rates } \\
\text { (mean) }\end{array}$} & \multicolumn{3}{|c|}{$\begin{array}{l}I_{T} \text {, Factor Increase to Account } \\
\text { for Aging at Time T }\end{array}$} \\
\hline & & & $\begin{array}{l}40 \\
\text { Years }\end{array}$ & $\begin{array}{c}60 \\
\text { Years }\end{array}$ & 80 Years \\
\hline \multicolumn{2}{|c|}{ All Failure Modes } & $5.72 \mathrm{E}-06$ & 1.3 & 2.1 & 3.0 \\
\hline \multirow{8}{*}{ EBS (in.) } & 0.032 & $1.56 \mathrm{E}-06$ & 1.3 & 2.1 & 3.0 \\
\hline & 0.10 & 5.54E-07 & 1.4 & 2.4 & 3.5 \\
\hline & 0.32 & 3.95E-07 & 1.4 & 2.5 & 3.7 \\
\hline & 1.0 & 2.95E-07 & 1.4 & 2.4 & 3.6 \\
\hline & 3.2 & $1.96 \mathrm{E}-07$ & 1.4 & 2.5 & 3.9 \\
\hline & 10 & 1.19E-07 & 1.5 & 2.9 & 4.5 \\
\hline & 31.6 & 7.46E-08 & 1.5 & 3.0 & 4.8 \\
\hline & 34 & 3.77E-08 & 1.5 & 3.0 & 4.8 \\
\hline
\end{tabular}

\subsection{Investigation of Aging via Direct Estimation of Failure Rates and Rupture Frequencies}

In the previous sections, estimates of the possible growth in failure rates and rupture frequencies due to aging in the Fire Protection and Feedwater and Condensate Systems were made based on the time dependent growth in the hazard rate evaluated at the end of 40 years design life and 60 years extended life in comparison to the average age of the plants in the service data which happens to be 32 years. A more direct estimation of the possible trends in failure rates due to aging can be made simply by comparing the estimates made at different snapshots in time. The estimates of pipe failure rates in the previous sections were made based on nuclear power plant service experience through 2010. For Fire Protection the data start date was 1970 and for the current estimates for FWC the start date is 1989 so that the experience prior to full implementation of the FAC programs was screened out. In Reference [1] there were estimates made for both of these systems based on the service data up through 2005. By comparing and decomposing these estimates it is possible to provide a direct estimation of the changes in failure rate behavior in the last 5 years since 2005.

As seen in this figure, failure rates for spray and flood modes in FP piping over the last 5 years has increased by more than an order of magnitude relative to that estimated over the time 
period from 1970 through 2005. The failure rate for major flooding (flood rates exceeding $2,000 \mathrm{gpm}$ ) has increased by somewhat less than an order of magnitude. This trend suggests that failure rates are on the rise and aging is a candidate explanation.

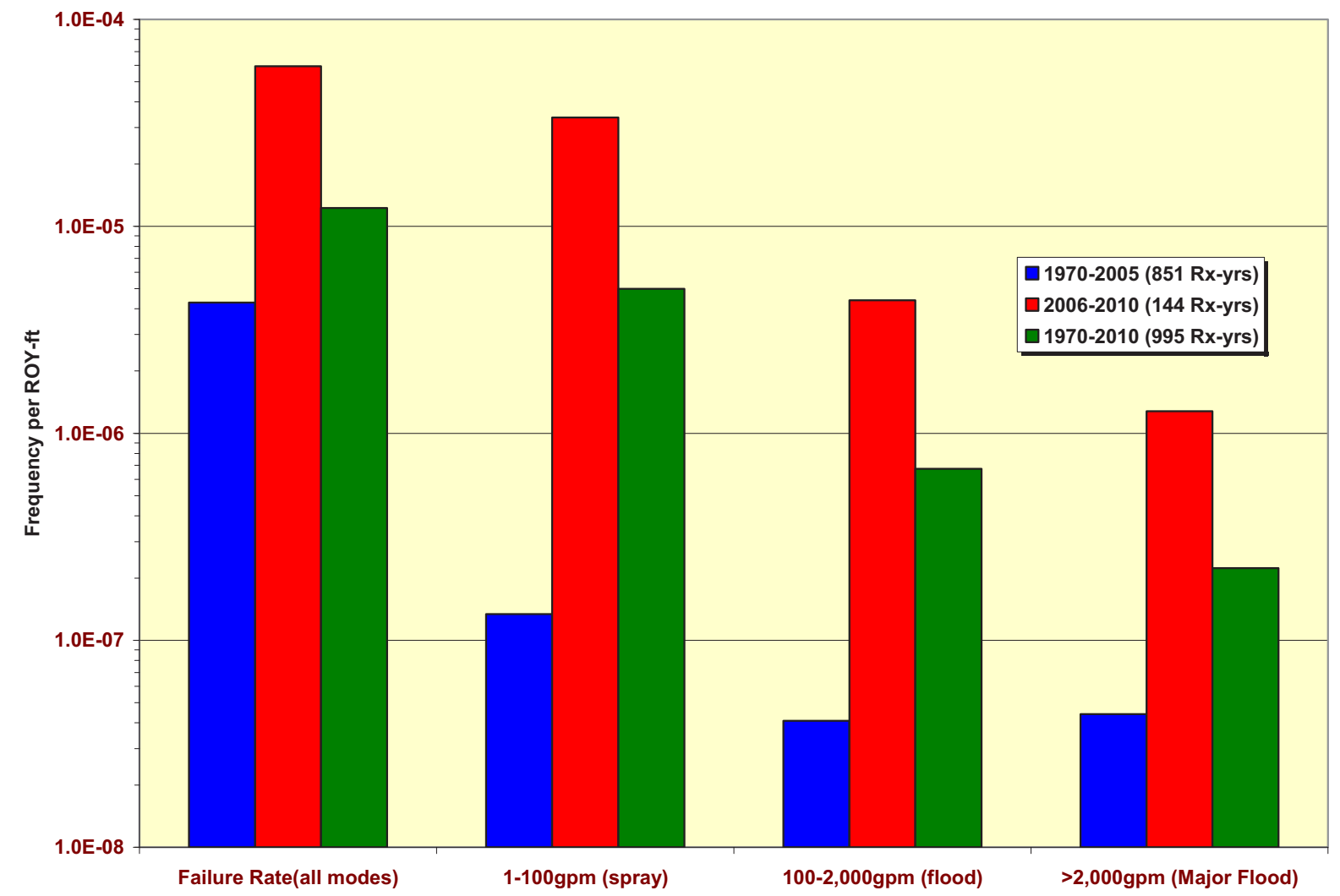

Figure 4-11 Comparison of Fire Protection System Failure Rates Over Different Time Periods

Another example of this type of direct estimate can be made with respect to PWR feedwater and condensate piping by comparing estimates that were made at different snapshots in time. In this case the current results are compared to the results of an earlier study that was performed for the Prairie Island nuclear power plant. The time frames of this comparison are 1988 through 2004 and 2005 through 2008. In this case only the total failure rate is compared as shown in Figure 4-12. As seen in this figure there is more modest evidence of pipe aging in the larger pipe sizes for this system that is subjected to FAC. In this case there appears to be an increase in the failure rate of large FWC pipes on the order of a factor of 5 compared to the estimate derived in Reference [2] for the time period 1988 through 2004. It is noted that the most recent time period estimates are subjected to larger uncertainties (unquantified here) as only 400 reactor years are available in this data set. 


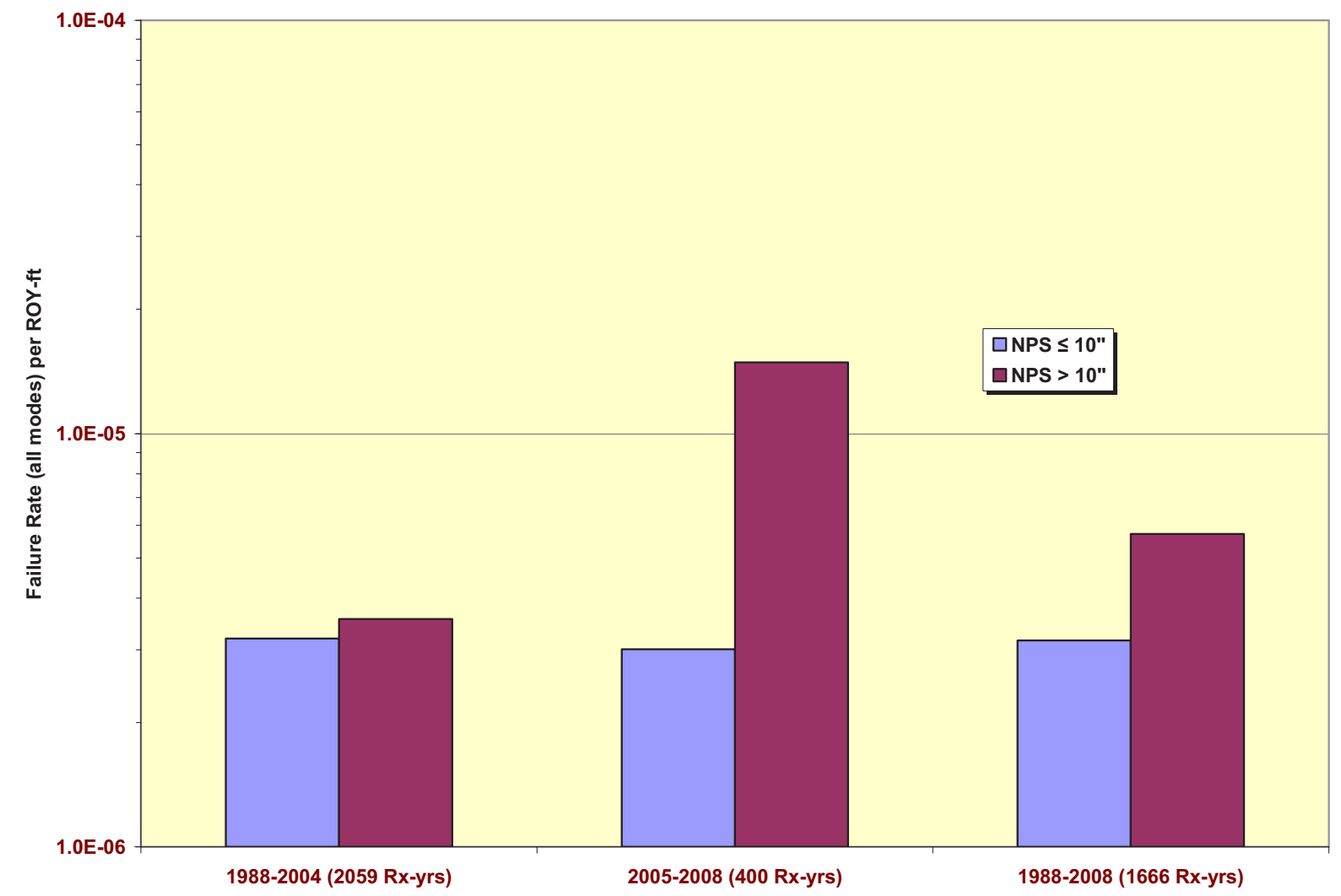

Figure 4-12 Comparison of PWR FWC Failure Rate Estimates for Different Time Periods 


\subsection{ASME Class 1 PWR Pressurizer Surge Line Nozzle}

The final passive component selected for evaluation in this study is the dissimilar weld for a PWR pressurizer surge line nozzle which is known to be susceptible to stress corrosion cracking. The baseline evaluation for this component using the current PRA methods described in Section 2 is the topic of a benchmark problem described in Section 5 which was selected to provide a basis for enhancements to the reliability evaluation that are investigated in this study. The cumulative failure rates vs. break size for this component are shown in Figure 4-13 and Table 4-17 using the methodology in Section 2. The assumptions and input data associated with these estimates are described in Section 5. Note that these rupture frequencies are expressed in terms of events per weld-year rather than foot-year as used in the non-safety related piping presented earlier in this section.

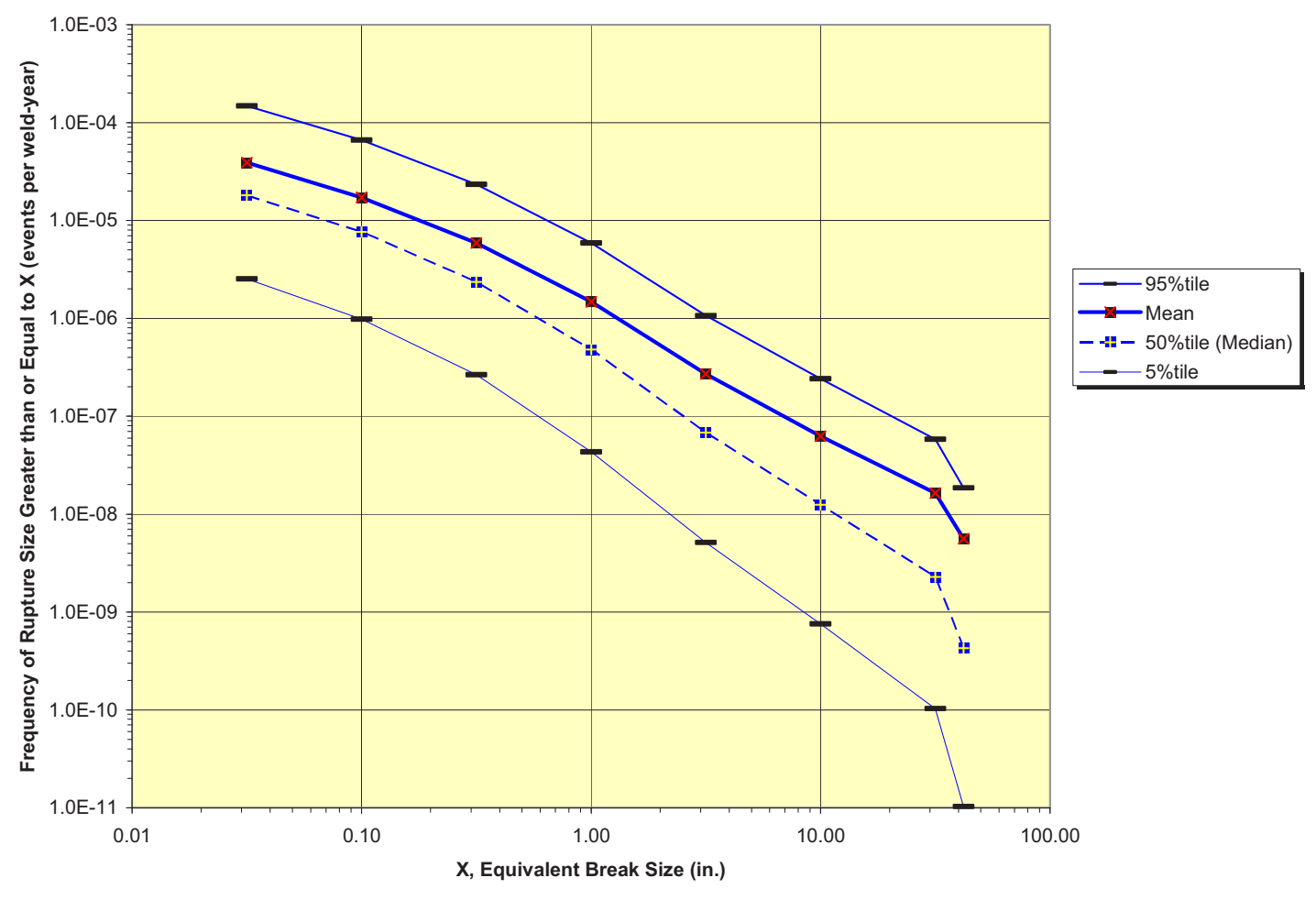

Figure 4-13 Cumulative Rupture Frequency vs. Break Size for PWR Nozzle Weld 
Table 4-17 Failure Rates and Cumulative Rupture Frequencies for PWR Nozzle Weld

\begin{tabular}{|c|c|c|c|c|c|c|}
\hline \multirow{2}{*}{\multicolumn{2}{|c|}{ Parameter }} & \multicolumn{5}{|c|}{ Frequency per ROY-ft. } \\
\hline & & Mean & $5 \%$ tile & $50 \%$ tile & $95 \%$ tile & $\mathrm{RF}^{\text {[Note 1] }}$ \\
\hline \multicolumn{2}{|c|}{ Failure Rate } & $2.72 \mathrm{E}-04$ & 2.08E-05 & $1.31 \mathrm{E}-04$ & $1.02 \mathrm{E}-03$ & 7.0 \\
\hline \multirow{9}{*}{ 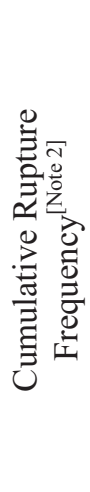 } & EBS (in.) & & & & & \\
\hline & 0.032 & $3.89 \mathrm{E}-05$ & 2.53E-06 & $1.80 \mathrm{E}-05$ & $1.49 \mathrm{E}-04$ & 7.7 \\
\hline & 0.10 & $1.72 \mathrm{E}-05$ & $9.82 \mathrm{E}-07$ & 7.64E-06 & $6.62 \mathrm{E}-05$ & 8.2 \\
\hline & 0.316 & $5.90 \mathrm{E}-06$ & $2.66 \mathrm{E}-07$ & $2.35 \mathrm{E}-06$ & $2.34 \mathrm{E}-05$ & 9.4 \\
\hline & 1.00 & $1.48 \mathrm{E}-06$ & 4.33E-08 & 4.81E-07 & $5.87 \mathrm{E}-06$ & 11.6 \\
\hline & 3.16 & 2.71E-07 & $5.12 \mathrm{E}-09$ & $6.80 \mathrm{E}-08$ & $1.06 \mathrm{E}-06$ & 14.4 \\
\hline & 10.00 & $6.25 \mathrm{E}-08$ & $7.56 \mathrm{E}-10$ & $1.25 \mathrm{E}-08$ & $2.42 \mathrm{E}-07$ & 17.9 \\
\hline & 31.62 & $1.64 \mathrm{E}-08$ & $1.03 \mathrm{E}-10$ & 2.28E-09 & $5.80 \mathrm{E}-08$ & 23.7 \\
\hline & 42.00 & $5.61 \mathrm{E}-09$ & $1.03 \mathrm{E}-11$ & $4.28 \mathrm{E}-10$ & $1.86 \mathrm{E}-08$ & 42.5 \\
\hline
\end{tabular}

Note $1 . \mathrm{RF}=(95 \% \text { tile } / 5 \% \text { tile })^{0.5}$; These distributions can be approximated as lognormal distributions with the indicated mean and the calculated range factor (RF)

Note 2. Frequency of pipe rupture with EBS equal to or greater than indicated EBS value; use 42.0in. values for frequency of rupture with pipe whip potential. 


\section{Evaluation of Alternative Markov Model Solution Approaches}

\subsection{Definition of Selected Component}

Stress corrosion cracking (SCC) of an RCS Alloy 82/182 dissimilar metal weld has been selected by the RISMC team as the initial application for examining improvements to the current approach to passive component reliability that was exercised in the previous sections. Two types of improvements are investigated. In this section, advanced computational approaches to solving the existing and more advanced Markov models are investigated. In Section 6, the use of a physics-based model to improve the capabilities of the reliability assessment is explored and methodological bases for addressing deviations from Markov assumptions identified. For both of these sections, a common component is selected, namely a weld in PWR reactor coolant system made from Alloy $82 / 182$. Alloy $82 / 182$ welds are found in several key locations in class 1 piping structures, such as the vessel reactor coolant pipe welds and pressurizer surge line pipe weld. Figure 5-1 shows a Westinghouse surge line nozzle with an alloy 182 weld joining the stainless steel safe end to the low alloy steel nozzle. This component forms the basis of the Benchmark problem that is used in this section to evaluate improved methods for solving the Markov model equations described in Section 2.

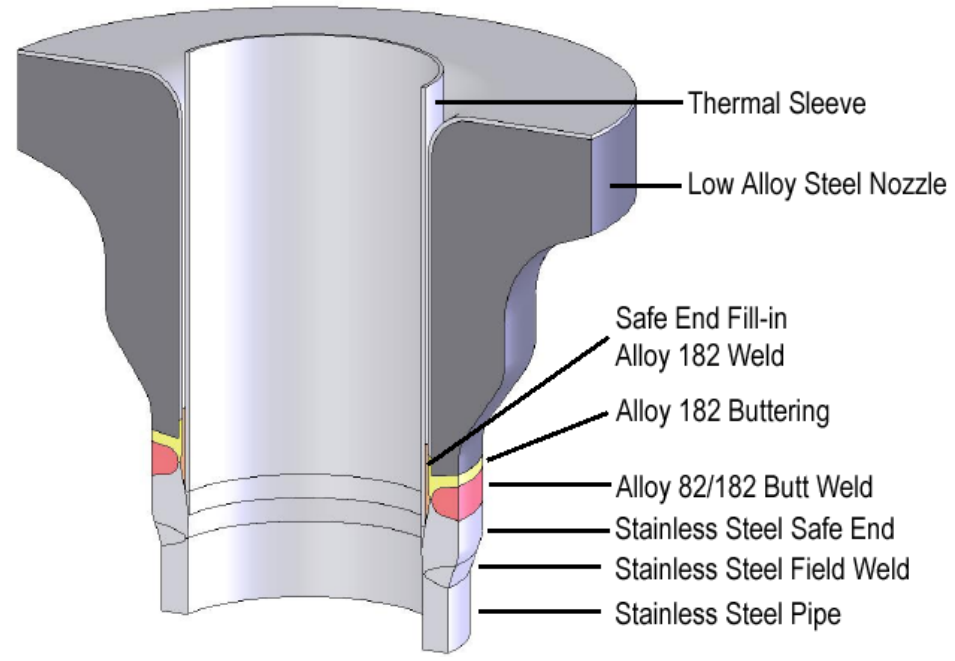

Figure 5-1 Layout of a Westinghouse PWR surge line nozzle connection to the pressurizer (Courtesy of Westinghouse).

\subsection{Baseline Assessment Using Current Reliability Methods}

\subsubsection{Markov Model}

For this Benchmark problem, which is selected to provide comparisons of alternative Markov model solution schemes, the original 4-state Markov model is used as shown in Figure 5-2. As a Markov model, there is an assumption of constant transition rates. 


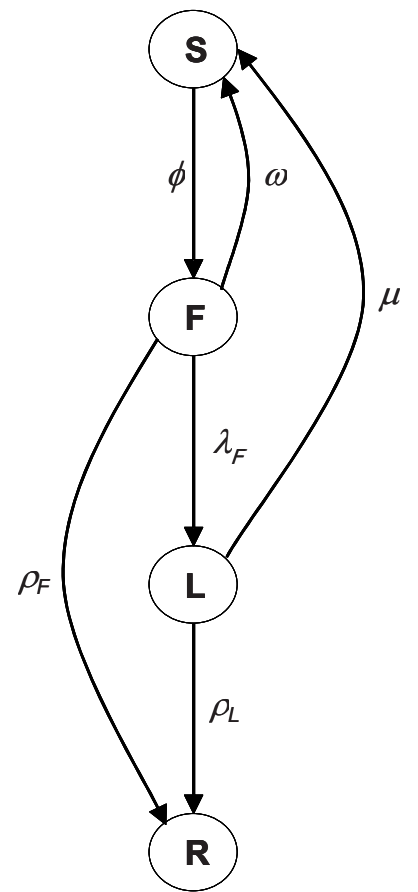

Pipe Element States

S - success, no detectable damage

$\mathrm{F}$ - flaw detectable via NDE

$\mathrm{L}$ - detectable leak

$\mathrm{R}$ - rupture

State Transition Rates

$\phi$ - flaw occurrence rate

$\lambda_{F}$ - leak failure rate given flaw

$\rho_{F}-$ rupture failure rate given flaw

$\rho_{L}-$ rupture failure rate given leak

$\omega$ - repair rate via NDE

$\mu$ - repair rate via leak detection

Figure 5-2 Markov Model for PWR RCS Weld Susceptible to Stress Corrosion Cracking

\subsubsection{Derivation of Transition Rates}

Failure rates and rupture frequencies for this component are defined first and these then provide a starting point for estimating the Markov model transition rates. The failure rate for this component is assumed to be constant in time and is assumed to account for any pipe failure that involves repair or replacement. In Class 1 piping system components like this one, the repair and replacement rules are subject to specific ASME requirements. Failures include nonthrough wall flaws sufficient to meet repair/replacement criteria, wall thinning, cracks, pinhole leaks, leaks, and ruptures.

The failure rate and a formula for estimating the failure rate from service data is expressed in the following equation:

$$
\lambda_{i j}=\sum_{k=1}^{M_{i j}} \lambda_{i j k}=\sum_{k=1}^{M_{i j}} \frac{n_{i j k}}{f_{i j k} N_{i j} T_{i j}}
$$

Where:

$$
\begin{aligned}
& \lambda_{i j} \quad=\quad \text { Failure rate of component } \mathrm{i} \text { in system } \mathrm{j} \text {, per weld year } \\
& n_{i j k} \quad=\quad \text { the number of failures (cracks, wall thinning, leaks and ruptures) } \\
& T_{i j} \quad=\quad \text { the total time in reactor-years over which failure events were } \\
& \text { collected for pipe size } \mathrm{i} \text { in system } \mathrm{j} \\
& N_{i j} \quad=\quad \text { the number of components that provided the observed pipe } \\
& \text { failures for size i in system j, number of welds providing exposure } \\
& \text { for } n_{i j k}
\end{aligned}
$$


$f_{i j k} \quad=\quad$ the fraction of number of components of size $\mathrm{i}$ in system $\mathrm{j}$ that are susceptible to failure from damage mechanism $\mathrm{k}$ for conditional failure rates given susceptibility to damage mechanism $\mathrm{k}$.

Failure mechanisms include damage mechanisms such as stress corrosion cracking, thermal fatigue, etc. as well as severe loading conditions, e.g. overpressure, overstressed, water hammer, etc.

For this benchmark exercise component size and system are fixed so we shall drop the i,j indices from the subsequent nomenclature. Regarding the parameter $f_{i j k}$; For failure rates that are conditioned on the susceptibility to a given failure mechanism, this parameter is less than or equal to 1.0 depending on what fraction of the components in the collected service data are susceptible that mechanism. For the benchmark problem it is assumed that the weld is susceptible to stress corrosion cracking. For unconditional failure rates (i.e. no knowledge of the susceptibility of the weld to the failure mechanism) this parameter is set to 1.0. In the benchmark it is assumed that the weld is only subject to stress corrosion cracking as a damage mechanism but all welds especially those welded in the field are subject to design and construction defects that are not picked up in the pre-service in-service inspections. Hence, the total failure rate for the benchmark weld can be rewritten as:

$$
\lambda=\lambda_{S C}+\lambda_{D C}=\frac{n_{S C}}{f_{S C} N T}+\frac{n_{D C}}{f_{D C} N T}
$$

Where $\lambda$ is the total component failure rate, $\lambda_{S C}$ and $\lambda_{D C}$ are the failure rates for stress corrosion cracking and design and construction defects, respectively, $n_{S C}$ and $n_{D C}$ are the observed number of failures for these failure mechanisms in the service data, $f_{S C}$ and $f_{D C}$ are the fractions of welds in the RCS that are susceptible to these failure mechanism across the population of plants in the service data, $N$ is the number of welds per reactor in the reactor coolant system, and $T$ is the number of reactor years of service data collected.

In the uncertainty analysis for calculating the failure rates, a Bayes' approach is used which starts with assumed prior distributions for $\lambda_{S C}$ and $\lambda_{D C}$ and then uses the failure counts and exposure as evidence to update the priors for each failure rate. The Bayes uncertainties for each failure rate are then propagated through equation (2) via Monte Carlo sampling to obtain the uncertainty on the total failure rate.

A complication is that there is substantial uncertainty in establishing the exposure terms for the Bayes' update. While there is no uncertainty in $f_{D C}=1$, and very little uncertainty in the failure counts and $T$, there is in fact significant uncertainty in $\mathrm{N}$, the weld counts per reactor, and $\mathrm{f}_{\mathrm{Sc}}$, the fraction of the reactor coolant system welds in the service data that are susceptible to stress corrosion cracking. In previous evaluations to support RI-ISI evaluation these uncertainties were addressed via simple discrete distributions, one for $\mathrm{f}_{\mathrm{SC}}$ and one for $\mathrm{N}$ as shown in Figure 5-3. Application of this model requires 9 separate Bayes' updates. 


\begin{tabular}{|l|r|}
\hline Welds & 366 \\
\hline Rx-yrs & 3089 \\
\hline Base Exposure & $1,130,428$ \\
\hline
\end{tabular}

\begin{tabular}{|c|c|c|c|c|c|}
\hline Weld Count Uncertainty & $\begin{array}{c}\text { Fraction of Welds } \\
\text { Susceptible to Stress } \\
\text { Corrosion Cracking (SC) }\end{array}$ & $\begin{array}{l}\text { Exposure } \\
\text { Case } \\
\text { Probability }\end{array}$ & $\begin{array}{l}\text { Exposure } \\
\text { Multiplier }\end{array}$ & \multicolumn{2}{|c|}{ Exposure } \\
\hline \multirow[b]{3}{*}{$p=.25$} & $p=.25$ & 0.0625 & 0.375 & 423,910 & weld-yrs \\
\hline & High (.25 X Base) & & & & \\
\hline & p- .50 & 0.125 & 0.075 & 84,782 & weld-yrs \\
\hline \multirow[t]{5}{*}{ High (1.5 X Base) } & Medium (.05 X Base) & & & & \\
\hline & $p=.25$ & 0.0625 & 0.015 & 16,956 & weld-yrs \\
\hline & Low (.01 X Base) & & & & \\
\hline & $p=.25$ & 0.125 & 0.25 & 282,607 & weld-yrs \\
\hline & High (.25 X Base) & & & & \\
\hline$p=.50$ & p- .50 & 0.25 & 0.05 & 56,521 & weld-yrs \\
\hline \multirow[t]{5}{*}{ Medium (1.0 X Base) } & Medium (.05 X Base) & & & & \\
\hline & $p=.25$ & 0.125 & 0.01 & 11,304 & weld-yrs \\
\hline & Low (.01 X Base) & & & & \\
\hline & $p=.25$ & 0.0625 & 0.125 & 141,303 & weld-yrs \\
\hline & High (.25 X Base) & & & & \\
\hline $\mathrm{p}=.25$ & p- .50 & 0.125 & 0.025 & 28,261 & weld-yrs \\
\hline \multirow[t]{2}{*}{ High (0.5 X Base) } & Medium (.05 X Base) & & & & \\
\hline & $p=.25$ & 0.0625 & 0.005 & 5,652 & weld-yrs \\
\hline
\end{tabular}

\section{Figure 5-3 Discrete Distribution Model for Service Data Exposure Uncertainty}

For the D\&C failure rate, there is only 3 exposure cases reflecting the uncertainty in the weld counts. Bayes' updates each prior with a different hypothesis on the correct exposure to use with the observed numbers of failures. Then a Bayes' posterior weighting procedure is used to combine the 9 distributions for SC and the 3 distributions for DC into one for each using a discrete probability distribution over the 9 exposure cases for SC and the distribution over the 3 cases for DC. In each Monte Carlo trial an exposure case is selected from the discrete distribution for DC and the discrete distribution for SC and Equation (2) is calculated for that sample.

\subsubsection{Rupture Mode Frequencies}

Given knowledge of the total failure rate and its uncertainty obtained using the above described approach, the frequency of each pipe rupture mode is obtained using the following:

$$
\rho_{l}=\lambda P\left(R_{l}\right)
$$

Where $\rho_{l}$ is the frequency of pipe rupture in rupture mode $I$ and $P\left(R_{l}\right)$ is the conditional probability of rupture in mode I given a pipe failure. In principle one could use different conditional rupture probability models for each failure mechanism but that is beyond the current state of knowledge for this problem, i.e. there is no reason to believe that a pipe rupture from SC would be any different than a pipe rupture for DC failure mechanisms.

There are large uncertainties in the estimation of the conditional rupture mode probabilities and the uncertainty increases with increasing severity of the assumed pipe rupture. 


\subsubsection{Markov Model Parameters}

From the above models for estimating the component failure rates and rupture mode frequencies for each applicable failure mechanism, models and data for the Markov model transition parameters associated with pipe degradation may be estimated using service data.

\section{Flaw Occurrence Rate, $\phi$}

Each occurrence of pipe failure in the service data is evidence of a pipe flaw. Some pipe failures are actually discovered during NDE exams or other types of ISI examinations as modeled in the Markov model. Other pipe failures occur when pipe leaks and ruptures occur and these are also associated with an historical flaw. In addition there are unknown occurrences of flaws due to the fact that all pipe welds are not inspected and even those that are inspected may have flaws that are not picked up in the exams. Hence, it is reasonable to model the flaw occurrence rate as a multiple of the failure rate, such as expressed by the following equation.

$$
\phi=m_{F} \lambda
$$

Failure Rate For Leaks given a Flaw, $\lambda_{F}$

This is the transition rate from State $F$ to $L$ in Figure 5-2. Since $F$ is the starting state, the failure rate is conditional on the existence of a flaw. This rate is related to the previously defined failure rate according to the following equation.

$$
\lambda_{F}=\frac{f_{L} \lambda}{f_{F}}
$$

Where $f_{L}$ is the fraction of the failure rate involving leaks that are large enough to be detected by the leak surveillance program, and $f_{F}$ is the fraction of the pipe components in the service data used to estimate $\lambda$ that have flaws. Both of these parameters involve significant uncertainties.

For a 30" pipe, the following leak and rupture modes are considered for this benchmark. These leak and rupture modes cover a range of pipe break sizes from .01 in size diameter for leaks and ruptures with larger sizes up to an including the break size of a double ended break which is $\sqrt{2}$ times the insider diameter of the pipe or about 42 in. for a 30 " pipe. For modeling purposes the following leak and break sizes are considered: 0.01", 0.032", 0.1", 0.32", 1", 3.2", $10 "$, and 42". Failures at .01 are regarded as leaks and those at 0.32 " and larger are regarded as ruptures. Hence the possible rupture states are 0.032 ", $0.1 ", 0.32$ ", 1", 3.2", 10 ", and 42".

\section{Rupture Rate Given a Flaw, $\rho_{F}$}

This is the transition rate from State $\mathrm{F}$ to $\mathrm{R}$ in Figure 1. Since the Markov model only has one rupture state, the model must be solved separately for each rupture mode. For a 30" pipe the following rupture modes are considered for this benchmark. These rupture modes cover a range of pipe break sizes from .01 in break size diameter up to an including the break size of a double ended break which is $\sqrt{2}$ times the insider diameter of the pipe or about 42 in. for a 30 " pipe. When we solve the model for break size I, this transition rate is estimated as: 


$$
\rho_{l F}=\frac{\sum_{r=l}^{M} \rho_{r l}}{f_{F}}
$$

In other words the rupture frequency applied to the model corresponds to the frequency of ruptures of size I or larger and hence the formulation as a cumulative frequency. The fraction of welds with flaws $f_{F}$ is the same parameter used in Equation (5).

Rupture Rate Given a Leak, $\rho_{L}$

This parameter is uncertain and is assigned an uncertainty distribution directly without the need for an underlying model.

Repair Rate for NDE exams, $\omega$

The repair rate for the NDE program is estimated according to the following model.

$$
\omega=\frac{P_{I} P_{F D}}{\left(T_{F I}+T_{R}\right)}
$$

$P_{I}=$ probability that the weld will be inspected, either zero or one depending on whether the weld is selected for the inspection program. For this benchmark it is assumed it is being inspected so that all the degrees of freedom of the model can be exercised. This then has no uncertainty and is set to 1.0 for benchmark.

$P_{F D}=$ probability that a flaw will be detected given this segment is inspected. This parameter is related to the reliability of non destructive examination (NDE) inspection and is a conditional probability given that the location being inspected has a flaw that meets the criteria for repair according to the ASME code. This term is often referred to as the "probability of detection" or POD by NDE specialists. This parameter is subject to uncertainty

$T_{F I}=$ mean time between inspections for flaws, (inspection interval). Normally this parameter is fixed by the ISI program and hence is not assigned an uncertainty. Assume 10 years for benchmark.

$T_{R}=$ mean time to repair once detected. There is an assumption in this model that any significant flaw that is detected will be repaired. In principle this parameter also has uncertainty, however given the insight that this term is not significant to the results (dominated by $T_{F /}$ which is normally 10 years whereas TR is on the order of hours to days) this parameter is not treated with uncertainty. Assume 200 hours for the Benchmark.

Repair Rate for leaks, $\mu$

The repair rate for leaks is estimated according to the following model.

$$
\mu=\frac{P_{L D}}{\left(T_{L I}+T_{R}\right)}
$$

where: 
$P_{L D}=$ probability that the leak in the segment will be detected per inspection. This parameter is subject to uncertainty

$T_{L I}=$ mean time between inspections for leaks, this is normally assumed to be fixed according to the leak inspection program. There are ASME requirements for Class 1 piping system leak inspections that normally set the inspection interval. For the benchmark, this is assumed fixed at $1.5 y e a r s$ and not subject to uncertainty.

$T_{R}=$ as defined above but for full power applications, this time should be the minimum of the actual repair time and the time associated with any technical specification limiting condition for operation (LCO) if the leak rate exceeds technical specification requirements. For the benchmark, this is assumed fixed at 200 hours and not subject to uncertainty.

\subsubsection{Parameter Input Uncertainties}

A summary of the parameter input uncertainties assumed in this benchmark and the basis for the values is provided in Tables 5-1 and 5-2.

\subsubsection{Markov Model Uncertainties}

Hazard rates associated with the Markov model rupture state are developed from closed form analytical solutions to the 4-state Markov model of Figure 5-1 using the approach described in Reference [1]. Uncertainties in the hazard rates are obtained by propagating uncertainties in the parameter inputs through equations described above to compute the transition rate parameters, and equations for the solution of the differential equations and equation for calculating the hazard rate from the solutions via Monte Carlo uncertainty propagation via Crystal Ball. 


\section{Table 5-1 Uncertainty Distribution Assumption for Benchmark Problem Input Parameters}

Parameter

Symbol

$\lambda_{\mathrm{SC}}$ (prior)

$\lambda_{\mathrm{DC}}$ (prior)

$\mathrm{n}_{\mathrm{SC}}$

$\mathrm{n}_{\mathrm{DC}}$

$\mathrm{N}$

$\mathrm{T}$

$\lambda_{\mathrm{SC}}($ posterior)

$\lambda_{\mathrm{DC}}($ posterior)

$$
\text { Definition }
$$

Prior distribution for failure rate due to stress corrosion cracking

Prior distribution for failure rate due to design
and construction defects

Number of pipe failures due to stress corrosion cracking in PWR RCS welds Number of pipe failures due to design and construction defects in PWR RCS welds Average number of welds per plant in PWR RCS

Reactor years experience for service data collection

Posterior distribution for failure rate due to stress corrosion cracking

Posterior distribution for failure rate due to design and construction defects
Uncertainty Treatment

Basis

Lognormal distribution:

Mean $=4.27 \times 10^{-5}$ per weld-year

Range Factor $=100$

Lognormal distribution:

Mean $=1.24 \times 10^{-6}$ per weld-year

Range Factor $=100$

8 , no uncertainty assumed

4 , no uncertainty assumed

366, Uncertainty model in Figure 2

3,089

EPRI TR-111880

EPRI TR-111880

PIPExp-2005

PIPExp-2005

PIPExp-2005

PIPExp-2005

Posterior weighting using discrete distribution over 9 Bayes' update cases per Figure 2

Posterior weighting using discrete distribution over 3 Bayes' update cases per Figure 2 


Parameter
$f_{L}$
Fraction of pipe failures that involve leaks
(assumed to be the same for stress corrosion cracking and design and construction defects.

$P\left(R_{l}\right) \quad$ Conditional probability of rupture in rupture mode (break size) 1 given pipe failure

$m_{F}$

$f_{F}$

$P_{F D}$

undiscovered) per pipe failure

Fraction of the pipe welds in the database that have flaws

Probability that a detectable flaw is detected
Uncertainty Treatment

Beta Distribution:

Lower Bound: 0, upper bound: 1

Alpha: 1; Beta: 4

Mean: 0.20

Uncertainty treatment described in Table 2, different lognormal prior distribution for each rupture mode, updated using evidence of 0 pipe ruptures in 12 failures (sum of $\mathrm{n}_{\mathrm{SC}}$ and $\mathrm{n}_{\mathrm{DC}}$ ). Note the uncertainties across all the break sizes assumed to be fully correlated in the Monte Carlo sampling.

Beta Distribution:

Lower bound: 1; Upper Bound: 10

Alpha: 1; Beta: 2

Mean: 4.0 on each NDE inspection
Beta Distribution:

Lower bound: .01; Upper bound 1.0

Alpha 1; Beta: 2

Mean: 0.34

Triangular Distribution;

Lower bound: 0.1; Peak: 0.9

Upper bound 0.99

Mean: 0.66

\section{Basis}

General review of service data supports assumption that $25 \%$ of pipe failures involve through wall cracks and the assumption that all through wall flaws have break size of 0.01in.

NUREG-1829, essentially the results table for LOCA frequencies vs. break size for PWRs normalized to convert to conditional probability

Engineering judgment

Engineering judgment

Engineering judgment 


Paramete
Symbol

$\rho_{L}$

\section{Definition}

Probability that a detectable leak is detected on each leak inspection or test

Frequency of pipe rupture given a leak
Uncertainty Treatment

Triangular Distribution;

Lower bound: 0.5; Peak: 0.9

Upper bound 0.99

Mean: 0.80

Lognormal Distribution

Mean: $2 \times 10^{-2}$

Range Factor: 3

\section{Basis}

Engineering judgment 


\section{Table 5-2 Uncertainty Treatment for Conditional Pipe Rupture Probabilities Given Pipe Failure}

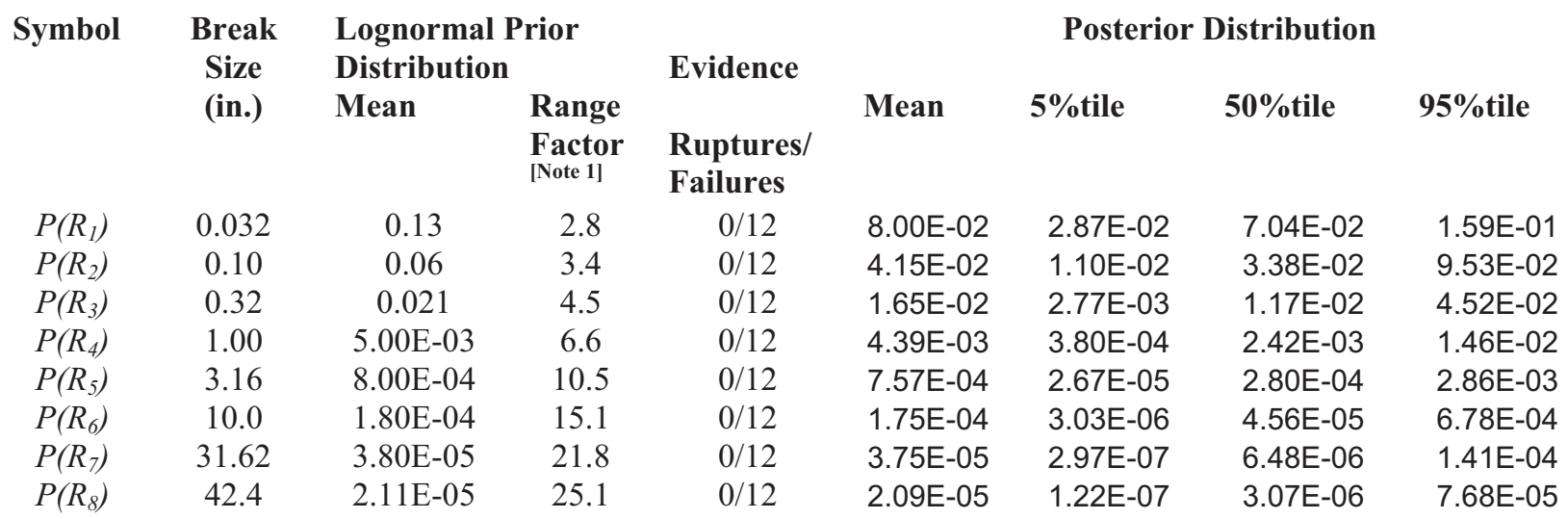

Note 1. Range factors are assumed to be directly correlated to conditional probability according to the following; Range factors are fixed at 3.0,10.0, and 30.0 to conditional probability values of $1 \mathrm{E}-01,1 \mathrm{E}-03$, and 1E-05, respectively. Range factors for intermediate probabilities are calculated based on an assumed linear function on a $\log -\log$ scale.

\subsubsection{Benchmark Results}

Benchmark results for selected hazard rates and intermediate parameters are shown in Table 53. Plots of the hazard rate for ruptures for break sizes of 0.1 in and $10 \mathrm{in}$. are shown in Figures 5-4 and 5-5. These are the most recent results for this version of the benchmark problem.

Table 5-3 Uncertainty Distribution Results for Selected Benchmark Parameters

\begin{tabular}{|c|c|c|c|c|c|}
\hline \multirow[t]{2}{*}{ Symbol } & \multirow[t]{2}{*}{ Definition } & \multicolumn{4}{|c|}{ Epistemic Uncertainty Distribution } \\
\hline & & $5 \%$ tile & $50 \%$ tile & Mean & $95 \%$ tile \\
\hline$\lambda_{S C}$ & Failure Rate-SC & 1.75E-05 & $1.28 \mathrm{E}-04$ & 2.69E-04 & 1.01E-03 \\
\hline$\lambda_{D C}$ & Failure Rate-D\&C & 1.08E-06 & 2.81E-06 & $3.48 \mathrm{E}-06$ & $8.16 \mathrm{E}-06$ \\
\hline$\lambda$ & Failure Rate-Total & 2.08E-05 & 1.31E-04 & 2.72E-04 & 1.02E-03 \\
\hline$\rho_{3}$ & Rupture Frequency 0.1 in. & 5.36E-07 & 4.68E-06 & 1.13E-05 & 4.46E-05 \\
\hline$\rho_{7}$ & Rupture Frequency 10.0in & $2.31 \mathrm{E}-10$ & 6.31E-09 & 4.61E-08 & 1.80E-07 \\
\hline$h(1,0.1)$ & 1 year hazard rate, 0.1 in & $2.06 \mathrm{E}-10$ & 1.46E-08 & 3.66E-07 & $1.28 \mathrm{E}-06$ \\
\hline$h(10,0.1)$ & 10 year hazard rate, 0.1 in & 1.69E-09 & 1.19E-07 & $2.81 \mathrm{E}-06$ & $1.01 \mathrm{E}-05$ \\
\hline$h(40,0.1)$ & 40 year hazard rate, 0.1 in. & 3.28E-09 & 2.35E-07 & 5.18E-06 & 1.94E-05 \\
\hline$h(100,0.1)$ & 100 year hazard rate, 0.1 in. & 3.58E-09 & 2.61E-07 & 5.66E-06 & $2.15 \mathrm{E}-05$ \\
\hline$h(1,10.0)$ & 1 year hazard rate, $10.0 \mathrm{in}$. & $3.09 E-12$ & $2.95 \mathrm{E}-10$ & $1.02 \mathrm{E}-08$ & 3.33E-08 \\
\hline$h(10,10.1)$ & 10 year hazard rate, $10.0 \mathrm{in}$. & $6.68 \mathrm{E}-11$ & 7.03E-09 & 2.58E-07 & 8.27E-07 \\
\hline$h(40,10.1)$ & 40 year hazard rate, $10.0 \mathrm{in}$. & $1.46 \mathrm{E}-10$ & 1.57E-08 & 5.36E-07 & 1.83E-06 \\
\hline$h(100,10.1)$ & 100 year hazard rate, $10.0 \mathrm{in}$. & $1.62 \mathrm{E}-10$ & 1.76E-08 & 5.89E-07 & 2.03E-06 \\
\hline
\end{tabular}




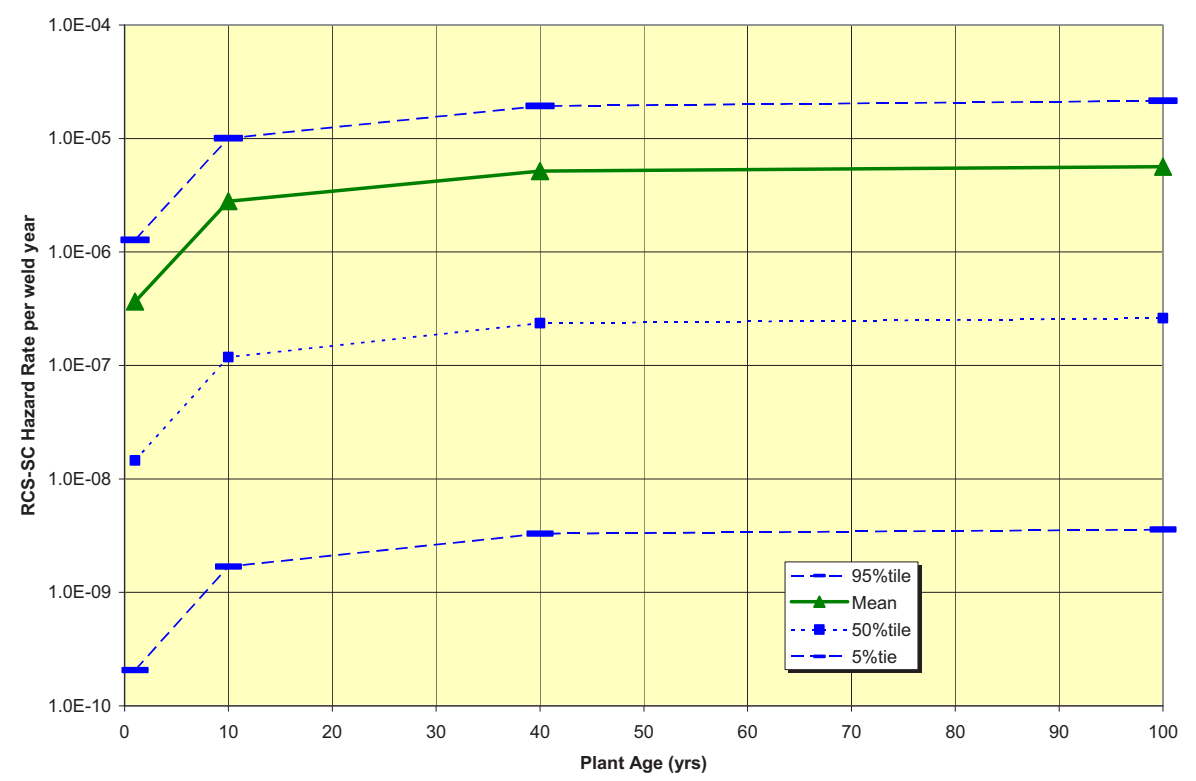

Figure 5-4 Uncertainty Distribution for Hazard Rate for 0.1 inch Breaks

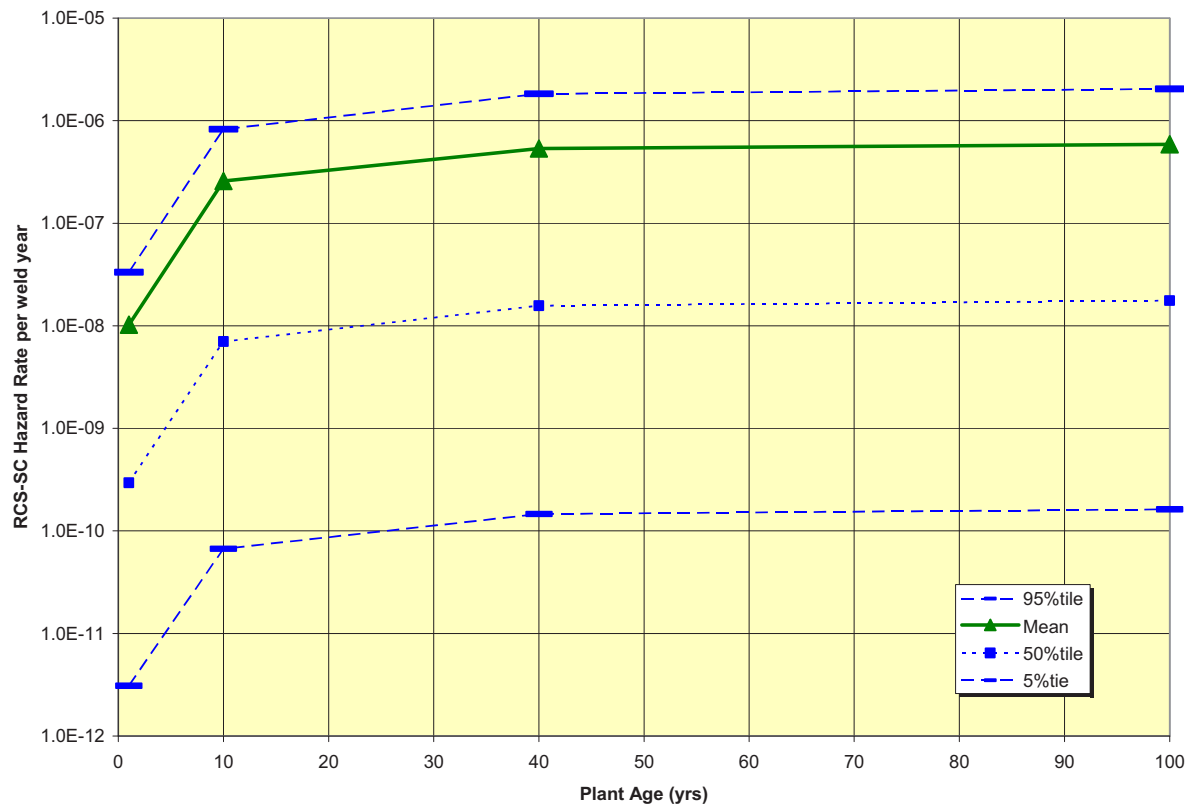

Figure 5-5 Uncertainty Distribution for Hazard Rate for 10.0 inch break 


\subsection{Benchmark Problem 1 Using Numerically Based Computational Approaches}

The solution to the Markov model in the original methodology was achieved analytically. This analytical solution was compared to the results of two alternative numerical methodologies for solving the Markov model. As noted earlier, the advantage of numerical methodologies would be that they could be used to solve more complex Markov models for which analytical solutions are not feasible. The Benchmark Markov model described in Sections 5.1 and 5.2 is the basis for comparison.

The two numerical solution methodologies are described in detail in Appendix C:

(a) The OpenBUGS software used to solve the Markov ODEs.

(b) Bayesian Flowgraph Methodology to solve the ODEs.

To facilitate reference to the model results, Table 5-4 introduces model result designations. The comparisons include an uncertainty analysis. Two cases of the Flowgraph methodology are identified corresponding to the use of differing prior distribution classes.

Table 5-4 Model Designations

\begin{tabular}{|l|l|}
\hline Designation & Model Description \\
\hline SDB-A & $\begin{array}{l}\text { Service Data Based Analytical solution to } \\
\text { benchmark model }\end{array}$ \\
\hline SDB-O & $\begin{array}{l}\text { Service Data Based model using OpenBUGS } \\
\text { software detailed in Appendix C }\end{array}$ \\
\hline SDB-FT & $\begin{array}{l}\text { Service Data Based model using Flowgraph } \\
\text { method with triangular failure prior probability } \\
\text { distribution detailed in Appendix C }\end{array}$ \\
\hline SDB-FB & $\begin{array}{l}\text { Service Data Based model using Flowgraph } \\
\text { method with beta failure prior probability } \\
\text { distribution detailed in Appendix C. }\end{array}$ \\
\hline
\end{tabular}

\subsubsection{Comparison of the Service Data Based Analytical Solution and the Service Data Based Numerical Solution}

The Numerical analyses showed good agreement in the uncertainty distribution results for all the parameters up to and including the parameters that are input to the Markov model. In addition, when running point estimates through the ODEs both solution approaches provided excellent agreement in the calculated hazard rates. However, good agreement was not reached in the Monte Carlo results of most of the hazard rate parameters which are dependent on the solutions to the ODEs and the calculation of the hazard rates, even though the point estimates for these solutions compared very well.

The following trends are observed in the comparison: 
- For the $\lambda_{\mathrm{F}}$ and $\rho_{\mathrm{F}}$ parameters that are input to the Markov model SDB-A means run from $3 \%$ to $8 \%$ below the corresponding SDB-O values. The $95 \%$ percentile upper tails also track consistently lower in the SDB-A results. These small changes may be significantly amplified in the hazard rate solutions.

- For hazard rates at 1 year there is fairly close agreement especially for the smaller break size; but the differences appear to grow with increasing time.

- For the 100 year 10 inch case, the difference in the means is a factor of 50.

The two sets of numerical methods showed good agreement with one another (see Table 5-5 and Figure 5-6). 
Table 5-5 Comparison of Current Benchmark Results

\begin{tabular}{|c|c|c|c|c|c|c|c|c|}
\hline \multirow[b]{2}{*}{ Parameter } & \multirow[b]{2}{*}{ Version\# } & \multicolumn{7}{|c|}{ Monte Carlo Results } \\
\hline & & 5th & 50th & Mean & 95th & $\begin{array}{c}\text { RF- } \\
\text { low** }\end{array}$ & $\begin{array}{c}\text { RF- } \\
\text { high*** }\end{array}$ & $\begin{array}{l}\text { Mean Ratio } \\
\text { Comparison } \\
\text { with SDB-O }\end{array}$ \\
\hline \multirow{3}{*}{$\lambda_{\mathrm{F}}=\lambda f_{L} / f_{f}$} & SDB-O & $2.80 \mathrm{E}-06$ & 7.40E-05 & $4.20 \mathrm{E}-04$ & 1.60E-03 & $2.64 \mathrm{E}+01$ & $2.16 \mathrm{E}+01$ & \\
\hline & SDB-A & $2.92 \mathrm{E}-06$ & 7.46E-05 & $4.00 \mathrm{E}-04$ & 1.55E-03 & $2.56 \mathrm{E}+01$ & $2.08 \mathrm{E}+01$ & 0.952 \\
\hline & SDB-F & 2.91E-06 & 7.30E-05 & 4.03E-04 & $1.59 \mathrm{E}-03$ & $2.51 \mathrm{E}+01$ & $2.18 \mathrm{E}+01$ & 0.960 \\
\hline \multirow{3}{*}{$\rho_{\mathrm{F}}(0.1-\mathrm{in})}$. & SDB-O & 2.60E-06 & $3.00 \mathrm{E}-05$ & $1.30 \mathrm{E}-04$ & $5.10 \mathrm{E}-04$ & $1.15 E+01$ & $1.70 \mathrm{E}+01$ & \\
\hline & SDB-A & $2.62 \mathrm{E}-06$ & 3.03E-05 & 1.27E-04 & $4.86 \mathrm{E}-04$ & $1.16 \mathrm{E}+01$ & $1.60 \mathrm{E}+01$ & 0.976 \\
\hline & SDB-F & $2.52 \mathrm{E}-06$ & $2.96 \mathrm{E}-05$ & 1.26E-04 & 4.89E-04 & $1.17 \mathrm{E}+01$ & $1.65 \mathrm{E}+01$ & 0.969 \\
\hline \multirow{3}{*}{$\rho F(10-$ in. $)$} & SDB-O & 2.30E-09 & $5.10 \mathrm{E}-08$ & $4.85 \mathrm{E}-07$ & 1.60E-06 & $2.22 \mathrm{E}+01$ & $3.14 \mathrm{E}+01$ & \\
\hline & SDB-A & $2.26 \mathrm{E}-09$ & $5.02 \mathrm{E}-08$ & $4.48 \mathrm{E}-07$ & $1.54 \mathrm{E}-06$ & $2.22 \mathrm{E}+01$ & $3.06 \mathrm{E}+01$ & 0.923 \\
\hline & SDB-F & 2.16E-09 & 4.94E-08 & 4.82E-07 & 1.56E-06 & $2.29 E+01$ & $3.16 \mathrm{E}+01$ & 0.994 \\
\hline \multirow{4}{*}{$\mathrm{h}(1,0.1)^{*}$} & SDB-O & $2.10 \mathrm{E}-10$ & $1.40 \mathrm{E}-08$ & 4.00E-07 & $1.40 \mathrm{E}-06$ & $6.67 \mathrm{E}+01$ & $1.00 \mathrm{E}+02$ & \\
\hline & SDB-A & $2.06 \mathrm{E}-10$ & 1.46E-08 & 3.66E-07 & $1.28 \mathrm{E}-06$ & $7.07 E+01$ & $8.79 \mathrm{E}+01$ & 0.914 \\
\hline & SDB-FT & $2.16 \mathrm{E}-10$ & $1.49 \mathrm{E}-08$ & $3.78 \mathrm{E}-07$ & $1.38 \mathrm{E}-06$ & $6.90 \mathrm{E}+01$ & $9.26 \mathrm{E}+01$ & 0.945 \\
\hline & SDB-FB & $2.16 \mathrm{E}-10$ & 1.49E-08 & $3.78 \mathrm{E}-07$ & $1.38 \mathrm{E}-06$ & $6.90 \mathrm{E}+01$ & $9.26 \mathrm{E}+01$ & 0.945 \\
\hline \multirow{4}{*}{$\mathrm{h}((10,0.1)$} & SDB-O & $2.50 \mathrm{E}-09$ & 1.80E-07 & $4.60 \mathrm{E}-06$ & 1.60E-05 & $7.20 \mathrm{E}+01$ & $8.89 \mathrm{E}+01$ & \\
\hline & SDB-A & 1.69E-09 & 1.19E-07 & $2.81 \mathrm{E}-06$ & $1.01 \mathrm{E}-05$ & $7.02 \mathrm{E}+01$ & $8.49 \mathrm{E}+01$ & 0.610 \\
\hline & SDB-FT & 2.99E-09 & $2.01 \mathrm{E}-07$ & 4.45E-06 & 1.77E-05 & $6.72 E+01$ & $8.81 \mathrm{E}+01$ & 0.967 \\
\hline & SDB-FB & 2.98E-09 & $2.00 \mathrm{E}-07$ & 4.43E-06 & $1.76 \mathrm{E}-05$ & $6.71 \mathrm{E}+01$ & $8.80 \mathrm{E}+01$ & 0.963 \\
\hline \multirow[t]{4}{*}{$\mathrm{h}(40,0.1)$} & SDB-O & 1.30E-08 & $9.50 \mathrm{E}-07$ & $2.10 \mathrm{E}-05$ & $8.30 \mathrm{E}-05$ & $7.31 \mathrm{E}+01$ & $8.74 \mathrm{E}+01$ & \\
\hline & SDB-A & $3.28 \mathrm{E}-09$ & 2.35E-07 & $5.18 \mathrm{E}-06$ & 1.94E-05 & $7.16 \mathrm{E}+01$ & $8.24 \mathrm{E}+01$ & 0.247 \\
\hline & SDB-FT & $1.63 \mathrm{E}-08$ & $1.12 \mathrm{E}-06$ & $2.18 \mathrm{E}-05$ & $9.23 \mathrm{E}-05$ & $6.87 \mathrm{E}+01$ & $8.24 \mathrm{E}+01$ & 1.038 \\
\hline & SDB-FB & $1.59 \mathrm{E}-08$ & 1.10E-06 & $2.14 \mathrm{E}-05$ & 9.03E-05 & $6.92 \mathrm{E}+01$ & $8.21 \mathrm{E}+01$ & 1.019 \\
\hline \multirow[t]{4}{*}{$\mathrm{h}(100,0.1)$} & SDB-O & $3.70 \mathrm{E}-08$ & $2.70 \mathrm{E}-06$ & $5.00 \mathrm{E}-05$ & $2.10 \mathrm{E}-04$ & $7.30 \mathrm{E}+01$ & $7.78 \mathrm{E}+01$ & \\
\hline & \begin{tabular}{|l|} 
SDB-A \\
\end{tabular} & $3.58 \mathrm{E}-09$ & $2.61 \mathrm{E}-07$ & $5.66 \mathrm{E}-06$ & $2.15 \mathrm{E}-05$ & $7.28 \mathrm{E}+01$ & $8.26 \mathrm{E}+01$ & 0.113 \\
\hline & SDB-FT & 4.76E-08 & $3.30 \mathrm{E}-06$ & $5.40 \mathrm{E}-05$ & 2.46E-04 & $6.93 \mathrm{E}+01$ & $7.45 \mathrm{E}+01$ & 1.080 \\
\hline & SDB-FB & $4.51 \mathrm{E}-08$ & $3.12 \mathrm{E}-06$ & 5.13E-05 & $2.34 \mathrm{E}-04$ & $6.92 \mathrm{E}+01$ & $7.50 \mathrm{E}+01$ & 1.026 \\
\hline \multirow{4}{*}{$\mathrm{h}(1,10)$} & SDB-O & $3.40 \mathrm{E}-12$ & $3.40 \mathrm{E}-10$ & $1.40 \mathrm{E}-08$ & $4.20 \mathrm{E}-08$ & $1.00 \mathrm{E}+02$ & $1.24 \mathrm{E}+02$ & \\
\hline & SDB-A & $3.09 \mathrm{E}-12$ & $2.95 \mathrm{E}-10$ & 1.02E-08 & 3.33E-08 & $9.52 \mathrm{E}+01$ & $1.13 \mathrm{E}+02$ & 0.731 \\
\hline & SDB-FT & $0.00 \mathrm{E}+00$ & $3.63 \mathrm{E}-10$ & $1.30 \mathrm{E}-08$ & 4.22E-08 & & $1.16 \mathrm{E}+02$ & 0.929 \\
\hline & SDB-FB & $0.00 \mathrm{E}+00$ & $3.62 \mathrm{E}-10$ & $1.30 \mathrm{E}-08$ & 4.22E-08 & & $1.17 \mathrm{E}+02$ & 0.929 \\
\hline \multirow[t]{4}{*}{$\mathrm{h}(10,10)$} & SDB-O & $2.20 \mathrm{E}-10$ & $2.55 \mathrm{E}-08$ & $1.00 \mathrm{E}-06$ & 3.30E-06 & $1.16 \mathrm{E}+02$ & $1.29 \mathrm{E}+02$ & \\
\hline & SDB-A & $6.68 \mathrm{E}-11$ & 7.03E-09 & $2.58 \mathrm{E}-07$ & $8.27 \mathrm{E}-07$ & $1.05 \mathrm{E}+02$ & $1.18 \mathrm{E}+02$ & 0.258 \\
\hline & SDB-FT & $2.41 \mathrm{E}-10$ & $2.60 \mathrm{E}-08$ & $1.01 \mathrm{E}-06$ & $3.27 \mathrm{E}-06$ & $1.08 \mathrm{E}+02$ & $1.26 \mathrm{E}+02$ & 1.010 \\
\hline & SDB-FB & $2.40 \mathrm{E}-10$ & $2.59 \mathrm{E}-08$ & $1.00 \mathrm{E}-06$ & $3.25 \mathrm{E}-06$ & $1.08 E+02$ & $1.25 \mathrm{E}+02$ & 1.000 \\
\hline \multirow[t]{4}{*}{$\mathrm{h}(40,10)$} & SDB-O & $2.70 \mathrm{E}-09$ & $3.00 \mathrm{E}-07$ & $1.00 \mathrm{E}-05$ & $3.70 \mathrm{E}-05$ & $1.11 \mathrm{E}+02$ & $1.23 \mathrm{E}+02$ & \\
\hline & SDB-A & $1.46 \mathrm{E}-10$ & 1.57E-08 & 5.36E-07 & 1.83E-06 & $1.07 \mathrm{E}+02$ & $1.16 \mathrm{E}+02$ & 0.054 \\
\hline & SDB-FT & 2.82E-09 & 3.10E-07 & $1.03 \mathrm{E}-05$ & $3.72 \mathrm{E}-05$ & $1.10 \mathrm{E}+02$ & $1.20 \mathrm{E}+02$ & 1.030 \\
\hline & SDB-FB & $2.76 \mathrm{E}-09$ & $3.02 \mathrm{E}-07$ & $1.01 \mathrm{E}-05$ & $3.63 \mathrm{E}-05$ & $1.09 \mathrm{E}+02$ & $1.20 \mathrm{E}+02$ & 1.010 \\
\hline \multirow{4}{*}{$\mathrm{h}(100,10)$} & SDB-O & $1.10 \mathrm{E}-08$ & 1.20E-06 & $3.10 \mathrm{E}-05$ & 1.30E-04 & $1.09 \mathrm{E}+02$ & $1.08 \mathrm{E}+02$ & \\
\hline & SDB-A & $1.62 \mathrm{E}-10$ & $1.76 \mathrm{E}-08$ & 5.89E-07 & $2.03 \mathrm{E}-06$ & $1.09 \mathrm{E}+02$ & $1.15 \mathrm{E}+02$ & 0.019 \\
\hline & SDB-FT & $1.71 \mathrm{E}-08$ & 1.25E-06 & $3.25 \mathrm{E}-05$ & 1.32E-04 & $7.31 \mathrm{E}+01$ & $1.06 \mathrm{E}+02$ & 1.048 \\
\hline & SDB-FB & $1.10 \mathrm{E}-08$ & 1.18E-06 & $3.08 \mathrm{E}-05$ & $1.26 \mathrm{E}-04$ & $1.07 \mathrm{E}+02$ & $1.07 \mathrm{E}+02$ & 0.994 \\
\hline
\end{tabular}


Table 5-5 Footnotes

\begin{tabular}{|c|c|}
\hline *h(time (yr), break size (in.) & $\begin{array}{l}\text { \# SDB-O (Service Data Based using OpenBUGS) model results are } \\
\text { found in Appendix C }\end{array}$ \\
\hline & $\begin{array}{l}\text { SDB-A (Service Data Based - Analytical Updated) model results are the } \\
\text { updated service data based benchmark model results from Section } 5.1 \\
\text { and } 5.2\end{array}$ \\
\hline${ }^{* *}$ RF-Low $=50$ th $/ 5$ th & $\begin{array}{l}\text { SDB-FT (Service Data Based using Flowgraphs - Triangular Distribution) } \\
\text { model results are found in Appendix C }\end{array}$ \\
\hline${ }^{* * *}$ RF-Low $=95$ th $/ 50$ th & $\begin{array}{l}\text { SDB-FB (Service Data Based using Flowgraphs - Beta Distribution) } \\
\text { model results are found in Appendix C }\end{array}$ \\
\hline
\end{tabular}

No conclusions for the differences in the uncertainty analysis results between the numerical and analytical solutions have been reached. All issues with the original analytical solutions to the ODEs were addressed and found to be insignificant. More time will be required to resolve this numerical issue. The SDB-A results use Excel to calculate all the ODE solutions and the numerical precision of these calculations is not as good as that provided by the numerical service data methods. There may be some differences in the way Crystal Ball generates random numbers from a distribution compared to the numerical methods. Resolution of this question is left for further research on this topic.

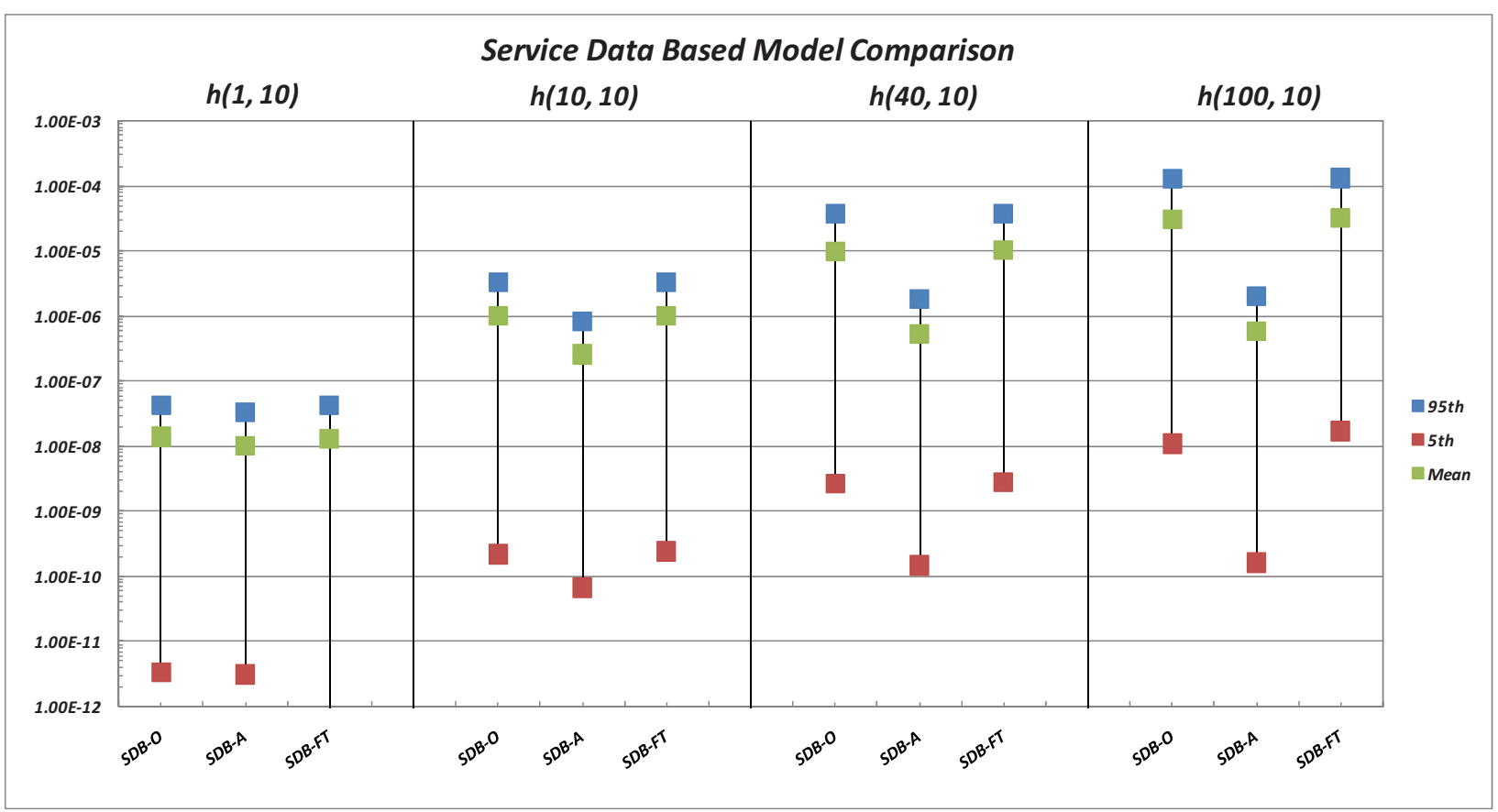

Figure 5-6 Comparison of Analytical and Numerical Solutions for Service Data-Based Model - 10.0 inch break 


\section{Enhanced Markov Model Based on Physics of Failure}

The purpose of this section is to document the development of improved models for passive component reliability based on a physics-of-failure approach, in contrast with the Bayes' analysis of service data approach that is exercised in the previous sections. For reasons described in Section 3, we have selected stress corrosion cracking in a Class 1 piping dissimilar metal weld as the basis for exploring a physics-based model (the same component identified for the benchmark problem in Section 5). The ultimate objective of this section is to investigate possible improvements to passive component reliability assessment that will be needed to meet RISMC objectives. By addressing component reliability explicitly in the context of physics-based models, the intent is that the thermal hydraulic modeling environment being developed as part of the RISMC framework will provide a basis for tuning the physics models governing component reliabilities and aging.

\subsection{Physics of Failure Enhancements to Markov Model}

\subsubsection{Introduction}

This Section describes a preliminary "Markov" model. (This report will continue to use the term "Markov" throughout although, strictly, Markov assumptions will be seen to be violated for the physics model and new solution algorithms will be required). The intent is to assess the feasibility of constructing Markov models of component reliability that contain physics-based transition rates; that is, the rates are based on the physical processes of material degradation as opposed to a statistical parametric characterization based on service data. The model presented here is not complete, but should provide a good basis for deciding how we might proceed with the Markov approach.

Stress corrosion cracking (SCC) of an RCS Alloy 82/182 dissimilar metal weld has been selected as the initial application for examining the feasibility of a physics-based Markov model. Alloy 82/182 welds are found in several key locations in class 1 piping structures, such as the vessel reactor coolant pipe welds and pressurizer surge line pipe weld. Figure 6-1 shows a Westinghouse surge line nozzle with an alloy 182 weld joining the stainless steel safe end to the low alloy steel nozzle. Cracks that form in these structures will grow from inner to outer diameter with one of three principal morphologies. The first is an axial crack where the crack plane lies in the cutaway plane of Figure 6-1. The other two crack morphologies, represented in Figure 6-2, lie in the cross-flow plane and grow in a guillotine style. In the first of these latter two the crack tends to grow primarily outward from the initiation site towards the outer diameter as shown in Figure 6-2A. We will refer to this as a radial crack. In the second, the crack grows relatively evenly around the circumference as shown in Figure 6-2B, potentially resulting in an SCC crack that can transition to rupture before a leak is detected. We will refer to this as a circumferential crack. This analysis focuses on the cross-flow plane cracks as shown in Figure 6-2 since these are the morphologies associated with the potential for LOCAs. 


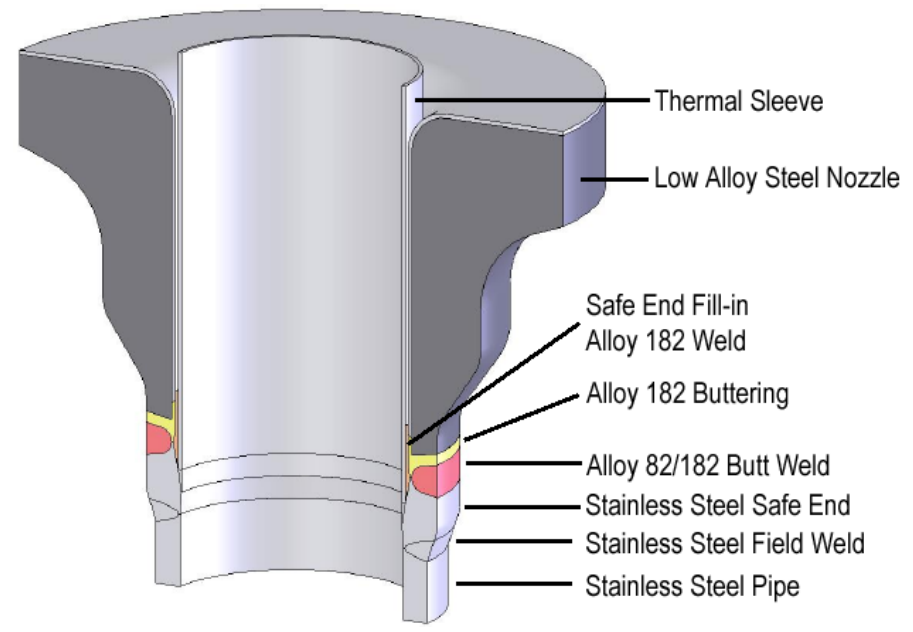

Figure 6-1 Layout of a Westinghouse PWR surge line nozzle connection to the pressurizer (Courtesy of Westinghouse).

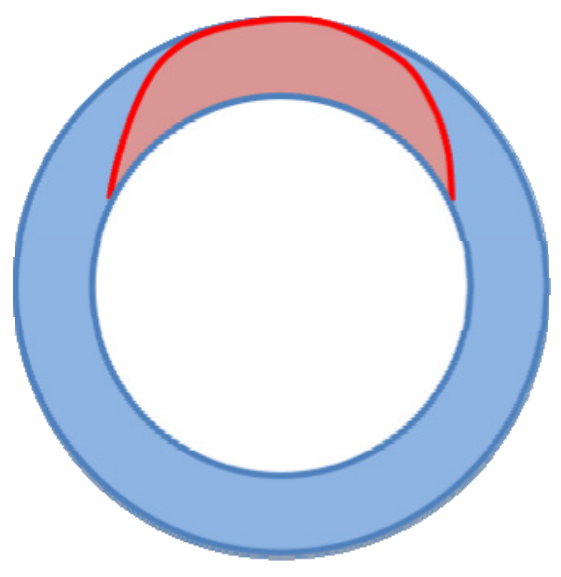

A

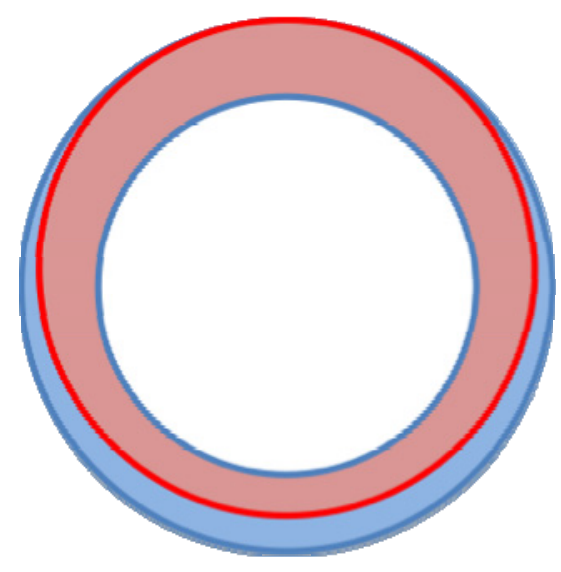

B

Figure 6-2 Two basic cross-flow crack morphologies: radial and circumferential.

For our Phase 0 model, SCC is considered in alloy 82/182 to be a two step process consisting of (1) crack initiation, followed by (2) crack propagation. Ultimately, a broader range of phenomena will need to be considered to fully model weld failures (addressed later), but this limited scope analysis will allow some basic issues associated with the feasibility of physicsbased Markov modeling to be framed.

Similar to other nucleation and growth phenomena, SCC is generally modeled as, first, a nucleation step governed by statistical processes, and then as crack growth that has a more deterministic basis. The probability of nucleation is governed both by the presence of preexisting surface flaws in the material and the rate of formation of surface flaws due to the environment. Published models of crack initiation typically do not attempt to define initial flaw characteristics, since, because of the practical difficulty in identifying a surface flaw, such a 
model could not be implemented. As will be discussed, the Weibull distribution is the most common framework for quantifying SCC initiation probability.

Compared to SCC initiation, there are abundant data on SCC crack growth. Numerous laboratories have performed SCC crack growth testing on alloys 182 and 82, and several organizations have published data compilations and accompanying phenomenological models of crack growth. These models are generally similar, and typically contain stress intensity and temperature dependences.

\subsubsection{Physics Models}

\section{Stress Corrosion Crack Initiation}

SSC initiation is the nucleation of a stress corrosion crack. A stress corrosion crack is considered nucleated when the crack growth rate can be described by crack growth rate models (to be defined). A number of alternative models have been used to characterize initiation [31-36], the Weibull model being the most widely adopted [31-34]. In the Weibull model, the cumulative probability of crack initiation by time $t, P(t)$, is given by

$$
P(t)=1-e^{\left[-\left(\frac{t}{\tau}\right)^{b}\right]}
$$

where

$\mathrm{T}=$ a time constant - Weibull scale parameter

$\mathrm{b}=\mathrm{a}$ fitting parameter - Weibull shape parameter.

The time constant $\mathrm{T}$ has been observed to have both a stress and a temperature dependence, and can be expressed as

$$
\tau=A \sigma^{n} e^{\left(\frac{Q}{R T}\right)}
$$

where

$A=a$ fitting parameter that may include material and environmental dependences

$\sigma=$ explicit stress factor

$\mathrm{n}=$ stress exponent factor

$\mathrm{Q}=$ an activation energy

$\mathrm{T}=$ absolute temperature

$\mathrm{R}=$ the universal gas constant.

A general plot of $P(t)$ is shown in Figure 6-3 and depicts the effect of an increasing Weibull fitting parameter on the probability evolution. Because of difficulties in measuring SCC initiation, well-defined values for the fitting parameters do not exist for alloy 182/82 (or most other RCS materials). One study [37] provides the following equation for $\mathrm{T}$

$$
\tau=9.2 \times 10^{7} \sigma^{-7} e^{\left(\frac{129}{R T}\right)}
$$


There are also more physically in-depth approaches [34] in which reference stresses and temperatures are reflected in the probability equation. Reference [38] suggests an activation energy of $185 \mathrm{~kJ} / \mathrm{mole}$ and a stress exponent of -7 for alloy 182 and -6 for alloy 82 .

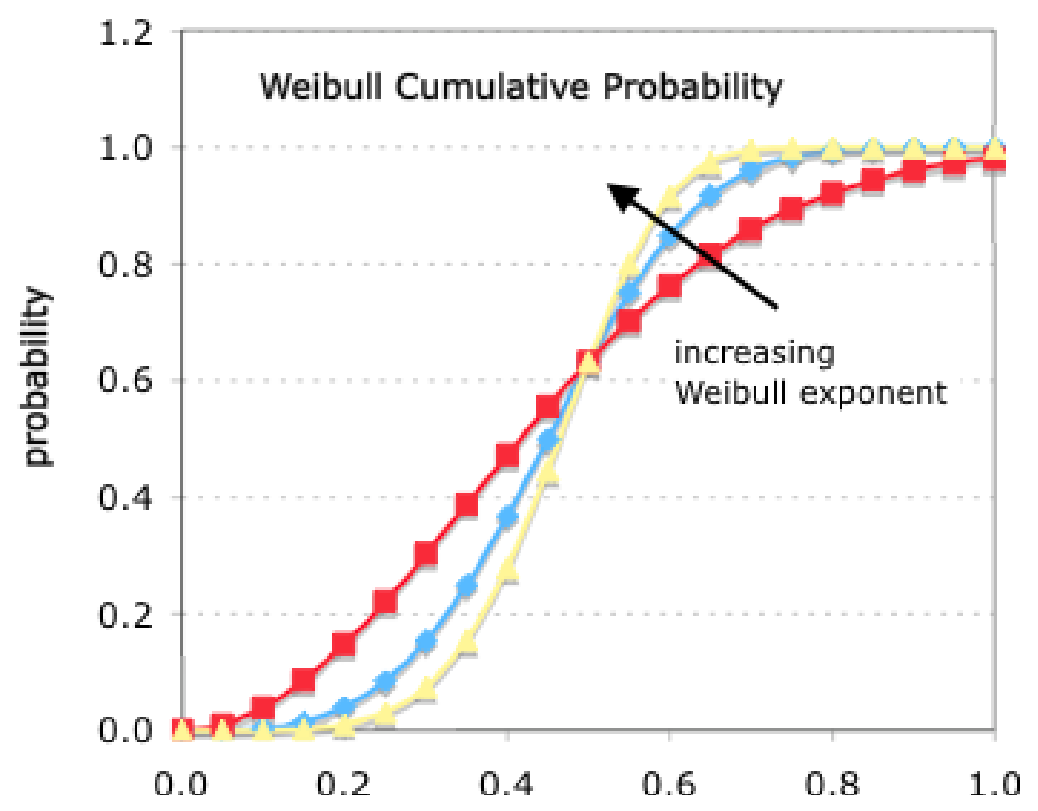

Figure 6-3 Example Weibull cumulative probability plot for crack initiation- The horizontal axis is a scaled time variable.

\section{SCC Crack Growth}

Data compilations for alloy 182 SCC crack growth rates, along with phenomenological SCC crack growth rate equations, have been generated by numerous organizations including Ringhals AB [39], Electricité de France [40], and the Electric Power Research Institute [41, 42]. All the models have a similar form that includes a stress and Arrhenius temperature dependence. EPRI report MRP-115 [42] is the most recent report with the most comprehensive data set and is therefore the best choice for our current purposes. The equation developed in the report is:

$$
\dot{a}=\alpha f_{\text {alloy }} f_{\text {orient }} K^{\beta} e^{\left[-\left(\frac{Q}{R}\right)\left(T^{-1}-T_{\text {ref }}{ }^{-1}\right)\right]}
$$

where (quoting MRP-115 quantifications)

å $=\mathrm{da} / \mathrm{dt}(\mathrm{m} / \mathrm{s})$

$\mathrm{t}=$ time after crack initiation (s)

$\mathrm{a}=$ crack length $(\mathrm{m})$

$\alpha=$ fitting constant - crack growth amplitude $\left(1.5 \times 10^{-12} \mathrm{MPa} \sqrt{\mathrm{m}}\right)$ 
$\mathrm{T}=$ absolute operating temperature at crack location $\left({ }^{\circ} \mathrm{K}\right)$

$\mathrm{T}_{\text {ref }}=$ absolute reference temperature used to normalize data $\left(598.15^{\circ} \mathrm{K}\right)$

$\mathrm{Q}=$ thermal activation energy for crack growth $(130 \mathrm{~kJ} / \mathrm{mole})$

$\mathrm{R}=$ the universal gas constant $\left(8.314 \times 10^{-3} \mathrm{~kJ} / \mathrm{mole}-\mathrm{K}\right)$

$\mathrm{K}=$ crack tip stress intensity factor (units of MPa $\sqrt{\mathrm{m}}$ )

$f_{\text {alloy }}=1.0$ for Alloy 182 or 132 and $1 / 2.6$ for Alloy 82

$f_{\text {orient }}=1.0$, except 0.5 for crack propagation that is perpendicular to dendrite solidification direction.

$\beta=$ stress intensity exponent (1.6).

The MRP 115 curve fit to the screened data sets for alloy 182 and alloy 82 are shown Figures 64 and 6-5, respectively, as a function of stress intensity factor, K [42]. The datasets can be used to estimate uncertainty in selected fitting parameters in the phenomenological equation. In particular, these plots can provide information about the uncertainty in the values of $\alpha$ and $\beta$. The screened dataset provided in MRP-115 allows uncertainty analysis of the other fitting parameters.

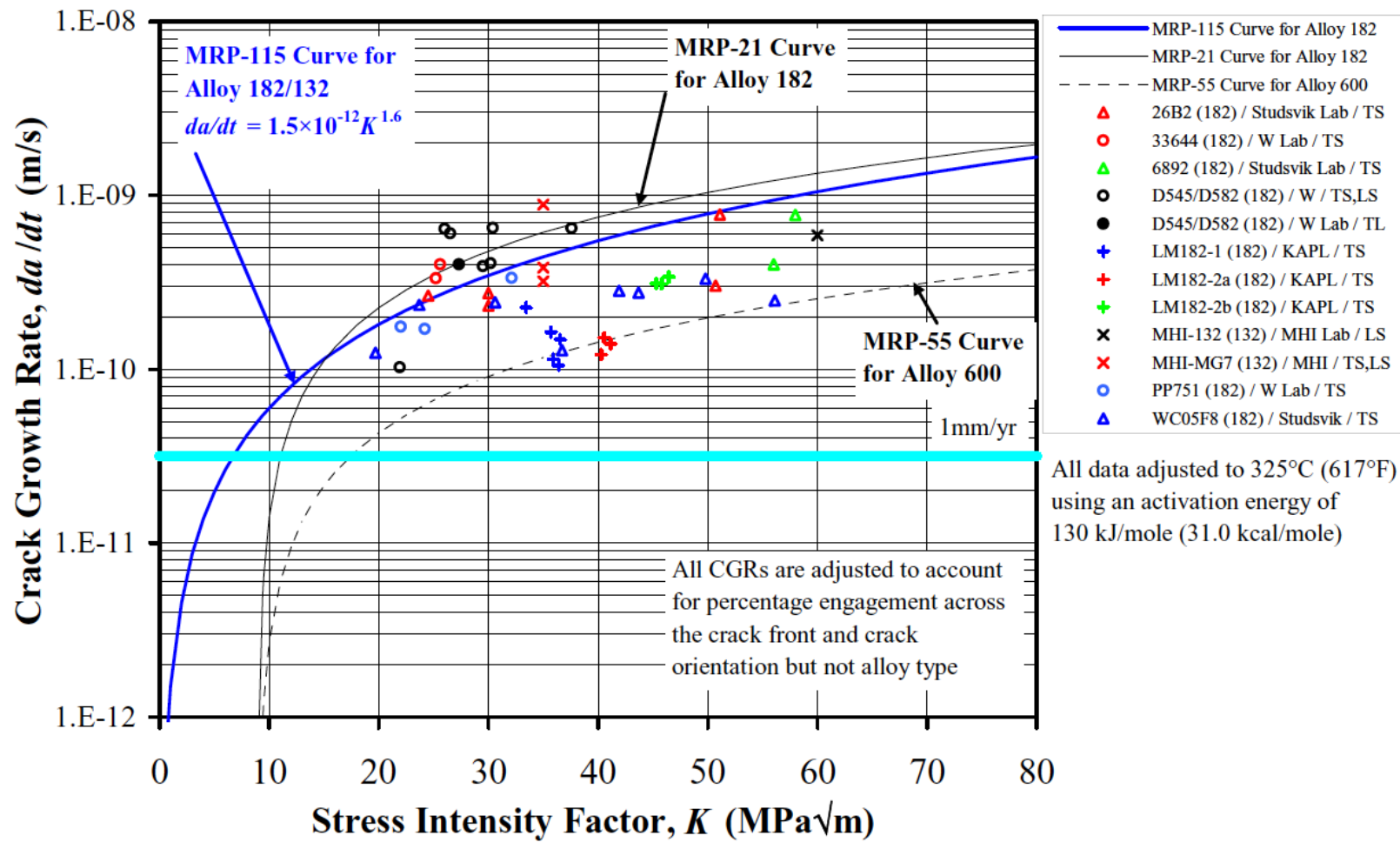

Figure 6-4 Screen data set assembled by EPRI for the MRP-115 crack growth rate equation for alloy 182 (From EPRI MRP-115) 


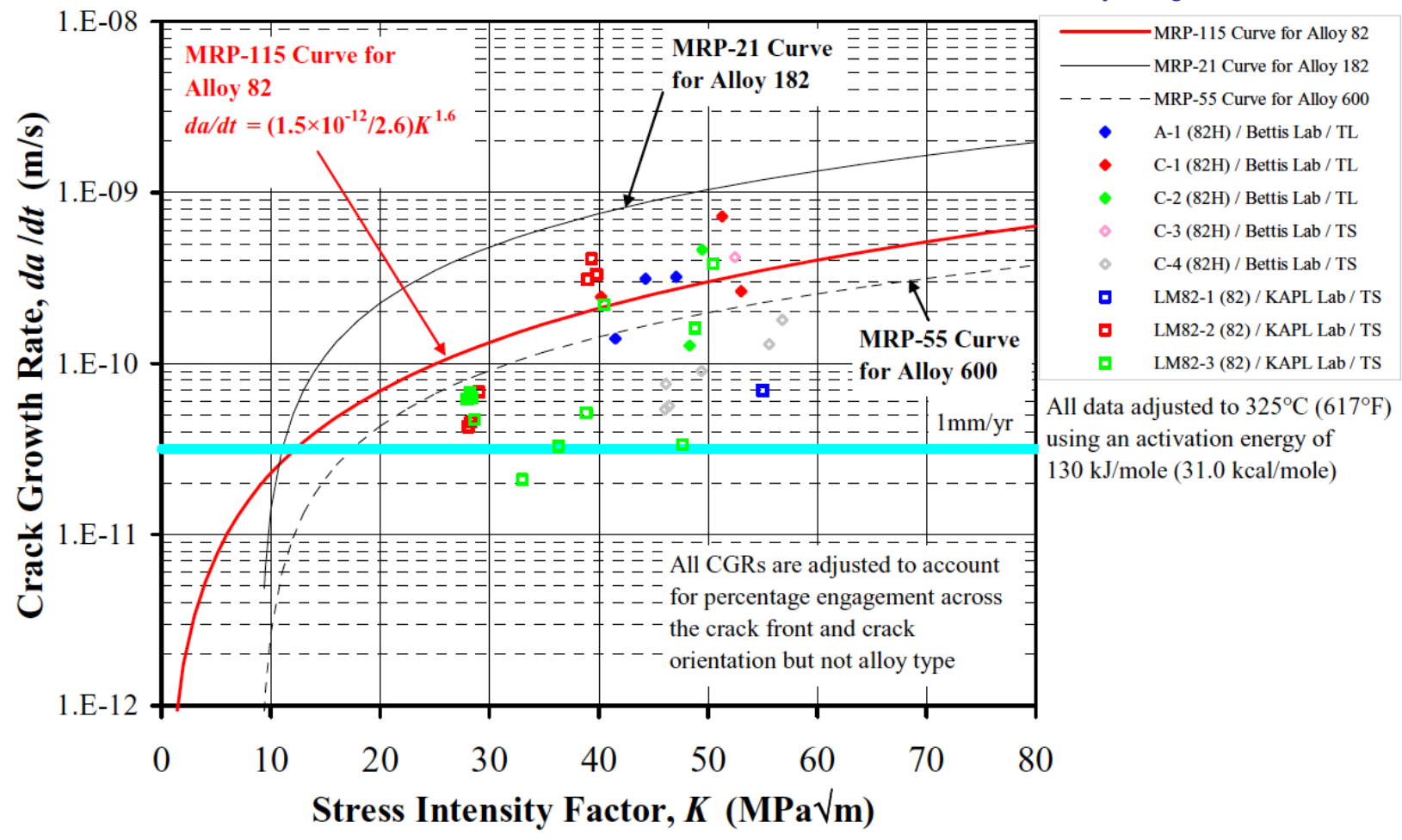

Figure 6-5 Screen data set assembled by EPRI for the MRP-115 crack growth rate equation for alloy 82 (From EPRI MRP-115) 


\subsubsection{Physics Based Markov Model}

The Phase 0 Physics Based Markov model is assumed to have the form shown in Figure 6-6.

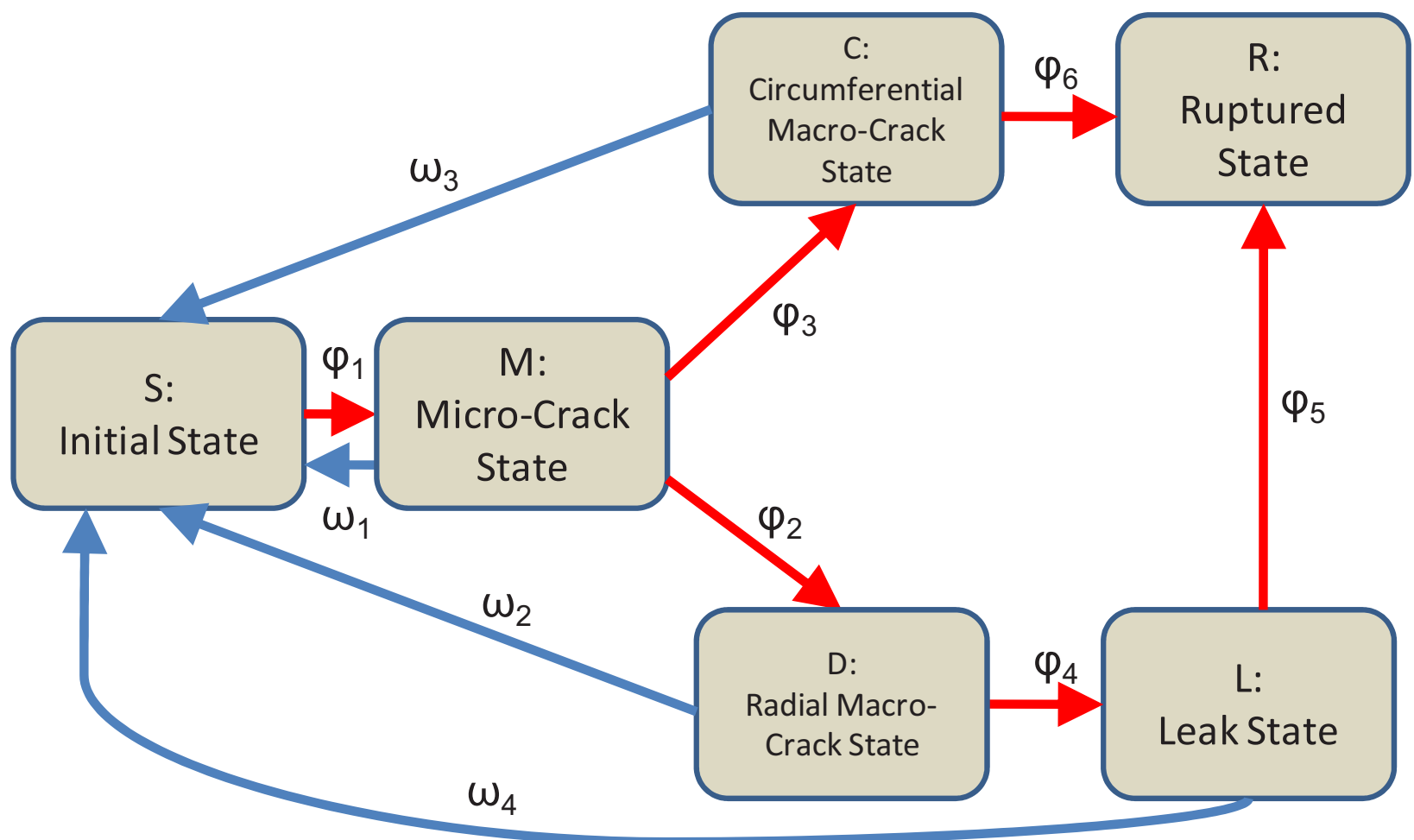

Figure 6-6 Form of the Phase 0 Physics Based Markov Model

Relative to the Service Data Based model described in Section 2 there are two structural modifications to this model. (1) A micro-crack state has been added which will allow the physics of crack initiation to be captured in the transition model from the initial state. (2) The model makes distinction between weld cracks that have (a) principally a circumferential morphology, these being most likely to transition directly to rupture without leak, and (b) principally a radial morphology, these being more likely to transition to the leak state before rupture.

The states of the model are (used interchangeably with the state probabilities):

$S=$ Initial State (with possible presence of flaws)

$\mathrm{M}=$ Micro-crack initiated

$\mathrm{C}=$ Macro-crack of mainly circumferential orientation (detectable by conventional NDE)

$\mathrm{D}=$ Macro-crack of mainly radial orientation (detectable by conventional NDE)

$\mathrm{L}=$ Leak

$\mathrm{R}=$ Rupture. 
The state equations are assumed to be:

$$
\begin{aligned}
& \mathrm{dS} / \mathrm{dt}=-\Phi_{1} S+\omega_{1} \mathrm{M}+\omega_{2} \mathrm{D}+\omega_{3} \mathrm{C}+\omega_{4} \mathrm{~L} \\
& \mathrm{dM} / \mathrm{dt}=\Phi_{1} S-\omega_{1} \mathrm{M}-\Phi_{2} \mathrm{M}-\Phi_{3} \mathrm{M} \\
& \mathrm{dC} / \mathrm{dt}=\Phi_{3} \mathrm{M}-\omega_{3} \mathrm{C}-\Phi_{6} \mathrm{C} \\
& \mathrm{dD} / \mathrm{dt}=\Phi_{2} \mathrm{M}-\omega_{2} \mathrm{D}-\Phi_{4} \mathrm{D} \\
& \mathrm{dL} / \mathrm{dt}=\Phi_{4} \mathrm{D}-\omega_{4} \mathrm{~L}-\Phi_{5} \mathrm{~L} \\
& \mathrm{dR} / \mathrm{dt}=\Phi_{6} \mathrm{C}+\Phi_{5} \mathrm{~L}
\end{aligned}
$$

where

$\Phi_{1}$ is the micro-crack initiation transition rate

$\Phi_{2}, \Phi_{3}, \Phi_{4}$ are crack growth transition rates associated with differing crack morphologies

$\Phi_{5}, \Phi_{6}$ are transition rates associated with transient loads that result in ruptures

$\omega_{1}$ is a transition rate associated with micro-crack detection/repair

$\omega_{2}, \omega_{3}$ are transition rates associated with macro-crack detection/repair

$\omega_{4}$ is a transition rate associated with leak detection and repair.

Note, as will be seen in the following section, the $\Phi$ parameters in Equations (6.5) through (6.10) are not necessarily deterministic quantities (that is, they can be random variables), and a methodology for solving these equations is outlined in Appendix D. For the purposes of this Phase 0 model, and reflective of the physics models described in Section 2, the focus here will be on the transition rates $\Phi_{1}, \Phi_{2}, \Phi_{3}$, and $\Phi_{4}$.

\subsubsection{Association of Physics and Markov Models}

\section{Crack initiation:}

$\Phi_{1}$

Here we characterize the transition rate from $S$ to M. From Equation 6.1 we can write

$$
M(t)=1-\exp \left[-(t / T)^{b}\right]
$$

if, for now, we ignore downstream transitions and recovery transitions. In this simplified model consisting of just the $\mathrm{S}$ and $\mathrm{M}$ states, where

$$
M+S=1
$$


then Equation 6.6 simplifies to

$$
\mathrm{dM} / \mathrm{dt}=\Phi_{1}(1-\mathrm{M})
$$

and so

$$
\Phi_{1}=\mathrm{dM} / \mathrm{dt} \cdot(1-\mathrm{M})^{-1}
$$

Note that Equation 6-11 is a probability contingent on knowledge of the parameters $\mathrm{T}$ and $\mathrm{b}$. If we assume that there is aleatory variability over these parameters characterized by the joint distribution $\Pi(\mathrm{\tau}, \mathrm{b})$ (which, in turn, would be derived from the aleatory distributions over the physical variables of Equation 6.2), then

$$
\Phi_{1}=\int\left[d M / d t .(1-M)^{-1}\right] \Pi(\tau, b) d T . d b
$$

where the integral is taken over the domains of $\mathrm{T}$ and $\mathrm{b}$. Therefore, since

$$
\mathrm{dM} / \mathrm{dt} \cdot(1-\mathrm{M})^{-1}=(\mathrm{b} / \mathrm{T}) \cdot(\mathrm{t} / \mathrm{T})^{\mathrm{b}-1}
$$

then

$$
\Phi_{1}=\int(b / T) \cdot(t / T)^{b-1} \cdot \Pi(T, b) d T \cdot d b .
$$

We assume this transition rate from $S$ to $M$ due to crack initiation should be valid even when we add back in the downstream states from $\mathrm{M}$ and the repair transitions. Note that the timedependence of the transition rate reflected in Equation 6-17 implies that the Markov model will be time-inhomogeneous.

\section{Crack Growth:}

$\Phi_{3}$.

Let $\mathrm{a}_{\mathrm{c}}$ represent the threshold length of a circumferential crack that would be characterized as a macro-crack, where this is defined as a crack detectable by conventional NDE techniques.

Therefore, at time $u$ after crack initiation, the probability of the state $C$ is

$$
C(u)=\operatorname{Prob}\left[a_{c} \leq{ }_{0} \int^{u} a ̊\left(u^{\prime}\right) d u^{\prime}\right] . P_{C}
$$

where $\mathrm{Pc}$ is the probability that the crack grows as a circumferential (as opposed to a radial/through wall or axial) crack. The parameters in the crack growth model are assumed to be time-independent such that the rate of crack growth, å, is constant. While the stress intensity factor may in fact vary as the crack grows, this time-dependence will not be addressed in this initial version of the model. Therefore,

$$
C(u)=\operatorname{Prob}\left(a_{c} \leq a ̊ u\right) \cdot P_{C} .
$$

So, if we assume that the aleatory distribution over the value of å is $\Pi(a ̊)$ (which would be based on aleatory variabilities in the constituting physical parameters in Equation 6.4), then

$$
\mathrm{C}(\mathrm{u})=\left(\mathrm{ac} / \mathrm{u}^{\infty} \Pi(\mathrm{a}) \cdot \mathrm{då}\right) \cdot \mathrm{P}_{\mathrm{C}}
$$

and 


$$
d C(u) / d u=\left(a_{c} / u^{2}\right) \cdot \Pi\left(a_{c} / u\right) \cdot P_{C}
$$

Therefore

$$
\Phi_{3}=[d C(u) / d u] /(1-C(u))=\left(a_{c} / u^{2}\right) \cdot \Pi\left(a_{c} / u\right) \cdot P_{C} /\left[1-\left(a_{c} / u^{\infty} \Pi(a ̊) \cdot d a ̊ ~\right) \cdot P_{C}\right]
$$

Note that the probability $\mathrm{P}_{\mathrm{C}}$ representing the split fraction between crack morphologies would be a function of stress orientation and operational environment. The Phase 0 model does not address the relatively unexplored physics underlying the estimation of $\mathrm{P}_{\mathrm{C}}$, and for now we'll assume that it will be estimated empirically, based on experimental and service data. Note also that the time variable $u$ (time from crack initiation) does not coincide with the time variable, $t$, appearing in transition rate $\Phi_{1}$.

$\Phi_{2-}$

Analogously, the transition rate $\Phi_{2}$ from $M$ to $D$ can be expressed as

$$
\Phi_{2}=\left(a_{D} / u^{2}\right) \cdot \Pi\left(a_{D} / u\right) \cdot P_{D} /\left[1-\left(a_{a D} / \int^{\infty} \Pi(a ̊) \cdot d a ̊ ~\right) \cdot P_{D}\right]
$$

where $a_{D}$ denotes the radial macro-crack threshold for state $D$ and $P_{D}$ is the probability that the crack evolves in a radial morphology. (Note $1-\mathrm{P}_{C}+\mathrm{P}_{\mathrm{D}}$ is the probability of an axial morphology).

$\Phi_{4}$ -

The leak state, $\mathrm{L}$, is assumed to be the result of radial (through-wall) crack propagation. Therefore the $D \rightarrow L$ transition reflects a growth in crack size to a threshold $a_{L}$ associated with leakage. The probability of the Leak state at time $w$ after macro-crack formation is given by

$$
\mathrm{L}(\mathrm{w})=\operatorname{Prob}\left(\mathrm{a}_{\mathrm{L}}-\mathrm{a}_{\mathrm{D}} \leq \text { å. } \mathrm{w}\right)=\left[(\mathrm{aL}-\mathrm{aD}) / \mathrm{w} \int^{\infty} \Pi(\mathrm{a}) \cdot \text { då }\right]
$$

and

$$
d L(w) / d w=\left[\left(a_{L}-a_{D}\right) / w^{2}\right] \cdot \Pi\left[\left(a_{L}-a_{D}\right) / w\right]
$$

so

$$
\left.\Phi_{4}=\left[\left(\mathrm{a}_{\mathrm{L}}-\mathrm{a}_{\mathrm{D}}\right) / \mathrm{w}^{2}\right)\right] \cdot \Pi\left[\left(\mathrm{a}_{\mathrm{L}}-\mathrm{a}_{\mathrm{D}}\right) / \mathrm{w}\right] /\left\{1-\left[\left({ }_{(\mathrm{LL}-\mathrm{aD}) / \mathrm{w}}\right\rfloor^{\infty} \Pi(\mathrm{a}) \cdot d a ̊\right.\right.
$$

\section{Other Transitions to be addressed:}

This Phase 0 model has not addressed rupture transitions $\Phi_{5}, \Phi_{6}$ and detection/repair transitions $(\underline{\omega})$. Failure pressure models based on crack geometry, materials properties, and operating environment will form the basis for estimating $\Phi_{5}$ and $\Phi_{6}$. We could retain the SDB approach to estimating the $\omega$ repair transitions, although estimation of $\omega_{1}$ would need ultimately to revolve around consideration of emerging monitoring technologies for micro-crack detection.

\subsubsection{Model Implementation}

To assess the feasibility of executing the physics-based phase 0 model, some simplifying assumptions have been made for the purposes of a demonstration analysis. Section 6.2 describes those assumptions and the results of the demo. As noted earlier, the transition rates, $\Phi$, in the model can be random variables (because the initiation times for the time variables 
appearing in the transition rate formulas are randomly distributed), and this presents a methodological challenge. Appendix D outlines the implementation methodology we have used.

\subsection{Bases for Preliminary Model Implementation}

This Section outlines simplified transition rates expressions used to demonstrate and evaluate methodology for implementation of the Markov model.

\section{Crack initiation - $\Phi_{1}$}

Based on Equation 6.17, the transition rate $\Phi_{1}$ will be set to

$$
\Phi_{1}=(b / T) \cdot(t / T)^{b-1}
$$

where $t$ is the time variable. This excludes consideration of aleatory variability in the parameters $\mathrm{b}$ and $\mathrm{T}$.

\section{Crack growth to radial macro-crack - $\Phi_{2}$}

Since the physics model for crack growth is deterministic, we need to accommodate aleatory variability in the parameters of the model to produce a stochastic transition rate, $\Phi_{2}$. Equation 6.23 for $\Phi_{2}$ is

$$
\Phi_{2}=\left(a_{D} / u^{2}\right) \cdot \Pi\left(a_{D} / u\right) \cdot P_{D} /\left[1-\left({ }_{a D / u}[\infty \Pi(a ̊) \cdot d a ̊) \cdot P_{D}\right]\right.
$$

where $u$ is the time (from crack initiation) variable. We'll make a simplifying assumption that the aleatory distribution over crack growth rate å is uniform up to a maximum value of $a_{M}$; i.e.

$$
\begin{aligned}
\Pi(a ̊) & =\left(1 / a_{M}\right), & & \text { if } a ̊ a_{M} \\
& =0, & & \text { otherwise. }
\end{aligned}
$$

In this case Equation 6.28 reduces to

$$
\begin{aligned}
& \Phi_{2}=a_{D} \cdot P_{D} /\left\{u^{2} a_{M}\left[1-P_{D}\left(1-\left(a_{D} / u a_{M}\right)\right)\right\}, \text { if } u>a_{D} / a_{M}\right. \\
& \Phi_{2}=0, \text { otherwise. }
\end{aligned}
$$

\section{Crack growth to circumferential macro-crack $-\Phi_{3}$}

Assuming the same aleatory distribution over crack growth rate, then

$$
\begin{aligned}
& \Phi_{3}=a_{c} \cdot P_{C} /\left\{u^{2} a_{M}\left[1-P_{C}\left(1-\left(a_{C} / u a_{M}\right)\right)\right\}, \text { if } u>a_{c} / a_{M}\right. \\
& \Phi_{3}=0, \text { otherwise. }
\end{aligned}
$$

where $u$ is the time (from crack initiation) variable. 


\section{Crack growth to leak $-\Phi_{4}$}

Again, assuming the same aleatory distribution over crack growth rate, then

$$
\begin{aligned}
& \Phi_{4}=1 / w, \text { if } w>\left(a_{L}-a_{D}\right) / a_{M} \\
& \Phi_{4}=0, \text { otherwise }
\end{aligned}
$$

where $\mathrm{w}$ is the time (from radial macro-crack formation) variable.

\section{Transitions to rupture $-\Phi_{5}, \Phi_{6}$}

Physics models for rupture have not yet been developed. For the purposes of the methodology demonstration, $\Phi_{5}$ (leak to rupture) and $\Phi_{6}$ (macro-crack to rupture) will be set as constants:

$$
\begin{aligned}
& \Phi_{5}=2 \times 10^{-2} / \mathrm{yr} \\
& \Phi_{6}=1 \times 10^{-5} / \mathrm{yr}
\end{aligned}
$$

These are placeholders and based approximately on values used in Section 5.

\section{Detection and repair transitions $-\omega_{1}, \omega_{2}, \omega_{3}, \omega_{4}$}

The repair transition rates $\omega_{1}$ (from micro-crack), $\omega_{2}$ (from radial macro-crack), $\omega 3$ (from circumferential macro-crack), and $\omega 4$ (from leak) will be set as constants:

$$
\begin{aligned}
& \omega_{1}=1 \times 10^{-3} / \mathrm{yr} \\
& \omega_{2}=2 \times 10^{-2} / \mathrm{yr} \\
& \omega_{3}=2 \times 10^{-2} / \mathrm{yr} \\
& \omega_{4}=8 \times 10^{-1} / \mathrm{yr}
\end{aligned}
$$

where the $\omega_{1}$ estimate is a placeholder while the other factors are based approximately on values used in Section 5.

\section{Input Summary}

In summary, the parameters that enter the demonstration model are shown in Table 6-1. 
Table 6-1 Preliminary Implementation: Model Input Parameters

\begin{tabular}{|l|l|}
\hline $\mathrm{b}-$-Weibull shape parameter for crack initiation model & 2.0 \\
\hline $\mathrm{T}-$ Weibull scale parameter for crack initiation model & 4 and 40 years \\
\hline $\mathrm{a}_{\mathrm{D}}-$ Crack length threshold for radial macro-crack & $10 \mathrm{~mm}$ \\
\hline$P_{D}-$ Probability that micro-crack evolves as radial crack & 0.009 \\
\hline $\mathrm{a}_{M}-$ Maximum credible crack growth rate & $9.46 \mathrm{~mm} / \mathrm{yr}$ \\
\hline $\mathrm{a}_{C}-$ Crack length threshold for circumferential macro-crack & $10 \mathrm{~mm}$ \\
\hline$P_{C}-$ Probability that micro-crack evolves as circumferential crack & 0.001 \\
\hline $\mathrm{a}_{L}-$ Crack length threshold for leak & $20 \mathrm{~mm}$ \\
\hline$\omega_{1}-$ Repair transition rate from micro-crack & $1 \times 10^{-3} / \mathrm{yr}$ \\
\hline$\omega_{2}-$ Repair transition rate from radial macro-crack & $2 \times 10^{-2} / \mathrm{yr}$ \\
\hline$\omega_{3}-$ Repair transition rate from circumferential macro-crack & $2 \times 10^{-2} / \mathrm{yr}$ \\
\hline$\omega_{4}-$ Repair transition rate from leak & $8 \times 10^{-1} / \mathrm{yr}$ \\
\hline$\Phi_{5}-$ Leak to rupture transition rate & $2 \times 10^{-2} / \mathrm{yr}$ \\
\hline$\Phi_{6}-$ Macro-crack to rupture transition rate & $1 \times 10^{-5} / \mathrm{yr}$ \\
\hline
\end{tabular}

\section{Results}

As noted, the physics-based transition model is not Markovian by virtue of it's timeinhomogenous, stochastic state transition rates. The methodology outlined in Appendix D was used to implement the model. Figures 6-7 through 6-10 show the results. Figure 6-7 displays the state probabilities up to an age of 80 years when т (the scale parameter in the crack initiation model) is set to 4 years. In this case there is an early, rapid transition from the Initial state to the Micro-crack state. The Rupture state probability appears to reach an asymptote of about $10^{-4}$ (which is high, but our current quantification is intended primarily to demonstrate the feasibility of the methodology). Setting $\mathrm{T}=40$ years (see Figure 6-8) retards the transition from the Initial state to the Micro-crack state, but results in a similar 80-year Rupture state probability.

The rupture hazard rate curve displays more interesting behavior. Figure 6-9 shows the hazard rates for $\mathrm{T}=4$ and 40 years. At $\mathrm{T}=4$ years, a maximum hazard rate of $10^{-5}$ per year occurs at about 10 years and then appears to decrease towards an asymptote of about $10^{-7}$ per year. At $\mathrm{T}$ $=40$ years, the maximum hazard rate of about $2 \times 10^{-6}$ per year occurs around 40 years and then has a shallow decrease towards 80 years. Figure 6-10 compares these results with the analytical Benchmark analysis of Section 5.2.

What's clear from this physics-based model is that hazard rates do not necessarily increase monotonically with age over the plant lifetime. Therefore, standard aging reliability models of failure rate, such as Weibull or linear aging models, would not provide good fits to this behavior. It's possible that as we improve the basis for quantifying the model, the hazard rate behavior over the plant lifetime will be more intuitive, but the functional form of these results does raise questions about what phenomena we should consider to constitute materials aging. 
Our effort to identify additional data resources continues, but for now it appears that implementation of this type of physics-based model is feasible.

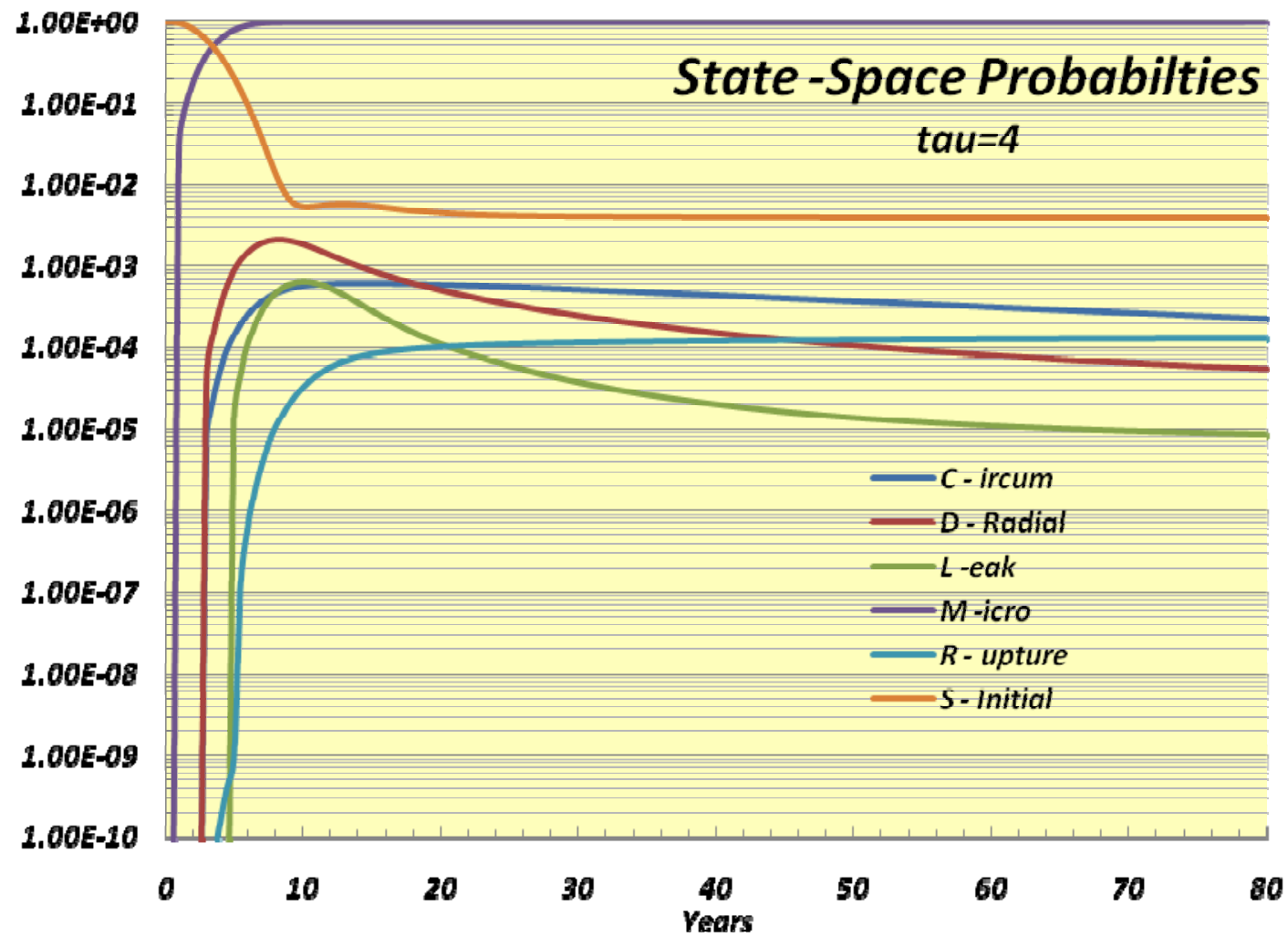

Figure 6-7 State Probabilities for tau $=4$ years 


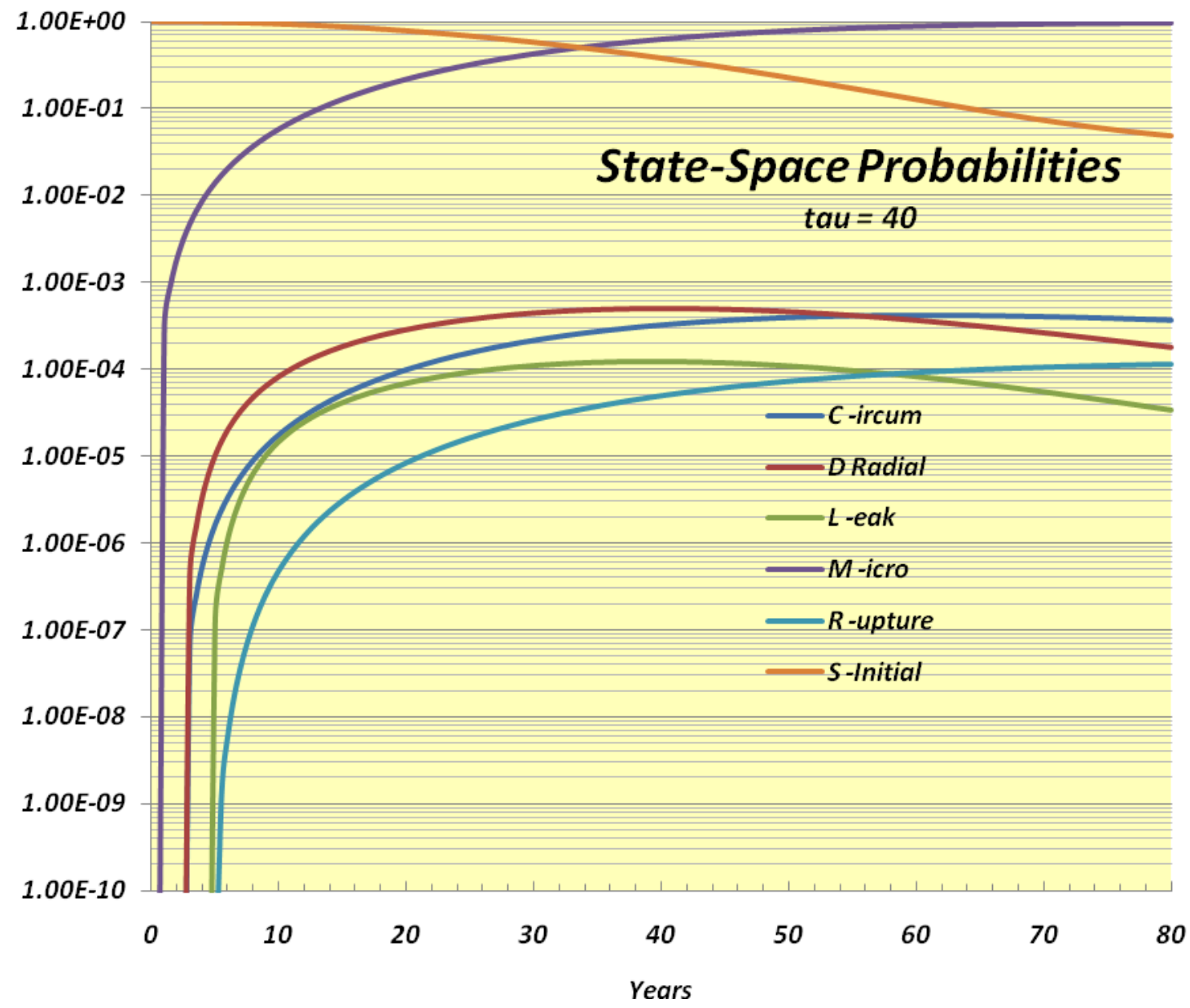

Figure 6-8 State Probabilities for tau $=\mathbf{4 0}$ years 


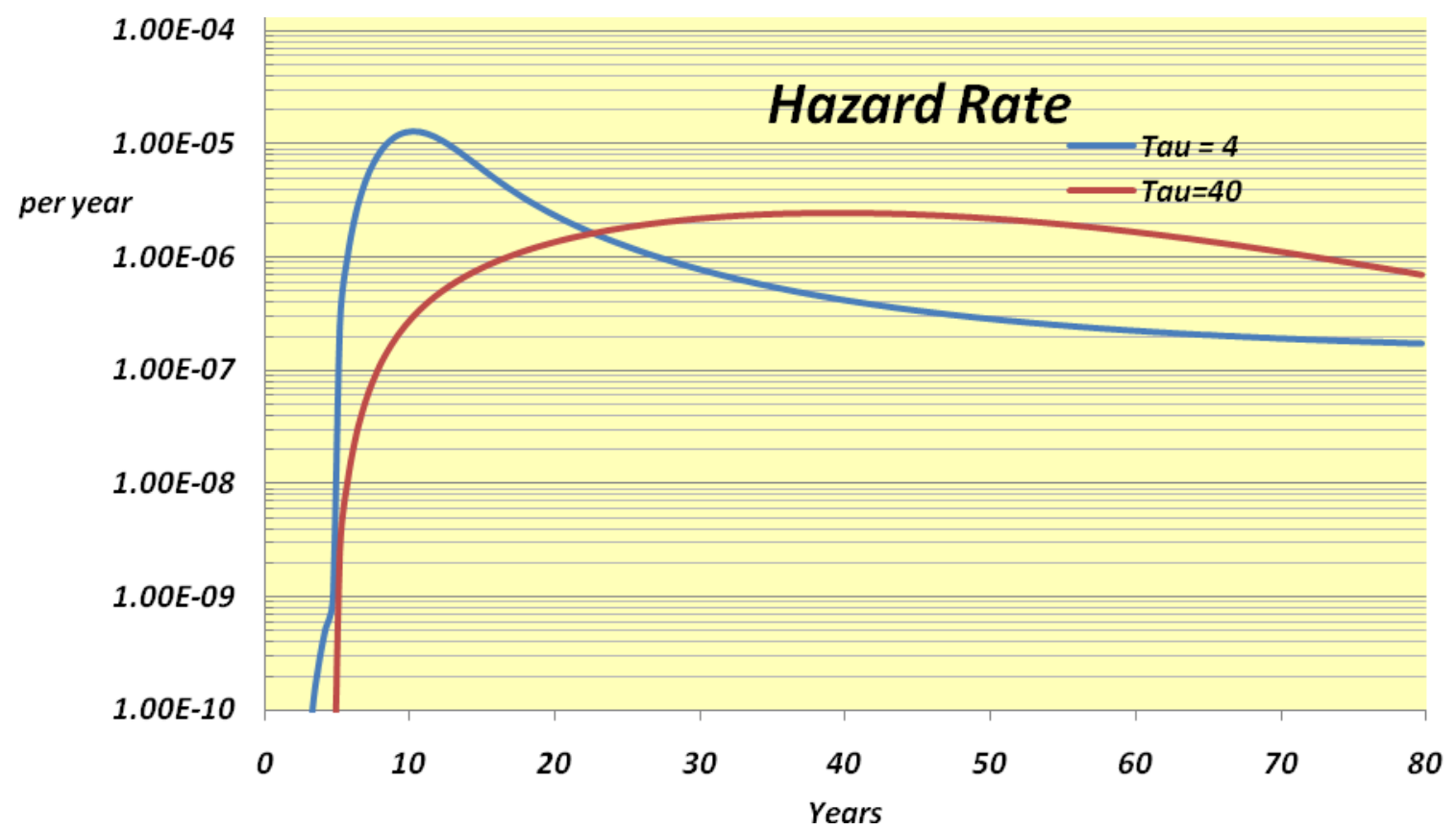

Figure 6-9 Rupture Hazard Rates 


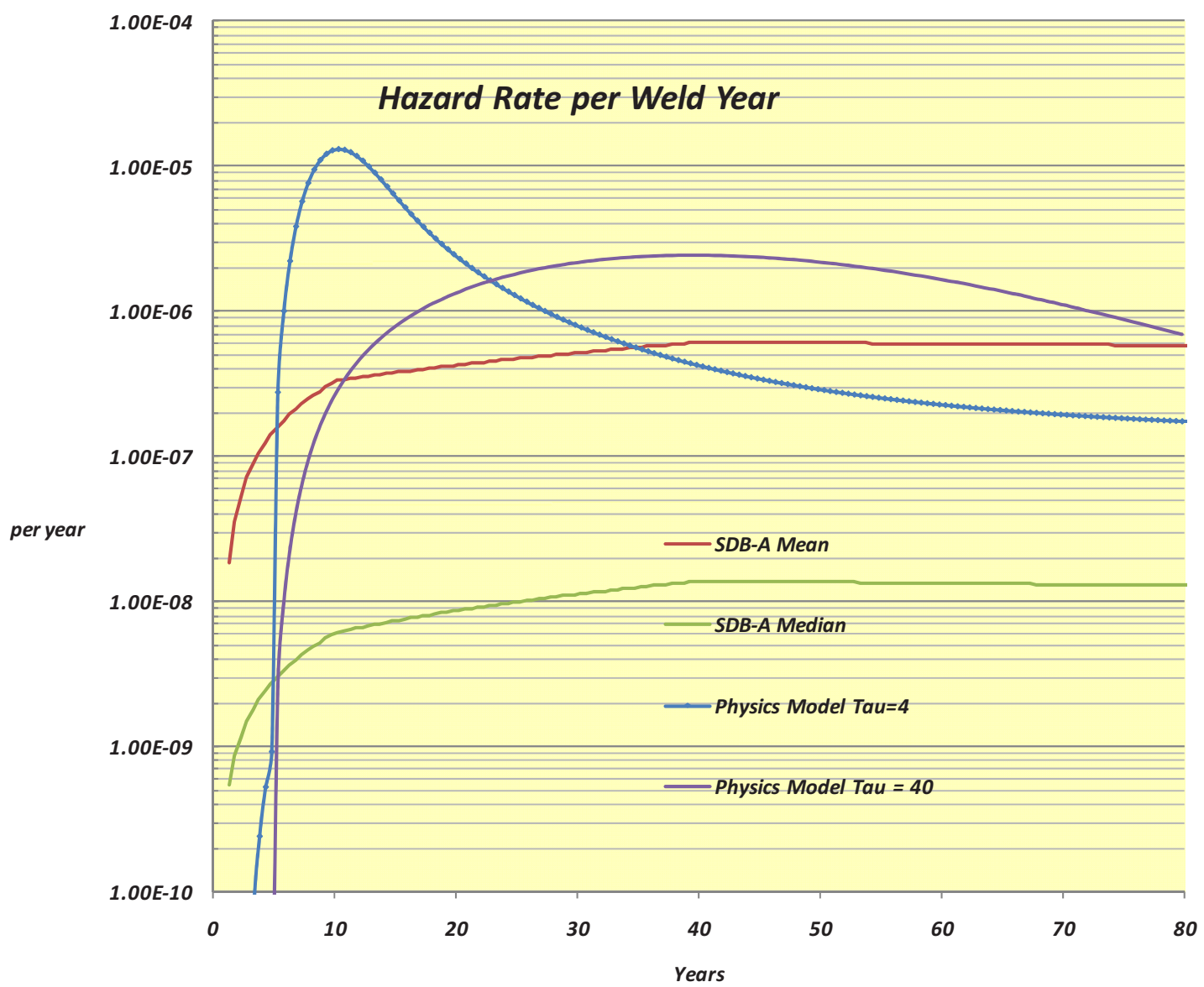

Figure 6-10 Comparison of Rupture Hazard Rates to Service Data Based Benchmark 


\section{Conclusions}

First, the availability of several options for the computational implementation of Markov and Markov-type models eliminates any practical impediments to solving these problem classes. While there remain some residual discrepancies in reconciliation of the benchmark methodologies, these are not expected to represent significant issues of feasibility. It is clear, however, that the original analytical approach to solving Markov models is unlikely to be feasible for more complex models with additional states and time dependent transition rates.

Second, while direct analysis of service data for the fire protection and feedwater/ condensate piping clearly indicates the existence of reliability degradation, it is unclear to what extent we are currently capturing the sources and mechanisms for aging in the context of the service databased and the physics-based Markov models. For instance, the service data-based model of Class 1 weld degradation displays an initial increase in hazard rate over a short period of about 10 years before approaching an asymptote. This rapid, initial hazard rate increase followed by a relatively flat performance is not the behavior that might be expected of aging degradation. Note that the state transition rates in this model are constant in time, and a relevant question is whether state transition rates (at least those characterizing component degradation) should instead be expected to increase with component age.

In the physics-based model, the state transition rates are time-dependent; however, the hazard rate predictions raise their own questions, particularly in light of the hazard rate maxima. Again, one question is whether this current version of the model, in which micro-cracks form in accordance with a Weibull process and then grow at a constant rate, is capturing the phenomena (associated with stress corrosion cracking) that define component aging. What needs to be considered is whether certain simplifying assumptions made for the purposes of this demonstration model (such as constant crack growth rates) have served to eliminate effects that are relevant to component aging. Nevertheless, the demonstration analysis has established that the computational framework is available to implement time-inhomogeneous models with randomly distributed transition rates.

Issues associated with both the service data-based and the physics-data based models point to the need to establish a deeper understanding of phenomena critical to the modeling of component aging. Also there is the need to develop a better understanding of the role of hazard rate metrics in predicting aging effects. For example, how would the hazard rate prediction compare to actual statistical trends in service data if aging effects were present?

\section{Path Forward}

Several areas of research are identified to advance this task in FY11:

1. Continued development of the physics-based model to address additional phenomena of relevance to component aging along with collection of associated physical data resources. 
2. Development of the means to integrate service data-based and physics-based Markov analyses to allow both materials degradation models and operational data to be incorporated into aging-based hazard rate prediction. Here, there will be the need to address multiple failure mechanisms that may apply to a component, including both degradation phenomena and loading conditions.

3. Establishment of the conceptual and analytical interfaces between the passives reliability methodology and the RISMC framework, with emphasis on integration of the passives models into the R7 environment and development of a margins-based characterization of passives performance. 


\section{REFERENCES}

[1] Fleming, K.N. and B.O.Y. Lydell, "Pipe Rupture Frequencies for Internal Flooding PRAs, Revision 1", prepared by Karl N. Fleming Consulting Services LLC for EPRI, EPRI Report No. 1013141, March 2006

[2] Fleming, K.N. and B.O.Y. Lydell, " High Energy Line Break Pipe Failure Rates for the Prairie Island PRA”, Prepared by KNF Consulting Services LLC for Xcel Energy, April 2009

[3] Fleming, K.N. and B.O.Y. Lydell, " High Energy Line Break Initiating Event Frequencies for the Kewaunee PRA", prepared by Karl N. Fleming Consulting Services for Dominion Energy, October 2005

[4] Fleming, K.N. and B.O.Y. Lydell, "Pipe Failure Rates for the Columbia Generating Station PRA”, Prepared by KNF Consulting Services LLC for Energy Northwest, June 2009

[5] Fleming, K. N., "Markov Models for Evaluating Risk Informed In-Service Inspection Strategies for Nuclear Power Plant Piping Systems", Reliability Engineering and System Safety, Vol. 83, No. 1 pp.:27-45, 2004.

[6] American Society of Mechanical Engineers and American Nuclear Society, RA-S-2008, "Standard for Level 1/Large Early Release Frequency PRA for Nuclear Power Plant Applications" December 2008

[7] Karl Fleming, " PBMR Passive Component Reliability - Application of Markov Model to Evaluate Alternative Integrity Management Strategies”, Prepared by Technology Insights for PBMR Pty., Final Report, June 2007

[8] Poloski, J.P. et al, Rates of Initiating Events at U.S. Nuclear Power Plants, NUREG/CR5750, U.S. Nuclear Regulatory Commission, Washington (DC), 1999.

[9] Tregoning, R., L. Abramson and P. Scott, Estimating Loss-of-Coolant Accident (LOCA) Frequencies Through the Elicitation Process, Draft Report for Comment, NUREG-1829, U.S. Nuclear Regulatory Commission, Washington (DC), June 2005.

[10] Lydell, B.O.Y., "PIPExp/PIPE-2008: Monthly Summary of Database Content (Status as of 31-Dec-2008)", RSA-R-2004-01.07, RSA Technologies, Fallbrook (CA). Monthly summary reports have been issued since January 1999.

[11] Fleming, K.N. et al, "Piping System Reliability and Failure Rate Estimation Models for Use in Risk-Informed In-Service Inspection Applications", TR-110161 (EPRI Licensed Material), EPRI, Palo Alto (CA), 1998.

[12] U.S. Nuclear Regulatory Commission, Safety Evaluation Report Related to 'Revised RiskInformed In-service Inspection Evaluation Procedure (EPRI TR-112657, Rev. B, July 1999, Washington (DC), 1999.

[13] H. Martz, TSA-1/99-164: "Final (Revised) Review of the EPRI-Proposed Markov Modeling/Bayesian Updating Methodology for Use in Risk-Informed Inservice Inspection of Piping in Commercial Nuclear Power Plants,", Los Alamos National Laboratory, June 1999

[14] Simonen, F.A., Gosselin, S.R., Lydell, B.O.Y., Rudland, D.L. and Wilkowski, G.M., Probabilistic Fracture Mechanics Evaluation of Selected Passive Components, Letter Report PNNL-16625, Pacific Northwest National Laboratory, Richland (WA), May 2007.

[15] Gosselin, S.R., Simonen, F.A., Pilli, S.P. and Lydell, B.O.Y., Probabilities of Failure and Uncertainty Estimates for Passive Components - A Literature Survey, NUREG/CR-6936, U.S. Nuclear Regulatory Commission, Washington (DC), May 2007. 
[16] Fleming, K.N., Mikschl, T.J., "Piping System Failure Rates and Rupture Frequencies for Use in Risk Informed In-service Inspection Applications", EPRI Report No. TR-111880 (EPRI Licensed Material), EPRI, Palo Alto (CA), 1999.

[17] Fleming, K.N. and B.O.Y. Lydell, "Database Development and Uncertainty Treatment for Estimating Pipe Failure Rates and Rupture Frequencies," Reliability Engineering and System Safety, 86:227-246, 2004

[18] Bush, S. et al, "Piping Failures in the US Nuclear Power Plants 1961-1995," SKI Report 96:20, Swedish Nuclear Power Inspectorate, Stockholm (Sweden), January 1996

[19] Lunn D. J. [et al.] WinBUGS - A Bayesian Modelling Framework: Concepts, Structure, and Extensibility [Journal] // Statistics and Computing. - 2000. - pp. 325-337.

[20] Lunn David [et al.] The BUGS Project: Evolution, Critique, and Future Directions [Journal] // Statistics in Medicine. - 2009. - Vol. 28. - pp. 3049-3067.

[21] International Atomic Energy Agency, Engineering Safety Section, "Assessment and Management of Ageing of Major Nuclear Power Plant Components Important to Safety", IAEA-TECDOC-1361, July 2003 .

[22] R Development Core Team R: A language and environment for statistical computing. - Vienna : R Foundation for Statistical Computing, 2010.

[23] U.S. General Accounting Office, "Action Needed to Ensure That Utilities Monitor and Repair Pipe Damage,” GAO/RCED-88-73, Washington (DC), March 1988.

[24] Cragnolino, G., C. Czajkowski and W.J. Shack, Review of Erosion-Corrosion in SinglePhase Flows, NUREG/CR-5156, U.S. Nuclear Regulatory Commission, Washington (DC), April 1988.

[25] International Atomic Energy Agency, "Corrosion and Erosion Aspects in Pressure Boundary Components of Light Water Reactors," Proceedings of a Specialists Meeting organized by the IAEA and Held in Vienna, 12-14 September 1988, IWG-RRCP-88-1, Vienna (Austria), April 1990.

[26] OECD Nuclear Energy Agency, "Specialist Meeting on Erosion and Corrosion of Nuclear Power Plant Materials," NEA/CSNI/R(94)26, Issy-les-Moulineaux (France), 1995.

[27] Beliczey, S. and H. Schulz, "The Probability of Leakage in Piping Systems of Pressurized Water Reactors on the Basis of Fracture Mechanics and Operating Experience," Nuclear Engineering and Design, 102:431-438, 1987.

[28] Fleming, K.N., and B.O.Y. Lydell, Guidelines for Performance of Internal Flooding Probabilistic Risk Assessment (IFPRA), Prepared by KNF Consulting Services LLC for EPRI, EPRI Report No. 1019194, December 2009

[29] Fleming, K. N., "Markov Models for Evaluating Risk Informed In-Service Inspection Strategies for Nuclear Power Plant Piping Systems", Reliability Engineering and System Safety, Vol. 83, No. 1 pp.:27-45, 2004.

[30] NUREG/CR-6923, "Expert Panel Report on Proactive Materials Degradation Assessment”, US NRC, BNL-NUREG-77111-2006, February 2007

[31] W.J. Shack, O.K. Chopra, Statistical Initiation and Crack Growth Models for Stress Corrosion Cracking, Proceedings of the Pressure Vessels and Piping Conference (PVP2007), ASME, July 22-26, 2007, San Antonio, Texas, pp. 337344.

[32] Statistical Analysis of Steam Generator Tube Degradation, EPRI NP-7493, 1991. 
[33] Bases for Predicting the Earliest Penetrations Due to SCC for Alloy 600 on the Secondary Side of PWR Steam Generators, NUREG/CR-6737, U.S. Nuclear Regulatory Commission, 2001.

[34] PWSCC Prediction Guidelines, EPRI Report TR-104030, July, 1994.

[35] S. Le Hong, "Influence of Surface Condition on Primary Water Stress Corrosion Cracking Initiation of Alloy 600", Corrosion, Vol. 57, No. 4, 2001, pp. 323-333.

[36] M. Kamaya, T. Haruna, "Crack Initiation Model for Sensitized 304 Stainless Steel in High Temperature Water", Corrosion Science, Vol. 48, 2006, pp. 2442-2456.

[37] O.F. Aly, et al., "Preliminary Study for Extension and Improvement on Modeling of Primary Water Stress Corrosion Cracking at Control Rod Drive Mechanism Nozzles of Pressurized Water Reactors", International Nuclear Atlantic Conference (INAC) 2009, Rio de Janeiro.

[38] P. Scott, et al., "Comparison of Laboratory and Field Experience of PWSCC in Alloy 182 Weld Metal", 13th International Conference on Environmental Degradation of Materials in Nuclear Power Systems, Whistler, BC, August 2007.

[39] S. Le Hong, J. M. Boursier, C. Amzallag, and J. Daret, "Measurements of Stress Corrosion Cracking Growth Rates in Weld Alloy 182 in Primary Water of PWR," Proceedings of 10th International Conference on Environmental Degradation of Materials in Nuclear PowerSystems-Water Reactors, NACE International, 2002.

[40] A. Jenssen, K. Norrgård, C. Jansson, J. Lagerström, G. Embring, and P. Efsing, "Structural Assessment of Defected Nozzle to Safe-End Welds in Ringhals 3 and 4," Fontevraud V International Symposium on Contribution of Materials Investigation to the Resolution of Problems Encountered in Pressurized Water Reactors, SFEN, 2002, pp. 43-54.

[41] Crack Growth of Alloy 182 Weld Metal in PWR Environments (PWRMRP-21), EPRI, Palo Alto, CA, 2000, 1000037.

[42] Materials Reliability Program Crack Growth Rates for Evaluating Primary Water Stress Corrosion Cracking (PWSCC) of Alloy 82,182, and 132 Welds (MRP-115), EPRI, Palo Alto, CA, 2003, 1006696.

[43] Extremely Low Probability of Rupture (xLPR) Program Pilot Study, NRC 2009 
Treatment of Passive Component Reliability in Risk-Informed Safety Margin Characterization

\section{APPENDIX A}

\section{PIPExp Database Description}




\section{A.1PIPExp / OPDE Overview}

This appendix describes the PIPExp database content and structure, and its relationship with the OECD Pipe Failure Data Exchange Project (OPDE). OPDE was established in 2002 as a cost-shared, multi-national co-operation in piping reliability. The initial objective of OPDE was to establish a comprehensive database on pipe failures in commercial nuclear power plants worldwide and to make the database available to project member organizations that provide data. The project is operated under the umbrella of the OECD Nuclear Energy Agency (NEA). A Clearinghouse is operating the database and provides the quality assurance function. The Clearinghouse is operated by one of the authors of this report.

\section{A.1.1 Historical Background}

The Swedish Nuclear Power Inspectorate ${ }^{1}$ (SKI) in 1994 launched a R\&D project with the objective of advancing the state-of-art in piping reliability. The stated objective included the following tasks:

- Develop a high-quality, comprehensive database on the service history of piping systems in commercial nuclear power plants.

- In parallel with the database development, identify and develop a general framework for statistical analysis of the service data as recorded in the pipe failure database.

- Perform a pilot application to demonstrate how the pipe failure database and piping reliability analysis framework can be used to develop plant-specific loss of coolant accident (LOCA) frequencies.

A long term strategy for the pipe failure database was formulated during the discussions leading up to the project initiation in mid-1994. This strategy included considerations to establish an international cooperation to support the long term database maintenance and applications program. The R\&D project was concluded at the end of 1998. Results of the project included:

- A pipe failure database in Microsoft ACCESS. At the time this database was referred to as "SKI-PIPE", a proprietary database. It included 2291 pipe failure records as of 31Dec-1998. This version formed the basis of OPDE in 2002 (Figure A-1).

- A series of technical reports (e.g., SKI Reports 95:58, 97:26, 97:32 and 98:30, all available from www.ski.se.

Independent of SKI and in preparation for and support of an international cooperative effort, the maintenance and update of the pipe failure database has continued post-1998. Figure A-1 is a top-level summary of this post-1998 maintenance and update program including the relationship between PIPExp and OPDE. Insights from practical database applications have played a significant role in enhancing and restructuring the database to become tool for piping reliability assessments.

\footnotetext{
${ }^{1}$ SKI became Swedish Radiation Safety Authority (SSM) as of July 1, 2008
} 


\section{A.2 PIPExp Quality Management}

All work associated with database maintenance is controlled by a QA program. Source information including text files, drawings and photographs associated with each database record is stored in an electronic archive. Each data record in PIPExp is assigned a "Quality Index" (or completeness index) per the definitions in Table A-1. The Quality Index is used to assess the completeness and technical accuracy of the source information as well as the classified and coded information in the database. Table A-2 summarizes the evolution of the database since 1998.

Table A-1 Definition of Quality Index for Database Management

\begin{tabular}{|c|l|}
\hline Quality-Index & \multicolumn{1}{|c|}{ Definition } \\
\hline 1 & $\begin{array}{l}\text { Validated - all source data has been } \\
\text { accessed \& reviewed }\end{array}$ \\
\hline 2 & $\begin{array}{l}\text { Validated - source data may be missing } \\
\text { some, non-critical information - no further } \\
\text { action anticipated }\end{array}$ \\
\hline 3 & Not validated - validation is pending \\
\hline
\end{tabular}

Table A-2 Classification of Records by Quality Index as of March 31, 2009

\begin{tabular}{|c|c|c|c|c|c|c|c|c|}
\hline \multirow[t]{2}{*}{$\begin{array}{l}\text { Plant } \\
\text { Type }\end{array}$} & \multicolumn{4}{|c|}{$\begin{array}{l}\text { Database as of } 12-31-1998 \\
\text { No. of Records by Completeness Index }\end{array}$} & \multicolumn{4}{|c|}{$\begin{array}{l}\text { Database as of 05-31-2009 } \\
\text { No. of Records by Completeness } \\
\text { Index }\end{array}$} \\
\hline & Totals & Totals & Totals & Totals & Totals & 1 & 2 & 3 \\
\hline BWR & 637 & 276 & 84 & 277 & 3080 & 2050 & 1002 & 19 \\
\hline GCR, HWLWR & -- & -- & -- & -- & 14 & 14 & -- & -- \\
\hline CANDU / PHWR & 100 & 33 & 57 & 10 & 208 & 85 & 124 & -- \\
\hline PWR & 1496 & 509 & 241 & 746 & 4248 & 1867 & 2333 & 32 \\
\hline RBMK & 57 & 9 & 47 & 1 & 183 & 33 & 150 & \\
\hline & 2291 & 827 & 430 & 1034 & 7733 & 4049 & 3609 & 51 \\
\hline
\end{tabular}




\section{SKI R\&D Project 1994-1998}

- $\quad$ SOAR on piping reliability analysis as it relates to PSA (SKI Report 95:58)

- $\quad$ Basis for deriving pipe failure parameters from service data (SKI Report 97:26;

- $\quad$ SKI-PIPE (1998) pipe failure database (2291 records as of 12-31-1998)

PIPExp Database Project (1999 - to date) - independent of SKI

- $\quad$ Active maintenance program (weekly updates);

- QA program - extensive data validation;

- $\quad$ Practical applications \& enhancements to db-structure

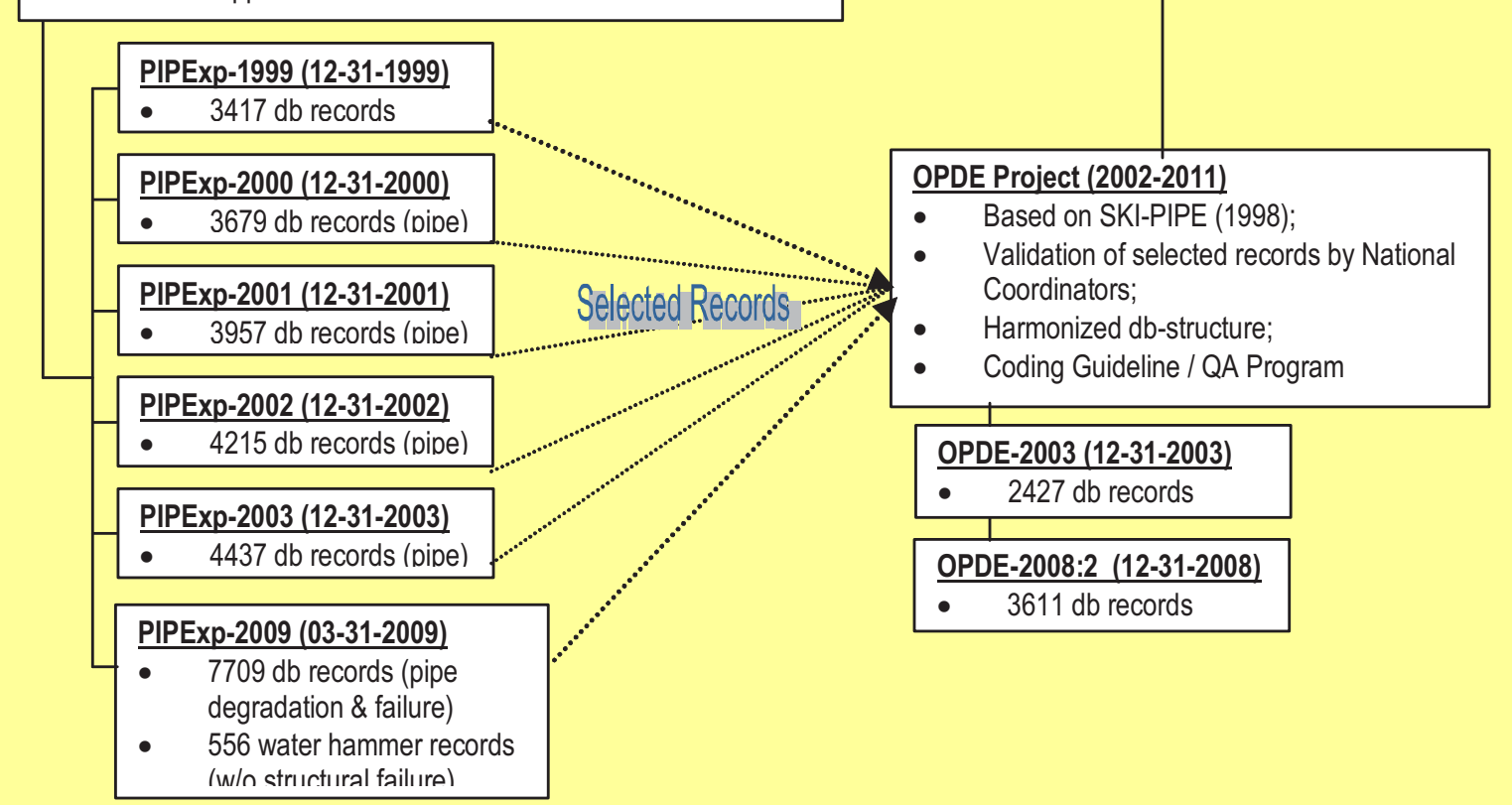

Figure A-1 Evolution of PIPExp Pipe Failure Database 


\section{A.3 PIPExp Database Input Forms}

This section gives and overview of the database input requirements. All data entry is done via the four forms (Form 1 through Form 4).

\section{A.3.1 Form 1 - Event Descriptions}

Form 1 is shown in Figure A-2. It consists of 35 fields; seven of which are free-format with the balance defined by roll-down menus with key words (or data filters). The data entry requirements are defined below:

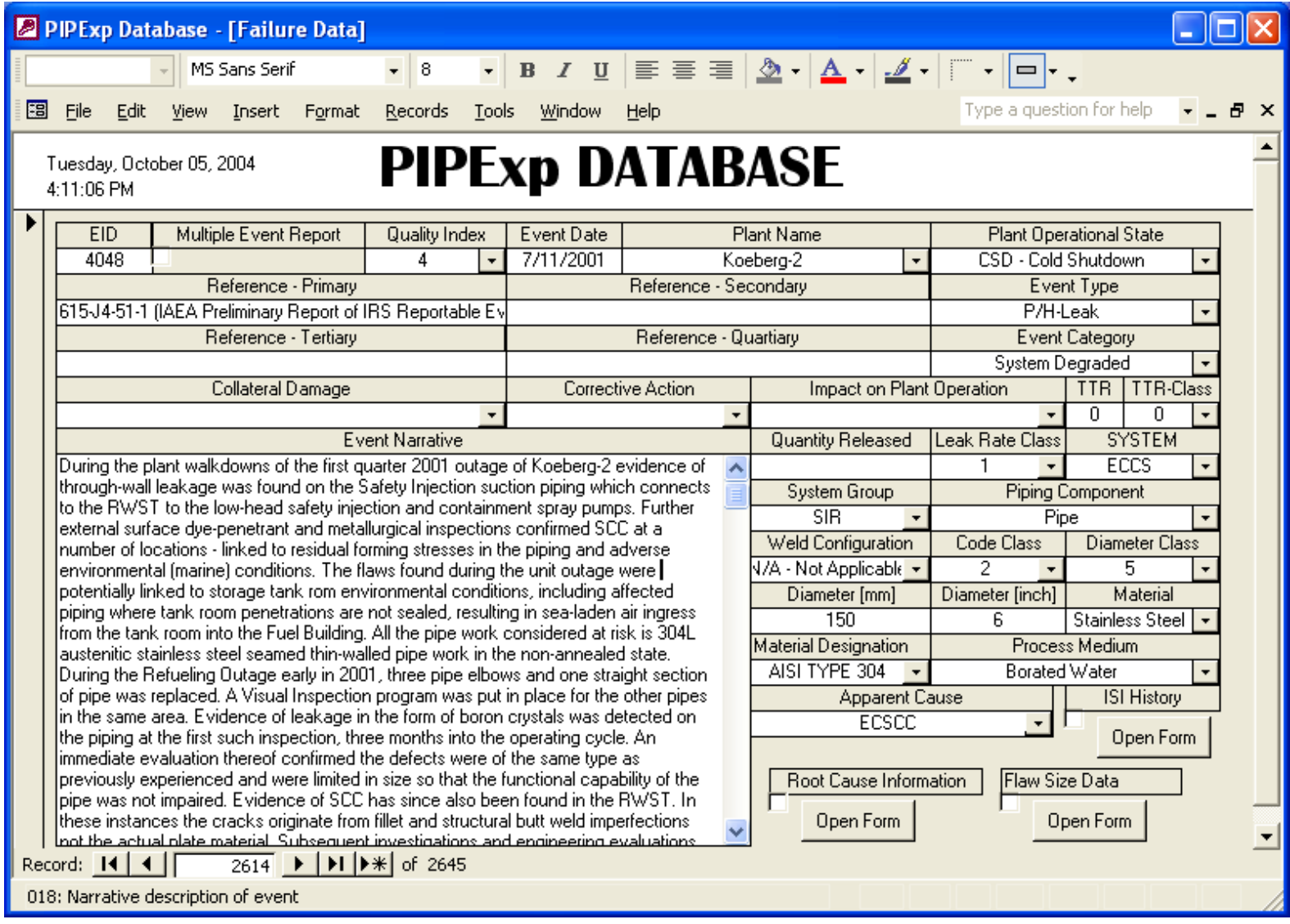

\section{Figure A-2 Event Descriptions - Form 1}

Form 1 Data Entry Requirements

- $\quad$ EID (Event ID) is a uniquely defined database record number (or "primary key"); it is generated automatically by Access.

- Multiple Event Report is checked if one source document (reference) includes information about more than one pipe failure and at different piping system locations. Mainly, this field supports database management activities (e.g., answer to question "have all pipe failures been adequately recorded in PIPExp?").

- Quality Index (a number 1 to 6); a roll-down menu defines the different options together with definitions. 
- Event Date is always required.

- Plant Name; a roll-down menu with listing of all commercial nuclear power plants in NEA member and non-member countries.

- Plant Operational State; a roll-down menu defines the different options.

- Reference; there are four free-format fields for primary and supplemental references. Electronic copies of each reference are stored on CD.

- Event Type; a roll-down menu defines the different options.

- Event Category; a roll-down menu defines the different options.

- Collateral Damage; a roll-down menu defines the different options. "N/A - None" is used as the default.

- Corrective Action; a roll-down menu defines the different options. Note that the term "Temporary Repair" always implies that a "Code Repair" or "Replacement" be performed during the next scheduled outage lasting 30 days or more, but no later than the next refueling outage.

- TTR (Time to Repair) is for the repair time in hours.

- TT-Class is a data filter; a roll-down menu defines the different options with definitions.

- Event Narrative is a free-format memo field.

- Quantity Released is free format field; the dimension can be [lb], [kg], [ton], or [ $\left.\mathrm{m}^{3}\right]$.

- Leak Rate Class is a data filter; a roll-down menu defines the different options with definitions.

- System is a free format field for the system name; a roll-down menu includes a selection of BWR- and PWR-specific, English language names.

- System Group is a data filter; a roll-down menu defines the different options.

- Piping Component is a data filter; a roll-down menu defines the different options.

- Weld Configuration; a roll-down menu defines the different options.

- Code Class; a roll-down menu defines the different options. A cross-reference table compares the different national safety classifications with ASME Section III.

- Diameter Class is a data filter; a roll-down menu defines the different options and definitions.

- Diameter [mm] is used for the measured diameter.

- Diameter [inch] is used for the measured diameter.

- Material is a data filter; a roll-down menu defines the different options.

- Material Designation; a roll-down menu defines the different options. A cross-reference includes different carbon steel and stainless steal material designations.

- Process Medium, a roll-down menu defines the different options.

- ISI History (Form 3) is checked only if information is available.

- Root Cause Information (Form 4) is checked only if information is available.

- Flaw Size Information (Form 2) is checked only if flaw size (e.g., crack orientation, depth, length) information is available. 


\section{A.3.2 Form 2 - Flaw Size Information}

Form 2 is shown in Figure A-3. It consists of 28 fields. The data entry requirements are defined below:

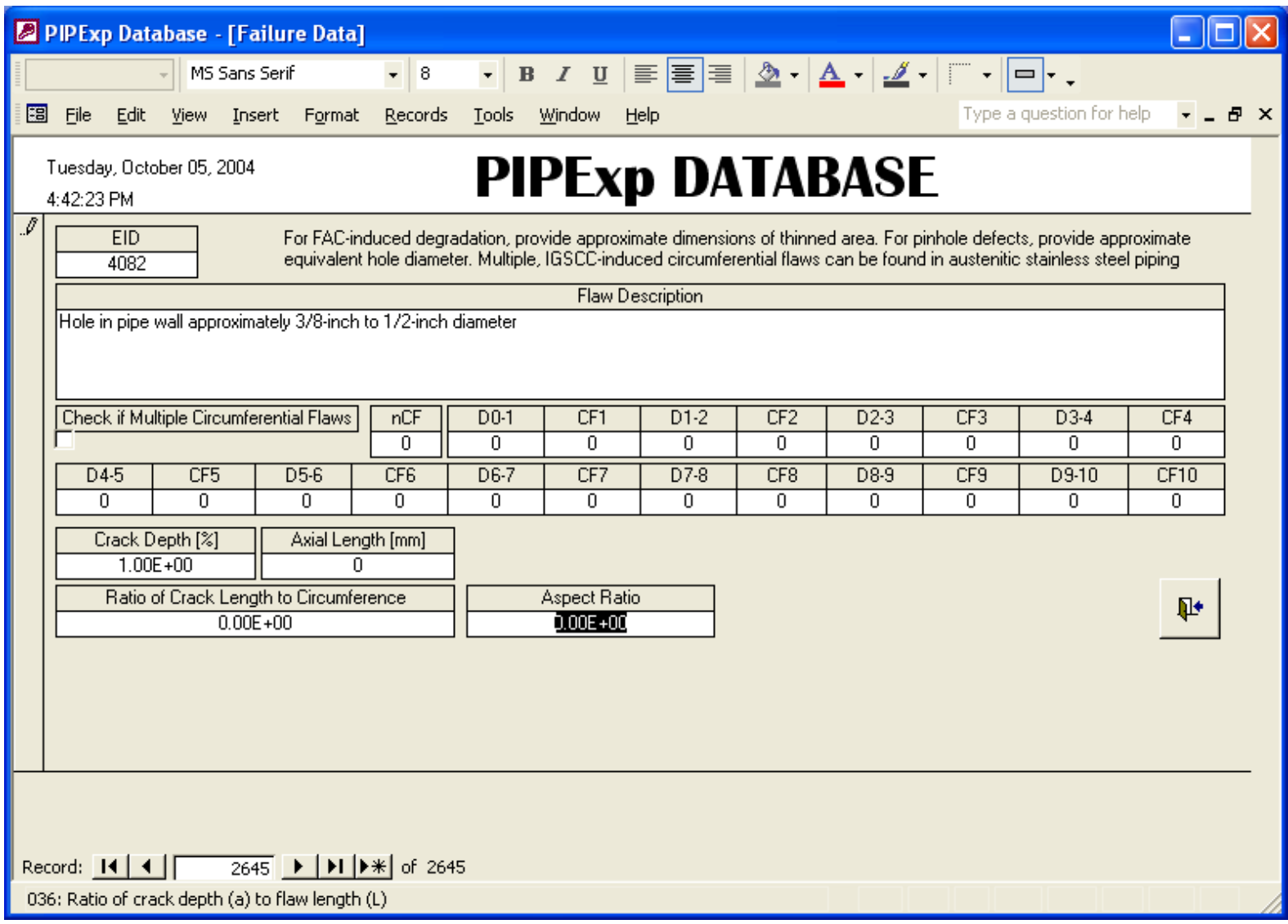

\section{Figure A-3 Flaw Size Information - Form 2}

\section{Form 2 Data Entry Requirements}

- Flaw Description is a free-format memo field. For through-wall flaws, information about dimensions (e.g., equivalent diameter) should be included in this field. For part throughwall flaws, this field should include information on flaw depth (a) and length (I), and orientation. For multiple flaws, the number of flaws and their lengths are recorded in the designated fields.

- Check if Multiple Circumferential Flaws. This check box typically applies to flaws attributed to IGSCC. In PIPExp, on the order of $15 \%$ of the records on IGSCC involve multiple, single plane circumferential cracks.

- $\mathrm{nCF}$ (number of Circumferential Flaws) includes the total number of flaws in an affected weld.

- D\#-\#\# is the distance, in [mm], between adjacent circumferential flaws; e.g., D0-1 is the distance from the TDC (12 o'clock) position to flaw \#1, and D2-3 is the distance between flaw \#2 and flaw \#3, etc. A blank field indicates that no information on the spacing is available in the database. 
- CF-\# is the length of circumferential flaw '\#' [mm]. The flaw number is relative to the 0degree position; CF-1 is the first circumferential flaw from the reference position, etc.

- $\quad$ Crack Depth [\%] is the ratio of crack depth to pipe wall thickness.

- Axial Length [mm]; this field relates to the Flaw Description.

- Ratio of Crack Length to Circumference; this ratio should be relative to the inside pipe circumference.

- Aspect Ratio; this is the ratio of crack depth to crack length and relates to the information under Flaw Description.

\section{A.3.3 Form 3 - ISI History}

Form 3 is shown in Figure A-4. It consists of 3 fields. While primarily intended for ISI program weaknesses, the free-format field may be used to document any information pertaining to the ISI of the affected component, or ISI history such as time of most recent inspection.

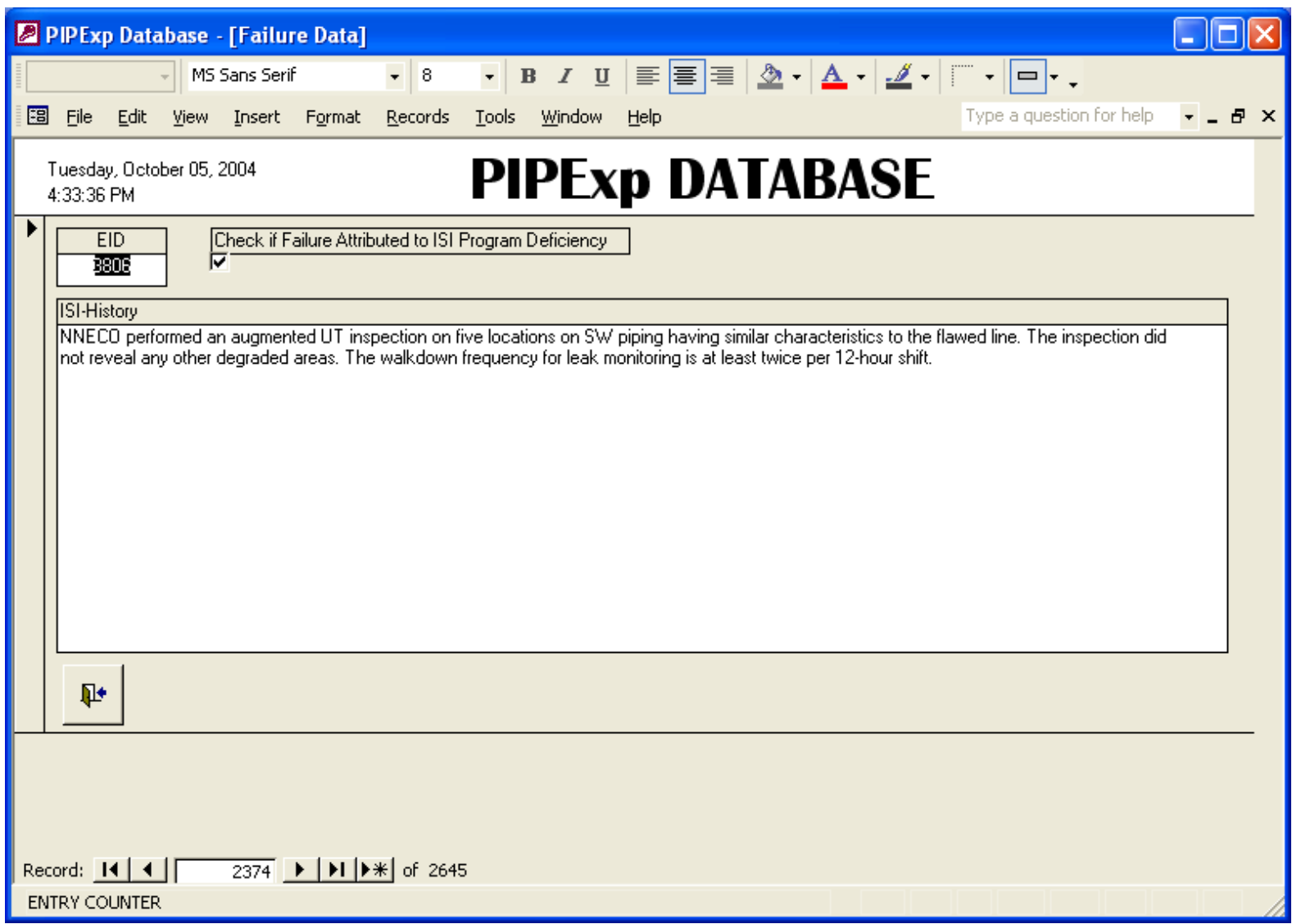

Figure A-4 ISI History - Form 3 


\section{A.3.4 Form 4 - Root Cause Information}

Form 4 is shown in Figure A-5. It consists of 9 fields. The data entry requirements are defined below:

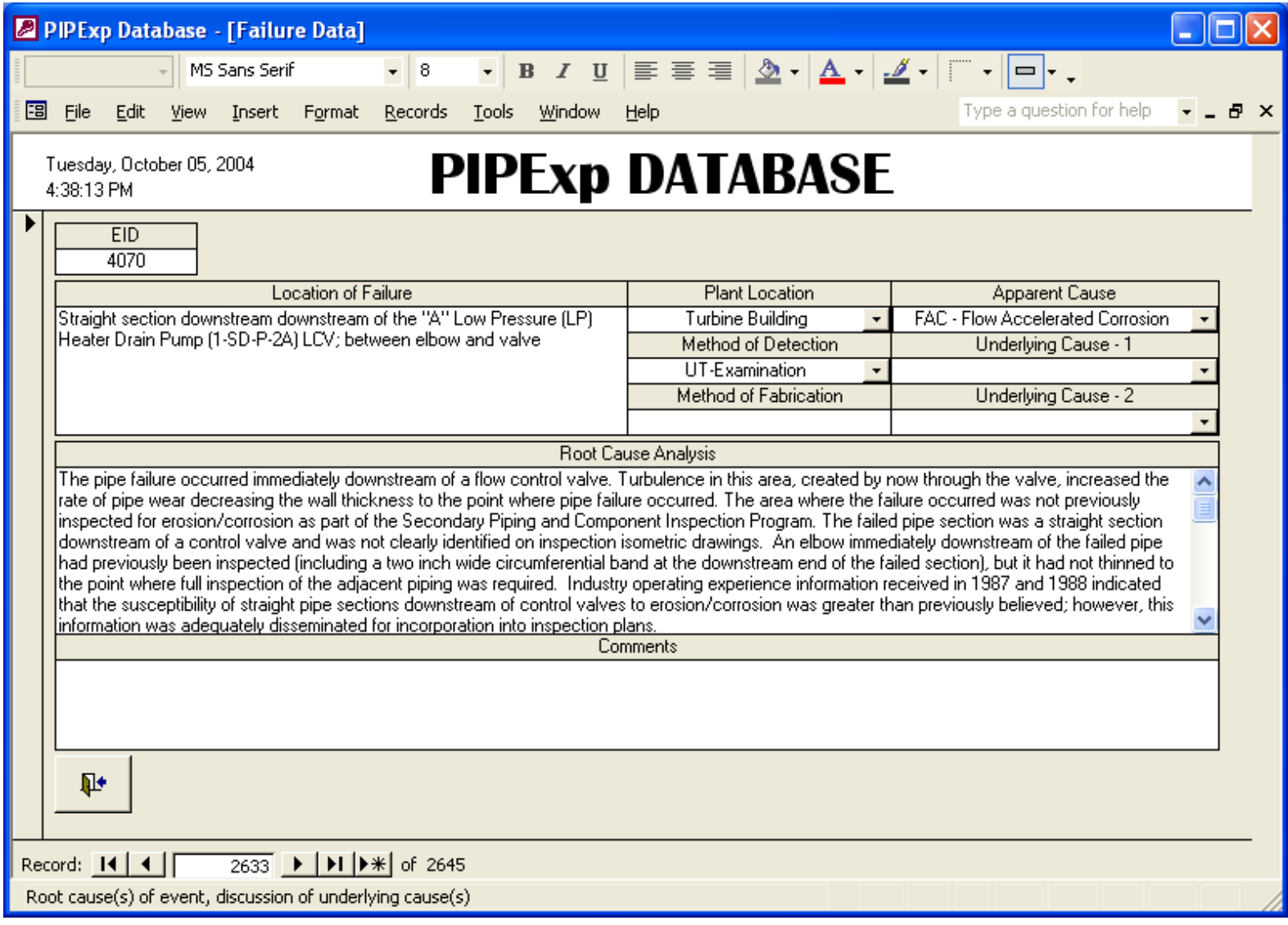

\section{Figure A-5 Root Cause Information - Form 4}

\section{Form 4 Data Entry Requirements}

- Location of Failure; this is a free-format memo field describing the location of a flaw (e.g., line or weld number, or using a P\&ID reference).

- Plant Location; a roll-down menu defines the different options.

- Method of Detection; a roll-down menu defines the different options.

- Method of Fabrication; a free-format text field.

- Apparent Cause; a roll-down menu defines the different options. Normally this field has already been filled in.

- Underlying Cause - 1; a roll-down menu defines possible contributing factors.

- Underlying Cause - 2; a roll-down menu defines possible contributing factors.

- Root Cause Analysis; a free-format memo field. This field should include any relevant information on the cause-consequence relationship and should be supplemental to the Event Narrative in Form 1.

- Comments; a free-format memo field. It is intended for any other, relevant information that is not captured by other database fields. 


\section{A.4Database Accessibility}

PIPExp is a proprietary database, whereas the OECD Pipe Failure Data Exchange (OPDE) database is restricted to organizations that supply data in accordance with Terms \& Condition of the OPDE Project. 


\section{APPENDIX B}

Evaluation of Pipe Failure Rates and Rupture Frequencies in Non-Safety Piping Systems 


\section{Table of Contents}

B. EVALUATION OF PIPE FAILURE RATES AND RUPTURE FREQUENCIES IN NON-

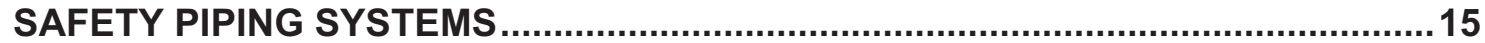

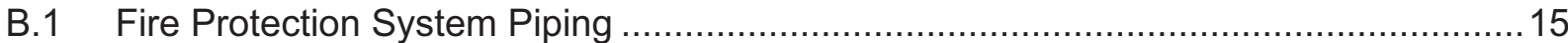

B.1.1 Data Collection for Fire Protection System ……........................................15

B.1.2 Conditional Probability of Pipe Rupture Given Failure for FP...............................16

B.1.3 Estimates of Failure Rates and Rupture Frequencies.....................................25

B.1.4 Impact of Plant Age on Estimated Failure Rates for FP System .........................32

B.1.5 Open Issues for Evaluation of Fire-water piping ...........................................34

B.1.6 Impact of Alternative Inspection and Surveillance Strategies for FP System........37

B.1.7 Impact of Plant Age on Estimated Failure Rates for FP System .........................41

B.2 Feedwater, Condensate, and Steam Piping …….............................................4

B.2.1 System Boundaries ..................................................................... 44

B.2.2 Failure Data Collection for Feedwater, Condensate and Steam Piping ................44

B.2.3 Conditional Probability of Pipe Rupture Given Failure ...................................49

B.2.4 Failure Rates and Cumulative Rupture Frequencies for FAC Susceptible Systems 53

B.2.5 Evaluation of Temporal Trends in Failure Rates for FAC Susceptible Systems ...69

B.2.6 Impact of Alternative Inspection and Surveillance Strategies on FWC Piping .......70

B.2.7 Impact of Plant Age on Estimated Failure Rates for FAC Susceptible Systems ... 73

B.3 Investigation of Aging via Direct Estimation of Failure Rates and Rupture Frequencies 73

B.3.1 Open Issues with FAC Susceptible Systems …………………………….....75

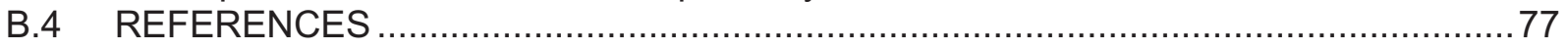




\section{Table of Figures}

Figure B-1 Empirical Conditional Probability of Pipe Failure as a Function of Type of Piping System \& Through-Wall Flow Rate Threshold Value.

Figure B-2 Continuous vs. Discrete Model for Prior Conditional Rupture Probability ................ 19

Figure B-3 Conditional Rupture Size Probability Model for 24" Service Water Pipe and

Comparison to NUREG-1860 Data ...................................................................... 22

Figure B-4 Prior Distribution for Conditional Probability of FP System Rupture Given Failure for

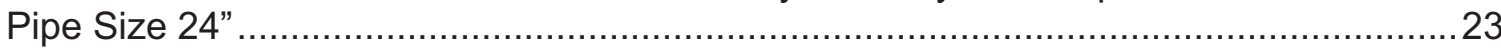

Figure B-5 Results for Rupture Frequency vs. Break Size for NPS 24" FP Header ..................25

Figure B-6 Cumulative Pipe Rupture Frequency for FP NPS 4" ......................................2

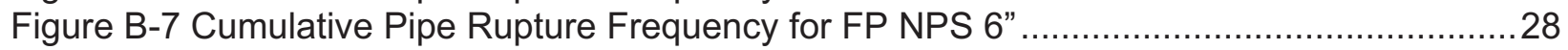

Figure B-8 Cumulative Pipe Rupture Frequency for FP NPS 24" ....................................29

Figure B-9 Impact of Design and Inspection Strategies to Reduce the Frequency of Fire

Protection Header Pipe Ruptures ......................................................................... 32

Figure B-10 Plant Age Dependent Hazard Rates for Selected Break Sizes in 24" FP Pipe ....... 34

Figure B-11 Hazard Rate Sensitivity Study - Vary Flaw to Leak Ratio ...................................34

Figure B-12 Results for Rupture Frequency vs. Break Size for NPS 24” FP Header .................36

Figure B-13 Cumulative Pipe Rupture Frequency for FP NPS 24" ..................................... 37

Figure B-14 Impact of Design and Inspection Strategies to Reduce the Frequency of Fire

Protection Header Pipe Ruptures ...................................................................... 41

Figure B-15 Plant Age Dependent Hazard Rates for Selected Break Sizes in 24" FP Pipe .......43

Figure B-16 Hazard Rate Sensitivity Study - Vary Flaw to Leak Ratio ..................................43

Figure B-17 PWR Worldwide Experience with non-Code FWC Piping 1970-2004.................. 46

Figure B-18 PWR Worldwide Experience with non-Code Steam Piping 1970-2004 ................47

Figure B-19 Cumulative Rupture Frequency vs. Break Size for NPS > 10" FWC Pipe ............54

Figure B-20 Comparison of Prior Means for Conditional Probability of Rupture vs. Break Size for

Service Water, Fire Protection, Feedwater, Condensate and Steam Systems ..............56

Figure B-21 Cumulative Rupture Frequency vs. Break Size for NPS $\leq 10$ " FWC Pipe ............61

Figure B-22 Cumulative Rupture Frequency vs. Break Size for NPS > 10" FWC Pipe .............62

Figure B-23 Cumulative Rupture Frequency vs. Break Size for NPS $\leq 10$ " LPS Pipe...............63

Figure B-24 Cumulative Rupture Frequency vs. Break Size for NPS > 10" LPS Pipe..............64

Figure B-25 Cumulative Rupture Frequency vs. Break Size for NPS $\leq 10$ " HPS Pipe ...............65

Figure B-26 Cumulative Rupture Frequency for NPS > 10" HPS Pipe ................................66

Figure B-27 Cumulative Rupture Frequency for EXT-ST $\leq 10$ " EXS Pipe ..............................67

Figure B-28 Cumulative Rupture Frequency for NPS > 10" EXS Pipe ..................................6 68

Figure B-29 Comparison of Pipe Failure Rates in Large (>6") FAC Susceptible Piping Based on

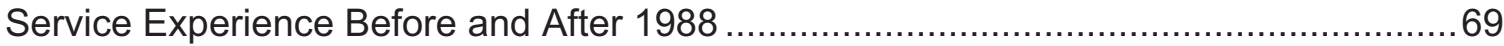

Figure B-30 Temporal Trends in the Frequency of Large Pipe Breaks in FAC Susceptible

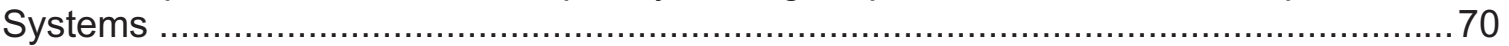

Figure B-31 Comparison of Fire Protection System Failure Rates Over Different Time Periods74

Figure B-32 Comparison of PWR FWC Failure Rate Estimates for Different Time Periods .......75

\section{$\underline{\text { Table of Tables }}$}

Table B-1 Pipe Lengths Used to Establish Fire Protection System Exposure .........................15

Table B-2 Fire Protection System Failure Counts by Failure Mode, Pipe Size and Failure

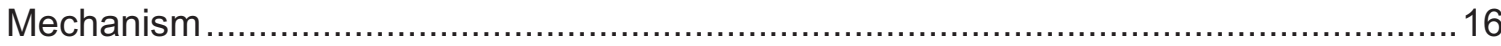

Table B-3 Comparison of Flood Rates, EBS, and Conditional Probabilities for SW Prior

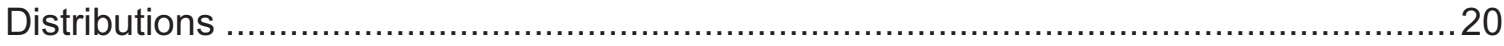

B-xiii 
Table B-4 Bayes' Update of Conditional Rupture Mode Probabilities For FP Base Case with Water Hammer Events Included ...........................................................................24

Table B-5 Bayes' Update of Conditional Rupture Mode Probabilities For FP With Water Hammer Events Excluded ............................................................................................... 24

Table B-6 Failure Rates and Cumulative Rupture Frequencies for FP NPS 4" Pipe ................26

Table B-7 Pipe Failure Rates and Cumulative Rupture Frequencies for FP NPS 6" ................27

Table B-8 Failure Rates and Cumulative Rupture Frequencies for FP NPS 24" ....................28

Table B-9 Impact of Alternative Leak Detection Strategies to Reduce Fire Protection System

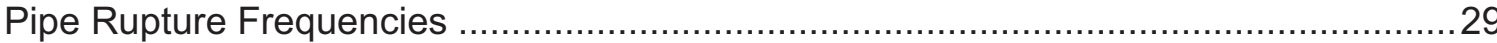

Table B-10 Impact of NDE and Alternative Leak Detection Strategies to Reduce Fire Protection

System Pipe Rupture Frequencies ...................................................................... 30

Table B-11 Integrity Management Factors for Various Combinations of NDE and Leak Inspections for Fire Protection System ............................................................... 31

Table B-12 Factors To Account for Aging Effects on NPS 24" FP Header ............................33

Table B-13 Failure Rates and Cumulative Rupture Frequencies for FP NPS 24" and No Water Hammer Protection ........................................................................................... 38

Table B-14 Impact of Alternative Leak Detection Strategies to Reduce Fire Protection System

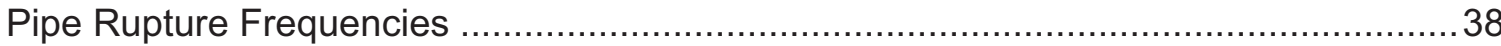

Table B-15 Impact of NDE and Alternative Leak Detection Strategies to Reduce Fire Protection System Pipe Rupture Frequencies ................................................................. 38

Table B-16 Integrity Management Factors for Various Combinations of NDE and Leak Inspections for Fire Protection System ............................................................ 40

Table B-17 Factors To Account for Aging Effects on NPS 24" FP Header ............................42

Table B-18 Service Experience with B31.1 Carbon Steel FWC Piping 1970 to $2008 \ldots \ldots \ldots \ldots . . .47$

Table B-19 Service Experience with B31.1 Carbon Steel Steam Piping 1970 to 2008 ............48

Table B-20 Estimated Pipe Lengths for PWR Steam, Feedwater, and Condensate Systems ...49

Table B-21 Pipe Ruptures in BWR and PWR Feedwater, Condensate, and Steam Systems....50

Table B-22 Failure Rates and Cumulative Rupture Frequencies for NPS > 10" FWC System ..54

Table B-23 Pipe Ruptures in BWR and PWR Feedwater, Condensate, and Steam Systems....57

Table B-24 Bayes' Update of Prior Distribution for Conditional Rupture Probability for FAC

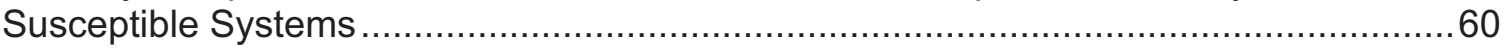

Table B-25 Failure Rates and Cumulative Rupture Frequencies for NPS $\leq 10$ " FWC System...61

Table B-26 Failure Rates and Cumulative Rupture Frequencies for NPS > 10" FWC System .. 62

Table B-27 Failure Rates and Cumulative Rupture Frequencies for NPS $\leq 10$ " LPS System ....63

Table B-28 Failure Rates and Cumulative Rupture Frequencies for NPS > 10" LPS System ....64

Table B-29 Failure Rates and Cumulative Rupture Frequencies for NPS $\leq 10$ " HPS System ...65

Table B-30 Failure Rates and Cumulative Rupture Frequencies for NPS > 10" HPS System ...66

Table B-31 Failure Rates and Cumulative Rupture Frequencies for NPS $\leq 10$ " EXS System....67

Table B-32 Failure Rates and Cumulative Rupture Frequencies for NPS > 10" EXS System ...68

Table B-33 Impact of Alternative Leak Detection Strategies to Reduce Feedwater-Condensate System Pipe Rupture Frequencies ..................................................................... 71

Table B-34 Impact of NDE and Alternative Leak Detection Strategies to Reduce Fire FeedwaterCondensate System Pipe Rupture Frequencies ................................................... 71

Table B-35 Integrity Management Factors for Various Combinations of NDE and Leak Inspections for Feedwater-Condensate System .................................................. 72

Table B-36 Factors To Account for Aging Effects on NPS 24" FWC Pipe ..............................73 


\section{EVALUATION OF PIPE FAILURE RATES AND RUPTURE FREQUENCIES IN NON-SAFETY PIPING SYSTEMS}

\subsection{Fire Protection System Piping}

\subsubsection{Data Collection for Fire Protection System}

The data analysis for fire protection system piping is presented in this section. The approach taken for this system is to update the service data developed in Reference [1], which was based on service experience at 34 plants and 851 reactor years from 1970 to 12-31-2005. The results presented here are for the same 34 plants and service experience through 3-31-2009 which adds 144.4 reactor years of service data for a total of 965.5 reactor years. While this is somewhat less than that used to develop the estimates for the service water systems, it is more than adequate to establish a valid statistical basis. The pipe lengths for 3 categories of fire protection system pipe sizes are the same as those from Reference [1] and are listed in Table 4-1.

Table B-2 Pipe Lengths Used to Establish Fire Protection System Exposure

\begin{tabular}{|c|c|}
\hline Nominal Pipe Size (NPS) & $\begin{array}{c}\text { Pipe Length per Reactor } \\
{[\mathrm{ft}]}\end{array}$ \\
\hline NPS $\leq 4$ " (sprinkler supply, hose stations) & 3,012 \\
\hline 4" $<$ NPS $\leq 6$ " (risers) & 1,920 \\
\hline NPS $>$ 6" (header piping) & 1,390 \\
\hline Totals: & 6,322 \\
\hline
\end{tabular}

The service data with pipe failures in the Fire Protection System is summarized in Table B-25 in terms of failure mode, pipe size category and failure mechanism. In comparison with the service data reported in Reference [1], this data exhibits a somewhat higher frequency in pipe failures and the number of significant rupture events has increased from 1 (Columbia water hammer event) to 3 . A total of 20 of the 138 observed piping system failures, including the Columbia event were due to water hammer. 
Table B-25 Fire Protection System Failure Counts by Failure Mode, Pipe Size and Failure Mechanism

\begin{tabular}{|c|c|c|c|c|c|c|}
\hline \multirow{2}{*}{$\begin{array}{c}\text { Pipe } \\
\text { Diameter } \\
\text { [inch] }\end{array}$} & \multirow{2}{*}{$\begin{array}{c}\text { Failure / Degradation } \\
\text { Mechanism }\end{array}$} & \multicolumn{5}{|c|}{ Number of Failure Records (as of 03-31-2009) } \\
\hline & & All & $\begin{array}{l}\text { Wall } \\
\text { Thinning }\end{array}$ & $\begin{array}{l}\text { Pinhole } \\
\text { Leak }\end{array}$ & Leak & MSF $^{[\text {Note 1] }}$ \\
\hline \multirow{7}{*}{ NPS $\leq 4 "$} & Corrosion & 24 & 0 & 23 & 1 & 0 \\
\hline & Design and Construction Errors & 6 & 0 & 3 & 2 & 1 \\
\hline & Erosion Corrosion & 1 & 0 & 1 & 0 & 0 \\
\hline & Erosion-Cavitation & 0 & 0 & 0 & 0 & 0 \\
\hline & Water Hammer & 0 & 0 & 0 & 0 & 0 \\
\hline & Vibration fatigue & 4 & 0 & 2 & 2 & 0 \\
\hline & NPS $\leq 4 "$ Totals: & 35 & 0 & 29 & 5 & 1 \\
\hline \multirow{7}{*}{$\begin{array}{c}4<\underset{6 "}{\text { NPS }} \leq \\
6 "\end{array}$} & Corrosion & 19 & 3 & 12 & 3 & 1 \\
\hline & Design and Construction Errors & 3 & 0 & 2 & 1 & 0 \\
\hline & Erosion Corrosion & 2 & 0 & 2 & 0 & 0 \\
\hline & Erosion-Cavitation & 1 & 0 & 1 & 0 & 0 \\
\hline & Water Hammer & 3 & 0 & 0 & 3 & 0 \\
\hline & Vibration fatigue & 1 & 0 & 0 & 1 & 0 \\
\hline & $4<$ NPS $\leq 6 "$ Totals: & 29 & 3 & 17 & 8 & 1 \\
\hline \multirow{7}{*}{ NPS > 6" } & Corrosion & 49 & 11 & 33 & 5 & 0 \\
\hline & Design and Construction Errors & 5 & 0 & 3 & 2 & 0 \\
\hline & Erosion Corrosion & 3 & 0 & 3 & 0 & 0 \\
\hline & Erosion-Cavitation & 0 & 0 & 0 & 0 & 0 \\
\hline & Water Hammer & 17 & 0 & 2 & 14 & 1 \\
\hline & Vibration fatigue & 0 & 0 & 0 & 0 & 0 \\
\hline & NPS > 6" Totals: & 74 & 11 & 41 & 21 & 1 \\
\hline & System Totals: & 138 & 14 & 87 & 34 & 3 \\
\hline
\end{tabular}

\subsubsection{Conditional Probability of Pipe Rupture Given Failure for FP}




\subsubsection{Use of the Beta Distribution to Model Conditional Rupture Probabilities}

The likelihood of a through-wall flaw propagating to a significant structural failure is expressed by the conditional failure probability $P_{i k}\left\{R_{x} \mid F\right\}$ that was defined in Section 2 in Equation (B.1). It is determined from service experience with pipe failures, insights from data analyses of service experience, and engineering judgment, with the uncertainty treated using the Beta Distribution.

The Beta Distribution takes on values between 0 and 1 and is defined by two parameters, $A$ and B (some texts refer to these as "Alpha" and "Beta"). It is often used to express the uncertainty in the estimation of dimensionless probabilities such as MGL common cause parameters and failure rates per demand. The mean of the Beta Distribution is given by:

$$
\text { Mean }=\frac{A}{A+B}
$$

If $A=B=1$, the beta distribution takes on a flat distribution between 0 and 1 . If $A=B=1 / 2$, the distribution is referred to as a Jeffery's non-informative prior and is a $U$ shaped distribution with peaks at 0 and 1 . Expert opinion can be incorporated by selecting $A$ and $B$ to match up with an expert estimate of the mean probability. For example, to represent an expert estimate of $10^{-2}$, $A=1$ and $B=99$ can be selected. These abstract parameters $A$ and $B$ can be associated with the number of failures and the number of successes in examining service data to estimate a failure probability on demand. $A+B$ represents the number of trials.

The beta distribution has some convenient and useful properties for use in Bayes' updating. A prior distribution can be assigned by selecting the initial parameters for $A$ and $B$, denoted as $A_{\text {Prior }}$ and $B_{\text {Prior. }}$ Then when looking at the service data, if there are $N$ failures and $M$ successes observed, the Bayes updated or posterior distribution is also a Beta distribution with the following parameters:

$$
\begin{aligned}
& A=A_{\text {Prior }}+N \\
& B=B_{\text {Prior }}+M
\end{aligned}
$$

The above explains how the Beta distribution is used in this study to estimate conditional rupture probabilities. The priors are selected to represent engineering estimates of the probabilities "prior" to the collection of evidence. Equations (B.2) and (B.3) are used to compute the parameters of the Bayes' updated distribution after applying the results of the data queries to determine $\mathrm{N}$ and $\mathrm{M}$. N corresponds to the number of ruptures in the specified size range and $\mathrm{M}$ corresponds to the number of pipe failures that do not result in a rupture in the specified size range. In the earlier EPRI study [1], rupture sizes were expressed in terms of flood leak rates in gallons per minute from the pipe rupture. In this study the rupture severity is treated both in terms of leak rates and equivalent break size as explained more fully in Section 4.1.3.2 below.

A review of service data provides some insights about the conditional pipe failure probability for different types of piping systems. Figure B-1 shows the conditional failure probability for different, observed through-wall flow rate threshold values based on the service data compiled in the PIPExp Database (See Appendix A). This information is presented to help justify the prior distribution parameters $A$ and $B$ selected for this analysis as explained more fully in the next section. 


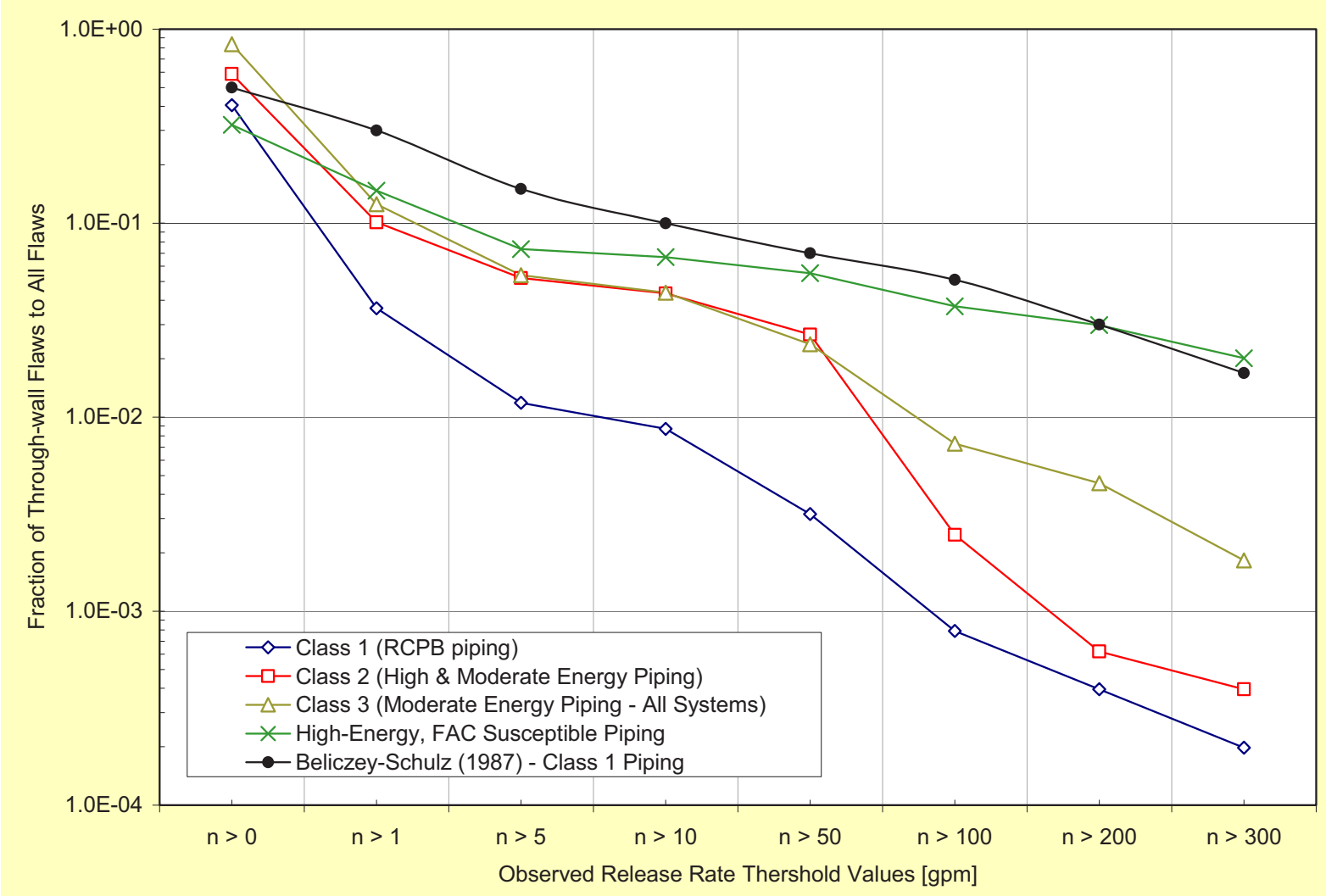
Figure B-11 Empirical Conditional Probability of Pipe Failure as a Function of
Type of Piping System \& Through-Wall Flow Rate Threshold Value

\subsubsection{Prior Distribution for Conditional Rupture Probabilities}

The approach for developing a prior distribution for conditional rupture probabilities that is used in this report was developed in References [1] through [4]. The approach is first explained using the example of service water system piping and based on this explanation, the approach is applied to the piping systems analyzed in this report.

In the earlier EPRI study of Reference [1], the prior distribution for service water system pipe ruptures was developed based on information presented in Figure B-11 for three discreet sizes of pipe ruptures as shown in the following table:

Conditional Rupture Model from Reference [1]

\begin{tabular}{|c|c|}
\hline Rupture Mode & $\begin{array}{l}\text { Rupture Leak Rate } \\
\text { (gpm) }\end{array}$ \\
\hline
\end{tabular}

Spray
.1
Flood Rate per Figure 3-1 for Class 3 Systems

\footnotetext{
${ }^{2}$ Plotted in the figure are the conditional probabilities of leak flow rates given pipe failure as estimated by the fraction of the pipe failures in the failure data population with the indicated leak flow rate. RCPB stands for Reactor Coolant System Pressure Boundary
} 


$\begin{array}{cccc}\text { Flood } & 100 \text { to } 2,000 & .01 & >90 \\ \text { Major Flood } & >2,000 & .001 & >300\end{array}$

The conditional rupture probability model used in the EPRI study is very conservative in the sense that the probability is assumed to be fixed over the entire range of the leak rates for each rupture mode. By contrast the service data supports a more realistic model in which the conditional failure probability is a continuously decreasing function of increasing flood rate. Such a more realistic model is shown in Figure B-12 in comparison with the original EPRI model and is adopted for use in the current study.

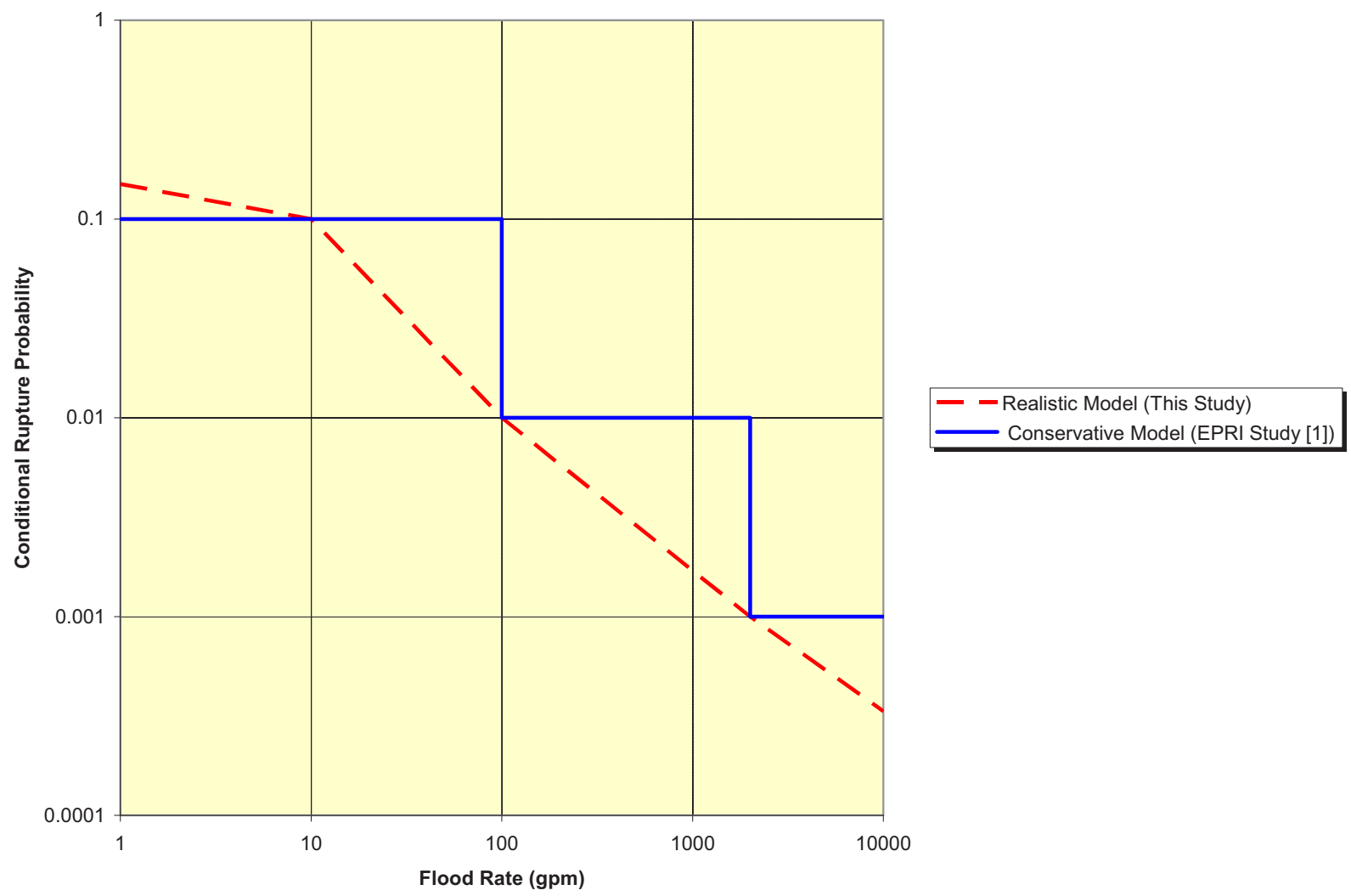

Figure B-12 Continuous vs. Discrete Model for Prior Conditional Rupture Probability

The next step in the model development is to convert from flood rates to equivalent break size. This is done for several reasons. First, it should be recognized that the original selection of flood rate was simply a figure of merit for measuring the severity of the pipe break. The actual flood rate from a given pipe break is a function of the break size and location and the system characteristics such as system pressure, pump characteristics, and the steps that might be taken to mitigate or terminate the flood. Second, the original EPRI method did not consider variations of the failure rate and severity of the break within the three rupture modes. Break size would appear a better way to standardize the definition of the pipe break severity. Insights that support this view were developed from recent studies to evaluate pipe rupture frequencies for high energy line breaks in the turbine building at Kewaunee [2] and Prairie Island [3]. Regardless of the method used to characterize the flood initiating event, it is necessary to perform plant and system specific analyses to determine the actual flood volumes. By using 
equivalent break size (EBS), which is defined as an equivalent circular opening in the piping system with a specified diameter, plant specific calculations on flood rates and volumes can easily be performed. The flood rate, $Q(\mathrm{gpm})$, from a pipe failure with EBS of $D$ (diameter of break in inches) and a system pressure of $P$ (psig) can be estimated using [28] :

$$
Q=29.9 \cdot D^{2} \cdot \sqrt{P}
$$

For service water systems, the size of the largest piping is typically NPS 24" (inside diameter of 24"). A complete double ended guillotine rupture of a 24" pipe would have an equivalent break size of $24^{*} 2^{0.5}=34$ inches $^{3}$. Hence, for the largest pipe size of 24 " we need to cover a range of break sizes up to 34". Converting the flood rate based model in Figure B-12 to an Equivalent Break Size based model using Equation (B.4) and a system pressure of 70 psig yields the model in Figure B-13 which is used in this study to set the prior distributions for the conditional rupture model probabilities. This curve is in excellent agreement with data from NUREG-1860 data for Class 1 piping systems and is consistent with but more realistic than the model used in the EPRI report [1]. The key points on this curve and its relationship to flow rates are listed in

\section{Table B-4.}

The conditional probability of pipe rupture given pipe failure was developed using the same approach as used for the service water systems. The priors developed in Reference [1] were converted to equivalent break size (EBS.) using Equation (B.4) and an assumed system pressure of 100 psig. The resulting prior distribution with its comparison to that developed for Class 3 service water and the discrete points from Reference [1] converted to EBS is shown in Figure B-14. As seen in comparison to the one developed for Class 3 Service Water a much higher probability is assigned to severe pipe ruptures consistent with the treatment in the EPRI study [1]. The events in Table B-25 involving leaks and ruptures were reviewed for flow rate and break size information. None of the pinhole leaks were found to have a measurable leak rate so they were assigned to the smallest leak rate category. Each of the 3 ruptures was found to have a break size on the order of the size of the pipe. The 34 leaks were estimated and converted to EBS. As with the treatment of SW the Beta Distribution were converted to lognormals to reflect greater uncertainty in the larger break size categories. The data used to estimate the conditional rupture mode probabilities for a base case of FP piping with water hammer events included is presented in Table B-5.

\section{Table B-4 Comparison of Flood Rates, EBS, and Conditional Probabilities for SW Prior} Distributions

\begin{tabular}{|r|r|c|l|}
\hline $\begin{array}{c}\text { Leak Flow } \\
\text { Rate } \\
\text { @70pote 1] }\end{array}$ & EBS (in.) & $\begin{array}{c}\text { Conditional } \\
\text { Rupture } \\
\text { Mode } \\
\text { Probability }\end{array}$ & EBS Reference \\
\hline 0.025 & 0.01 & 0.2 & $\begin{array}{l}\text { Based on a generic estimate of the } \\
\text { fraction of pipe failures involving }\end{array}$ \\
\hline
\end{tabular}

\footnotetext{
${ }^{3}$ This formula is easily derived by calculating the area of a single circle with diameter D which is equal to area of two circles with the diameter of the pipe corresponding to the flow area of a double ended break.
} 


\begin{tabular}{|r|r|c|l|}
\hline & & & through wall leaks or greater \\
\hline 1.0 & 0.063 & 0.1 & EPRI Lower bound of Spray \\
\hline 2.5 & 0.10 & 0.06 & Decade marker \\
\hline 100 & 0.32 & 0.021 & Half-decade marker \\
\hline 250 & 0.63 & 0.01 & EPRI Lower bound of flood \\
\hline 2,000 & 2.00 & $5.0 \mathrm{E}-03$ & Decade marker \\
\hline 2,502 & 3.16 & $8.0 \mathrm{E}-04$ & Half decade marker \\
\hline 8,014 & 5.66 & $4.0 \mathrm{E}-04$ & EBS for DEGB of NPS 4" pipe \\
\hline 25,016 & 10.00 & $1.8 \mathrm{E}-04$ & Decade marker \\
\hline 50,017 & 14.14 & $1.1 \mathrm{E}-04$ & EBS for DEGB of NPS 10" pipe \\
\hline 250,161 & 31.62 & $3.8 \mathrm{E}-05$ & Half Decade marker \\
\hline 288,186 & 33.94 & $3.3 \mathrm{E}-05$ & EBS for DEGB of NPS 24" pipe \\
\hline $\begin{array}{r}\text { Note 1. Calculated using Equation (4.4). Actual leak flow rates would be dependent on } \\
\text { system hydraulics and pump characteristics }\end{array}$ \\
\hline
\end{tabular}




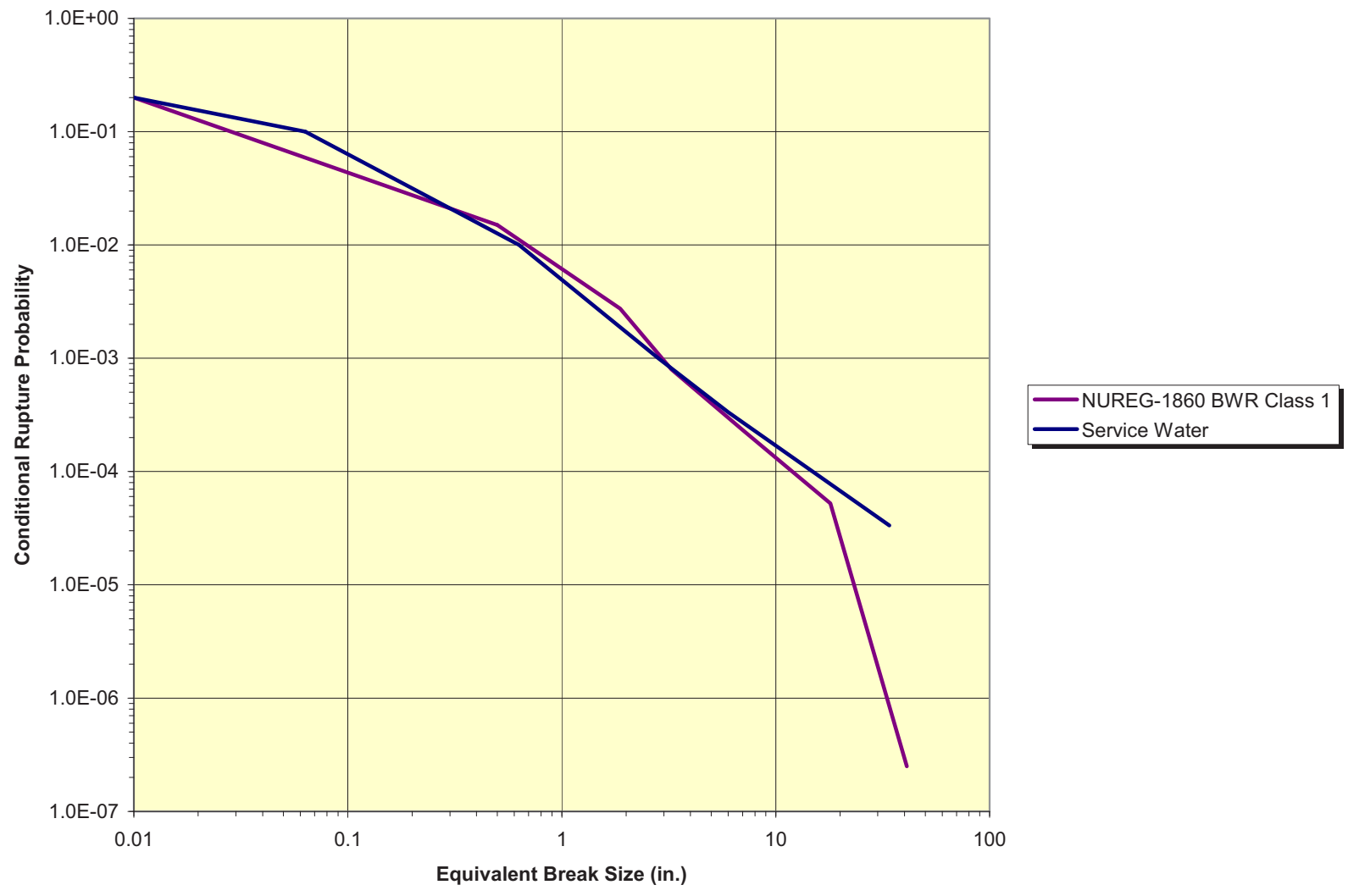

Figure B-13 Conditional Rupture Size Probability Model for 24" Service Water Pipe and Comparison to NUREG-1860 Data

In addition to the base case, another case was defined to evaluate the effects of design modifications, such as those made at Columbia Nuclear Generating Station [4], to eliminate the susceptibility of FP piping system components to water hammer. This was done by screening out all the events involving water hammer in the failure rate estimation as well as in the conditional rupture probability data. The revised data for the conditional rupture probability after screening out water hammer is shown in Table B-6 . 


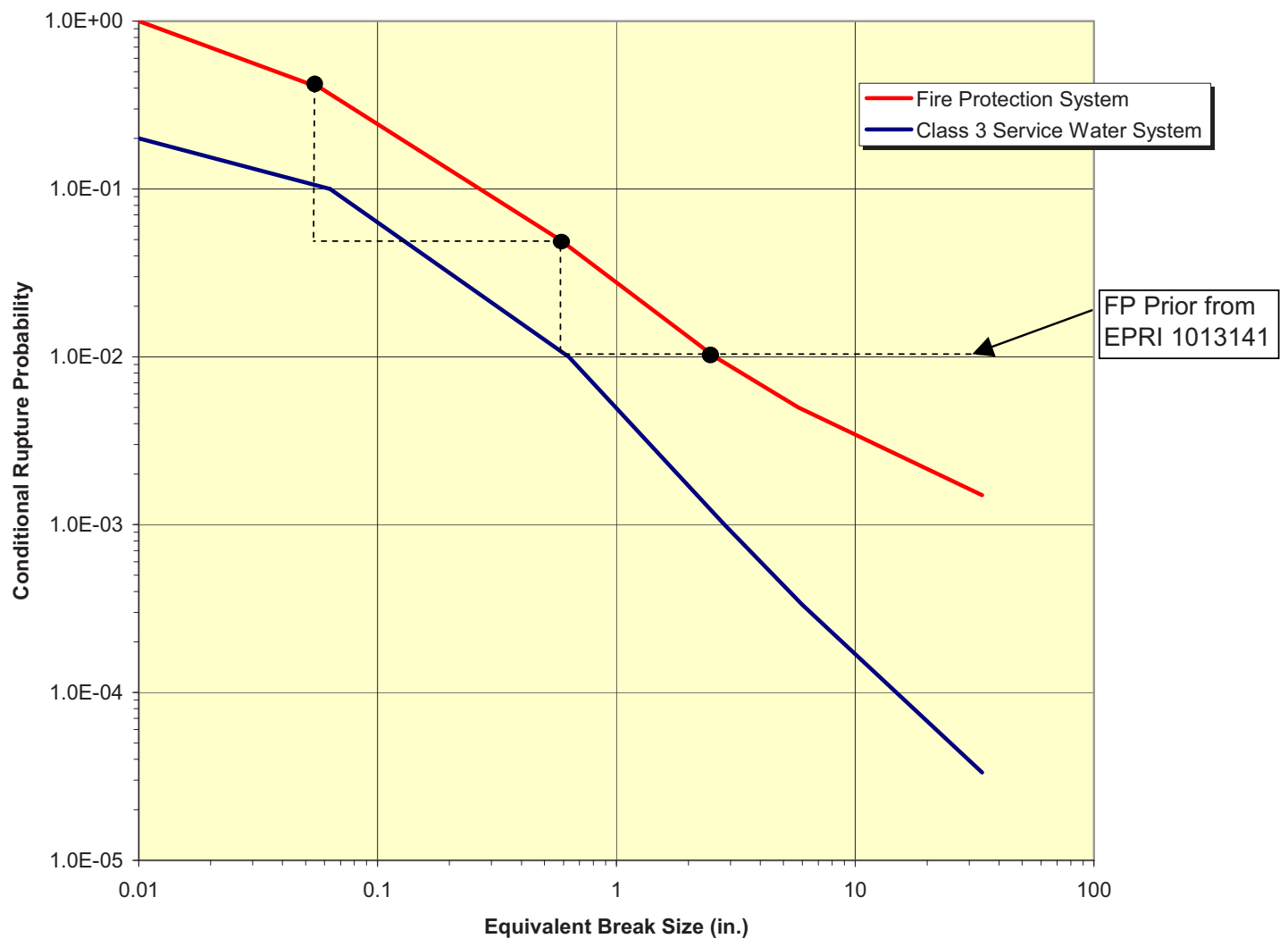

Figure B-14 Prior Distribution for Conditional Probability of FP System Rupture Given Failure for Pipe Size 24" 
Table B-5 Bayes' Update of Conditional Rupture Mode Probabilities For FP Base Case with Water Hammer Events Included

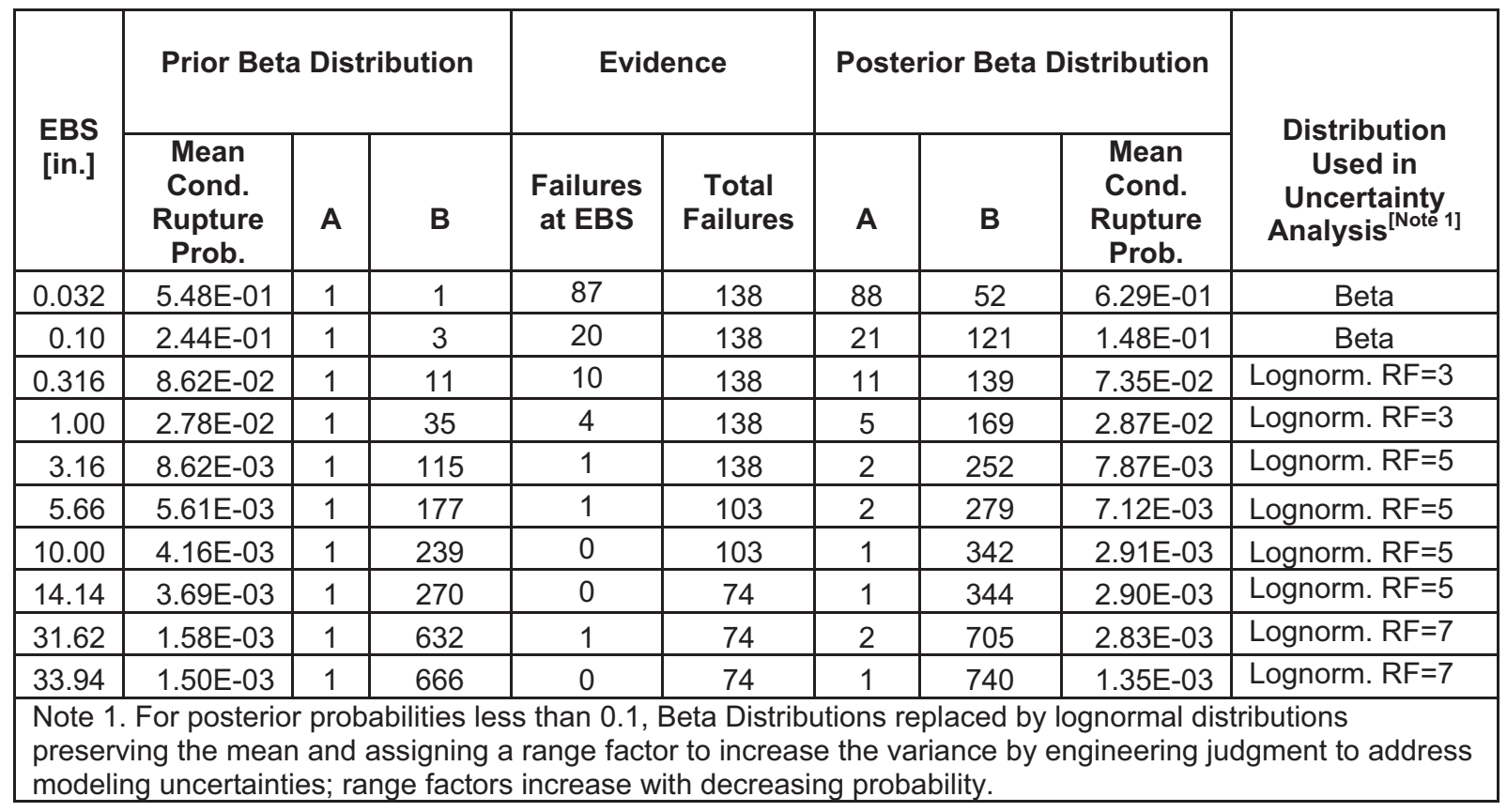

Table B-6 Bayes' Update of Conditional Rupture Mode Probabilities For FP With Water Hammer Events Excluded

\begin{tabular}{|c|c|c|c|c|c|c|c|c|c|}
\hline \multirow{2}{*}{$\begin{array}{l}\text { EBS } \\
\text { [in.] }\end{array}$} & \multicolumn{3}{|c|}{ Prior Distribution } & \multicolumn{2}{|c|}{ Evidence } & \multicolumn{3}{|c|}{ Posterior Distribution } & \multirow[b]{2}{*}{$\begin{array}{l}\text { Distribution } \\
\text { Used in } \\
\text { Uncertainty } \\
\text { Analysis }^{[\text {Note 1] }}\end{array}$} \\
\hline & $\begin{array}{l}\text { Mean } \\
\text { Cond. } \\
\text { Rupture } \\
\text { Prob. } \\
\end{array}$ & A & B & $\begin{array}{c}\text { Failures } \\
\text { at EBS }\end{array}$ & $\begin{array}{c}\text { Total } \\
\text { Failures }\end{array}$ & A & B & $\begin{array}{l}\text { Mean } \\
\text { Cond. } \\
\text { Rupture } \\
\text { Prob. } \\
\end{array}$ & \\
\hline 0.032 & $5.48 \mathrm{E}-01$ & 1 & 1 & 85 & 118 & 86 & 34 & 7.18E-01 & Beta \\
\hline 0.10 & 2.44E-01 & 1 & 3 & 14 & 118 & 15 & 107 & $1.23 \mathrm{E}-01$ & Beta \\
\hline 0.316 & 8.62E-02 & 1 & 11 & 3 & 118 & 4 & 126 & 3.09E-02 & Lognorm. RF=3 \\
\hline 1.00 & 2.78E-02 & 1 & 35 & 1 & 118 & 2 & 152 & 1.30E-02 & Lognorm. RF=3 \\
\hline 3.16 & 8.62E-03 & 1 & 115 & 1 & 118 & 2 & 232 & 8.55E-03 & Lognorm. RF=5 \\
\hline 5.66 & 5.61E-03 & 1 & 177 & 0 & 83 & 1 & 260 & 3.83E-03 & Lognorm. RF=5 \\
\hline 10.00 & 4.16E-03 & 1 & 239 & 0 & 83 & 1 & 322 & 3.09E-03 & Lognorm. RF=5 \\
\hline 14.14 & 3.69E-03 & 1 & 270 & 0 & 57 & 1 & 327 & 3.05E-03 & Lognorm. RF=5 \\
\hline 31.62 & $1.58 \mathrm{E}-03$ & 1 & 632 & 0 & 57 & 1 & 689 & 1.45E-03 & Lognorm. RF=7 \\
\hline 33.94 & $1.50 \mathrm{E}-03$ & 1 & 666 & 0 & 57 & 1 & 723 & 1.38E-03 & Lognorm. RF=7 \\
\hline
\end{tabular}




\subsubsection{Estimates of Failure Rates and Rupture Frequencies}

\subsubsection{Baseline Results}

The results were developed using the methodology presented in Section 2. A summary of the results for the pipe rupture exceedance frequency, i.e. frequency of pipe ruptures equal to or greater than an equivalent break size (EBS), is shown in Figure 4-1 for a FP system header with assumed NPS of 24" for three cases: the results of the current study with and without the design features to protect against water hammer, and the results from the earlier EPRI study [1]. These results reflect several differences relative to the earlier EPRI study, including an increase in the rupture frequency for EBS up to several inches due to an observed increase in the frequency of FP failures and ruptures in the service data in last hundred reactor-years of experience since 2004, perhaps due to aging or improvements in the event reporting systems. There are significant reductions in pipe rupture frequency due to the design features to limit the contribution of water hammer, but since water hammer is only a significant but not a dominant failure mechanism, these improvements are not as dramatic as perhaps might be expected. [Note: The typical header size is NPS12 - i.e., the largest size FP pipe found in plants.]

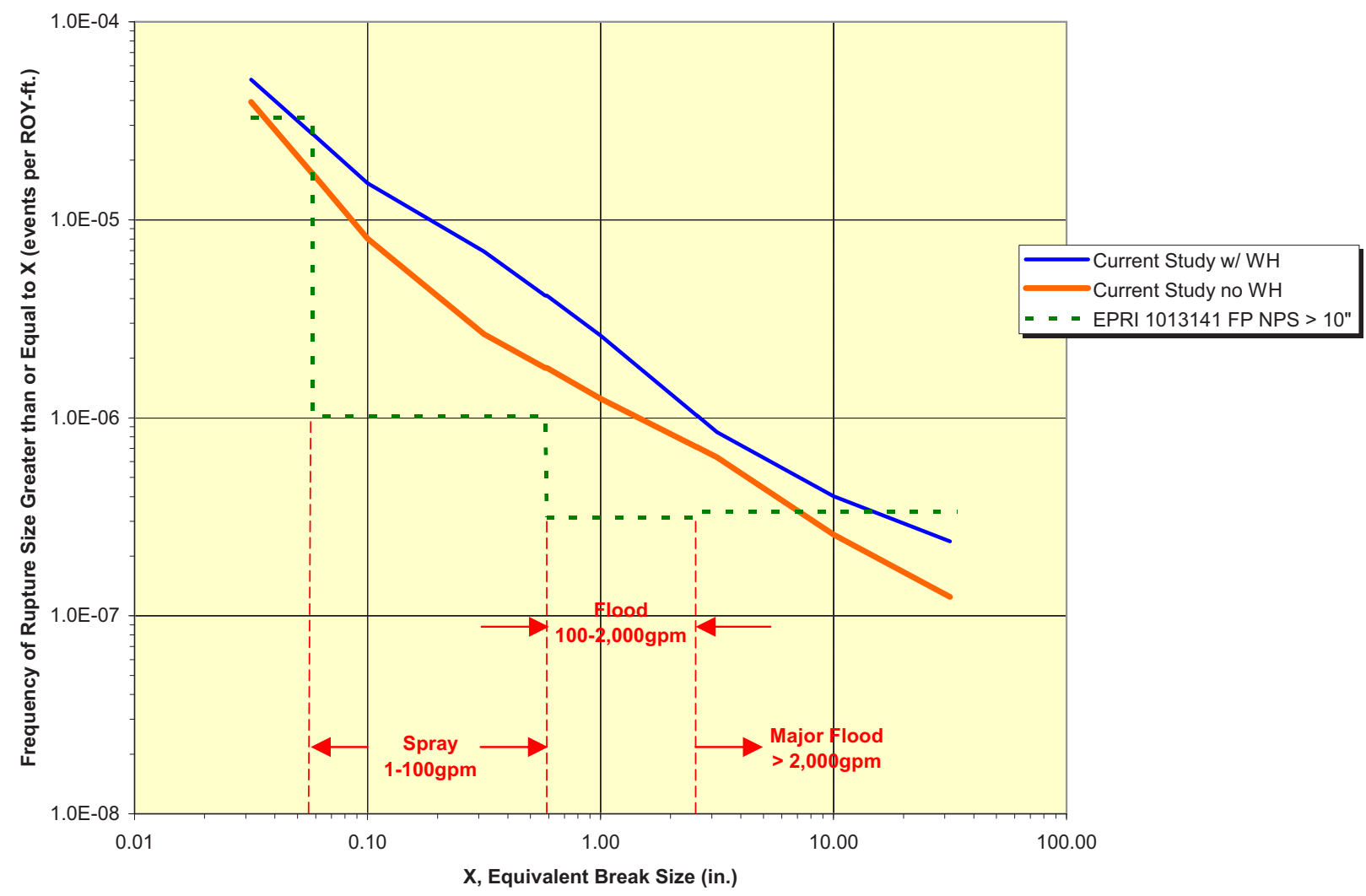

Figure B-15 Results for Rupture Frequency vs. Break Size for NPS 24" FP Header

As will be shown in the next section, very significant additional improvements can be realized by adding some leak inspections and/or volumetric NDE to the RIM program for the FP system. If there are already RIM strategies in the Columbia FP system beyond those reflected in the service data, those are not credited in this figure. 


\subsubsection{Results for Basic FP Design with No Protection Against Water-Hammer}

10.1.4Because few plants have design features to protect the FP system against remaining results presented for the FP system assume no such protection. The and cumulative rupture frequencies for FP system with no credit for water are presented in Table B-7, Table B-8, and Impact of Alternative Inspection and Surveillance Strategies for FP System

The impact of alternative inspection strategies to reduce the frequency of pipe rupture was evaluated using the Markov Model and selected results are shown in Table 4-4, and in Figure 4-3. Table 4-4 and show how varying the frequency of leak testing with and without additional NDE and a fixed $90 \%$ POD for both strategies change the Integrity Management factor. Table 4-6 shows how alternative POD with fixed frequencies of NDE (every 10 years) and leak testing (every quarter) impact the Integrity Management factor. These Integrity Management Factors are evaluated for the plant age of 32 years which corresponds to the average age of the plants in the service data. 
Table 4-3 for three pipe size categories: up to NPS4", between NPS4" and NPS6", and greater than NPS6". These include the mean values and uncertainty distribution parameters for selected break sizes. Plots of these results for pipe sizes of NPS 4", NPS 6", and NPS 24" pipes are shown in Figure B-16, Figure B-17, and Figure 4-2.

Table B-7 Failure Rates and Cumulative Rupture Frequencies for FP NPS 4" Pipe

\begin{tabular}{|c|c|c|c|c|c|c|}
\hline \multirow{2}{*}{\multicolumn{2}{|c|}{ Parameter }} & \multicolumn{5}{|c|}{ Frequency per ROY-ft. } \\
\hline & & Mean & $5 \%$ tile & $50 \%$ tile & $95 \%$ tile & $\mathrm{RF}^{[\text {Note 1] }}$ \\
\hline \multicolumn{2}{|c|}{ Failure Rate } & $1.23 \mathrm{E}-05$ & $7.45 \mathrm{E}-06$ & $1.14 \mathrm{E}-05$ & $2.27 \mathrm{E}-05$ & 1.74 \\
\hline \multirow{7}{*}{ 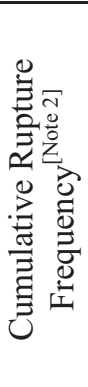 } & EBS (in.) & & & & & \\
\hline & 0.032 & $1.11 \mathrm{E}-05$ & $5.94 \mathrm{E}-06$ & $9.95 \mathrm{E}-06$ & $2.15 \mathrm{E}-05$ & 1.90 \\
\hline & 0.10 & $3.32 \mathrm{E}-06$ & $1.30 \mathrm{E}-06$ & $2.78 \mathrm{E}-06$ & $7.31 \mathrm{E}-06$ & 2.37 \\
\hline & 0.316 & $1.50 \mathrm{E}-06$ & $3.24 \mathrm{E}-07$ & $1.10 \mathrm{E}-06$ & $3.96 \mathrm{E}-06$ & 3.49 \\
\hline & 1.00 & $5.65 \mathrm{E}-07$ & $1.08 \mathrm{E}-07$ & $3.97 \mathrm{E}-07$ & $1.57 \mathrm{E}-06$ & 3.80 \\
\hline & 3.16 & $1.84 \mathrm{E}-07$ & $2.03 \mathrm{E}-08$ & $1.08 \mathrm{E}-07$ & $5.86 \mathrm{E}-07$ & 5.37 \\
\hline & 5.66 & $8.74 \mathrm{E}-08$ & $9.63 \mathrm{E}-09$ & $5.11 \mathrm{E}-08$ & $2.79 \mathrm{E}-07$ & 5.38 \\
\hline
\end{tabular}

Note $1 . \mathrm{RF}=(95 \% \text { tile } / 5 \% \text { tile })^{0.5}$; These distributions can be approximated as lognormal distributions with the indicated mean and the calculated range factor (RF)

Note 2. Frequency of pipe rupture with EBS equal to or greater than indicated EBS value 


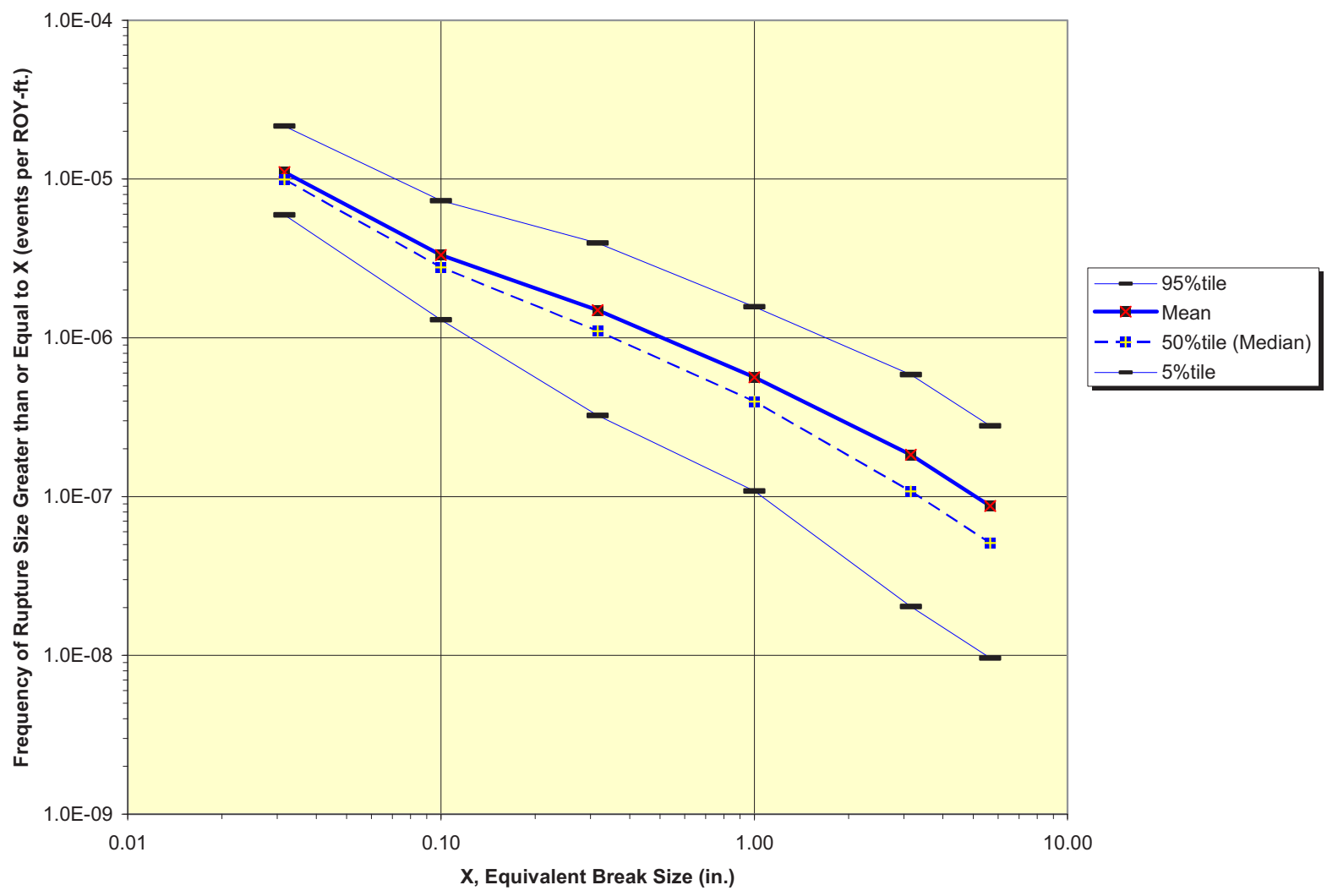

Figure B-16 Cumulative Pipe Rupture Frequency for FP NPS 4"

Table B-8 Pipe Failure Rates and Cumulative Rupture Frequencies for FP NPS 6"

\begin{tabular}{|c|c|c|c|c|c|c|}
\hline \multirow{2}{*}{\multicolumn{2}{|c|}{ Parameter }} & \multicolumn{5}{|c|}{ Frequency per ROY-ft. } \\
\hline & & Mean & $5 \%$ tile & $50 \%$ tile & $95 \%$ tile & $\mathrm{RF}^{[\text {Note 1] }}$ \\
\hline \multicolumn{2}{|c|}{ Failure Rate } & $1.59 \mathrm{E}-05$ & $9.53 \mathrm{E}-06$ & $1.47 \mathrm{E}-05$ & 2.93E-05 & 1.75 \\
\hline \multirow{7}{*}{ 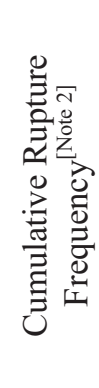 } & EBS (in.) & & & & & \\
\hline & 0.032 & $1.43 \mathrm{E}-05$ & $7.59 \mathrm{E}-06$ & $1.28 \mathrm{E}-05$ & $2.77 \mathrm{E}-05$ & 1.91 \\
\hline & 0.10 & 4.24E-06 & $1.66 \mathrm{E}-06$ & $3.55 \mathrm{E}-06$ & $9.32 \mathrm{E}-06$ & 2.37 \\
\hline & 0.316 & $1.87 \mathrm{E}-06$ & $4.10 \mathrm{E}-07$ & $1.39 \mathrm{E}-06$ & 4.94E-06 & 3.47 \\
\hline & 1.00 & $6.65 \mathrm{E}-07$ & $1.32 \mathrm{E}-07$ & 4.74E-07 & $1.82 \mathrm{E}-06$ & 3.72 \\
\hline & 3.16 & $1.71 \mathrm{E}-07$ & $1.89 \mathrm{E}-08$ & $1.01 \mathrm{E}-07$ & $5.50 \mathrm{E}-07$ & 5.40 \\
\hline & 8.49 & 4.64E-08 & $5.11 \mathrm{E}-09$ & 2.72E-08 & $1.49 \mathrm{E}-07$ & 5.39 \\
\hline \multicolumn{7}{|c|}{$\begin{array}{l}\text { Note } 1 . \mathrm{RF}=(95 \% \text { tile } / 5 \% \text { tile })^{0.5} \text {; These distributions can be approximated as lognormal distributions } \\
\text { with the indicated mean and the calculated range factor }(\mathrm{RF})\end{array}$} \\
\hline \multicolumn{7}{|c|}{ Note 2. Frequency of pipe rupture with EBS equal to or greater than indicated EBS value } \\
\hline
\end{tabular}




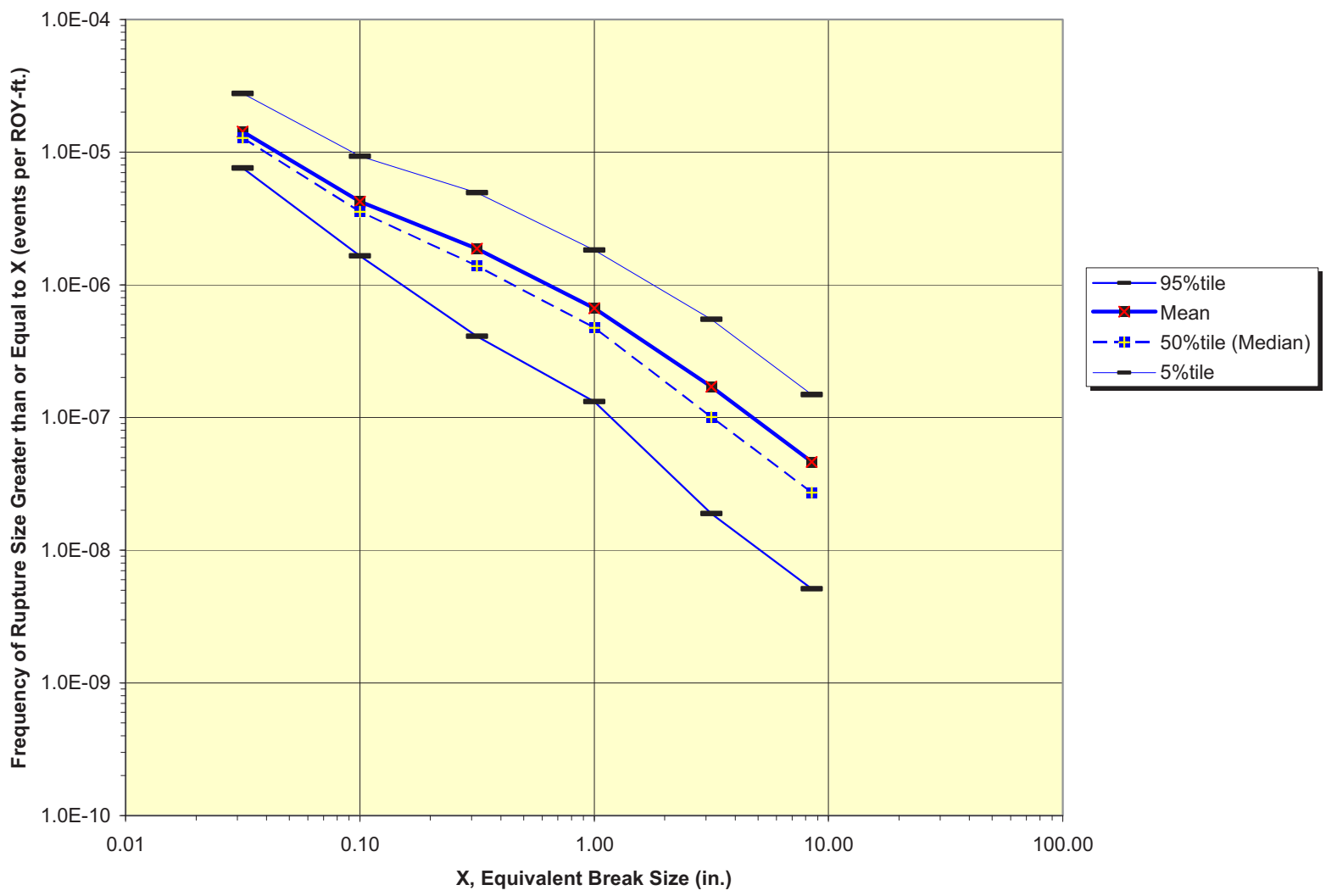

Figure B-17 Cumulative Pipe Rupture Frequency for FP NPS 6”

Table B-9 Failure Rates and Cumulative Rupture Frequencies for FP NPS 24"

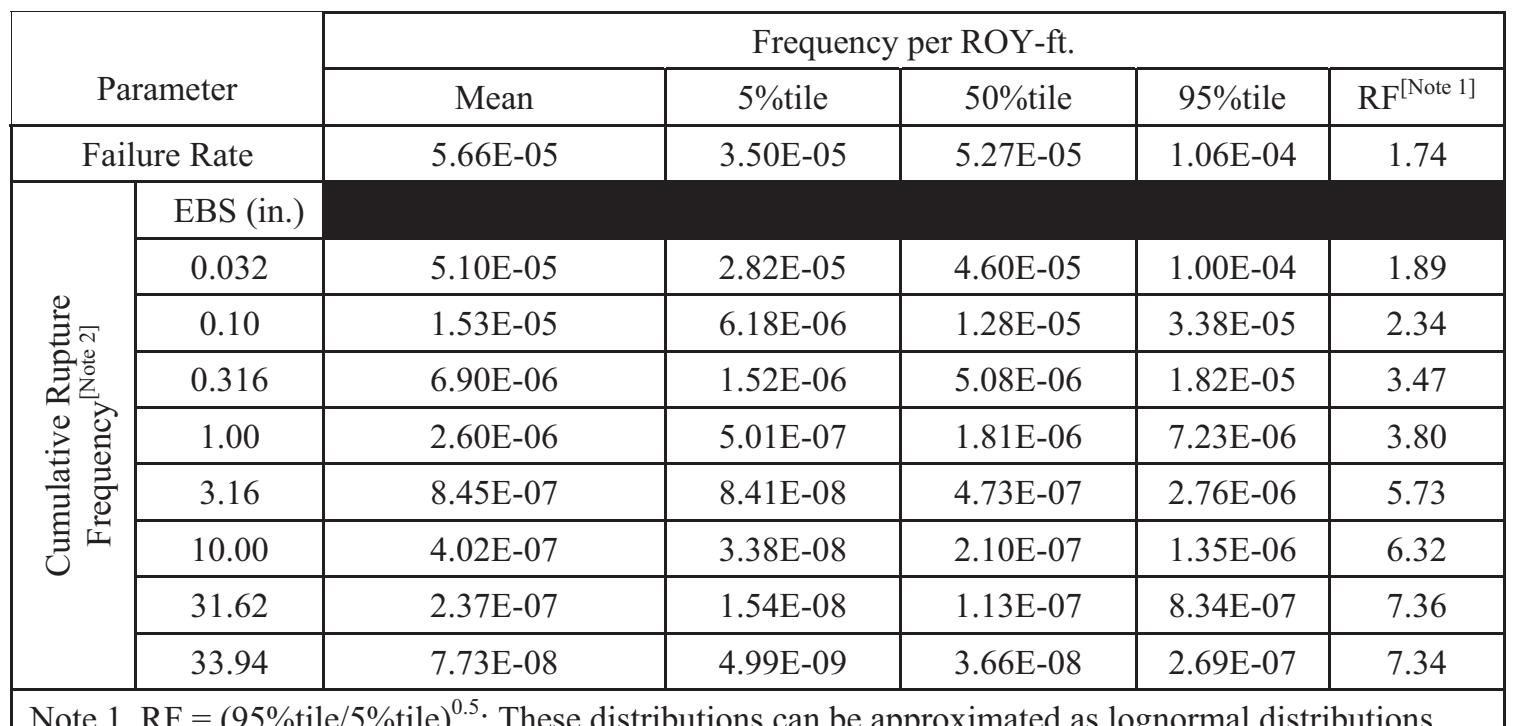


with the indicated mean and the calculated range factor $(\mathrm{RF})$

Note 2. Frequency of pipe rupture with EBS equal to or greater than indicated EBS value

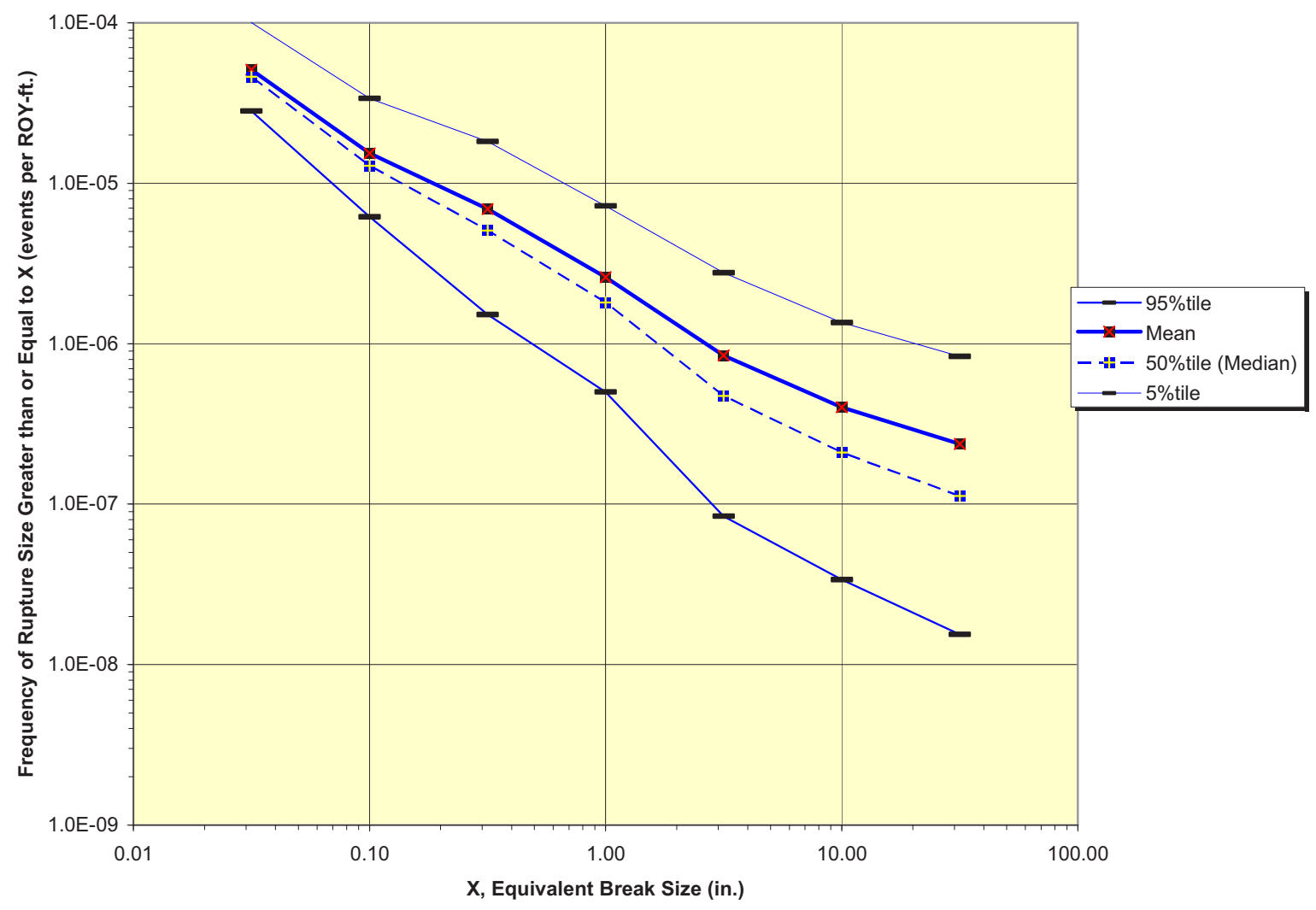

Figure B-18 Cumulative Pipe Rupture Frequency for FP NPS 24"

\subsubsection{Impact of Alternative Inspection and Surveillance Strategies}

The impact of alternative inspection strategies to reduce the frequency of pipe rupture evaluated using the Markov Model and selected results are shown in Table 4-4, 
Treatment of Passive Component Reliability in Risk-Informed Safety Margin Characterization

Table 4-5, and

B-31 
Table 4-6 and in Figure 4-3. Table 4-4 and 
Table 4-5 show how varying the frequency of leak testing with and without additional NDE and a fixed $90 \%$ POD for both strategies change the Integrity Management factor. 
Table 4-6 shows how alternative POD with fixed frequencies of NDE (every 10 years) and leak testing (every quarter) impact the Integrity Management factor. These Integrity Management Factors are evaluated for the plant age of 32 years which corresponds to the average age of the plants in the service data.

\section{Table B-10 Impact of Alternative Leak Detection Strategies to Reduce Fire Protection System Pipe Rupture Frequencies}

\begin{tabular}{|c|c|c|c|c|}
\hline \multirow{3}{*}{$\begin{array}{l}\text { Equivalent } \\
\text { Break Size } \\
\text { (in.) }\end{array}$} & \multicolumn{4}{|c|}{ No NDE with Variable Leak Testing Frequency } \\
\hline & \multirow[t]{2}{*}{$\begin{array}{l}\text { Base Rate } \\
\text { per ROY-ft. }\end{array}$} & \multicolumn{3}{|c|}{$\begin{array}{l}\text { Factor Reduction in Base Rate for } \\
\text { Periodic Leak Test @ 90\% POD }\end{array}$} \\
\hline & & Yearly & Quarterly & Weekly \\
\hline 0.032 & 3.57E-05 & 7.60E-01 & 7.34E-01 & 7.29E-01 \\
\hline 0.10 & 8.43E-06 & 4.60E-01 & 4.01E-01 & 3.89E-01 \\
\hline 0.32 & 4.30E-06 & 3.33E-01 & 2.61E-01 & 2.46E-01 \\
\hline 1.0 & 1.76E-06 & 2.21E-01 & $1.36 \mathrm{E}-01$ & 1.19E-01 \\
\hline 3.2 & 4.43E-07 & 1.47E-01 & $5.42 \mathrm{E}-02$ & 3.56E-02 \\
\hline 10 & $1.64 \mathrm{E}-07$ & $1.29 \mathrm{E}-01$ & 3.47E-02 & 1.56E-02 \\
\hline 31.6 & $1.60 \mathrm{E}-07$ & $1.24 \mathrm{E}-01$ & 3.44E-02 & $9.30 \mathrm{E}-03$ \\
\hline 34 & 7.73E-08 & 1.24E-01 & 2.84E-02 & 9.30E-03 \\
\hline
\end{tabular}

Table B-11 Impact of NDE and Alternative Leak Detection Strategies to Reduce Fire Protection System Pipe Rupture Frequencies

\begin{tabular}{|c|c|c|c|c|c|}
\hline \multirow{2}{*}{$\begin{array}{c}\text { Equivalent } \\
\text { Break Size } \\
\text { (in.) }\end{array}$} & \multicolumn{4}{|c|}{ NDE every 10 years at 90\% POD with Variable Leak Testing } \\
& $\begin{array}{c}\text { Base Rate } \\
\text { Frequency }\end{array}$ & \multicolumn{4}{|c|}{ Factor Reduction in Base Rate for Periodic Leak } \\
& per ROY-ft. & & Test @ 90\% POD \\
\cline { 2 - 6 } & & None & Yearly & Quarterly & Weekly \\
\hline 0.032 & $3.57 \mathrm{E}-05$ & $3.62 \mathrm{E}-01$ & $2.50 \mathrm{E}-01$ & $2.41 \mathrm{E}-01$ & $2.40 \mathrm{E}-01$ \\
\hline 0.10 & $8.43 \mathrm{E}-06$ & $4.03 \mathrm{E}-01$ & $1.52 \mathrm{E}-01$ & $1.32 \mathrm{E}-01$ & $1.28 \mathrm{E}-01$ \\
\hline
\end{tabular}




\begin{tabular}{|c|c|c|c|c|c|}
\hline 0.32 & $4.30 \mathrm{E}-06$ & $4.21 \mathrm{E}-01$ & $1.11 \mathrm{E}-01$ & $8.59 \mathrm{E}-02$ & $8.10 \mathrm{E}-02$ \\
\hline 1.0 & $1.76 \mathrm{E}-06$ & $4.36 \mathrm{E}-01$ & $7.42 \mathrm{E}-02$ & $4.49 \mathrm{E}-02$ & $3.93 \mathrm{E}-02$ \\
\hline 3.2 & $4.43 \mathrm{E}-07$ & $4.46 \mathrm{E}-01$ & $5.00 \mathrm{E}-02$ & $1.79 \mathrm{E}-02$ & $1.17 \mathrm{E}-02$ \\
\hline 10 & $1.64 \mathrm{E}-07$ & $4.49 \mathrm{E}-01$ & $4.42 \mathrm{E}-02$ & $1.15 \mathrm{E}-02$ & $5.15 \mathrm{E}-03$ \\
\hline 31.6 & $1.60 \mathrm{E}-07$ & $4.49 \mathrm{E}-01$ & $4.41 \mathrm{E}-02$ & $1.14 \mathrm{E}-02$ & $5.06 \mathrm{E}-03$ \\
\hline 34 & $7.73 \mathrm{E}-08$ & $4.50 \mathrm{E}-01$ & $4.24 \mathrm{E}-02$ & $9.41 \mathrm{E}-03$ & $3.06 \mathrm{E}-03$ \\
\hline
\end{tabular}


Table B-12 Integrity Management Factors for Various Combinations of NDE and Leak Inspections for Fire Protection System

\begin{tabular}{|c|c|c|c|c|c|c|c|}
\hline \multicolumn{8}{|c|}{ NO NDE with Quarterly Leak Testing and Variable Leak Testing POD } \\
\hline EBS & $\begin{array}{l}\text { No Leak } \\
\text { Test }\end{array}$ & $\mathrm{POD}=.50$ & $\mathrm{POD}=.60$ & $\mathrm{POD}=.70$ & $\mathrm{POD}=.80$ & $\mathrm{POD}=.90$ & $\mathrm{POD}=1.00$ \\
\hline 0.03 & $1.00 \mathrm{E}+00$ & 7.39E-01 & 7.37E-01 & 7.36E-01 & 7.35E-01 & 7.34E-01 & 7.33E-01 \\
\hline 0.10 & $1.00 \mathrm{E}+00$ & 4.12E-01 & 4.08E-01 & 4.05E-01 & 4.03E-01 & 4.01E-01 & 4.00E-01 \\
\hline 0.32 & $1.00 \mathrm{E}+00$ & 2.74E-01 & 2.69E-01 & 2.66E-01 & 2.63E-01 & 2.61E-01 & 2.59E-01 \\
\hline 1.00 & $1.00 \mathrm{E}+00$ & $1.52 \mathrm{E}-01$ & 1.46E-01 & $1.42 \mathrm{E}-01$ & 1.39E-01 & 1.36E-01 & 1.34E-01 \\
\hline 3.20 & $1.00 \mathrm{E}+00$ & 7.14E-02 & $6.50 \mathrm{E}-02$ & 6.04E-02 & 5.69E-02 & 5.42E-02 & $5.20 \mathrm{E}-02$ \\
\hline 10.00 & $1.00 \mathrm{E}+00$ & 5.22E-02 & 4.57E-02 & 4.10E-02 & 3.74E-02 & 3.47E-02 & $3.24 \mathrm{E}-02$ \\
\hline 31.60 & $1.00 \mathrm{E}+00$ & 5.19E-02 & 4.54E-02 & 4.07E-02 & $3.72 E-02$ & $3.44 \mathrm{E}-02$ & $3.22 E-02$ \\
\hline 34.00 & $1.00 \mathrm{E}+00$ & 4.61E-02 & $3.95 \mathrm{E}-02$ & $3.48 \mathrm{E}-02$ & $3.12 \mathrm{E}-02$ & 2.84E-02 & 2.62E-02 \\
\hline \multicolumn{8}{|c|}{ 10yr. NDE with $50 \%$ POD with Quarterly Leak Testing with Variable Leak Testing POD } \\
\hline EBS & $\begin{array}{l}\text { No Leak } \\
\text { Test }\end{array}$ & $\mathrm{POD}=.50$ & $\mathrm{POD}=.60$ & $\mathrm{POD}=.70$ & $\mathrm{POD}=.80$ & $\mathrm{POD}=.90$ & $\mathrm{POD}=1.00$ \\
\hline 0.03 & 5.31E-01 & 3.69E-01 & 3.69E-01 & 3.68E-01 & 3.67E-01 & 3.67E-01 & 3.67E-01 \\
\hline 0.10 & 5.69E-01 & 2.06E-01 & 2.04E-01 & 2.03E-01 & 2.01E-01 & 2.01E-01 & 2.00E-01 \\
\hline 0.32 & 5.85E-01 & $1.37 \mathrm{E}-01$ & 1.35E-01 & 1.33E-01 & 1.32E-01 & $1.30 \mathrm{E}-01$ & 1.30E-01 \\
\hline 1.00 & 5.99E-01 & 7.63E-02 & 7.33E-02 & $7.12 \mathrm{E}-02$ & $6.95 \mathrm{E}-02$ & 6.83E-02 & 6.73E-02 \\
\hline 3.20 & $6.09 E-01$ & $3.59 \mathrm{E}-02$ & $3.26 \mathrm{E}-02$ & 3.03E-02 & $2.85 E-02$ & $2.72 \mathrm{E}-02$ & 2.61E-02 \\
\hline 10.00 & 6.11E-01 & 2.63E-02 & $2.30 \mathrm{E}-02$ & 2.06E-02 & 1.88E-02 & 1.74E-02 & 1.63E-02 \\
\hline 31.60 & $6.11 \mathrm{E}-01$ & $2.62 E-02$ & $2.28 \mathrm{E}-02$ & $2.05 E-02$ & 1.87E-02 & 1.73E-02 & 1.61E-02 \\
\hline 34.00 & $6.12 \mathrm{E}-01$ & 2.32E-02 & 1.99E-02 & $1.75 \mathrm{E}-02$ & 1.57E-02 & 1.43E-02 & 1.31E-02 \\
\hline \multicolumn{8}{|c|}{ 10yr. NDE with $90 \%$ POD with Quarterly Leak Testing with Variable Leak Testing POD } \\
\hline EBS & \begin{tabular}{|l|} 
No Leak \\
Test
\end{tabular} & $\mathrm{POD}=.50$ & $\mathrm{POD}=.60$ & $\mathrm{POD}=.70$ & $\mathrm{POD}=.80$ & $\mathrm{POD}=.90$ & $\mathrm{POD}=1.00$ \\
\hline 0.03 & $3.62 \mathrm{E}-01$ & 2.43E-01 & 2.42E-01 & 2.42E-01 & 2.42E-01 & 2.41E-01 & $2.41 \mathrm{E}-01$ \\
\hline 0.10 & 4.03E-01 & 1.36E-01 & 1.34E-01 & 1.33E-01 & 1.33E-01 & $1.32 \mathrm{E}-01$ & 1.31E-01 \\
\hline 0.32 & 4.21E-01 & 9.04E-02 & 8.87E-02 & 8.75E-02 & 8.66E-02 & 8.59E-02 & 8.53E-02 \\
\hline 1.00 & 4.36E-01 & 5.02E-02 & 4.82E-02 & 4.68E-02 & 4.58E-02 & 4.49E-02 & 4.43E-02 \\
\hline 3.20 & 4.46E-01 & $2.37 \mathrm{E}-02$ & $2.15 \mathrm{E}-02$ & $2.00 \mathrm{E}-02$ & $1.88 \mathrm{E}-02$ & 1.79E-02 & 1.72E-02 \\
\hline 10.00 & 4.49E-01 & 1.74E-02 & 1.52E-02 & 1.36E-02 & $1.24 \mathrm{E}-02$ & $1.15 \mathrm{E}-02$ & 1.07E-02 \\
\hline 31.60 & 4.49E-01 & 1.73E-02 & $1.51 \mathrm{E}-02$ & 1.35E-02 & 1.23E-02 & 1.14E-02 & 1.06E-02 \\
\hline 34.00 & 4.50E-01 & 1.53E-02 & $1.31 \mathrm{E}-02$ & 1.15E-02 & 1.03E-02 & 9.41E-03 & 8.66E-03 \\
\hline
\end{tabular}

Depending on the break size pipe rupture frequency reductions of upwards of two orders of magnitude can be achieved in the pipe rupture frequency by periodic leak testing with a moderate to high probability of detection. As shown in Figure 4-3 it is seen that these strategies will more than offset the unexpected increases we found when updating the fire protection 
system failure rates to account for service data from 2004 to 2009 compared with the earlier EPRI report [1].

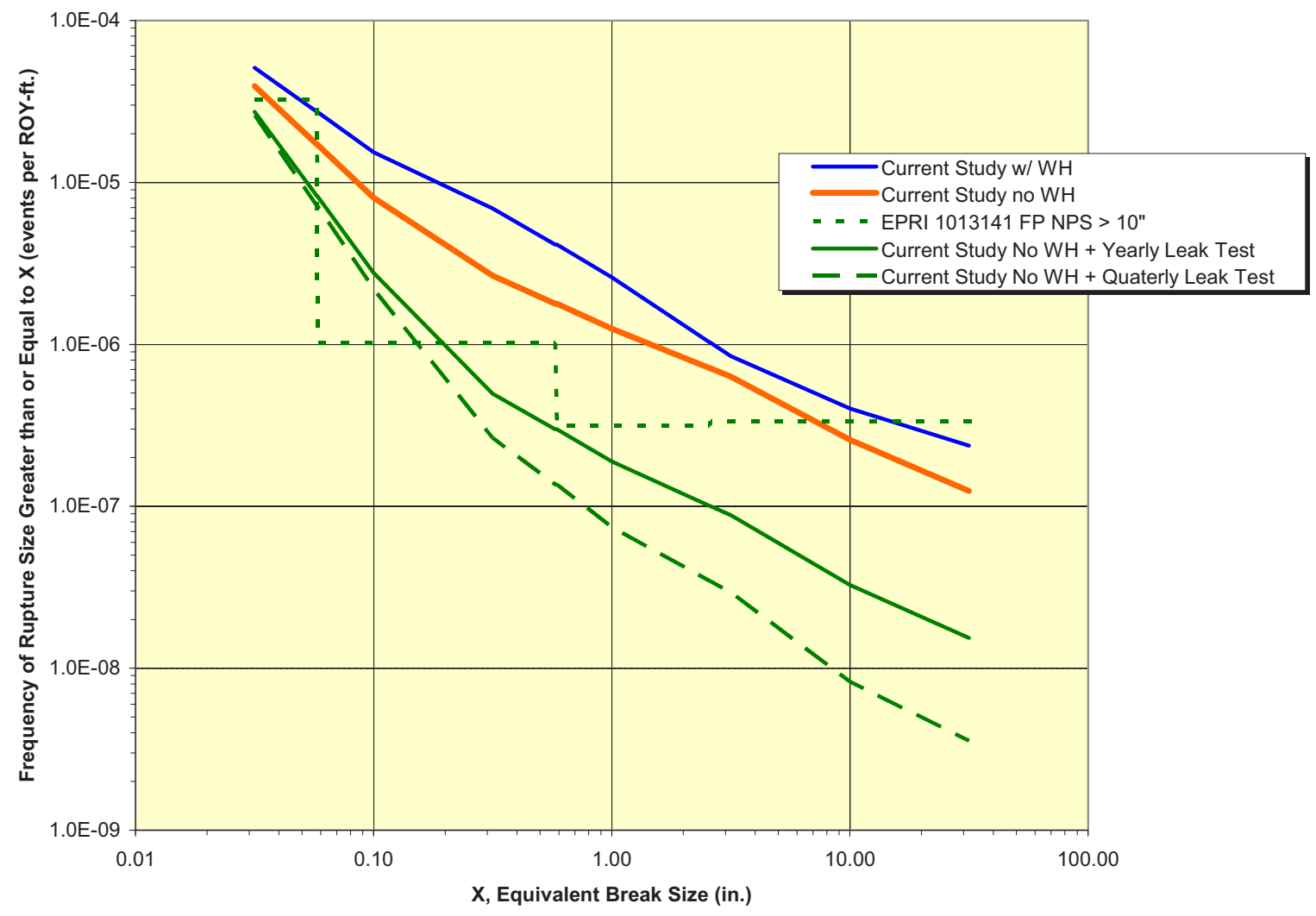

Figure B-19 Impact of Design and Inspection Strategies to Reduce the Frequency of Fire Protection Header Pipe Ruptures

\subsubsection{Impact of Plant Age on Estimated Failure Rates for FP System}

The impact of plant age on FP system pipe failure rates vs. EBS can be evaluated by using the expression in Equation 2.2 in which the hazard rate at various plant ages is normalized against that for a plant age of 32 years which corresponds to the average plant age of the plants that produced the service data used to estimate the base failure rates. The factor increase increases with increasing age and EBS. For the larger break sizes, the Markov model suggests that pipe rupture frequencies are expected to increase by a factor of 1.5 in the 8 years until $40 y r s$, a factor of 3 increase to $60 y$ rs., and a factor of 5 increase at age $80 y r s$. 
Table B-13 Factors To Account for Aging Effects on NPS 24" FP Header

\begin{tabular}{|c|c|c|c|c|c|}
\hline \multirow{2}{*}{\multicolumn{2}{|c|}{ Pipe Failure Mode }} & \multirow{2}{*}{$\begin{array}{l}\text { Base } \\
\text { Rates } \\
\text { (mean) }\end{array}$} & \multicolumn{3}{|c|}{$\begin{array}{l}I_{T} \text {, Factor Increase to Account } \\
\quad \text { for Aging at Time } T\end{array}$} \\
\hline & & & $\begin{array}{l}40 \\
\text { Years }\end{array}$ & $\begin{array}{c}60 \\
\text { Years }\end{array}$ & 80 Years \\
\hline \multicolumn{2}{|c|}{ All Failure Modes } & 5.66E-05 & 1.3 & 2.2 & 3.1 \\
\hline \multirow{8}{*}{ EBS (in.) } & 0.032 & 5.10E-05 & 1.3 & 2.2 & 3.1 \\
\hline & 0.10 & 1.53E-05 & 1.4 & 2.6 & 3.9 \\
\hline & 0.32 & 6.90E-06 & 1.4 & 2.7 & 4.2 \\
\hline & 1.0 & 2.60E-06 & 1.5 & 2.9 & 4.5 \\
\hline & 3.2 & 8.45E-07 & 1.5 & 3.0 & 4.7 \\
\hline & 10 & $4.02 E-07$ & 1.5 & 3.0 & 4.7 \\
\hline & 31.6 & 2.37E-07 & 1.5 & 3.0 & 4.7 \\
\hline & 34 & 7.73E-08 & 1.5 & 3.0 & 4.8 \\
\hline
\end{tabular}

A plot of the hazard rates for selected break sizes is shown in Figure 4-4 which shows that the rate of growth of the hazard rate slows as the break size is increased. Eventually, each of the hazard rates reaches an asymptote that corresponds to one of the eigenvalues of the solution to the ordinary differential equations (ODEs) that are derived from the Markov Model. However, the time to reach these asymptotes is typically much longer than a reactor lifetime - on the order of hundreds of years. The rate approach is dependent on the model transition rates. A sensitivity study was performed on the hazard rate for 3.2in breaks holding all the transition rates at their base case values except for the frequency of detectable flaws. The results are shown in Figure 4-5 which shows that the asymptote is approached more rapidly as the ratio of the flaw rate to the failure rate for leaks increases from its reference value of 4 to higher values. 


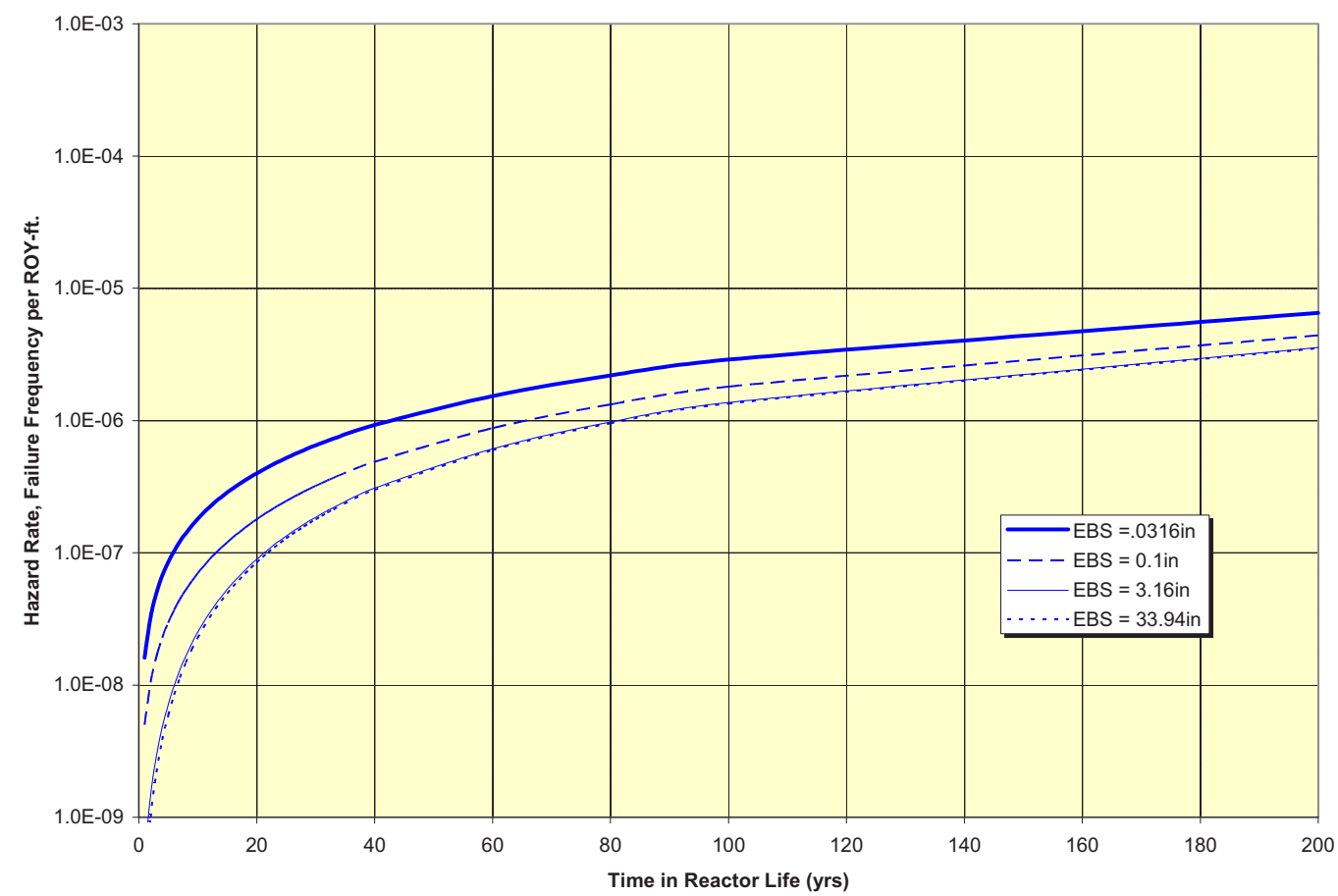

Figure B-20 Plant Age Dependent Hazard Rates for Selected Break Sizes in 24" FP Pipe

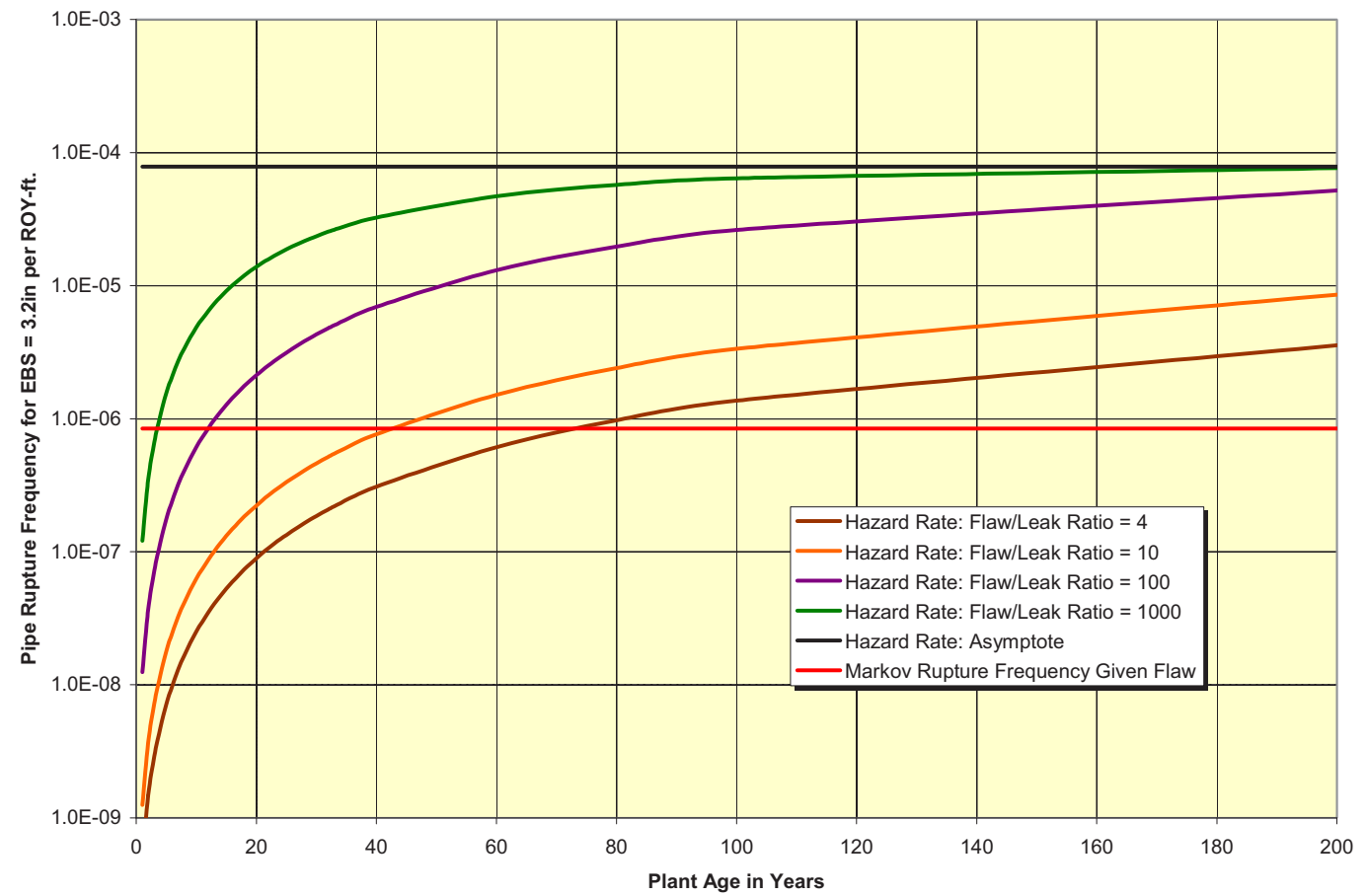

Figure B-21 Hazard Rate Sensitivity Study - Vary Flaw to Leak Ratio

\subsubsection{Open Issues for Evaluation of Fire-water piping}


Some of the key assumptions made in the current estimation of failure rates and rupture frequencies include the following:

- Assumption that all pipe failures are precursors to pipe ruptures

- Assumptions regarding the pooling of data for failure rates across the entire industry which may mask variability in FP piping designs, materials, water quality, etc.

- Assumption that modeling uncertainty on pipe exposure captures this uncertainty

- Assumption that the failure data are complete

- Uncertainty in the classification of pipe ruptures

- Uncertainty in the modeling of conditional pipe break probabilities vs. break size

- Uncertainty in the assumed prior distributions for pipe failure rates and conditional rupture probabilities

- Assumption that Markov model transition rates are time independent

- Assumption that discrete inspections can be modeled as continuous processes

- Uncertainties in assumptions regarding flaw to leak ratios

- Assumption that transition rates for leaks and ruptures can be estimated based on estimated average failure rates from service data

- Assumption that time dependent growth in hazard rate can be used to forecast aging.

The results were developed using the methodology presented in Section 2 which include the following steps.

8. Failure rates and rupture frequencies are developed per linear foot of pipe and reactoroperating year. This form is useful for supporting internal flooding PRAs which must address many different flood areas in a nuclear power plant. Within the PRA the internal flood initiating event frequencies are developed in terms of events per reactor-calendar year so the accident sequence frequencies are in the proper units for PRA applications.

9. Different failure rates and rupture frequencies are developed for different pipe size categories selected to capture the range of pipe sizes used in this system in existing nuclear power plants.

10. Rupture frequencies are estimated as the product of the failure rate and the conditional probability of pipe rupture, which in turn is a function of the rupture break size. A range of pipe break sizes ranging from a small through wall leak up to and including complete severance of the pipe is considered.

11. Bayes' prior distributions are developed based on piping system reliability estimates that were available prior to the collection of service data

12. Uncertainty in the pipe component exposure that produced the failure counts was addressed by using different hypotheses about the variation of exposure about the point estimates derived from plant data. Separate Bayes' updates of the common prior are made for each hypothesis of component exposure.

13. Conditional probabilities as a function of break size are also estimated using a Bayes update procedure using prior distributions based on expert opinion and updated based on counts of failures in each discrete rupture size category.

14. Final results are obtained in terms of excedance frequency, i.e. the frequency of a pipe rupture that exceeds an indicated break size from a small through wall leak up to and including complete severance of the pipe. The family of curves produced by Monte Carlo propagation of the Bayes' uncertainties in the failure rates, posterior weighting of the posterior distribution over the different hypotheses about exposure, and the conditional rupture mode probabilities express the epistemic uncertainty in the rupture frequency. 
A summary of the results for the pipe rupture exceedance frequency, i.e. frequency of pipe ruptures equal to or greater than an equivalent break size (EBS), is shown in Figure 4-1 for a FP system header with assumed NPS of 24" for three cases: the results of the current study with and without the design features to protect against water hammer, and the results from the an EPRI study published in 2006 based on service data through 2004[1]. These results reflect several differences relative to the earlier EPRI study, including an increase in the rupture frequency for EBS up to several inches due to an observed increase in the frequency of FP failures and ruptures in the service data in last hundred reactor-years of experience since 2004, perhaps due to aging or improvements in the event reporting systems. There are significant reductions in pipe rupture frequency due to the design features to limit the contribution of water hammer, but since water hammer is only a significant but not a dominant failure mechanism, these improvements are not as dramatic as perhaps might be expected. [Note: The typical header size is NPS12 - i.e., the largest size FP pipe found in plants.]

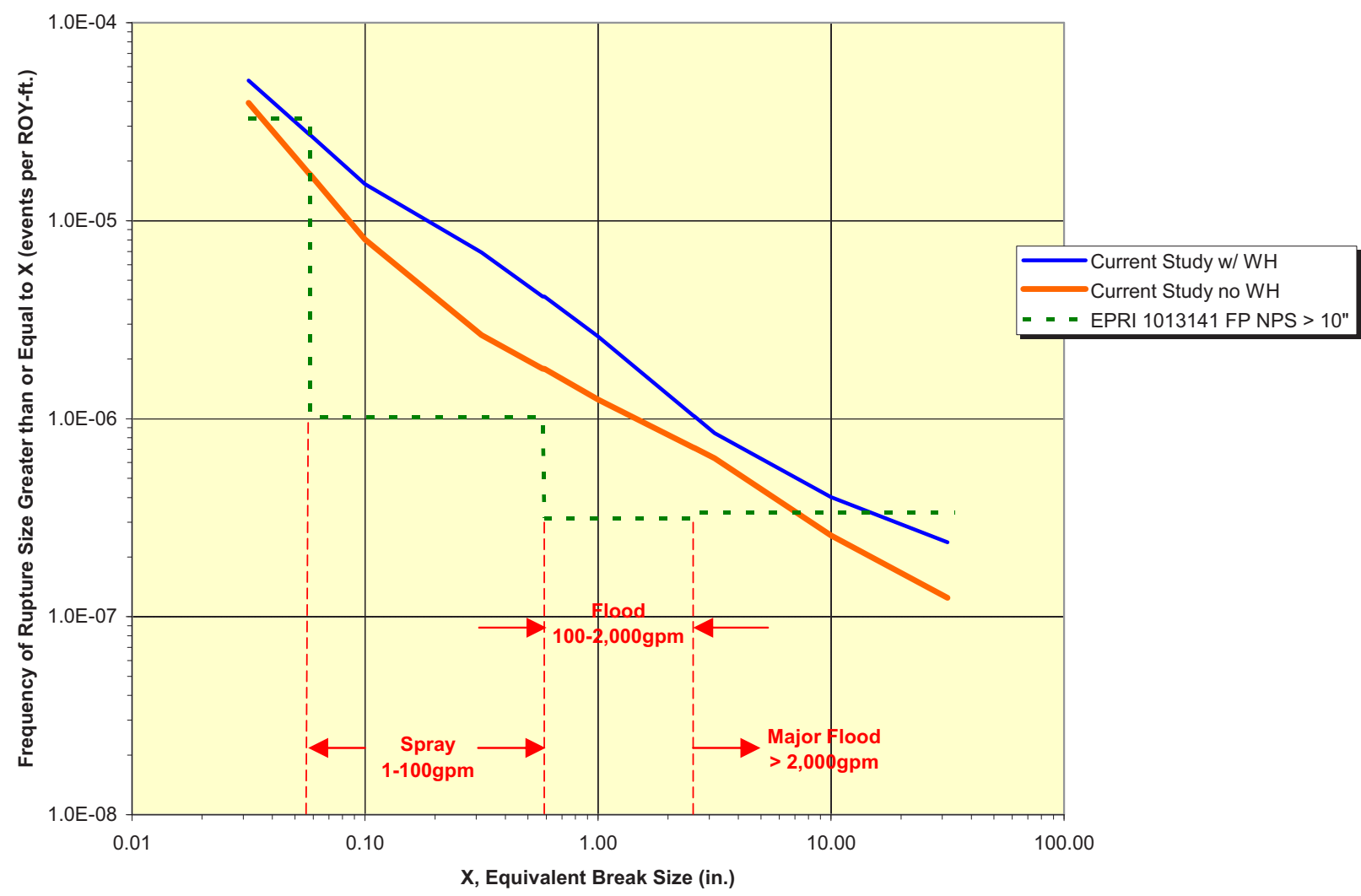

Figure B-22 Results for Rupture Frequency vs. Break Size for NPS 24" FP Header

As will be shown in the next section, very significant additional improvements can be realized by adding some leak inspections and/or volumetric NDE to the RIM program for the FP system. If there are already RIM strategies in the Columbia FP system beyond those reflected in the service data, those are not credited in this figure.

Because few plants have design features to protect the FP system against water hammer, the remaining results presented for the FP system assume no such protection. The failure rates and cumulative rupture frequencies for FP system headers with nominal pipe size of 24 " with no 
credit for water hammer protection are presented in Figure 4-2 and Table 4-3. Failure rate and cumulative rupture frequencies for other pipe sizes are found in Appendix B.

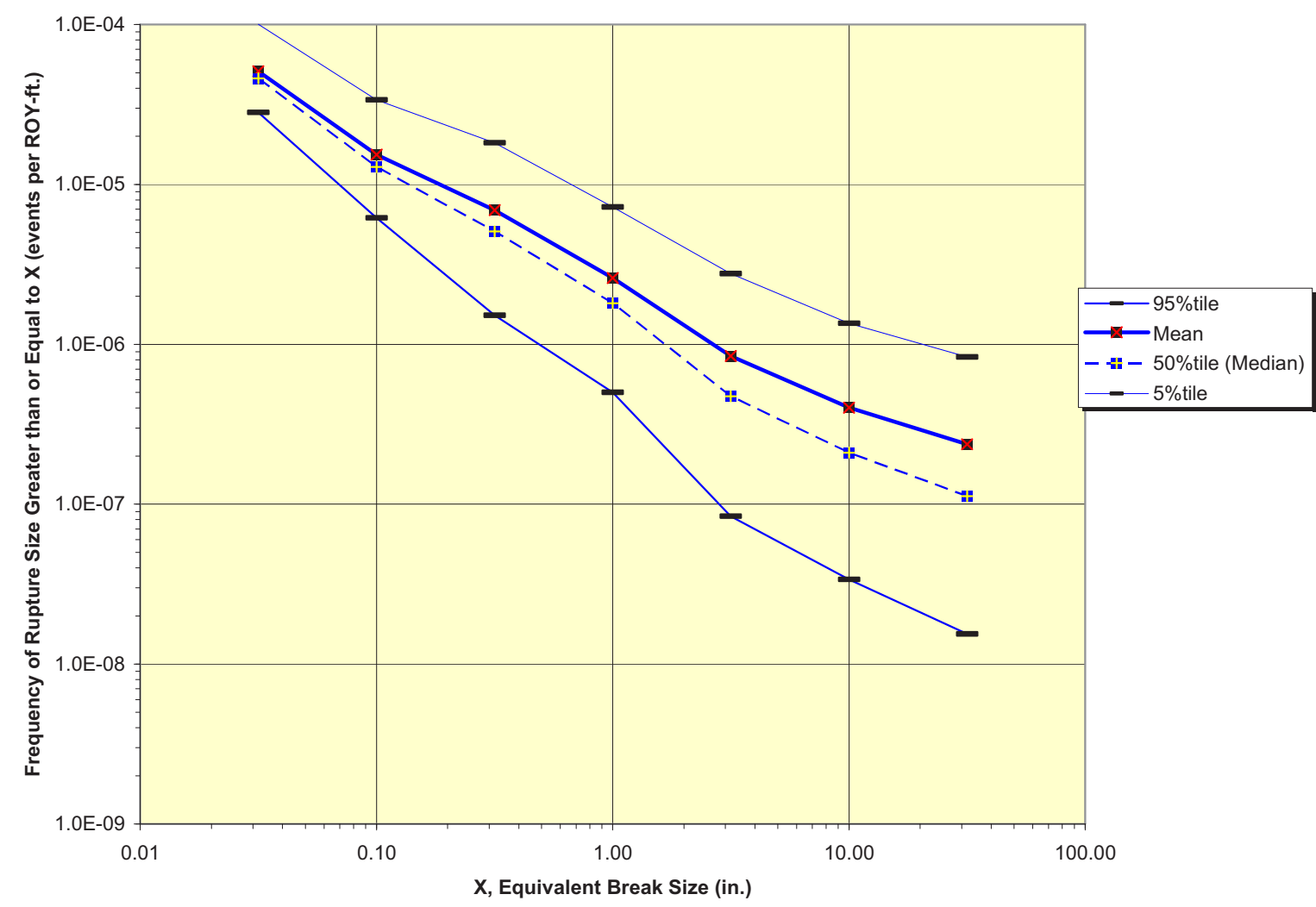

Figure B-23 Cumulative Pipe Rupture Frequency for FP NPS 24"

\subsubsection{Impact of Alternative Inspection and Surveillance Strategies for FP System}

The impact of alternative inspection strategies to reduce the frequency of pipe rupture was evaluated using the Markov Model and selected results are shown in Table 4-4, 
Treatment of Passive Component Reliability in Risk-Informed Safety Margin Characterization

Table 4-5, 
Table 4-6 and in Figure 4-3. Table 4-4 and 
Table 4-5 show how varying the frequency of leak testing with and without additional NDE and a fixed $90 \%$ POD for both strategies change the Integrity Management factor. 
Table 4-6 shows how alternative POD with fixed frequencies of NDE (every 10 years) and leak testing (every quarter) impact the Integrity Management factor. These Integrity Management Factors are evaluated for the plant age of 32 years which corresponds to the average age of the plants in the service data. 
Table B-14 Failure Rates and Cumulative Rupture Frequencies for FP NPS 24" and No Water Hammer Protection

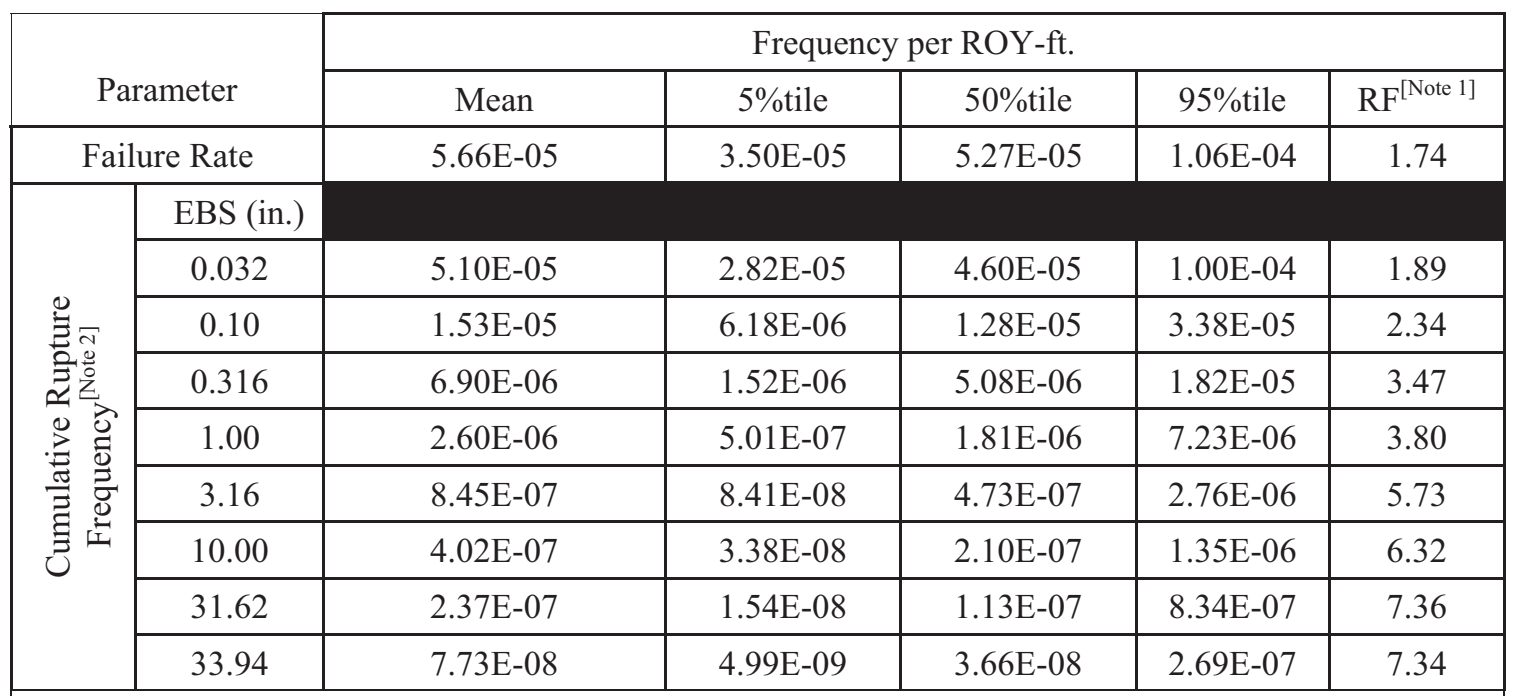

Note $1 . \mathrm{RF}=(95 \% \text { tile } / 5 \% \text { tile })^{0.5}$; These distributions can be approximated as lognormal distributions with the indicated mean and the calculated range factor $(\mathrm{RF})$

Note 2. Frequency of pipe rupture with EBS equal to or greater than indicated EBS value

Table B-15 Impact of Alternative Leak Detection Strategies to Reduce Fire Protection System Pipe Rupture Frequencies

\begin{tabular}{|c|c|c|c|c|}
\hline \multirow{3}{*}{$\begin{array}{c}\text { Equivalent } \\
\text { Break Size } \\
\text { (in.) }\end{array}$} & \multicolumn{4}{|c|}{ No NDE with Variable Leak Testing Frequency } \\
\hline & \multirow[t]{2}{*}{$\begin{array}{l}\text { Base Rate } \\
\text { per ROY-ft. }\end{array}$} & \multicolumn{3}{|c|}{$\begin{array}{l}\text { Factor Reduction in Base Rate for } \\
\text { Periodic Leak Test @ 90\% POD }\end{array}$} \\
\hline & & Yearly & Quarterly & Weekly \\
\hline 0.032 & 3.57E-05 & 7.60E-01 & 7.34E-01 & 7.29E-01 \\
\hline 0.10 & 8.43E-06 & 4.60E-01 & 4.01E-01 & 3.89E-01 \\
\hline 0.32 & 4.30E-06 & 3.33E-01 & 2.61E-01 & 2.46E-01 \\
\hline 1.0 & 1.76E-06 & 2.21E-01 & $1.36 \mathrm{E}-01$ & 1.19E-01 \\
\hline 3.2 & 4.43E-07 & 1.47E-01 & $5.42 \mathrm{E}-02$ & $3.56 \mathrm{E}-02$ \\
\hline 10 & $1.64 \mathrm{E}-07$ & $1.29 \mathrm{E}-01$ & 3.47E-02 & 1.56E-02 \\
\hline 31.6 & $1.60 \mathrm{E}-07$ & $1.24 \mathrm{E}-01$ & 3.44E-02 & 9.30E-03 \\
\hline 34 & 7.73E-08 & $1.24 \mathrm{E}-01$ & 2.84E-02 & $9.30 \mathrm{E}-03$ \\
\hline
\end{tabular}

Table B-16 Impact of NDE and Alternative Leak Detection Strategies to Reduce Fire Protection System Pipe Rupture Frequencies 


\begin{tabular}{|c|c|c|c|c|c|}
\hline \multirow{3}{*}{$\begin{array}{l}\text { Equivalent } \\
\text { Break Size } \\
\quad \text { (in.) }\end{array}$} & \multicolumn{5}{|c|}{$\begin{array}{c}\text { NDE every } 10 \text { years at } 90 \% \text { POD with Variable Leak Testing } \\
\text { Frequency }\end{array}$} \\
\hline & \multirow[t]{2}{*}{$\begin{array}{l}\text { Base Rate } \\
\text { per ROY-ft. }\end{array}$} & \multicolumn{4}{|c|}{$\begin{array}{c}\text { Factor Reduction in Base Rate for Periodic Leak } \\
\text { Test @ 90\% POD }\end{array}$} \\
\hline & & None & Yearly & Quarterly & Weekly \\
\hline 0.032 & 3.57E-05 & 3.62E-01 & 2.50E-01 & 2.41E-01 & $2.40 \mathrm{E}-01$ \\
\hline 0.10 & 8.43E-06 & 4.03E-01 & $1.52 \mathrm{E}-01$ & 1.32E-01 & $1.28 \mathrm{E}-01$ \\
\hline 0.32 & 4.30E-06 & 4.21E-01 & $1.11 \mathrm{E}-01$ & 8.59E-02 & $8.10 \mathrm{E}-02$ \\
\hline 1.0 & 1.76E-06 & 4.36E-01 & 7.42E-02 & 4.49E-02 & 3.93E-02 \\
\hline 3.2 & 4.43E-07 & 4.46E-01 & 5.00E-02 & 1.79E-02 & 1.17E-02 \\
\hline 10 & $1.64 \mathrm{E}-07$ & 4.49E-01 & 4.42E-02 & 1.15E-02 & $5.15 E-03$ \\
\hline 31.6 & 1.60E-07 & 4.49E-01 & 4.41E-02 & 1.14E-02 & 5.06E-03 \\
\hline 34 & 7.73E-08 & 4.50E-01 & 4.24E-02 & 9.41E-03 & 3.06E-03 \\
\hline
\end{tabular}


Table B-17 Integrity Management Factors for Various Combinations of NDE and Leak Inspections for Fire Protection System

\begin{tabular}{|c|c|c|c|c|c|c|c|}
\hline \multicolumn{8}{|c|}{ NO NDE with Quarterly Leak Testing and Variable Leak Testing POD } \\
\hline EBS & $\begin{array}{l}\text { No Leak } \\
\text { Test }\end{array}$ & $\mathrm{POD}=.50$ & $\mathrm{POD}=.60$ & $\mathrm{POD}=.70$ & $\mathrm{POD}=.80$ & $\mathrm{POD}=.90$ & $\mathrm{POD}=1.00$ \\
\hline 0.03 & $1.00 \mathrm{E}+00$ & 7.39E-01 & 7.37E-01 & 7.36E-01 & 7.35E-01 & 7.34E-01 & 7.33E-01 \\
\hline 0.10 & $1.00 \mathrm{E}+00$ & 4.12E-01 & 4.08E-01 & 4.05E-01 & 4.03E-01 & 4.01E-01 & 4.00E-01 \\
\hline 0.32 & $1.00 \mathrm{E}+00$ & 2.74E-01 & 2.69E-01 & 2.66E-01 & 2.63E-01 & 2.61E-01 & 2.59E-01 \\
\hline 1.00 & $1.00 \mathrm{E}+00$ & $1.52 \mathrm{E}-01$ & 1.46E-01 & 1.42E-01 & 1.39E-01 & 1.36E-01 & 1.34E-01 \\
\hline 3.20 & $1.00 \mathrm{E}+00$ & 7.14E-02 & $6.50 \mathrm{E}-02$ & 6.04E-02 & 5.69E-02 & $5.42 \mathrm{E}-02$ & $5.20 \mathrm{E}-02$ \\
\hline 10.00 & $1.00 \mathrm{E}+00$ & 5.22E-02 & 4.57E-02 & 4.10E-02 & 3.74E-02 & 3.47E-02 & 3.24E-02 \\
\hline 31.60 & $1.00 \mathrm{E}+00$ & 5.19E-02 & 4.54E-02 & 4.07E-02 & $3.72 \mathrm{E}-02$ & $3.44 \mathrm{E}-02$ & 3.22E-02 \\
\hline 34.00 & $1.00 \mathrm{E}+00$ & 4.61E-02 & $3.95 \mathrm{E}-02$ & $3.48 \mathrm{E}-02$ & $3.12 \mathrm{E}-02$ & $2.84 \mathrm{E}-02$ & 2.62E-02 \\
\hline \multicolumn{8}{|c|}{ 10yr. NDE with $50 \%$ POD with Quarterly Leak Testing with Variable Leak Testing POD } \\
\hline EBS & $\begin{array}{l}\text { No Leak } \\
\text { Test }\end{array}$ & $\mathrm{POD}=.50$ & $\mathrm{POD}=.60$ & $\mathrm{POD}=.70$ & $\mathrm{POD}=.80$ & $\mathrm{POD}=.90$ & $\mathrm{POD}=1.00$ \\
\hline 0.03 & 5.31E-01 & 3.69E-01 & 3.69E-01 & 3.68E-01 & 3.67E-01 & 3.67E-01 & 3.67E-01 \\
\hline 0.10 & 5.69E-01 & 2.06E-01 & 2.04E-01 & 2.03E-01 & 2.01E-01 & 2.01E-01 & 2.00E-01 \\
\hline 0.32 & 5.85E-01 & 1.37E-01 & 1.35E-01 & 1.33E-01 & 1.32E-01 & $1.30 \mathrm{E}-01$ & 1.30E-01 \\
\hline 1.00 & 5.99E-01 & 7.63E-02 & 7.33E-02 & 7.12E-02 & 6.95E-02 & 6.83E-02 & 6.73E-02 \\
\hline 3.20 & 6.09E-01 & 3.59E-02 & 3.26E-02 & 3.03E-02 & 2.85E-02 & 2.72E-02 & 2.61E-02 \\
\hline 10.00 & 6.11E-01 & 2.63E-02 & 2.30E-02 & 2.06E-02 & $1.88 \mathrm{E}-02$ & 1.74E-02 & 1.63E-02 \\
\hline 31.60 & $6.11 \mathrm{E}-01$ & $2.62 E-02$ & $2.28 \mathrm{E}-02$ & $2.05 E-02$ & 1.87E-02 & 1.73E-02 & 1.61E-02 \\
\hline 34.00 & $6.12 \mathrm{E}-01$ & 2.32E-02 & 1.99E-02 & $1.75 \mathrm{E}-02$ & 1.57E-02 & 1.43E-02 & 1.31E-02 \\
\hline \multicolumn{8}{|c|}{ 10yr. NDE with $90 \%$ POD with Quarterly Leak Testing with Variable Leak Testing POD } \\
\hline EBS & $\begin{array}{l}\text { No Leak } \\
\text { Test }\end{array}$ & $\mathrm{POD}=.50$ & $\mathrm{POD}=.60$ & $\mathrm{POD}=.70$ & $\mathrm{POD}=.80$ & $\mathrm{POD}=.90$ & $\mathrm{POD}=1.00$ \\
\hline 0.03 & $3.62 \mathrm{E}-01$ & 2.43E-01 & 2.42E-01 & 2.42E-01 & 2.42E-01 & 2.41E-01 & 2.41E-01 \\
\hline 0.10 & 4.03E-01 & $1.36 \mathrm{E}-01$ & 1.34E-01 & 1.33E-01 & 1.33E-01 & $1.32 \mathrm{E}-01$ & 1.31E-01 \\
\hline 0.32 & 4.21E-01 & 9.04E-02 & 8.87E-02 & 8.75E-02 & 8.66E-02 & 8.59E-02 & 8.53E-02 \\
\hline 1.00 & 4.36E-01 & $5.02 E-02$ & 4.82E-02 & 4.68E-02 & 4.58E-02 & 4.49E-02 & 4.43E-02 \\
\hline 3.20 & 4.46E-01 & 2.37E-02 & 2.15E-02 & $2.00 \mathrm{E}-02$ & $1.88 \mathrm{E}-02$ & 1.79E-02 & 1.72E-02 \\
\hline 10.00 & 4.49E-01 & $1.74 \mathrm{E}-02$ & $1.52 \mathrm{E}-02$ & 1.36E-02 & $1.24 \mathrm{E}-02$ & 1.15E-02 & 1.07E-02 \\
\hline 31.60 & 4.49E-01 & $1.73 \mathrm{E}-02$ & $1.51 \mathrm{E}-02$ & 1.35E-02 & 1.23E-02 & 1.14E-02 & 1.06E-02 \\
\hline 34.00 & 4.50E-01 & 1.53E-02 & 1.31E-02 & 1.15E-02 & 1.03E-02 & 9.41E-03 & 8.66E-03 \\
\hline
\end{tabular}

Depending on the break size pipe rupture frequency reductions of upwards of two orders of magnitude can be achieved in the pipe rupture frequency by periodic leak testing with a moderate to high probability of detection. As shown in Figure 4-3 it is seen that these strategies will more than offset the unexpected increases we found when updating the fire protection 
system failure rates to account for service data from 2004 to 2009 compared with the earlier EPRI report [1].

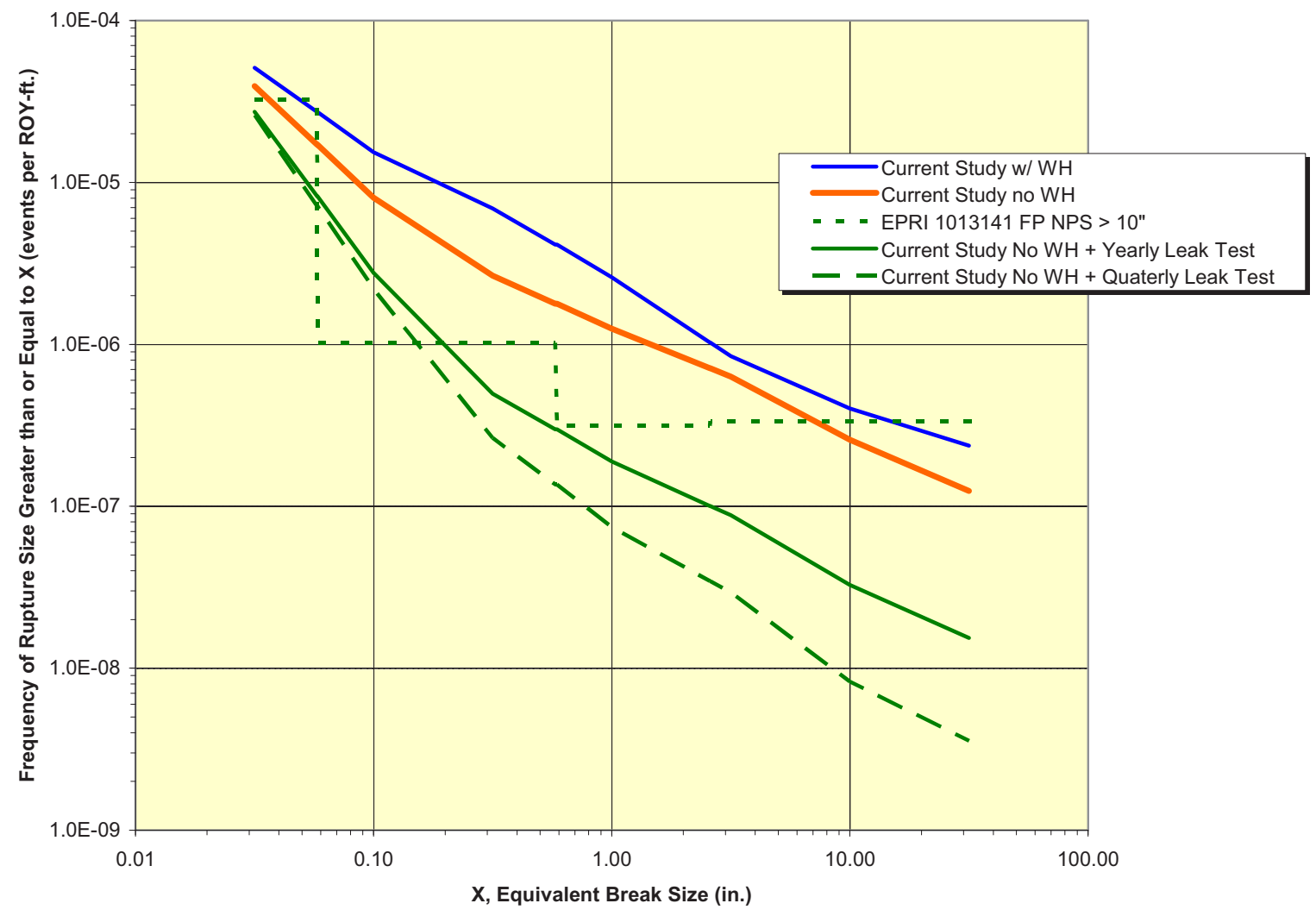

Figure B-24 Impact of Design and Inspection Strategies to Reduce the Frequency of Fire Protection Header Pipe Ruptures

\subsubsection{Impact of Plant Age on Estimated Failure Rates for FP System}

The impact of plant age on FP system pipe failure rates vs. EBS can be evaluated by using the expression in Equation 2.2 in which the hazard rate at various plant ages is normalized against that for a plant age of 32 years which corresponds to the average plant age of the plants that produced the service data used to estimate the base failure rates. The factor increase increases with increasing age and EBS. For the larger break sizes, the Markov model suggests that pipe rupture frequencies are expected to increase by a factor of 1.5 in the 8 years until $40 \mathrm{yrs}$, a factor of 3 increase to $60 \mathrm{yrs}$., and a factor of 5 increase at age $80 \mathrm{yrs}$. This information is presented in Table 4-7. 
Table B-18 Factors To Account for Aging Effects on NPS 24" FP Header

\begin{tabular}{|c|c|c|c|c|c|}
\hline \multirow{2}{*}{\multicolumn{2}{|c|}{ Pipe Failure Mode }} & \multirow{2}{*}{$\begin{array}{l}\text { Base } \\
\text { Rates } \\
\text { (mean) }\end{array}$} & \multicolumn{3}{|c|}{$\begin{array}{l}I_{T} \text {, Factor Increase to Account } \\
\text { for Aging at Time } T\end{array}$} \\
\hline & & & $\begin{array}{l}40 \\
\text { Years }\end{array}$ & $\begin{array}{c}60 \\
\text { Years }\end{array}$ & 80 Years \\
\hline \multicolumn{2}{|c|}{ All Failure Modes } & $5.66 \mathrm{E}-05$ & 1.3 & 2.2 & 3.1 \\
\hline \multirow{8}{*}{ EBS (in.) } & 0.032 & 5.10E-05 & 1.3 & 2.2 & 3.1 \\
\hline & 0.10 & 1.53E-05 & 1.4 & 2.6 & 3.9 \\
\hline & 0.32 & 6.90E-06 & 1.4 & 2.7 & 4.2 \\
\hline & 1.0 & 2.60E-06 & 1.5 & 2.9 & 4.5 \\
\hline & 3.2 & 8.45E-07 & 1.5 & 3.0 & 4.7 \\
\hline & 10 & 4.02E-07 & 1.5 & 3.0 & 4.7 \\
\hline & 31.6 & 2.37E-07 & 1.5 & 3.0 & 4.7 \\
\hline & 34 & 7.73E-08 & 1.5 & 3.0 & 4.8 \\
\hline
\end{tabular}

These estimates of increases in rupture frequencies due to plant age arise from the time dependent behavior of the hazard rates as discussed more fully in Section 2. A plot of the hazard rates for selected break sizes for the 24" FP header is shown in Figure 4-4 which shows that the rate of growth of the hazard rate slows as the break size is increased. Eventually, each of the hazard rates reaches an asymptote that corresponds to one of the eigenvalues of the solution to the ordinary differential equations (ODEs) that are derived from the Markov Model. However, the time to reach these asymptotes is typically much longer than a reactor lifetime on the order of hundreds of years. The rate approach is dependent on the model transition rates. A sensitivity study was performed on the hazard rate for 3.2in breaks holding all the transition rates at their base case values except for the frequency of detectable flaws. The results are shown in Figure 4-5 which shows that the asymptote is approached more rapidly as the ratio of the flaw rate to the failure rate for leaks increases from its reference value of 4 to higher values. 


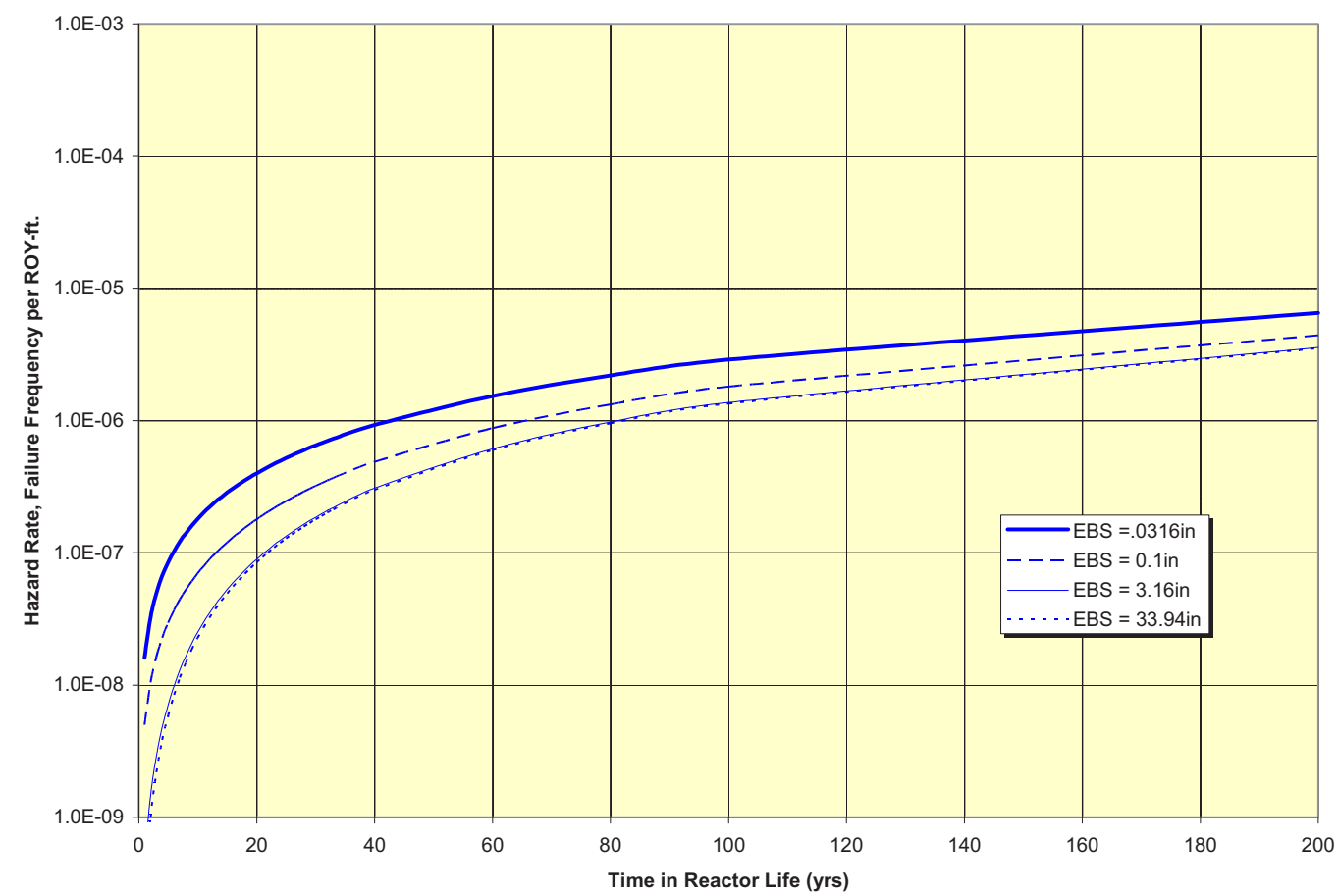

Figure B-25 Plant Age Dependent Hazard Rates for Selected Break Sizes in 24” FP Pipe

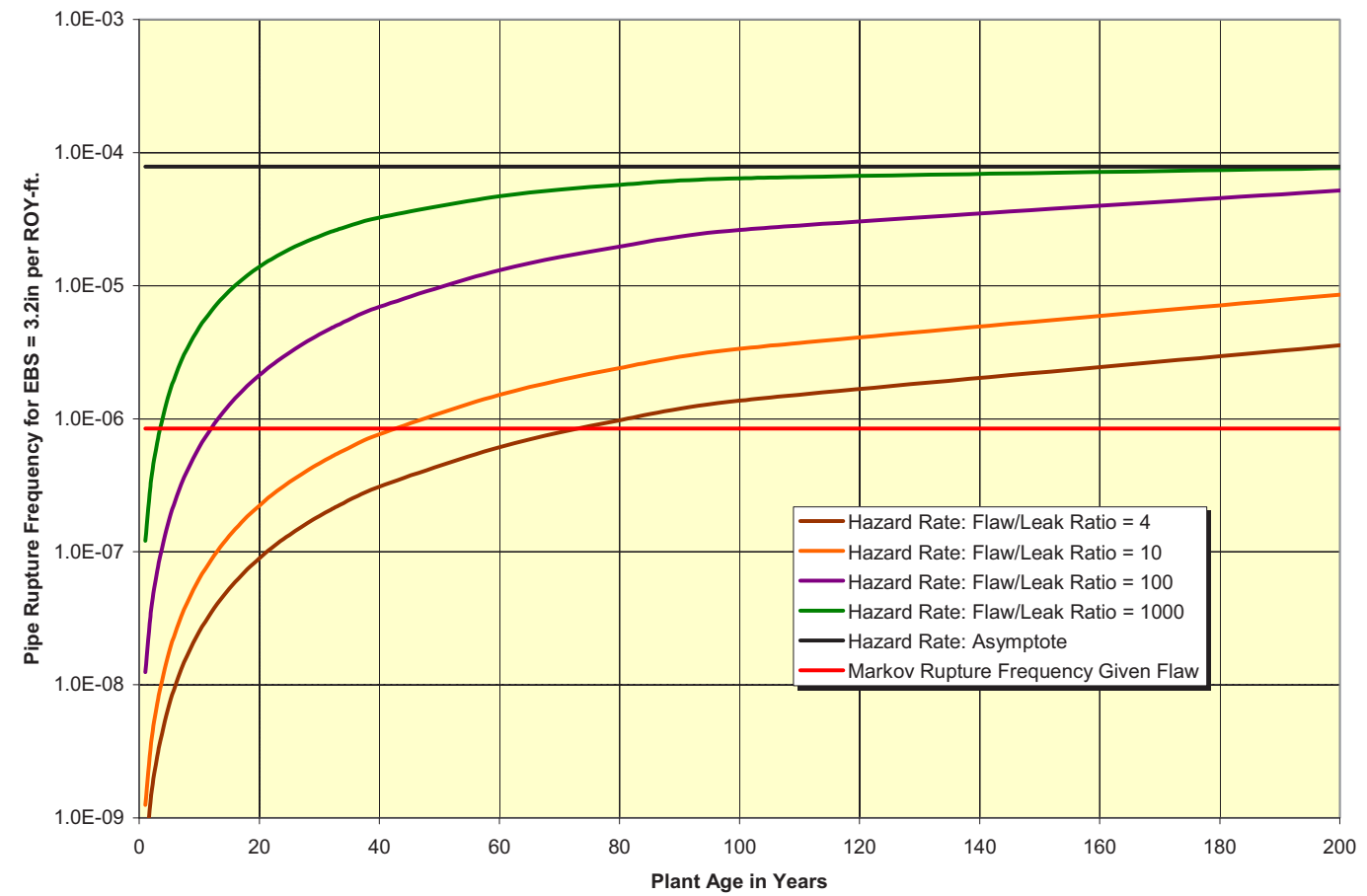

Figure B-26 Hazard Rate Sensitivity Study - Vary Flaw to Leak Ratio 


\subsection{Feedwater, Condensate, and Steam Piping}

\subsubsection{System Boundaries}

This evaluation is concerned with non-ASME Code piping systems inside the Turbine Building of Pressurized Water Reactor (PWR) plants. The following systems are considered:

- Feed-water \& Condensate (FWC) piping: The Condensate piping system extends from the Condenser Hot-well up to and including the Low Pressure Heaters. It also includes the Drains and Vents System piping from the Low Pressure and High Pressure Heaters. The Feed-water piping system boundary considered in this evaluation consists of the piping from the Low Pressure Heaters, the Feed-water pump suction/discharge piping, High Pressure Heater inlet/outlet piping up to the outboard containment isolation valves. Due to comparable susceptibilities to flow accelerated corrosion (FAC) and plant to plant variability in how the boundaries between these systems are defined, a composite set of data parameters are developed for FWC piping.

- Steam Extraction (EXS) piping: In a typical PWR the high pressure portion of the turbine has extraction connections for two stages of feed-water heating. The low pressure portion of the turbine has extraction connections for four stages of feed-water heating.

- Low Pressure Steam (LPS) piping: In this evaluation, the low pressure steam piping includes piping between the high pressure (HP) and low pressure (LP) turbine stages, including steam cross-over and cross-under piping, and Moisture Separator Reheater (MSR) piping. The MSR piping is also located between the HP and LP turbines and it is used to extract moisture from the steam and reheat the steam to improve the turbine performance.

- HP Steam (HPS) piping: In this evaluation the HP steam piping is upstream of the HP turbine throttle valve and extends to the outboard containment isolation valves.

\subsubsection{Failure Data Collection for Feedwater, Condensate and Steam Piping}

The data processing considers the different FAC-susceptibilities of BWR and PWR piping [1]. In an "unmitigated" operating environment, the average pipe wall wear rate of piping in BWR plants is approximately half of that experienced by the corresponding FWC-piping in PWR plants. The term "unmitigated" refers to piping that is not subjected to any scheduled volumetric examination using ultrasonic testing techniques or radiography. Nor does it encompass any consideration of preemptive replacements using FAC-resistant materials. Under an assumption of near equal exposure terms, in unmitigated form a BWR-specific pipe failure rate should be expected to be at least half of a corresponding PWR-specific failure rate. Disregarding pre-1988 service data for PWR plants, the global service experience for the two plant types is largely similar. The higher failure occurrence rate pre-1988 is reflective of the major structural FWC piping failures experienced at Surry and Trojan nuclear power plants. In response to these events the industry began implementing FAC Program Plans that involved the replacement of large quantities of pipe. The same kind of information and subsections are provided as with the previous section with the exception that water hammer screening is not performed (not a significant contributor for these systems) and RIM strategies are not evaluated because changes to the FAC program are outside the scope of this study. 
The pipe failure rates and rupture frequencies in this evaluation are derived from service data included in the PIPExp database (Appendix A). The full PIPExp includes on the order of 7,700 data records covering ASME Code Class 1-3 and non-Code piping in commercial light water reactor plants. Input parameters to the pipe failure rate calculation in this evaluation are obtained through database queries that include filters for excluding any non-relevant service data:

- Initial screening on the basis of Code Class and PWR plant system. Retain failure data associated with non-Code piping in Turbine Building including the following systems:

- Condensate System

- Extraction steam piping

- Feedwater heater drain and vent piping

- Main Feedwater (from LP feedwater heaters to outboard containment isolation valves)

- Main Steam (from outboard containment isolation valve to High Pressure turbine steam admission valve, and turbine cross-over/cross-under piping)

- Moisture Separator Reheater piping

- Results of initial screening subjected to additional screening on the basis of nominal pipe size and through-wall flaw or break size:

- The evaluation considers piping of nominal pipe size (NPS) greater than 2-inch diameter as piping less than 2-inch is not within the scope of this evaluation. Two pipe size categories are used to define the different failure rate cases in Table 2-1: the small pipe size category covers pipes with NPS between 2in. and 6in., whereas the large pipe category covers pipe sizes greater than NPS 6in.

The service data involving through-wall flaws are reviewed in accordance with the Prairie Island pipe break analysis requirements. This means that the service data are screened further on the basis of flaw size ('EBS or equivalent break size'). The results of this screening step are input to the derivation of posterior Beta distribution parameters for calculation of conditional pipe failure probabilities for each of the systems, pipe size categories, and failure modes considered in this study

Consistent with recent studies completed for Prairie Island [2] and Kewaunee [3], the FAC susceptible systems are divided into four categories of systems, each of which has different susceptibilities to FAC. The first category is feedwater and condensate systems, the second is extraction steam (EXS), the third is low pressure steam (LPS), and the fourth is high pressure steam (HPS). HPS accounts for the piping between the reactor and the inlet of the HP turbine and given the dry steam conditions and relatively straight runs of pipe, has a relatively low susceptibility to FAC. EXS has the relatively poorest quality steam and relatively high susceptibility to FAC. The LPS accounts for the remaining elements of the steam system piping. FWC is not separated into FW and CND systems because insights from service data indicate a relatively uniform level of service induced failures and also plants do not use consistent definitions for establishing the boundaries between these systems. FWC is the most important FAC susceptible system for PWRs.

The results of the database queries for the development of system specific and pipe size specific failure rates are summarized in charts (Figure 4-6 and Figure 4-7) and tables ( 
Table 4-8 and Table 4-9). Flow-accelerated corrosion (FAC) is a predominant degradation mechanism for the systems that are included in the study scope except for the high pressure steam system. Most if not all plant owners have implemented programs to mitigate FAC susceptibilities. These programs include implementing non-destructive examination (NDE) programs, pro-active monitoring of pipe wall wear rates, and replacing the original carbon steel piping with FAC-resistant piping material such as stainless steel, carbon steel clad on the inside diameter with stainless steel, or chrome-molybdenum alloy steel. The purpose of these initial data queries was to identify the appropriate data set to use that represents current industry practice for predicting the initiating event frequencies at Prairie Island. The use of time trend analysis is a requirement of the ASME PRA standard for Capability Category 3 analyses. In addition, evaluating the trending of events avoids important insights in the data that would be missed by simply averaging all the industry experience over the entire time span from 1970 to 2008.

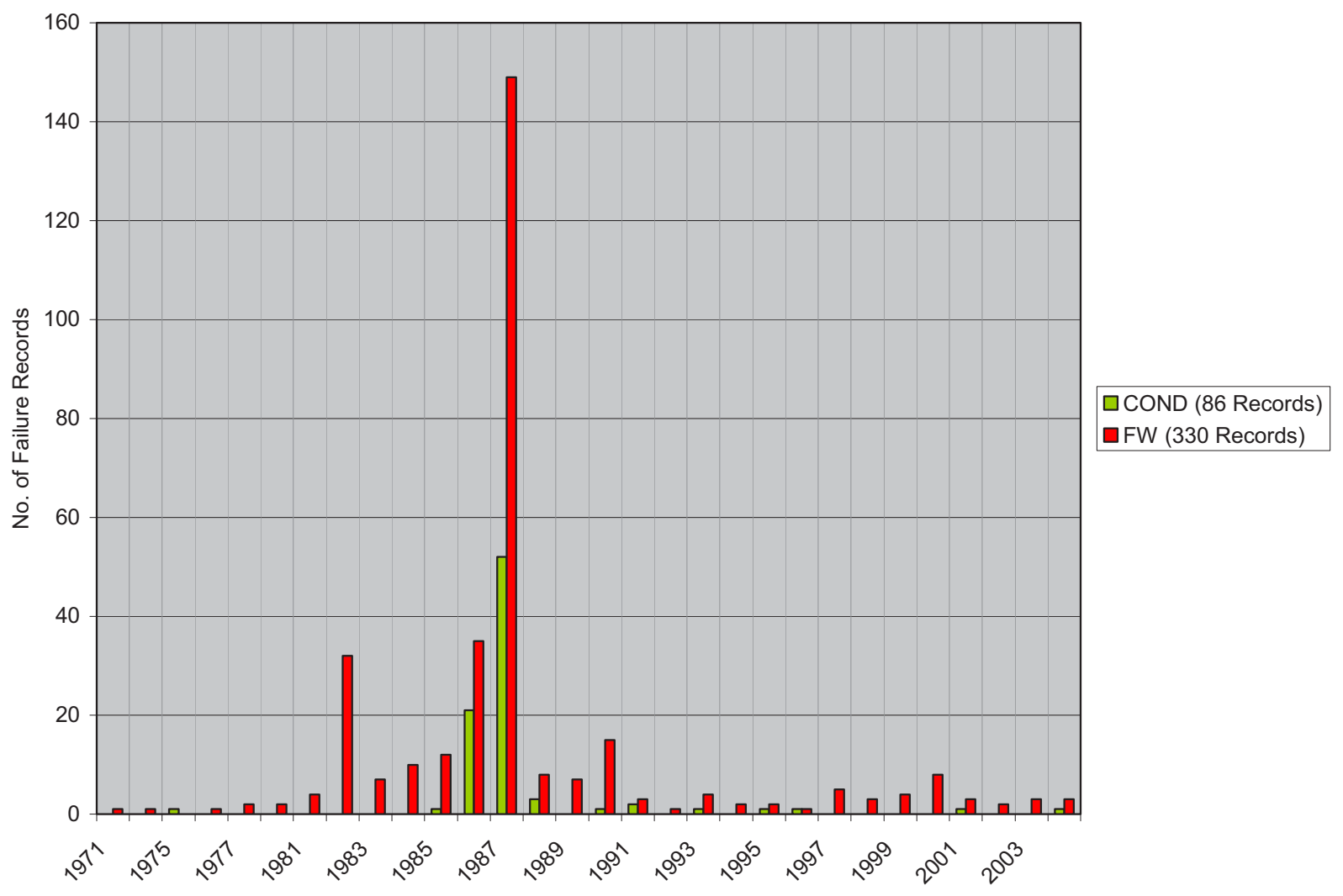

Figure B-27 PWR Worldwide Experience with non-Code FWC Piping 1970-2004 


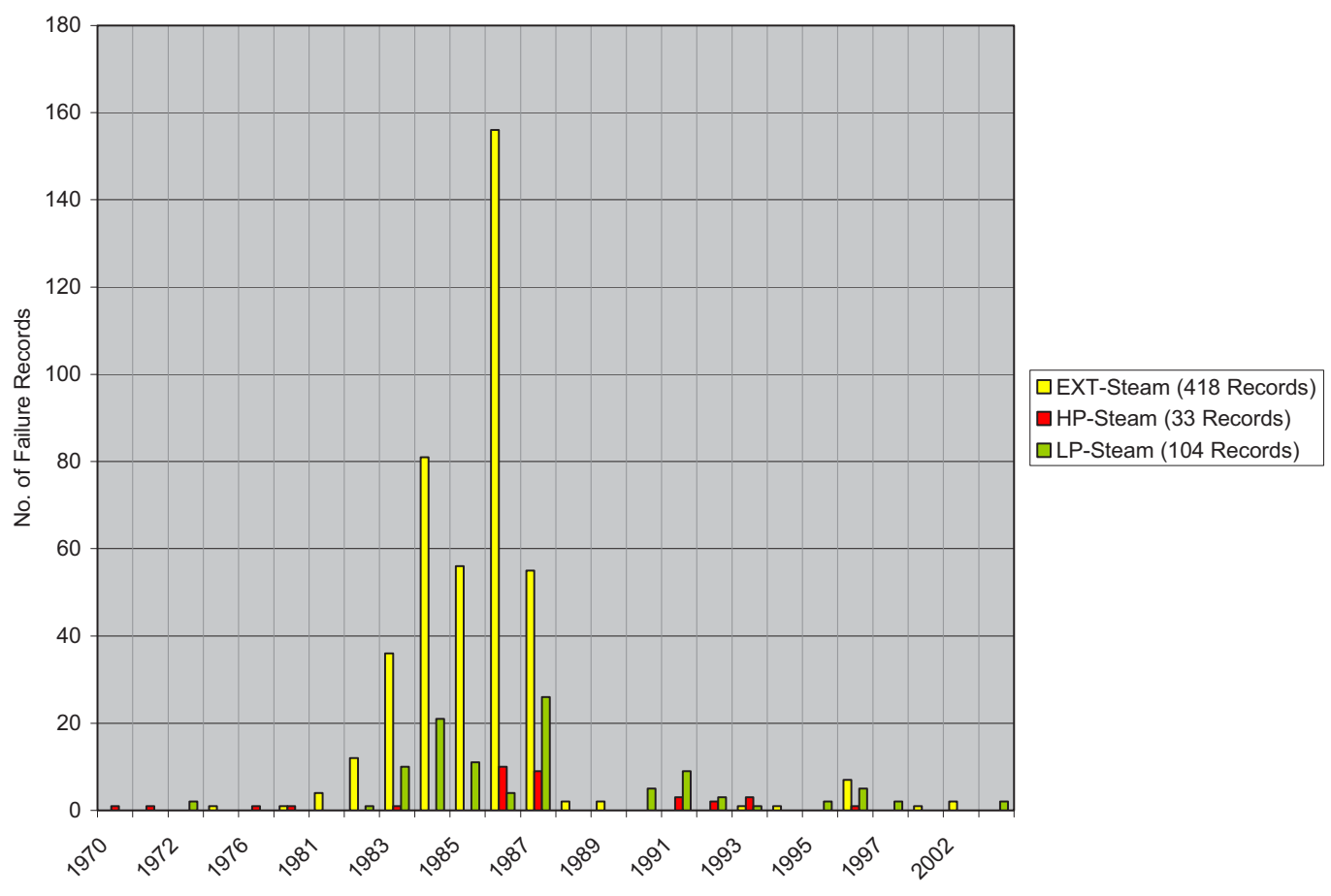

Figure B-28 PWR Worldwide Experience with non-Code Steam Piping 1970-2004

The two charts above show a distinctly higher incident rate of pipe failures before 1988 . The before/after-1988 trends in Figure 4-6 and Figure 4-7 are accounted for in the following quantitative evaluation of the service-data. The service data coverage in PIPExp corresponds to 858 PWR reactor years for the period 1/01/1970 - 12/31/1987 and 2059 PWR reactor years for the period $01 / 01 / 1988-12 / 31 / 2008$. By the early- to mid-1980's the industry experienced several major failures of non-Code carbon steel piping (e.g., Trojan in March 1985 and Surry-2 in December 1986) (See References [2] through [5] ). In response to these events as well as the industry-wide experience with pipe wall thinning and minor through-wall flaws attributed to FAC.

Table 4-8 and Table 4-9 show the same data sets as those included in Figure 4-6 and Figure 4-7 except that the data is organized by failure mode and pipe size to reflect the Prairie Island PRA HELB initiating event analysis requirements. The following failure mode definitions are used:

- Wall thinning; represents cases of severe wall thinning resulting in either weld overlay repair or preemptive replacement of affected piping section or fitting (e.g., elbow, tee).

- Leak; includes pinhole leak, leak or large leak resulting in isolation (where feasible) or manual reactor shutdown to effect repair or replacement.

- Rupture; significant through-wall flaw resulting in moderate or significant steam/water release and prompt manual shutdown or automatic turbine trip/reactor trip with estimated break size. 
Table B-19 Service Experience with B31.1 Carbon Steel FWC Piping 1970 to 2008

\begin{tabular}{|c|c|c|c|c|c|c|c|c|}
\hline \multirow{2}{*}{$\begin{array}{c}\text { Nominal Pipe } \\
\text { Size } \\
\text { (NPS) } \\
\text { [Inch] }\end{array}$} & \multicolumn{4}{|c|}{ 1970-1987 } & \multicolumn{4}{|c|}{ 1988-2008 } \\
\hline & Total & $\begin{array}{c}\text { Wall } \\
\text { Thinning }\end{array}$ & Leak & Rupture & Total & $\begin{array}{c}\text { Wall } \\
\text { Thinning }\end{array}$ & Leak & Rupture \\
\hline $2 "<$ NPS $\leq 6 "$ & 14 & 5 & 6 & 3 & 57 & 33 & 18 & 6 \\
\hline NPS > 6" & 300 & 275 & 17 & 8 & 155 & 126 & 23 & 6 \\
\hline Total: & 314 & 280 & 23 & 11 & 212 & 159 & 41 & 12 \\
\hline \multicolumn{9}{|c|}{$\begin{array}{l}\text { Notes: } \\
\text { - Service experience in Table 3-41 derived from } 2917 \text { reactor-years of PWR operation worldwide; } 858 \text { reactor-years pre-1988 } \\
\text { and } 2059 \text { reactor-years post-1987 and covers the period between Jan 1, } 1970 \text { and December 31, } 2008 \\
\text { - Failure data includes contributions from FAC (dominant degradation mechanism), vibration-fatigue and water hammer } \\
\text { - The root cause of post-1987 events in many cases is attributed to programmatic errors or weaknesses in the Owner's FAC } \\
\text { program } \\
\text { - Appendix A includes information on the coverage and completeness of the PIPExp database }\end{array}$} \\
\hline
\end{tabular}

Table B-20 Service Experience with B31.1 Carbon Steel Steam Piping 1970 to 2008

\begin{tabular}{|c|c|c|c|c|c|c|c|c|c|}
\hline \multirow[t]{2}{*}{ System } & \multirow{2}{*}{$\begin{array}{c}\text { Nominal Pipe } \\
\text { Size } \\
\text { (NPS) } \\
\text { [Inch] }\end{array}$} & \multicolumn{4}{|c|}{$1970-1987$} & \multicolumn{4}{|c|}{ 1988-2004 } \\
\hline & & Total & $\begin{array}{c}\text { Wall } \\
\text { Thinning }\end{array}$ & Leak & Rupture & Total & $\begin{array}{c}\text { Wall } \\
\text { Thinning }\end{array}$ & Leak & Rupture \\
\hline \multirow[t]{2}{*}{ EXS } & $2 "<$ NPS $\leq 6 "$ & 10 & 0 & 8 & 2 & 11 & 1 & 9 & 1 \\
\hline & NPS > 6" & 392 & 385 & 4 & 3 & 37 & 20 & 10 & 7 \\
\hline \multirow[t]{2}{*}{ LPS } & $2 "<\mathrm{NPS} \leq 6 "$ & 14 & 0 & 11 & 3 & 29 & 10 & 18 & 1 \\
\hline & NPS > 6" & 61 & 60 & 1 & 0 & 15 & 2 & 9 & 4 \\
\hline \multirow[t]{2}{*}{ HPS } & NPS > 2" & 24 & 19 & 3 & 2 & 59 & 24 & 30 & 5 \\
\hline & Totals & 501 & 464 & 27 & 10 & 151 & 57 & 76 & 18 \\
\hline \multicolumn{10}{|c|}{$\begin{array}{l}\text { - 'EXT-Steam' includes HP \& LP steam extraction piping. Most of this piping is > NPS6. } \\
\text { - 'LP-Steam' includes piping between the HP and LP turbine stages, including cross-over/under piping and Moisture Separator } \\
\text { Reheater piping. } \\
\text { - 'HP-Steam' includes piping upstream of the HP turbine throttle valve. } \\
\text { - Service experience in Table 3-42 derived from } 2917 \text { reactor-years of PWR operation worldwide; } 858 \text { reactor-years pre-1988 } \\
\text { and } 2059 \text { reactor-years January 1, } 1988 \text { through December 31, 2008. This experience was obtained by } 131 \text { U.S. and Foreign } \\
\text { PWR plants }\end{array}$} \\
\hline
\end{tabular}

The estimated pipe lengths presented in for PWR piping is based on pipe exposure information collected in Reference [13] and some assumptions about how the pipe is distributed between 
different systems and pipe length categories. The percentages assumed are consistent with actual counts from selected FAC programs as documented in Reference [2].

As discussed more fully in References [2] and [3], there has been a significant impact of augmented programs to address FAC in reducing the frequency of FAC induced pipe failures in both PWRs and BWRs since 1988. Hence only the service data since 1988 is accounted for in the query for pipe failures in these systems. From January 1, 1988 through March 31, 2009 the service data from both US and foreign PWR plants accounts for about 1,296 reactor operating years of service experience.

Table B-21 Estimated Pipe Lengths for PWR Steam, Feedwater, and Condensate Systems

\begin{tabular}{|c|c|c|}
\hline System / System Group & Linear $\mathrm{ft}$ of Piping & Information Source / Comment ${ }^{\text {[Note 1] }}$ \\
\hline FWC & $14,037 \mathrm{ft}$ & $\begin{array}{l}\text { EPRI TR-111880, Table A-5; in the failure rate } \\
\text { calculation the given length is input as a median } \\
\text { value for pipes > 6in. diameter and upper } \\
\text { bound for pipes between } 2 \text { " and 6" in diameter }\end{array}$ \\
\hline EXS & $1,500 \mathrm{ft}$ & $\begin{array}{l}\text { Entergy Nuclear Northeast (Indian Point-3 FAC } \\
\text { program information). In the failure rate } \\
\text { calculation the given length is input as a median } \\
\text { value for pipes between 2" and 6" in diameter } \\
\text { and the upper bound value for pipes > 6in. in } \\
\text { diameter }\end{array}$ \\
\hline LPS & $622 \mathrm{ft}$ & $\begin{array}{l}\text { Dominion Energy; the given length is for KNPP } \\
\text { and in the failure rate calculation it is input as a } \\
\text { lower bound value for pipes between } 2 \text { " and } 6 " \\
\text { in diameter: } 2 / 3 \text { of this length and the lower } \\
\text { bound value for pipes > 6in. in diameter }\end{array}$ \\
\hline HPS & $885 \mathrm{ft}$ & $\begin{array}{l}\text { Dominion Energy; the given length is for KNPP } \\
\text { and in the failure rate calculation it is input as a } \\
\text { lower bound value for all pipes }>2 \text { " in diameter }\end{array}$ \\
\hline \multicolumn{3}{|c|}{$\begin{array}{l}\text { Note } 1 \text {. For consistency with the approach used in References [1] and [2]; uncertainty in the exposure } \\
\text { is modeled as a } 10 \% \text { probability of the lower bound, } 80 \% \text { probability of the median, and } 10 \% \\
\text { probability of the upper bound. In all cases the upper and lower bounds are set at } 50 \% \text { of the } \\
\text { exposure above and below the median value, respectively. The probability weights are used to } \\
\text { combine Bayes' updates using each of the three hypotheses about exposure. See Section } 2 \text { for a } \\
\text { more detailed explanation of this approach to treatment of pipe component exposure uncertainty. }\end{array}$} \\
\hline
\end{tabular}

\subsubsection{Conditional Probability of Pipe Rupture Given Failure}

The conditional probability of pipe rupture given pipe failure was developed using the approach as used for the service water and FP systems. The priors developed in were converted to equivalent break size (EBS.) using Equation (4.4) and an assumed pressure of 1,100 psig. The resulting prior distribution with its comparison to that Class 3 service water and FP systems is shown in Figure B-30. As seen in comparison to the the prior distribution curve for FAC susceptible systems is similar that developed for 


\section{FP systems. Both of these curves reflect a significantly higher probability of a large pipe} rupture than is the case with ASME Class $3 \mathrm{SW}$. The events in

Table 4-8 and Table 4-9 involving leaks and ruptures were reviewed for flow rate and break size information. In addition a larger set of rupture events totaling 77 events that was collected and analyzed in References [2] and [3] was reviewed and incorporated into the model. These events include a mixture of PWR and BWR events and cover all the systems classified as susceptible to FAC. The events which had equivalent break sizes of at least 1" are listed in Table 4-11. The resulting parameters of the prior and Bayes update of the Beta Distribution parameters used to characterize uncertainty in the conditional pipe rupture probabilities are listed in Table B-25. None of the pinhole leaks were found to have a measurable leak rate so they were assigned to the smallest leak rate category. As with the treatment of FP systems, the Beta distributions were converted to lognormals to reflect greater uncertainty in the larger break size categories with conditional break size probabilities less than 0.1 . The mean is preserved and the range factor is selected to widen the spread between the $5 \%$ and $95 \%$ tiles with progressively larger range factors for lower conditional probabilities. This is done because the calculated Beta distributions were judged to be too narrow when large failure counts are applied. This is a form of modeling uncertainty and in part reflects the uncertainty in estimating the break sizes of the ruptures which were not always well documented and is based on the author's expert judgment.

The conditional probability of pipe rupture given pipe failure was developed using the approach as used for the service water and FP systems. Details of this development are provided in Appendix B. The events in

Table 4-8 and Table 4-9 involving leaks and ruptures were reviewed for flow rate and break size information. In addition a larger set of rupture events totaling 77 events that was collected and analyzed in References [2] and [3] was reviewed and incorporated into the model. These events include a mixture of PWR and BWR events and cover all the systems classified as susceptible to FAC. The events which had equivalent break sizes of at least 1" are listed in Table 4-16. The classification of these events for the purpose of updating the prior distributions for the conditional probabilities of rupture vs. break size is discussed in Appendix B.

Table B-21 Pipe Ruptures in BWR and PWR Feedwater, Condensate, and Steam Systems

\begin{tabular}{|c|c|c|c|c|c|c|c|}
\hline Event Date & Plant Name & $\begin{array}{c}\text { Plant } \\
\text { Type }\end{array}$ & Country & $\begin{array}{c}\text { System } \\
\text { Group } \\
{[\text { Note 1] }}\end{array}$ & $\begin{array}{c}\text { Nominal } \\
\text { Pipe Size } \\
\text { (in.) }\end{array}$ & $\begin{array}{c}\text { Damage } \\
\text { Mechanism } \\
{[\text { Note 2] }}\end{array}$ & $\begin{array}{c}\text { Rupture } \\
\text { Category } \\
{[\text { Note 3] }}\end{array}$ \\
\hline $4 / 11 / 2004$ & Krsko & PWR & Slovenia & MSR & 2 & VF & A \\
\hline $2 / 25 / 2002$ & Krsko & PWR & Slovenia & EX-ST & 2 & FAC & A \\
\hline $7 / 23 / 1998$ & Calvert Cliffs-2 & PWR & US & MSR & 2 & FAC & VF \\
\hline $3 / 10 / 1995$ & Paks-1 & PWR & Hungary & FW & 2 & VF & A \\
\hline $1 / 1 / 1995$ & Not disclosed & BWR & XX & FW & 2 & FAC & A \\
\hline $1 / 11 / 1994$ & Catawba-1 & PWR & US & EXT-ST & 2 & FAC & A \\
\hline $12 / 9 / 1993$ & Indian Point-2 & PWR & US & MS & 2 & FAC & A \\
\hline $9 / 17 / 1993$ & Zaporozhe-4 & PWR & Ukraine & MSR & 2 & F \\
\hline
\end{tabular}




\begin{tabular}{|c|c|c|c|c|c|c|c|}
\hline Event Date & Plant Name & $\begin{array}{l}\text { Plant } \\
\text { Type }\end{array}$ & Country & $\begin{array}{l}\text { System } \\
\text { Group } \\
\text { [Note 1] }\end{array}$ & $\begin{array}{c}\text { Nominal } \\
\text { Pipe Size } \\
\text { (in.) }\end{array}$ & $\begin{array}{c}\text { Damage } \\
\text { Mechanism } \\
\text { [Note 2] }\end{array}$ & $\begin{array}{l}\text { Rupture } \\
\text { Category } \\
\text { [Note 3] }\end{array}$ \\
\hline $5 / 24 / 1993$ & Koeberg-1 & PWR & $\begin{array}{l}\text { South } \\
\text { Africa }\end{array}$ & FW & 2 & VF & A \\
\hline $7 / 22 / 1992$ & Maine Yankee & PWR & US & MSR & 2 & FAC & A \\
\hline $1 / 6 / 1991$ & Duane Arnold & BWR & US & EXS & 2 & VF & A \\
\hline $8 / 8 / 1985$ & Kewaunee & PWR & US & MSR & 2 & FAC & $\mathrm{A}$ \\
\hline $6 / 24 / 1985$ & McGuire-2 & PWR & US & AFW & 2 & $\mathrm{TF}$ & A \\
\hline $1 / 9 / 1978$ & KWW Würgassen & BWR & Germany & FW & 2 & $\mathrm{VF}$ & $\mathrm{A}$ \\
\hline $7 / 1 / 1971$ & Haddam Neck & PWR & US & $\begin{array}{l}\text { Heater- } \\
\text { Drain }\end{array}$ & 2 & OVP & $\mathrm{A}$ \\
\hline $7 / 28 / 1991$ & Zion-2 & PWR & US & FW & 3 & FAC & $\mathrm{A}$ \\
\hline $3 / 19 / 1983$ & Oconee-2 & PWR & US & MSR & 3 & FAC & B \\
\hline $2 / 13 / 2001$ & Balakovo-2 & PWR & Russia & $\begin{array}{l}\text { Heater- } \\
\text { Drain }\end{array}$ & 3.2 & FAC & B \\
\hline $7 / 19 / 1988$ & Kola-2 & PWR & Russia & MS & 4 & VF & $\mathrm{D}$ \\
\hline 7/27/1972 & Surry-1 & PWR & US & MSR & 4 & OVP & $\mathrm{D}$ \\
\hline $11 / 24 / 1993$ & Kola-4 & PWR & Russia & MS & 4 & FAC & B \\
\hline $3 / 23 / 1990$ & Surry-1 & PWR & US & $\begin{array}{c}\text { Heater- } \\
\text { Drain }\end{array}$ & 4 & FAC & B \\
\hline $9 / 26 / 1989$ & Indian Point-2 & PWR & US & MS & 4 & FAC & B \\
\hline $12 / 30 / 1973$ & Millstone-1 & BWR & US & COND & 4 & WH & $\mathrm{B}$ \\
\hline $1 / 1 / 1972$ & Millstone-1 & BWR & US & MS & 4 & OVP & B \\
\hline 8/10/1999 & Callaway & PWR & US & $\begin{array}{l}\text { Heater- } \\
\text { Drain }\end{array}$ & 6 & FAC & $\mathrm{D}$ \\
\hline $12 / 31 / 1990$ & Millstone-3 & PWR & US & MSR & 6 & FAC & $\mathrm{D}$ \\
\hline $4 / 28 / 1970$ & H.B. Robinson-2 & PWR & US & MS & 6 & OVP & $\mathrm{D}$ \\
\hline $7 / 1 / 2005$ & South Ukraine-2 & PWR & Ukraine & $\begin{array}{l}\text { Heater- } \\
\text { Drain }\end{array}$ & 6 & VF & B \\
\hline $12 / 15 / 1996$ & Paks-3 & PWR & Hungary & $\begin{array}{c}\text { EXT- } \\
\text { STEAM }\end{array}$ & 6 & FAC & $\mathrm{A}$ \\
\hline $4 / 22 / 1995$ & Almaraz-1 & PWR & Spain & COND & 6 & FAC & $\mathrm{B}$ \\
\hline 7/27/1993 & Bohunice-3 & PWR & Slovakia & MS & 6 & FAC & B \\
\hline $4 / 3 / 1987$ & Indian Point-2 & PWR & US & FW & 6 & FAC & B \\
\hline $7 / 29 / 1986$ & R.E. Ginna & PWR & US & MS & 6 & FAC & B \\
\hline $3 / 16 / 1985$ & Haddam Neck & PWR & US & FW & 6 & FAC & $\mathrm{A}$ \\
\hline 9/28/1983 & Browns Ferry-1 & BWR & US & MSR & 6 & FAC & $\mathrm{B}$ \\
\hline $8 / 1 / 1983$ & Zion-1 & PWR & US & EXS & 6 & FAC & A \\
\hline $1 / 9 / 1982$ & Trojan & PWR & US & EXS & 6 & FAC & B \\
\hline
\end{tabular}




\begin{tabular}{|c|c|c|c|c|c|c|c|}
\hline Event Date & Plant Name & $\begin{array}{l}\text { Plant } \\
\text { Type }\end{array}$ & Country & $\begin{array}{c}\text { System } \\
\text { Group } \\
\text { [Note 1] }\end{array}$ & $\begin{array}{c}\text { Nominal } \\
\text { Pipe Size } \\
\text { (in.) }\end{array}$ & $\begin{array}{c}\text { Damage } \\
\text { Mechanism } \\
\text { [Note 2] }\end{array}$ & $\begin{array}{l}\text { Rupture } \\
\text { Category } \\
\text { [Note 3] }\end{array}$ \\
\hline $11 / 18 / 1977$ & Ringhals-2 & PWR & Sweden & FW & 6 & FAC & B \\
\hline $11 / 1 / 1977$ & Browns Ferry-3 & BWR & US & EXS & 6 & FAC & B \\
\hline $5 / 9 / 1976$ & Oskarshamn-1 & BWR & Sweden & AFW & 6 & FAC & $\mathrm{B}$ \\
\hline $2 / 25 / 1993$ & Loviisa-2 & Finland & PWR & FW & 8 & FAC & $\mathrm{D}$ \\
\hline $12 / 5 / 2003$ & Bohunice-1 & Slovakia & PWR & $\begin{array}{c}\text { EXT- } \\
\text { STEAM }\end{array}$ & 8 & FAC & A \\
\hline $8 / 28 / 2002$ & Turkey Point-3 & US & PWR & $\begin{array}{l}\text { Heater- } \\
\text { Drain }\end{array}$ & 8 & FAC & B \\
\hline $8 / 8 / 1995$ & Millstone-2 & US & PWR & $\begin{array}{l}\text { Heater- } \\
\text { Drain }\end{array}$ & 8 & WH & $\mathrm{B}$ \\
\hline $4 / 10 / 1993$ & Fermi-2 & US & BWR & $\begin{array}{c}\text { EXT- } \\
\text { STEAM }\end{array}$ & 8 & FAC & B \\
\hline $12 / 18 / 1991$ & Almaraz-1 & Spain & PWR & MS & 8 & FAC & $\mathrm{B}$ \\
\hline $11 / 6 / 1991$ & Millstone-2 & US & PWR & MSR & 8 & FAC & B \\
\hline $1 / 15 / 1988$ & Catawba-1 & US & PWR & COND & 8 & OVP & $\mathrm{C}$ \\
\hline $9 / 25 / 1987$ & Doel-1 & Belgium & PWR & MSR & 8 & FAC & $\mathrm{C}$ \\
\hline $8 / 15 / 1983$ & Browns Ferry-1 & US & BWR & MS & 8 & FAC & B \\
\hline 9/29/1982 & Browns Ferry-1 & US & BWR & MSR & 8 & FAC & B \\
\hline $6 / 24 / 1982$ & Browns Ferry-1 & US & BWR & MSR & 8 & FAC & B \\
\hline $3 / 1 / 1993$ & Sequoyah-2 & US & PWR & MS & 10 & FAC & $\mathrm{B}$ \\
\hline 9/17/1986 & Oconee-3 & US & PWR & MSR & 10 & FAC & $\mathrm{C}$ \\
\hline $5 / 28 / 1990$ & Loviisa-1 & Finland & PWR & FW & 12 & FAC & $\mathrm{D}$ \\
\hline $12 / 2 / 1971$ & Turkey Point-3 & US & PWR & MS & 12 & $\mathrm{OVP}+\mathrm{D \& C}$ & $\mathrm{D}$ \\
\hline $4 / 21 / 1997$ & Fort Calhoun-1 & US & PWR & $\begin{array}{c}\text { EXT- } \\
\text { STEAM }\end{array}$ & 12 & FAC & $\mathrm{C}$ \\
\hline $5 / 6 / 1991$ & Kuosheng-2 & Taiwan & BWR & COND & 12 & FAC & $\mathrm{B}$ \\
\hline $4 / 18 / 1989$ & ANO-2 & US & PWR & $\begin{array}{c}\text { EXT- } \\
\text { STEAM }\end{array}$ & 14 & FAC & B \\
\hline $3 / 9 / 1985$ & Trojan & US & PWR & FW & 14 & FAC & $\mathrm{C}$ \\
\hline $12 / 29 / 1984$ & Krsko & Slovenia & PWR & FW & 14 & FAC & $\mathrm{B}$ \\
\hline $6 / 14 / 1996$ & Maanshan-2 & Taiwan & PWR & MS & 16 & FAC & B \\
\hline $12 / 1 / 1989$ & $\begin{array}{l}\text { Santa Maria de } \\
\text { Garona }\end{array}$ & Spain & BWR & FW & 16 & FAC & B \\
\hline
\end{tabular}




\begin{tabular}{|c|c|c|c|c|c|c|c|}
\hline Event Date & Plant Name & $\begin{array}{l}\text { Plant } \\
\text { Type }\end{array}$ & Country & $\begin{array}{l}\text { System } \\
\text { Group } \\
\text { [Note 1] }\end{array}$ & $\begin{array}{l}\text { Nominal } \\
\text { Pipe Size } \\
\quad \text { (in.) }\end{array}$ & $\begin{array}{l}\text { Damage } \\
\text { Mechanism } \\
\text { [Note 2] }\end{array}$ & $\begin{array}{l}\text { Rupture } \\
\text { Category } \\
\text { [Note 3] }\end{array}$ \\
\hline $11 / 20 / 1984$ & Calvert Cliffs-1 & US & PWR & $\begin{array}{c}\text { EXT- } \\
\text { STEAM }\end{array}$ & 16 & FAC & $\mathrm{C}$ \\
\hline $9 / 10 / 1982$ & Maine Yankee & US & PWR & $\begin{array}{c}\text { EXT- } \\
\text { STEAM }\end{array}$ & 16 & FAC & A \\
\hline $2 / 9 / 1980$ & $\begin{array}{c}\text { Santa Maria de } \\
\text { Garona }\end{array}$ & Spain & BWR & $\begin{array}{l}\text { EXT- } \\
\text { STEAM }\end{array}$ & 16 & FAC & B \\
\hline 9/24/1996 & Oconee-2 & US & PWR & MSR & 18 & WH & $\mathrm{D}$ \\
\hline $6 / 10 / 1974$ & Quad Cities-2 & US & BWR & FW & 18 & OVP + D\&C & $\mathrm{D}$ \\
\hline $12 / 9 / 1986$ & Surry-2 & US & PWR & FW & 18 & FAC & $\mathrm{C}$ \\
\hline $6 / 27 / 1985$ & $\begin{array}{l}\text { KMK Mülheim- } \\
\text { Kärlich }\end{array}$ & Germany & PWR & FW & 18 & OVP & $\mathrm{C}$ \\
\hline $8 / 9 / 2004$ & Mihama-3 & Japan & PWR & FW & 20 & FAC & $\mathrm{C}$ \\
\hline $4 / 24 / 1986$ & Hatch-2 & US & BWR & FW & 20 & FAC & B \\
\hline $3 / 14 / 2007$ & Perry & US & BWR & $\begin{array}{c}\text { EXT- } \\
\text { STEAM }\end{array}$ & 24 & FAC & A \\
\hline $6 / 23 / 1982$ & Oconee-2 & US & PWR & $\begin{array}{c}\text { EXT- } \\
\text { STEAM }\end{array}$ & 24 & FAC & $\mathrm{C}$ \\
\hline $2 / 12 / 1982$ & Zion-1 & US & PWR & $\begin{array}{c}\text { EXT- } \\
\text { STEAM }\end{array}$ & 24 & FAC & B \\
\hline $10 / 15 / 1983$ & Surry-1 & US & PWR & $\begin{array}{l}\text { Heater- } \\
\text { Drain }\end{array}$ & 26 & OVP & $\mathrm{D}$ \\
\hline \multicolumn{8}{|c|}{$\begin{aligned} \text { MSR } & =\text { Moisture Separator Reheate } \\
\mathrm{FW} & =\text { Feedwater } \\
\mathrm{AFW} & =\text { Auxiliary Feedwater }\end{aligned}$} \\
\hline \multicolumn{8}{|c|}{$\begin{array}{ll}\text { Note 2: } & \text { Failure Mechanisms: } \\
& \text { FAC = Flow accelerated corrosion } \\
& \text { OVP }=\text { Over-pressurized }\end{array}$} \\
\hline $\begin{array}{l}\text { Note 3. } \mathrm{Ru} \\
\\
\\
\mathrm{A} \\
\mathrm{B}\end{array}$ & $\begin{array}{l}\text { ture Modes: } \\
<2 \text { in. EBS, no Pipe } \\
>2 \text { in. EBS, no Pipe }\end{array}$ & $\begin{array}{l}\text { hip Potential } \\
\text { hip Potential }\end{array}$ & $\begin{array}{l}\mathrm{C} \\
\mathrm{D}\end{array}$ & $\begin{array}{l}\text { n. EBS, no } \\
\text { mplete Rup }\end{array}$ & $\begin{array}{l}\text { Pipe Whip P } \\
\text { ture with Pip }\end{array}$ & $\begin{array}{l}\text { tential } \\
\text { Whip Potential }\end{array}$ & \\
\hline
\end{tabular}

\subsubsection{Failure Rates and Cumulative Rupture Frequencies for FAC Susceptible Systems}

The results for the failure rates and cumulative rupture frequencies for each of the four systems in the category of FAC susceptible systems are presented in the following sections.

The results for the failure rates and cumulative rupture frequencies for each of the four systems in the category of FAC susceptible systems and two categories of pipe sizes are presented in Appendix $B$. The results for the failure rates and cumulative rupture frequencies for feedwater 
and condensate (FWC) system piping are shown in Figure 4-8 and Table 4-12 for NPS > 10" pipe.

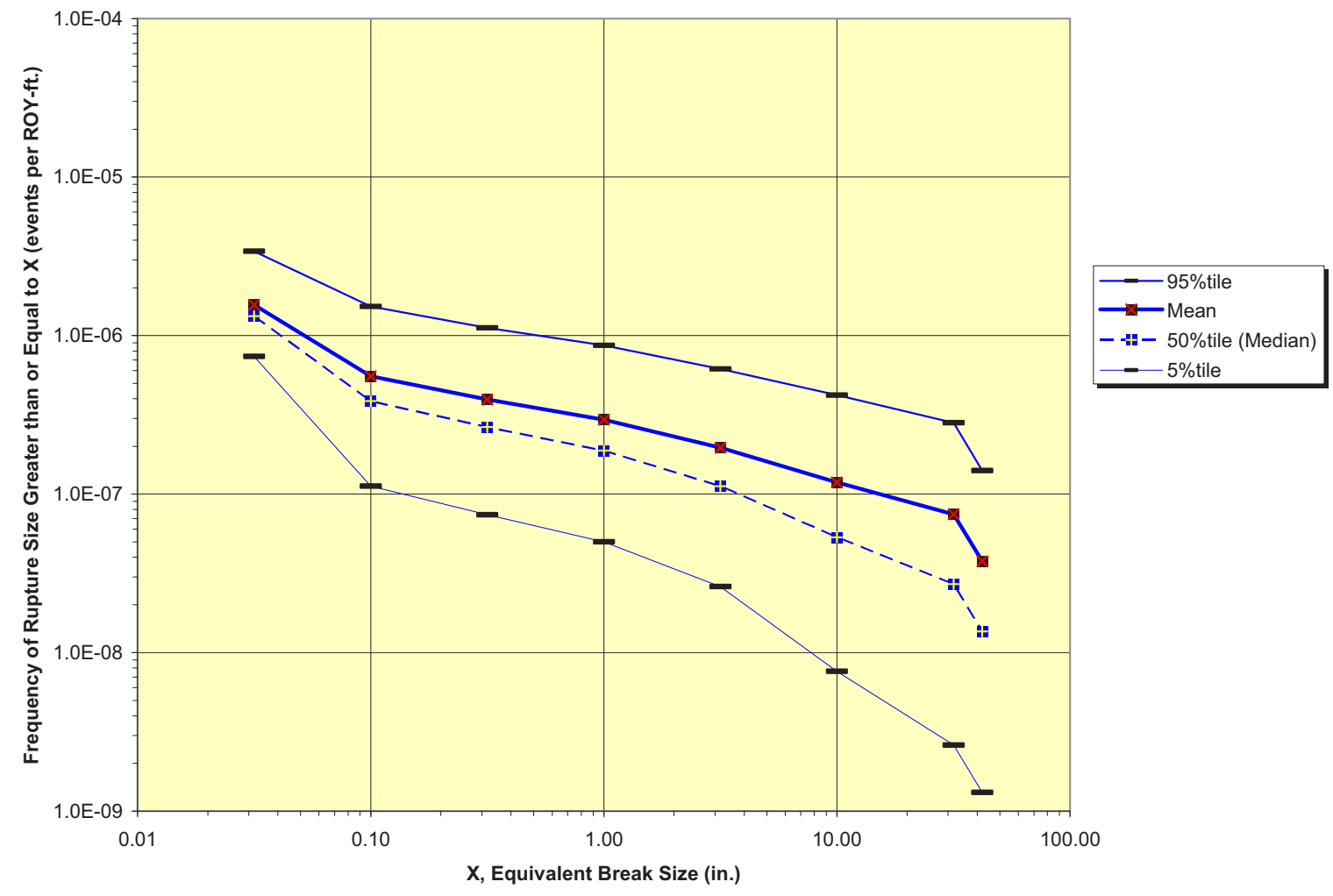

Figure B-52 Cumulative Rupture Frequency vs. Break Size for NPS > 10" FWC Pipe

Table B-22 Failure Rates and Cumulative Rupture Frequencies for NPS > 10" FWC System

\begin{tabular}{|c|c|c|c|c|c|c|}
\hline \multirow{2}{*}{\multicolumn{2}{|c|}{ Parameter }} & \multicolumn{5}{|c|}{ Frequency per ROY-ft. } \\
\hline & & Mean & $5 \%$ tile & $50 \%$ tile & $95 \%$ tile & $\mathrm{RF}^{[\text {Note 1] }}$ \\
\hline \multicolumn{2}{|c|}{ Failure Rate } & $5.72 \mathrm{E}-06$ & $3.56 \mathrm{E}-06$ & $5.34 \mathrm{E}-06$ & $1.07 \mathrm{E}-05$ & 1.73 \\
\hline \multirow{5}{*}{ 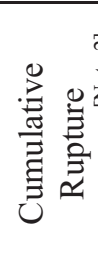 } & EBS (in.) & & & & & \\
\hline & 0.032 & $1.56 \mathrm{E}-06$ & 7.39E-07 & $1.33 \mathrm{E}-06$ & $3.41 \mathrm{E}-06$ & 2.15 \\
\hline & 0.10 & $5.54 \mathrm{E}-07$ & $1.12 \mathrm{E}-07$ & $3.86 \mathrm{E}-07$ & $1.52 \mathrm{E}-06$ & 3.69 \\
\hline & 0.316 & $3.95 \mathrm{E}-07$ & $7.40 \mathrm{E}-08$ & $2.64 \mathrm{E}-07$ & $1.12 \mathrm{E}-06$ & 3.89 \\
\hline & 1.00 & $2.95 \mathrm{E}-07$ & $4.99 \mathrm{E}-08$ & $1.88 \mathrm{E}-07$ & 8.67E-07 & 4.17 \\
\hline
\end{tabular}




\begin{tabular}{|c|c|c|c|c|c|}
\hline 3.16 & $1.96 \mathrm{E}-07$ & $2.61 \mathrm{E}-08$ & $1.12 \mathrm{E}-07$ & $6.16 \mathrm{E}-07$ & 4.86 \\
\hline 10.00 & $1.19 \mathrm{E}-07$ & $7.61 \mathrm{E}-09$ & $5.33 \mathrm{E}-08$ & $4.21 \mathrm{E}-07$ & 7.44 \\
\hline 31.62 & $7.46 \mathrm{E}-08$ & $2.61 \mathrm{E}-09$ & $2.71 \mathrm{E}-08$ & $2.82 \mathrm{E}-07$ & 10.38 \\
\hline 42.00 & $3.77 \mathrm{E}-08$ & $1.31 \mathrm{E}-09$ & $1.36 \mathrm{E}-08$ & $1.41 \mathrm{E}-07$ & 10.34 \\
\hline
\end{tabular}

Note $1 . \mathrm{RF}=(95 \% \text { tile } / 5 \% \text { tile })^{0.5}$; These distributions can be approximated as lognormal distributions with the indicated mean and the calculated range factor (RF)

Note 2. Frequency of pipe rupture with EBS equal to or greater than indicated EBS value; use 42.0in. values for frequency of rupture with pipe whip potential.

\subsubsection{Results for Feedwater and Condensate System Piping.}

The results for the failure rates and cumulative rupture frequencies for feedwater and condensate (FWC) system piping are shown in Table B-25 and Figure B-54 for NPS $\leq 10$ " and Table 4-12 and Figure 4-8 for NPS > 10" piping systems.

\subsubsection{Results for Low Pressure Steam System Piping.}

The results for the failure rates and cumulative rupture frequencies for LPS system piping are shown in Table B-27 and Figure B-56 for NPS $\leq 10$ " and Table B-28 and Figure B-57 for NPS > 10 " piping systems.

\subsubsection{Results for High Pressure Steam System Piping.}

The results for the failure rates and cumulative rupture frequencies for HPS system piping are shown in Table B-29 and Figure B-58 for NPS $\leq 10$ " and Table B-30 and Figure B-59 for NPS > 10 " piping systems.

\subsubsection{Results for Extraction Steam System Piping.}

The results for the failure rates and cumulative rupture frequencies for EXS system piping are shown in Table B-31 and Figure B-60 for NPS $\leq 10$ " and Table B-32 and Figure B-61 for NPS > 10 " piping systems. 


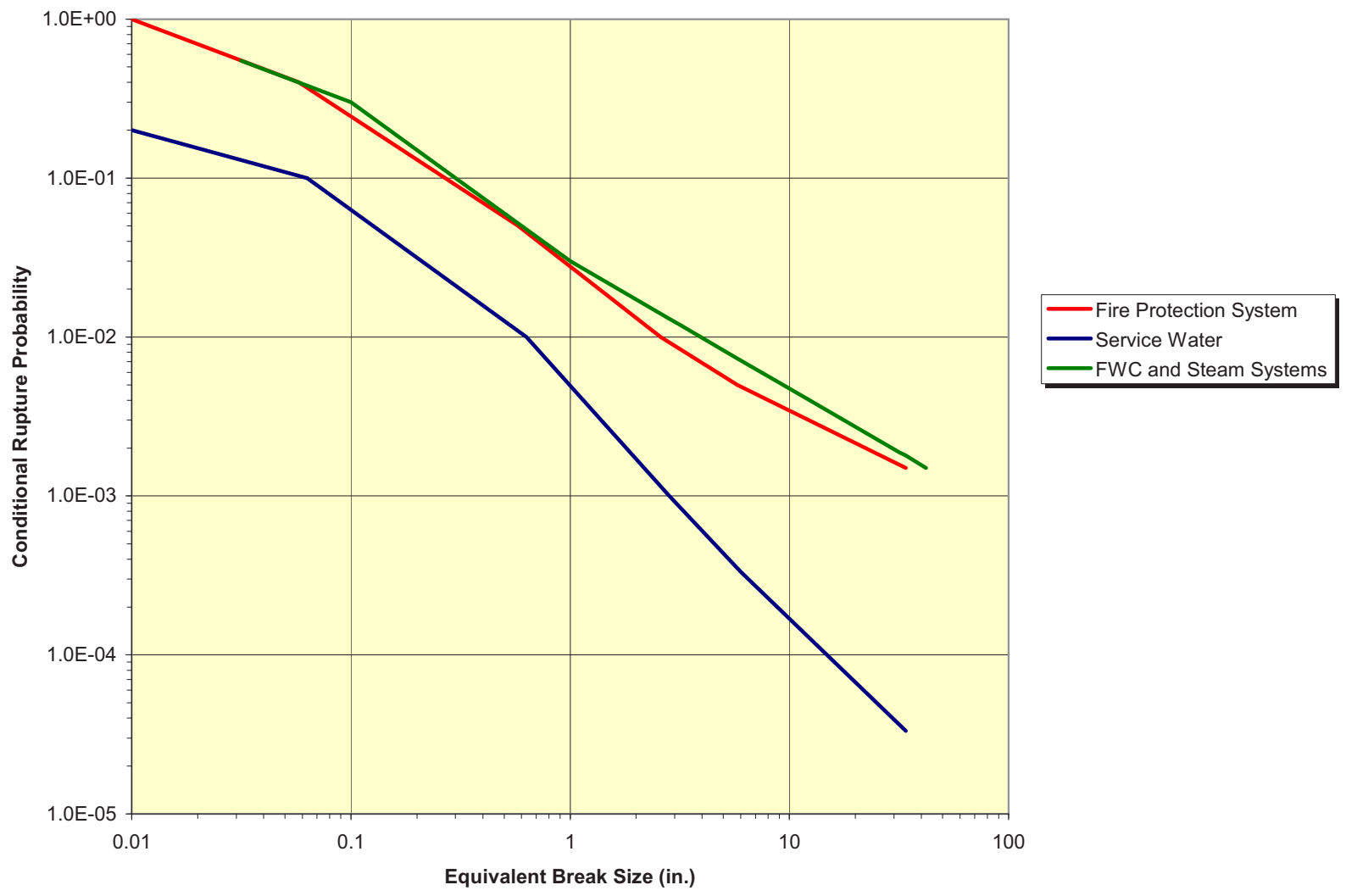

Figure B-30 Comparison of Prior Means for Conditional Probability of Rupture vs. Break Size for Service Water, Fire Protection, Feedwater, Condensate and Steam Systems 
Table B-50 Pipe Ruptures in BWR and PWR Feedwater, Condensate, and Steam Systems

\begin{tabular}{|c|c|c|c|c|c|c|c|}
\hline Event Date & Plant Name & $\begin{array}{l}\text { Plant } \\
\text { Type }\end{array}$ & Country & $\begin{array}{c}\text { System } \\
\text { Group } \\
\text { [Note 1] }\end{array}$ & $\begin{array}{l}\text { Nominal } \\
\text { Pipe Size } \\
\text { (in.) }\end{array}$ & $\begin{array}{c}\text { Damage } \\
\text { Mechanism } \\
\text { [Note 2] }\end{array}$ & $\begin{array}{c}\text { Rupture } \\
\text { Category } \\
\text { [Note 3] }\end{array}$ \\
\hline $4 / 11 / 2004$ & Krsko & PWR & Slovenia & MSR & 2 & VF & $\mathrm{A}$ \\
\hline $2 / 25 / 2002$ & Krsko & PWR & Slovenia & EX-ST & 2 & FAC & $\mathrm{A}$ \\
\hline $7 / 23 / 1998$ & Calvert Cliffs-2 & PWR & US & MSR & 2 & FAC & $\mathrm{A}$ \\
\hline $3 / 10 / 1995$ & Paks-1 & PWR & Hungary & FW & 2 & VF & $\mathrm{A}$ \\
\hline $1 / 1 / 1995$ & Not disclosed & BWR & XX & FW & 2 & VF & $\mathrm{A}$ \\
\hline $1 / 11 / 1994$ & Catawba-1 & PWR & US & EXT-ST & 2 & FAC & $\mathrm{A}$ \\
\hline $12 / 9 / 1993$ & Indian Point-2 & PWR & US & MS & 2 & FAC & $\mathrm{A}$ \\
\hline 9/17/1993 & Zaporozhe-4 & PWR & Ukraine & MSR & 2 & FAC & $\mathrm{A}$ \\
\hline $5 / 24 / 1993$ & Koeberg-1 & PWR & $\begin{array}{l}\text { South } \\
\text { Africa }\end{array}$ & FW & 2 & $\mathrm{VF}$ & $\mathrm{A}$ \\
\hline $7 / 22 / 1992$ & Maine Yankee & PWR & US & MSR & 2 & FAC & A \\
\hline $1 / 6 / 1991$ & Duane Arnold & BWR & US & EXS & 2 & VF & $\mathrm{A}$ \\
\hline $8 / 8 / 1985$ & Kewaunee & PWR & US & MSR & 2 & FAC & $\mathrm{A}$ \\
\hline $6 / 24 / 1985$ & McGuire-2 & PWR & US & AFW & 2 & $\mathrm{TF}$ & $\mathrm{A}$ \\
\hline $1 / 9 / 1978$ & KWW Würgassen & BWR & Germany & FW & 2 & $\mathrm{VF}$ & $\mathrm{A}$ \\
\hline $7 / 1 / 1971$ & Haddam Neck & PWR & US & $\begin{array}{c}\text { Heater- } \\
\text { Drain }\end{array}$ & 2 & OVP & $\mathrm{A}$ \\
\hline $7 / 28 / 1991$ & Zion-2 & PWR & US & FW & 3 & FAC & $\mathrm{A}$ \\
\hline $3 / 19 / 1983$ & Oconee-2 & PWR & US & MSR & 3 & FAC & $\mathrm{B}$ \\
\hline $2 / 13 / 2001$ & Balakovo-2 & PWR & Russia & $\begin{array}{c}\text { Heater- } \\
\text { Drain }\end{array}$ & 3.2 & FAC & $\mathrm{B}$ \\
\hline $7 / 19 / 1988$ & Kola-2 & PWR & Russia & MS & 4 & $\mathrm{VF}$ & $\mathrm{D}$ \\
\hline $7 / 27 / 1972$ & Surry-1 & PWR & US & MSR & 4 & OVP & $\mathrm{D}$ \\
\hline $11 / 24 / 1993$ & Kola-4 & PWR & Russia & MS & 4 & FAC & $\mathrm{B}$ \\
\hline $3 / 23 / 1990$ & Surry-1 & PWR & US & $\begin{array}{c}\text { Heater- } \\
\text { Drain }\end{array}$ & 4 & FAC & $\mathrm{B}$ \\
\hline 9/26/1989 & Indian Point-2 & PWR & US & $\mathrm{MS}$ & 4 & FAC & $\mathrm{B}$ \\
\hline $12 / 30 / 1973$ & Millstone-1 & BWR & US & COND & 4 & WH & B \\
\hline $1 / 1 / 1972$ & Millstone-1 & BWR & US & MS & 4 & OVP & $\mathrm{B}$ \\
\hline $8 / 10 / 1999$ & Callaway & PWR & US & $\begin{array}{c}\text { Heater- } \\
\text { Drain }\end{array}$ & 6 & FAC & $\mathrm{D}$ \\
\hline $12 / 31 / 1990$ & Millstone-3 & PWR & US & MSR & 6 & FAC & $\mathrm{D}$ \\
\hline $4 / 28 / 1970$ & H.B. Robinson-2 & PWR & US & MS & 6 & OVP & $\mathrm{D}$ \\
\hline $7 / 1 / 2005$ & South Ukraine-2 & PWR & Ukraine & $\begin{array}{c}\text { Heater- } \\
\text { Drain }\end{array}$ & 6 & VF & $\mathrm{B}$ \\
\hline
\end{tabular}




\begin{tabular}{|c|c|c|c|c|c|c|c|}
\hline Event Date & Plant Name & $\begin{array}{l}\text { Plant } \\
\text { Type }\end{array}$ & Country & $\begin{array}{c}\text { System } \\
\text { Group } \\
\text { [Note 1] }\end{array}$ & $\begin{array}{c}\text { Nominal } \\
\text { Pipe Size } \\
\text { (in.) }\end{array}$ & $\begin{array}{c}\text { Damage } \\
\text { Mechanism } \\
\text { [Note 2] }\end{array}$ & $\begin{array}{l}\text { Rupture } \\
\text { Category } \\
\text { [Note 3] }\end{array}$ \\
\hline $12 / 15 / 1996$ & Paks-3 & PWR & Hungary & $\begin{array}{c}\text { EXT- } \\
\text { STEAM }\end{array}$ & 6 & FAC & A \\
\hline $4 / 22 / 1995$ & Almaraz-1 & PWR & Spain & COND & 6 & FAC & B \\
\hline $7 / 27 / 1993$ & Bohunice-3 & PWR & Slovakia & MS & 6 & FAC & B \\
\hline $4 / 3 / 1987$ & Indian Point-2 & PWR & US & FW & 6 & FAC & B \\
\hline $7 / 29 / 1986$ & R.E. Ginna & PWR & US & MS & 6 & FAC & B \\
\hline $3 / 16 / 1985$ & Haddam Neck & PWR & US & FW & 6 & FAC & A \\
\hline $9 / 28 / 1983$ & Browns Ferry-1 & BWR & US & MSR & 6 & FAC & B \\
\hline $8 / 1 / 1983$ & Zion-1 & PWR & US & EXS & 6 & FAC & A \\
\hline $1 / 9 / 1982$ & Trojan & PWR & US & EXS & 6 & FAC & B \\
\hline $11 / 18 / 1977$ & Ringhals-2 & PWR & Sweden & FW & 6 & FAC & $\mathrm{B}$ \\
\hline $11 / 1 / 1977$ & Browns Ferry-3 & BWR & US & EXS & 6 & FAC & B \\
\hline $5 / 9 / 1976$ & Oskarshamn-1 & BWR & Sweden & AFW & 6 & FAC & B \\
\hline $2 / 25 / 1993$ & Loviisa-2 & Finland & PWR & FW & 8 & FAC & $\mathrm{D}$ \\
\hline $12 / 5 / 2003$ & Bohunice-1 & Slovakia & PWR & $\begin{array}{c}\text { EXT- } \\
\text { STEAM }\end{array}$ & 8 & FAC & A \\
\hline $8 / 28 / 2002$ & Turkey Point-3 & US & PWR & $\begin{array}{l}\text { Heater- } \\
\text { Drain }\end{array}$ & 8 & FAC & B \\
\hline $8 / 8 / 1995$ & Millstone-2 & US & PWR & $\begin{array}{c}\text { Heater- } \\
\text { Drain }\end{array}$ & 8 & WH & B \\
\hline $4 / 10 / 1993$ & Fermi-2 & US & BWR & $\begin{array}{c}\text { EXT- } \\
\text { STEAM }\end{array}$ & 8 & FAC & B \\
\hline $12 / 18 / 1991$ & Almaraz-1 & Spain & PWR & MS & 8 & FAC & $\mathrm{B}$ \\
\hline $11 / 6 / 1991$ & Millstone-2 & US & PWR & MSR & 8 & FAC & B \\
\hline $1 / 15 / 1988$ & Catawba-1 & US & PWR & COND & 8 & OVP & $\mathrm{C}$ \\
\hline $9 / 25 / 1987$ & Doel-1 & Belgium & PWR & MSR & 8 & FAC & $\mathrm{C}$ \\
\hline $8 / 15 / 1983$ & Browns Ferry-1 & US & BWR & MS & 8 & FAC & B \\
\hline $9 / 29 / 1982$ & Browns Ferry-1 & US & BWR & MSR & 8 & FAC & $\mathrm{B}$ \\
\hline $6 / 24 / 1982$ & Browns Ferry-1 & US & BWR & MSR & 8 & FAC & B \\
\hline $3 / 1 / 1993$ & Sequoyah-2 & US & PWR & MS & 10 & FAC & B \\
\hline 9/17/1986 & Oconee-3 & US & PWR & MSR & 10 & FAC & $\mathrm{C}$ \\
\hline $5 / 28 / 1990$ & Loviisa-1 & Finland & PWR & FW & 12 & FAC & $\mathrm{D}$ \\
\hline $12 / 2 / 1971$ & Turkey Point-3 & US & PWR & MS & 12 & $\mathrm{OVP}+\mathrm{D \& C}$ & $\mathrm{D}$ \\
\hline
\end{tabular}




\begin{tabular}{|c|c|c|c|c|c|c|c|}
\hline Event Date & Plant Name & $\begin{array}{l}\text { Plant } \\
\text { Type }\end{array}$ & Country & $\begin{array}{l}\text { System } \\
\text { Group } \\
\text { [Note 1] }\end{array}$ & $\begin{array}{l}\text { Nominal } \\
\text { Pipe Size } \\
\quad \text { (in.) }\end{array}$ & $\begin{array}{l}\text { Damage } \\
\text { Mechanism } \\
\text { [Note 2] }\end{array}$ & $\begin{array}{l}\text { Rupture } \\
\text { Category } \\
\text { [Note 3] }\end{array}$ \\
\hline $4 / 21 / 1997$ & Fort Calhoun-1 & US & PWR & $\begin{array}{c}\text { EXT- } \\
\text { STEAM }\end{array}$ & 12 & FAC & $\mathrm{C}$ \\
\hline $5 / 6 / 1991$ & Kuosheng-2 & Taiwan & BWR & COND & 12 & FAC & B \\
\hline $4 / 18 / 1989$ & ANO-2 & US & PWR & $\begin{array}{c}\text { EXT- } \\
\text { STEAM }\end{array}$ & 14 & FAC & B \\
\hline $3 / 9 / 1985$ & Trojan & US & PWR & FW & 14 & FAC & $\mathrm{C}$ \\
\hline $12 / 29 / 1984$ & Krsko & Slovenia & PWR & FW & 14 & FAC & B \\
\hline $6 / 14 / 1996$ & Maanshan-2 & Taiwan & PWR & MS & 16 & FAC & B \\
\hline $12 / 1 / 1989$ & $\begin{array}{l}\text { Santa Maria de } \\
\text { Garona }\end{array}$ & Spain & BWR & FW & 16 & FAC & B \\
\hline $11 / 20 / 1984$ & Calvert Cliffs-1 & US & PWR & $\begin{array}{l}\text { EXT- } \\
\text { STEAM }\end{array}$ & 16 & FAC & $\mathrm{C}$ \\
\hline $9 / 10 / 1982$ & Maine Yankee & US & PWR & $\begin{array}{c}\text { EXT- } \\
\text { STEAM }\end{array}$ & 16 & FAC & $\mathrm{A}$ \\
\hline $2 / 9 / 1980$ & $\begin{array}{l}\text { Santa Maria de } \\
\text { Garona }\end{array}$ & Spain & BWR & $\begin{array}{c}\text { EXT- } \\
\text { STEAM }\end{array}$ & 16 & FAC & B \\
\hline 9/24/1996 & Oconee-2 & US & PWR & MSR & 18 & WH & $\mathrm{D}$ \\
\hline $6 / 10 / 1974$ & Quad Cities-2 & US & BWR & FW & 18 & OVP + D\&C & $\mathrm{D}$ \\
\hline $12 / 9 / 1986$ & Surry-2 & US & PWR & FW & 18 & FAC & $\mathrm{C}$ \\
\hline $6 / 27 / 1985$ & $\begin{array}{l}\text { KMK Mülheim- } \\
\text { Kärlich }\end{array}$ & Germany & PWR & FW & 18 & OVP & $\mathrm{C}$ \\
\hline $8 / 9 / 2004$ & Mihama-3 & Japan & PWR & FW & 20 & FAC & $\mathrm{C}$ \\
\hline $4 / 24 / 1986$ & Hatch-2 & US & BWR & FW & 20 & FAC & B \\
\hline $3 / 14 / 2007$ & Perry & US & BWR & $\begin{array}{c}\text { EXT- } \\
\text { STEAM }\end{array}$ & 24 & FAC & A \\
\hline $6 / 23 / 1982$ & Oconee-2 & US & PWR & $\begin{array}{l}\text { EXT- } \\
\text { STEAM }\end{array}$ & 24 & FAC & $\mathrm{C}$ \\
\hline $2 / 12 / 1982$ & Zion-1 & US & PWR & $\begin{array}{l}\text { EXT- } \\
\text { STEAM }\end{array}$ & 24 & FAC & B \\
\hline $10 / 15 / 1983$ & Surry-1 & US & PWR & $\begin{array}{l}\text { Heater- } \\
\text { Drain }\end{array}$ & 26 & OVP & $\mathrm{D}$ \\
\hline \multicolumn{8}{|c|}{$\begin{aligned} \mathrm{FW} & =\text { Feedwater } \\
\mathrm{AFW} & =\text { Auxiliary Feedwater }\end{aligned}$} \\
\hline \multicolumn{8}{|c|}{$\begin{array}{ll}\text { Note 2: } & \text { Failure Mechanisms: } \\
& \text { FAC }=\text { Flow accelerated corrosion } \\
& \text { OVP }=\text { Over-pressurized } \\
\end{array}$} \\
\hline
\end{tabular}




\begin{tabular}{|c|c|c|c|c|c|c|c|}
\hline Event Date & Plant Name & $\begin{array}{l}\text { Plant } \\
\text { Type }\end{array}$ & Country & $\begin{array}{l}\text { System } \\
\text { Group } \\
\text { [Note 1] }\end{array}$ & $\begin{array}{l}\text { Nominal } \\
\text { Pipe Size } \\
\text { (in.) }\end{array}$ & $\begin{array}{c}\text { Damage } \\
\text { Mechanism } \\
\text { [Note 2] }\end{array}$ & $\begin{array}{c}\text { Rupture } \\
\text { Category } \\
\text { [Note 3] }\end{array}$ \\
\hline \multicolumn{8}{|c|}{ Note 3. Rupture Modes: } \\
\hline $\begin{array}{l}\text { A } \\
\text { B }\end{array}$ & $\begin{array}{l}<2 \text { in. EBS, no Pip } \\
>2 \text { in. EBS, no Pip }\end{array}$ & $\begin{array}{l}\text { hip Potentia } \\
\text { hip Potentia }\end{array}$ & $\begin{array}{l}\mathrm{C} \\
\mathrm{D}\end{array}$ & $\begin{array}{l}\text { in. EBS, no } \\
\text { mplete Rup }\end{array}$ & $\begin{array}{l}\text { ipe Whip P } \\
\text { ure with Pip }\end{array}$ & $\begin{array}{l}\text { ential } \\
\text { Whip Potential }\end{array}$ & \\
\hline
\end{tabular}

Table B-25 Bayes' Update of Prior Distribution for Conditional Rupture Probability for FAC Susceptible Systems

\begin{tabular}{|c|c|c|c|c|c|c|c|c|c|}
\hline \multirow[b]{2}{*}{$\begin{array}{l}\text { EBS } \\
\text { [in.] }\end{array}$} & \multicolumn{3}{|c|}{ Prior Distribution } & \multicolumn{2}{|c|}{ Evidence } & \multicolumn{3}{|c|}{ Posterior Distribution } & \multirow[b]{2}{*}{$\begin{array}{l}\text { Distribution } \\
\text { Used in } \\
\text { Uncertainty } \\
\text { Analysis } \\
\end{array}$} \\
\hline & $\begin{array}{l}\text { Mean } \\
\text { Cond. } \\
\text { Rupture } \\
\text { Prob. }\end{array}$ & A & B & $\begin{array}{c}\text { Failures } \\
\text { at EBS }\end{array}$ & $\begin{array}{c}\text { Total } \\
\text { Failures }\end{array}$ & A & B & $\begin{array}{c}\text { Mean } \\
\text { Cond. } \\
\text { Rupture } \\
\text { Prob. }\end{array}$ & \\
\hline 0.032 & 5.48E-01 & 1 & 1 & 259 & 1472 & 260 & 1214 & $1.76 \mathrm{E}-01$ & Beta \\
\hline 0.10 & 3.00E-01 & 1 & 2 & 40 & 1472 & 41 & 1434 & $2.78 \mathrm{E}-02$ & Lognorm. RF=3 \\
\hline 0.316 & 9.49E-02 & 1 & 10 & 25 & 1472 & 26 & 1457 & 1.75E-02 & Lognorm. RF=3 \\
\hline 1.00 & 3.00E-02 & 1 & 32 & 25 & 1472 & 26 & 1479 & 1.73E-02 & Lognorm. RF=3 \\
\hline 3.16 & 1.19E-02 & 1 & 83 & 20 & 1472 & 21 & 1535 & $1.35 \mathrm{E}-02$ & Lognorm. RF=3 \\
\hline 10.00 & 4.74E-03 & 1 & 210 & 12 & 1472 & 13 & 1670 & 7.72E-03 & Lognorm. RF=5 \\
\hline 14.14 & $3.59 \mathrm{E}-03$ & 1 & 278 & 9 & 1472 & 10 & 1741 & $5.71 \mathrm{E}-03$ & Lognorm. RF=7 \\
\hline 31.62 & $1.88 \mathrm{E}-03$ & 1 & 530 & 5 & 391 & 6 & 916 & $6.51 \mathrm{E}-03$ & Lognorm. RF=10 \\
\hline 34.00 & $1.50 \mathrm{E}-03$ & 1 & 666 & 6 & 391 & 7 & 1051 & $6.62 \mathrm{E}-03$ & Lognorm. RF=10 \\
\hline
\end{tabular}




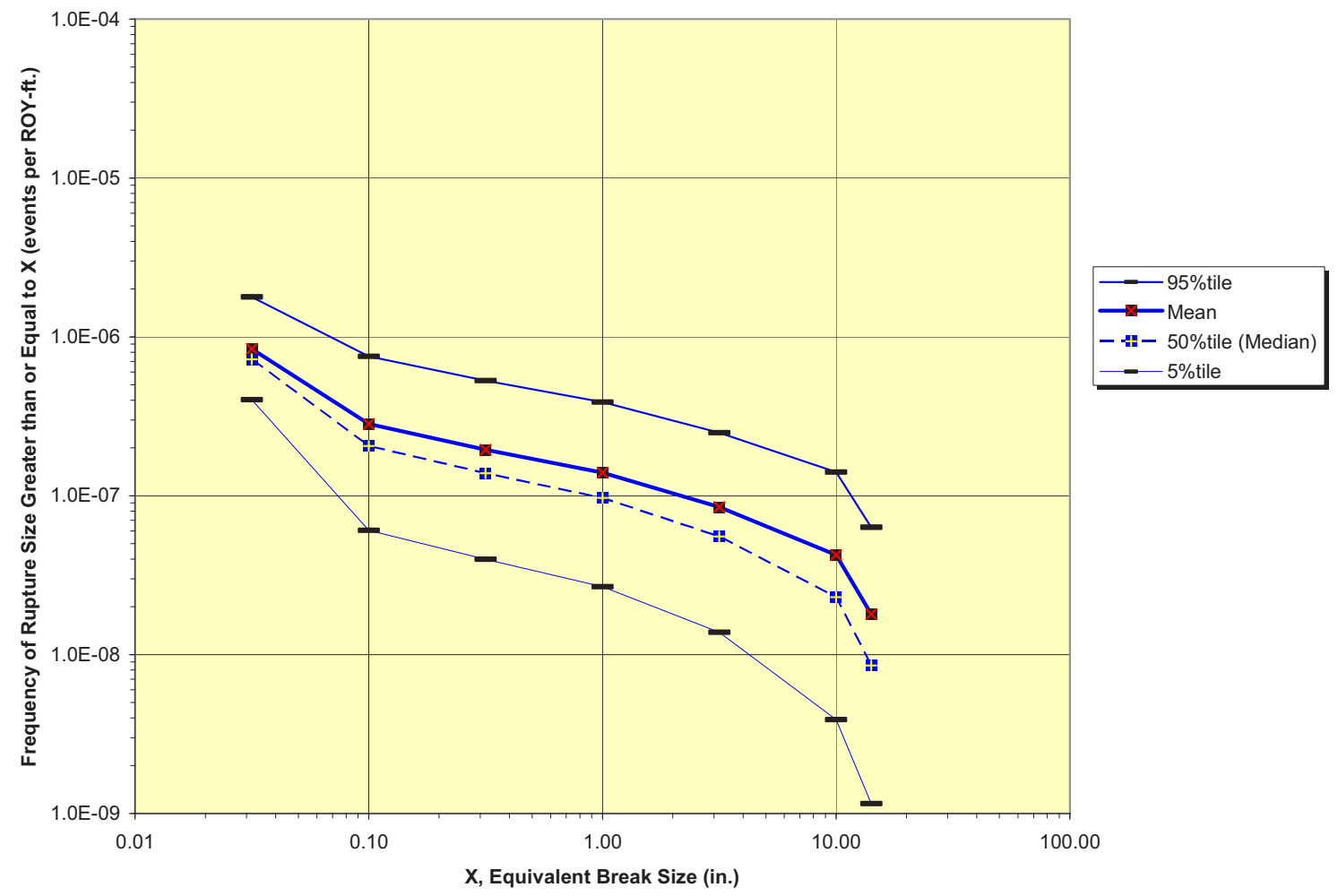

Figure B-54 Cumulative Rupture Frequency vs. Break Size for NPS $\leq 10$ " FWC Pipe Table B-25 Failure Rates and Cumulative Rupture Frequencies for NPS $\leq 10$ " FWC System

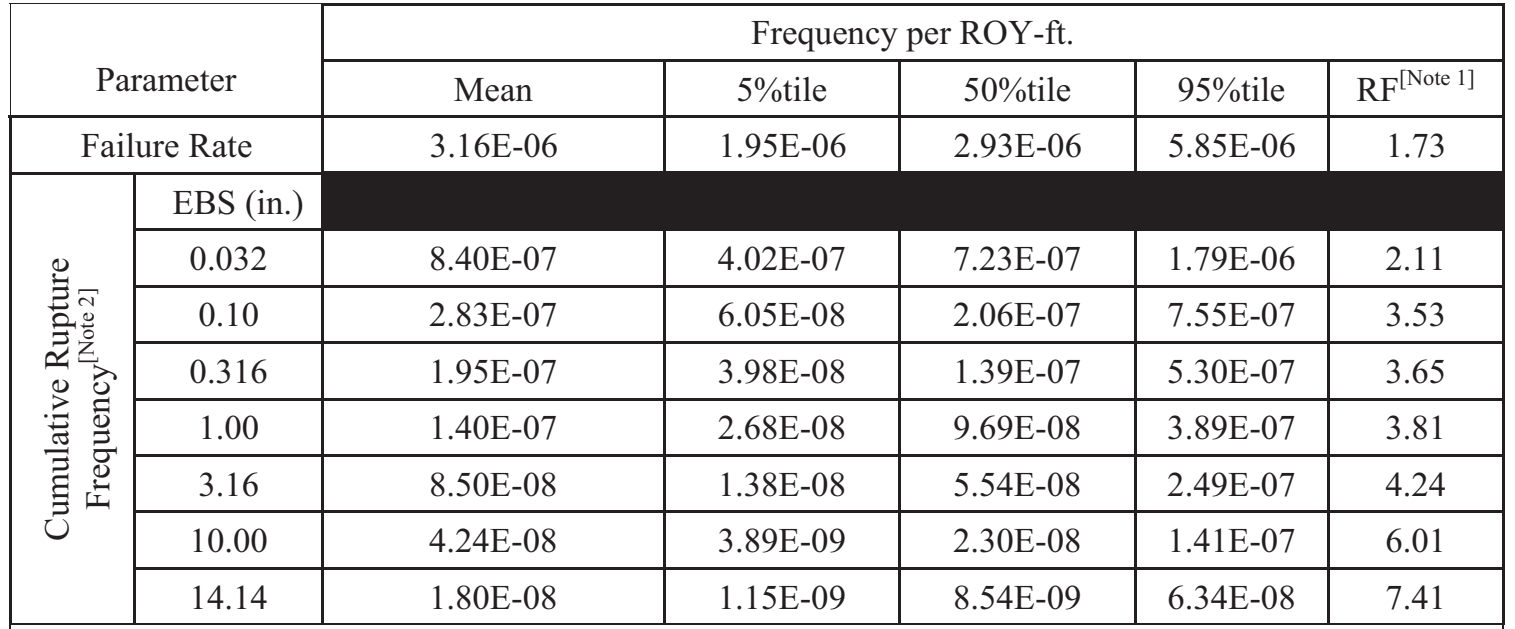

Note $1 . \mathrm{RF}=(95 \% \text { tile } / 5 \% \text { tile })^{0.5}$; These distributions can be approximated as lognormal distributions with the indicated mean and the calculated range factor (RF)

Note 2. Frequency of pipe rupture with EBS equal to or greater than indicated EBS value; use 14.14in. values for frequency of rupture with pipe whip potential. 


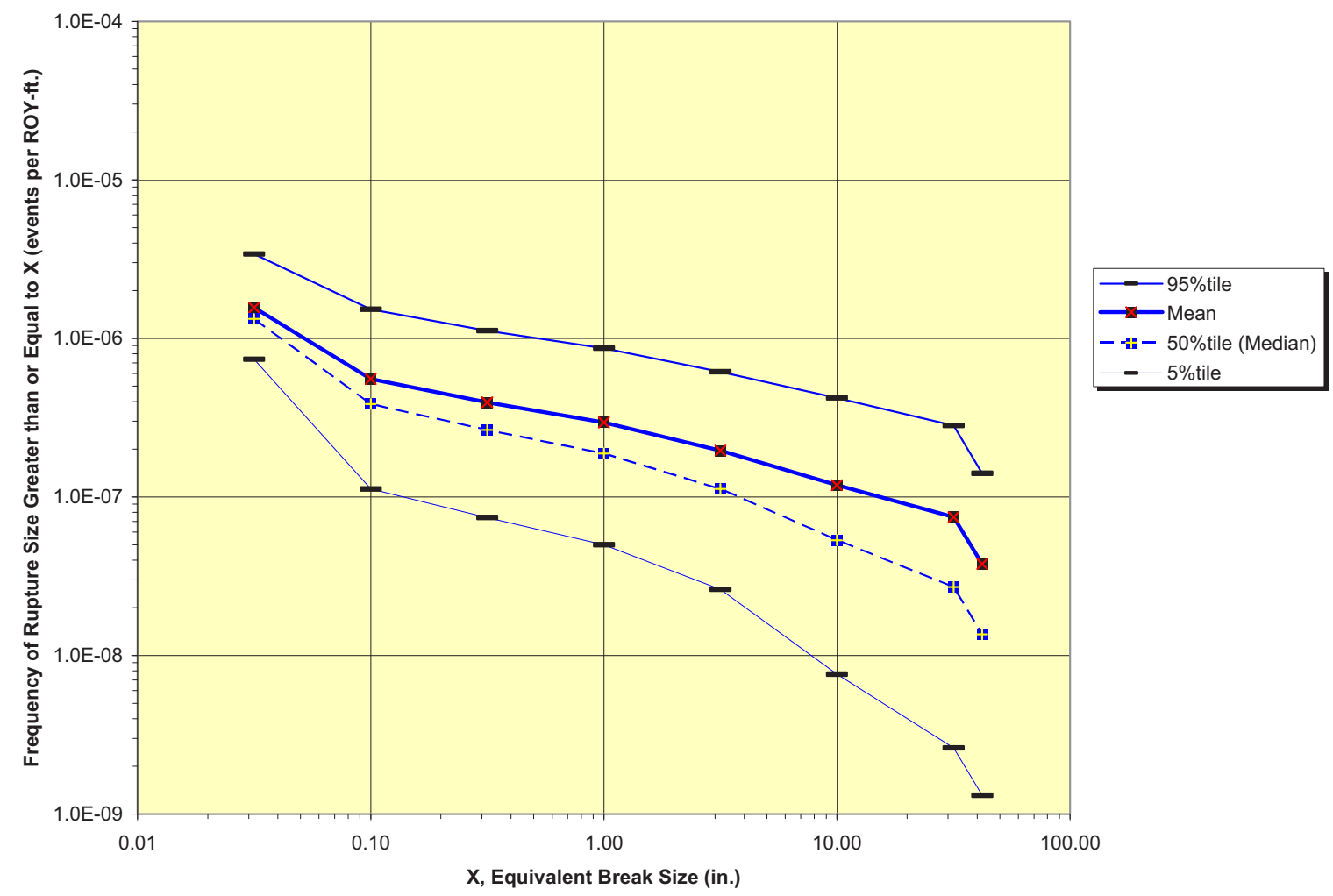

Figure B-55 Cumulative Rupture Frequency vs. Break Size for NPS > 10" FWC Pipe Table B-53 Failure Rates and Cumulative Rupture Frequencies for NPS > 10" FWC System

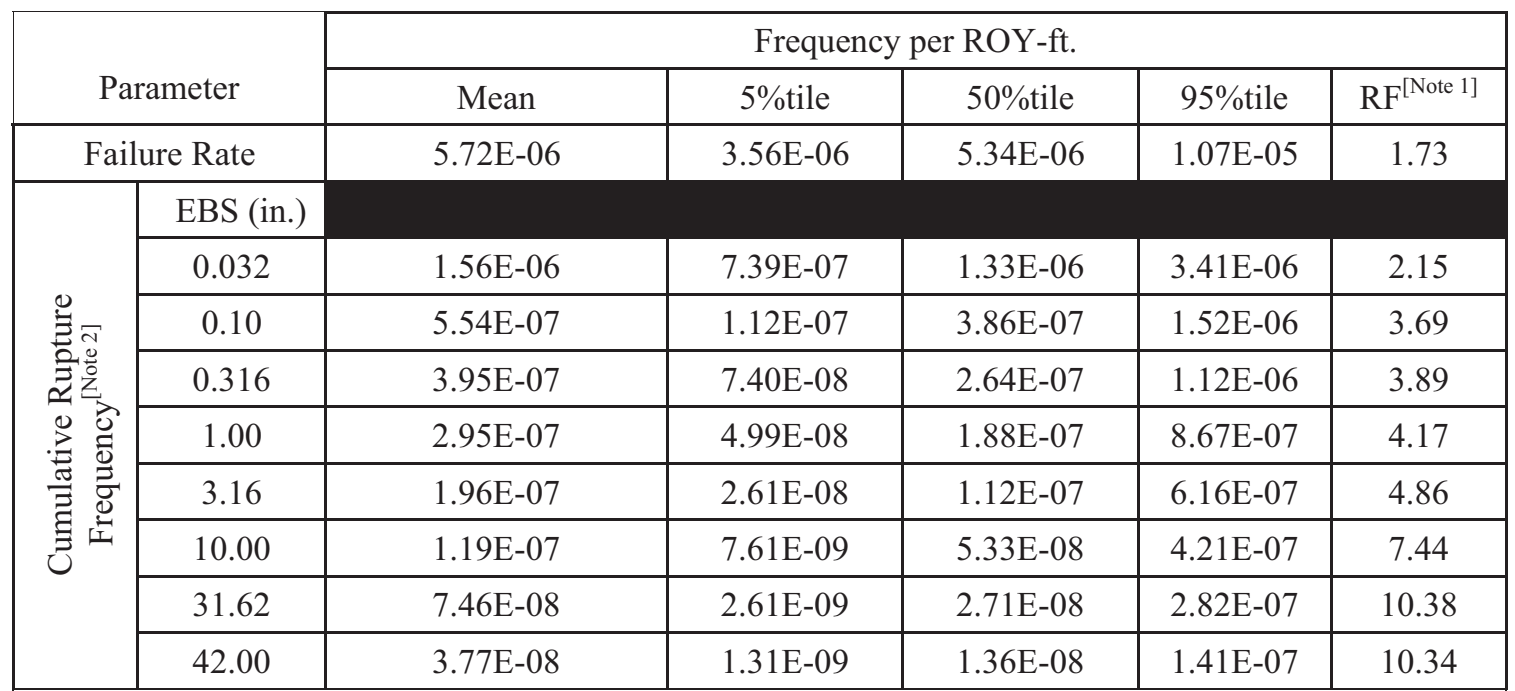

Note $1 . \mathrm{RF}=(95 \% \text { tile } / 5 \% \text { tile })^{0.5}$; These distributions can be approximated as lognormal distributions with the indicated mean and the calculated range factor (RF)

Note 2. Frequency of pipe rupture with EBS equal to or greater than indicated EBS value; use 42.0in. values for frequency of rupture with pipe whip potential. 


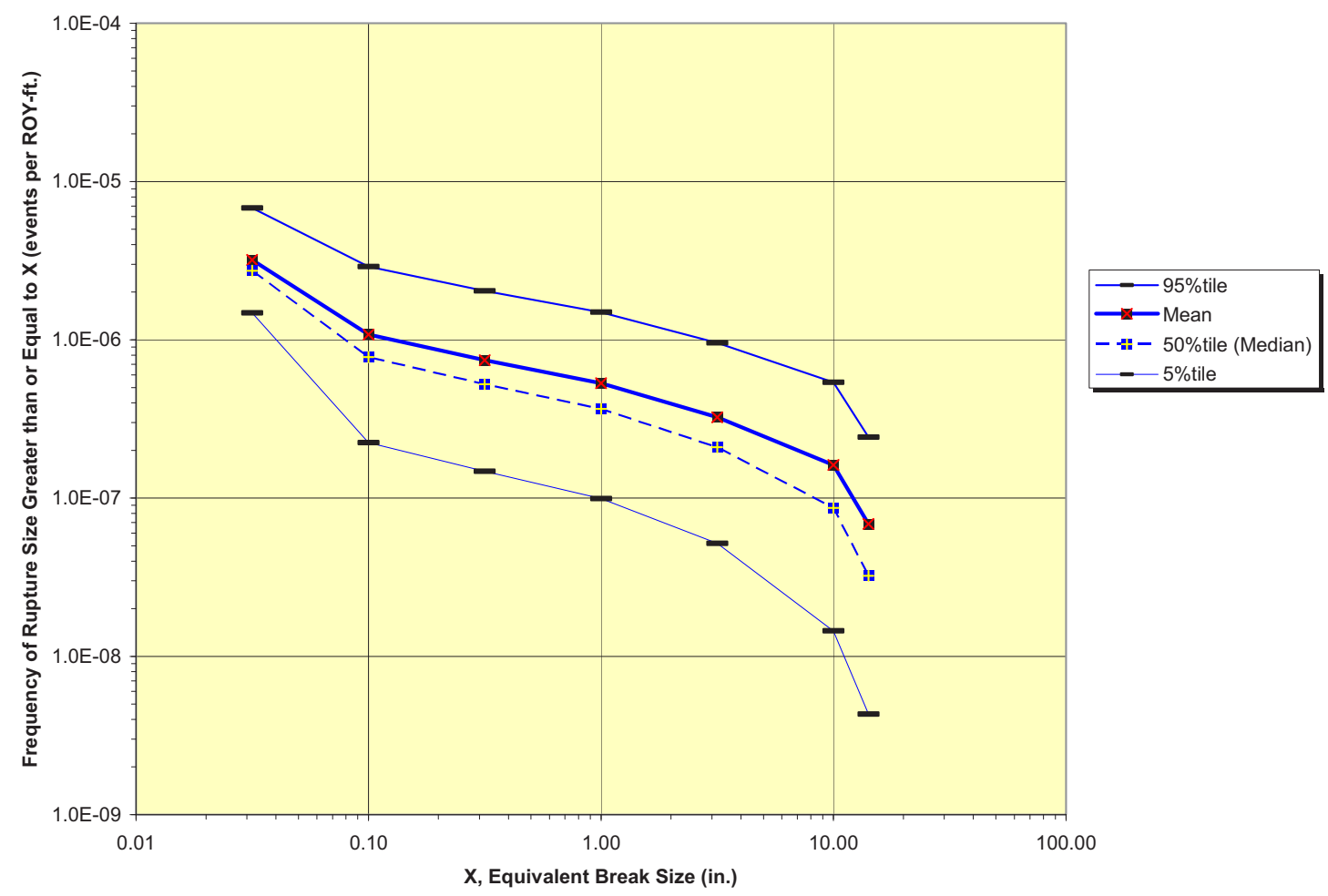

Figure B-56 Cumulative Rupture Frequency vs. Break Size for NPS $\leq 10$ " LPS Pipe Table B-27 Failure Rates and Cumulative Rupture Frequencies for NPS $\leq 10$ " LPS System

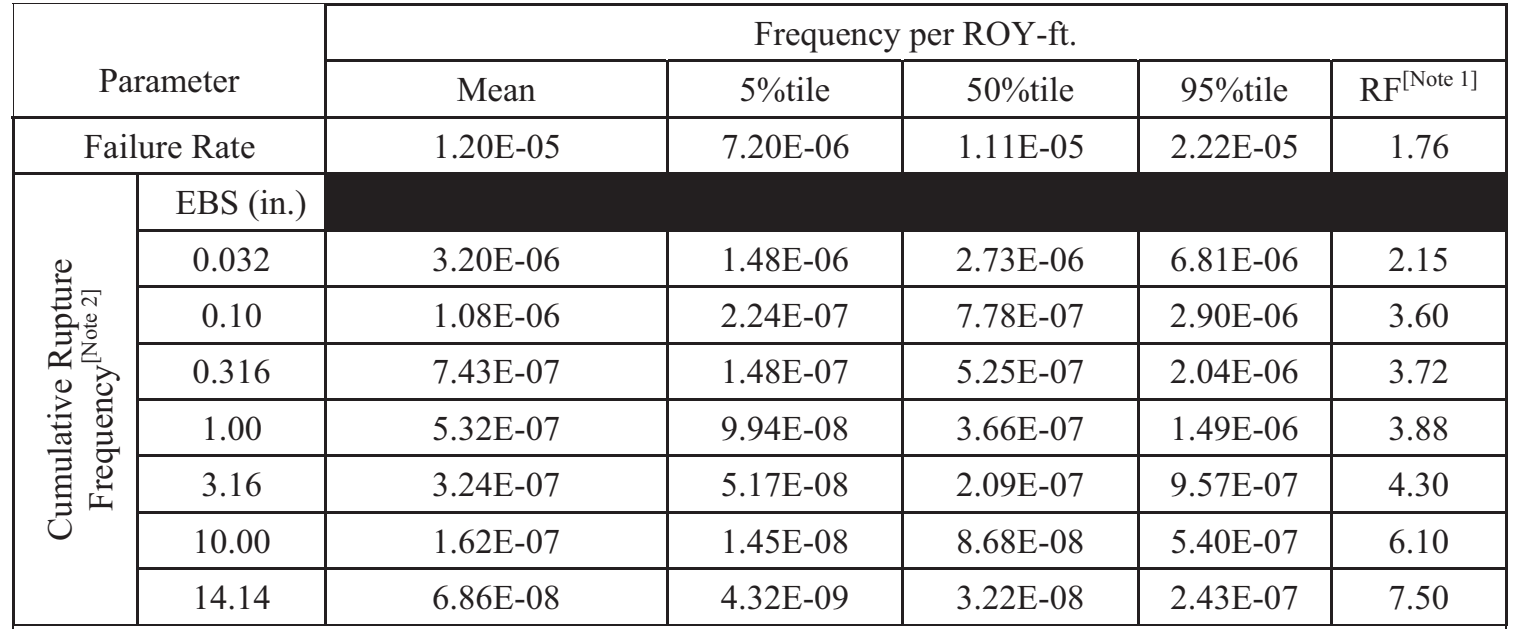

Note $1 . \mathrm{RF}=(95 \% \text { tile } / 5 \% \text { tile })^{0.5}$; These distributions can be approximated as lognormal distributions with the indicated mean and the calculated range factor (RF)

Note 2. Frequency of pipe rupture with EBS equal to or greater than indicated EBS value; use 14.14in. values for frequency of rupture with pipe whip potential. 


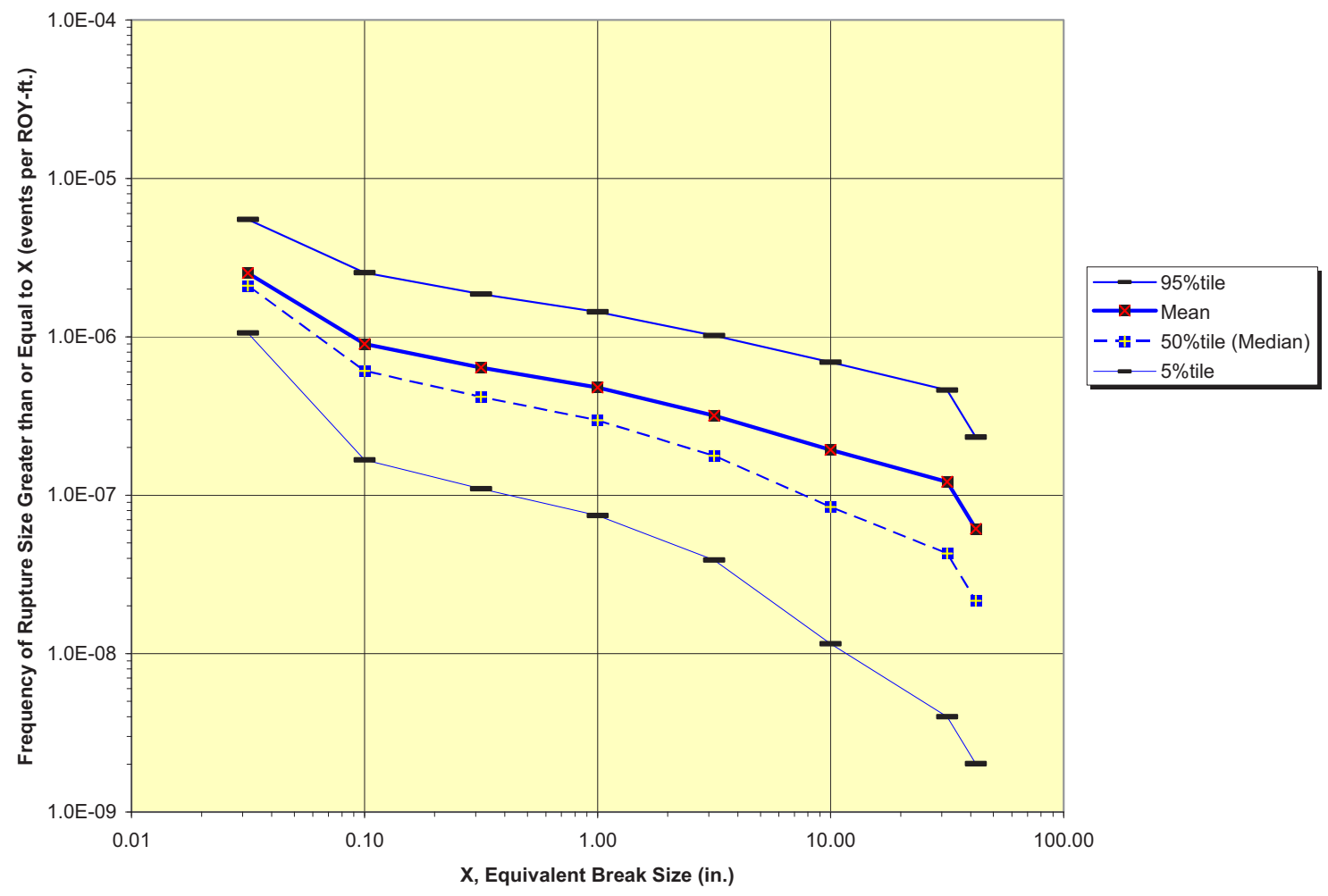

Figure B-57 Cumulative Rupture Frequency vs. Break Size for NPS > 10" LPS Pipe Table B-28 Failure Rates and Cumulative Rupture Frequencies for NPS > 10" LPS System

\begin{tabular}{|c|c|c|c|c|c|c|}
\hline \multirow{2}{*}{\multicolumn{2}{|c|}{ Parameter }} & \multicolumn{5}{|c|}{ Frequency per ROY-ft. } \\
\hline & & Mean & $5 \%$ tile & $50 \%$ tile & $95 \%$ tile & $\mathrm{RF}^{[\text {Note 1] }}$ \\
\hline \multicolumn{2}{|c|}{ Failure Rate } & $9.26 \mathrm{E}-06$ & $5.12 \mathrm{E}-06$ & 8.49E-06 & $1.69 \mathrm{E}-05$ & 1.81 \\
\hline \multirow{9}{*}{ 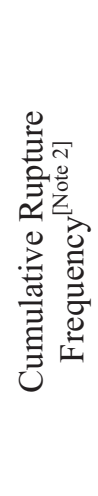 } & EBS (in.) & & & & & \\
\hline & 0.032 & 2.53E-06 & $1.06 \mathrm{E}-06$ & $2.10 \mathrm{E}-06$ & $5.51 \mathrm{E}-06$ & 2.28 \\
\hline & 0.10 & 8.99E-07 & $1.67 \mathrm{E}-07$ & $6.10 \mathrm{E}-07$ & $2.53 \mathrm{E}-06$ & 3.90 \\
\hline & 0.316 & $6.41 \mathrm{E}-07$ & $1.10 \mathrm{E}-07$ & 4.17E-07 & $1.86 \mathrm{E}-06$ & 4.11 \\
\hline & 1.00 & 4.79E-07 & 7.44E-08 & $2.97 \mathrm{E}-07$ & $1.44 \mathrm{E}-06$ & 4.40 \\
\hline & 3.16 & $3.18 \mathrm{E}-07$ & $3.90 \mathrm{E}-08$ & $1.77 \mathrm{E}-07$ & $1.02 \mathrm{E}-06$ & 5.11 \\
\hline & 10.00 & $1.93 \mathrm{E}-07$ & $1.15 \mathrm{E}-08$ & $8.43 \mathrm{E}-08$ & $6.92 \mathrm{E}-07$ & 7.74 \\
\hline & 31.62 & $1.21 \mathrm{E}-07$ & 4.00E-09 & $4.28 \mathrm{E}-08$ & 4.61E-07 & 10.74 \\
\hline & 42.00 & $6.14 \mathrm{E}-08$ & 2.01E-09 & $2.16 \mathrm{E}-08$ & $2.33 \mathrm{E}-07$ & 10.75 \\
\hline
\end{tabular}

Note $1 . \mathrm{RF}=(95 \% \text { tile } / 5 \% \text { tile })^{0.5}$; These distributions can be approximated as lognormal distributions with the indicated mean and the calculated range factor (RF)

Note 2. Frequency of pipe rupture with EBS equal to or greater than indicated EBS value; use 42.0in. values for frequency of rupture with pipe whip potential. 


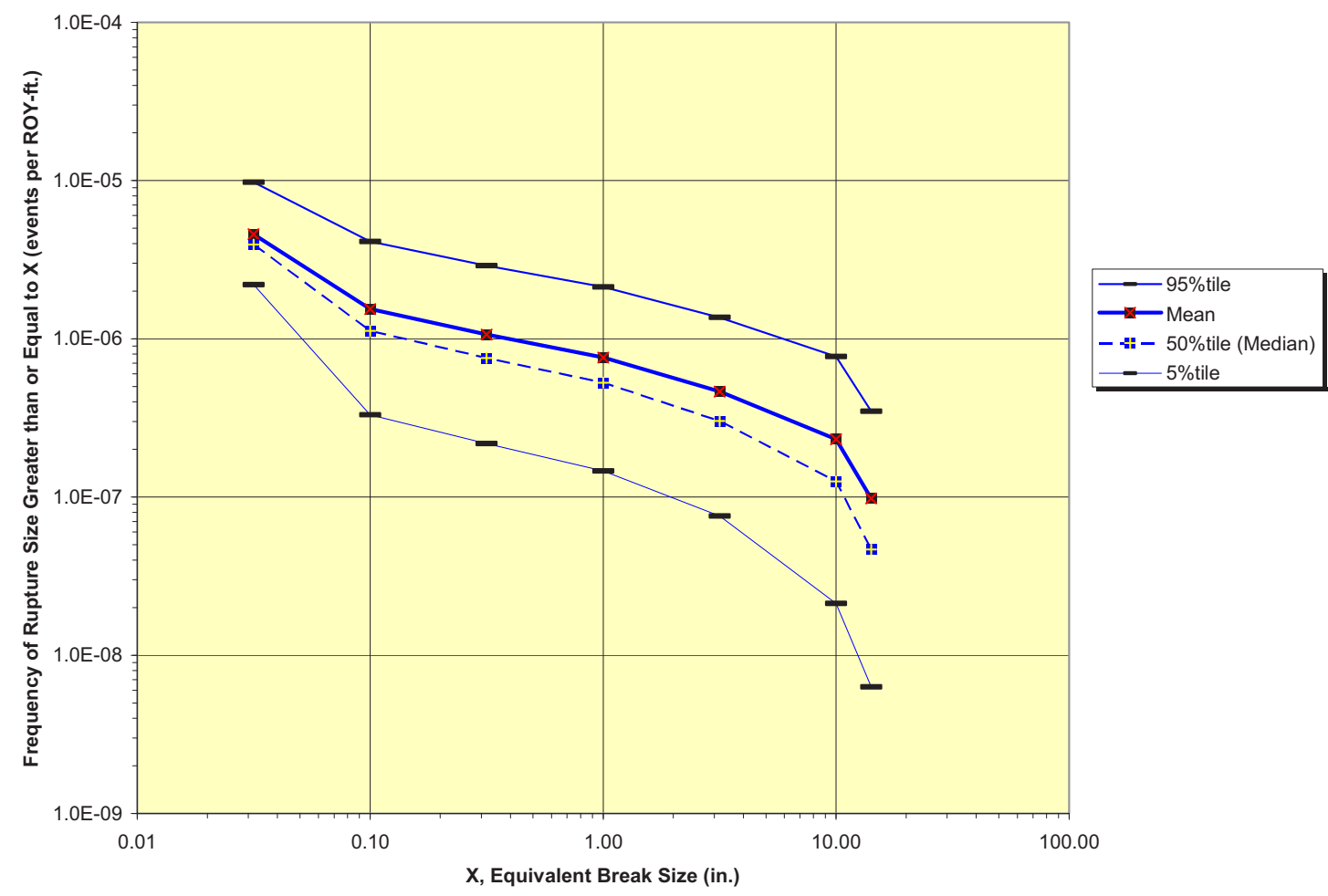

Figure B-58 Cumulative Rupture Frequency vs. Break Size for NPS $\leq 10$ " HPS Pipe Table B-29 Failure Rates and Cumulative Rupture Frequencies for NPS $\leq 10$ " HPS System

\begin{tabular}{|c|c|c|c|c|c|c|}
\hline \multirow{2}{*}{\multicolumn{2}{|c|}{ Parameter }} & \multicolumn{5}{|c|}{ Frequency per ROY-ft. } \\
\hline & & Mean & $5 \%$ tile & $50 \%$ tile & $95 \%$ tile & $\mathrm{RF}^{[\text {Note 1] }}$ \\
\hline \multicolumn{2}{|c|}{ Failure Rate } & $1.72 \mathrm{E}-05$ & $1.06 \mathrm{E}-05$ & $1.60 \mathrm{E}-05$ & $3.20 \mathrm{E}-05$ & 1.73 \\
\hline \multirow{8}{*}{ 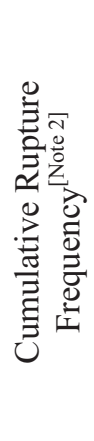 } & EBS (in.) & & & & & \\
\hline & 0.032 & $4.58 \mathrm{E}-06$ & $2.20 \mathrm{E}-06$ & $3.94 \mathrm{E}-06$ & $9.75 \mathrm{E}-06$ & 2.11 \\
\hline & 0.10 & $1.54 \mathrm{E}-06$ & $3.31 \mathrm{E}-07$ & $1.12 \mathrm{E}-06$ & 4.12E-06 & 3.53 \\
\hline & 0.316 & $1.06 \mathrm{E}-06$ & $2.18 \mathrm{E}-07$ & $7.58 \mathrm{E}-07$ & $2.90 \mathrm{E}-06$ & 3.65 \\
\hline & 1.00 & 7.62E-07 & $1.46 \mathrm{E}-07$ & 5.29E-07 & $2.13 \mathrm{E}-06$ & 3.81 \\
\hline & 3.16 & 4.64E-07 & $7.60 \mathrm{E}-08$ & $3.02 \mathrm{E}-07$ & $1.37 \mathrm{E}-06$ & 4.24 \\
\hline & 10.00 & 2.31E-07 & $2.12 \mathrm{E}-08$ & $1.25 \mathrm{E}-07$ & 7.73E-07 & 6.03 \\
\hline & 14.14 & $9.79 \mathrm{E}-08$ & 6.32E-09 & 4.66E-08 & $3.49 \mathrm{E}-07$ & 7.43 \\
\hline
\end{tabular}

Note $1 . \mathrm{RF}=(95 \% \text { tile } / 5 \% \text { tile })^{0.5}$; These distributions can be approximated as lognormal distributions with the indicated mean and the calculated range factor (RF)

Note 2. Frequency of pipe rupture with EBS equal to or greater than indicated EBS value; use 14.14in. values for frequency of rupture with pipe whip potential. 


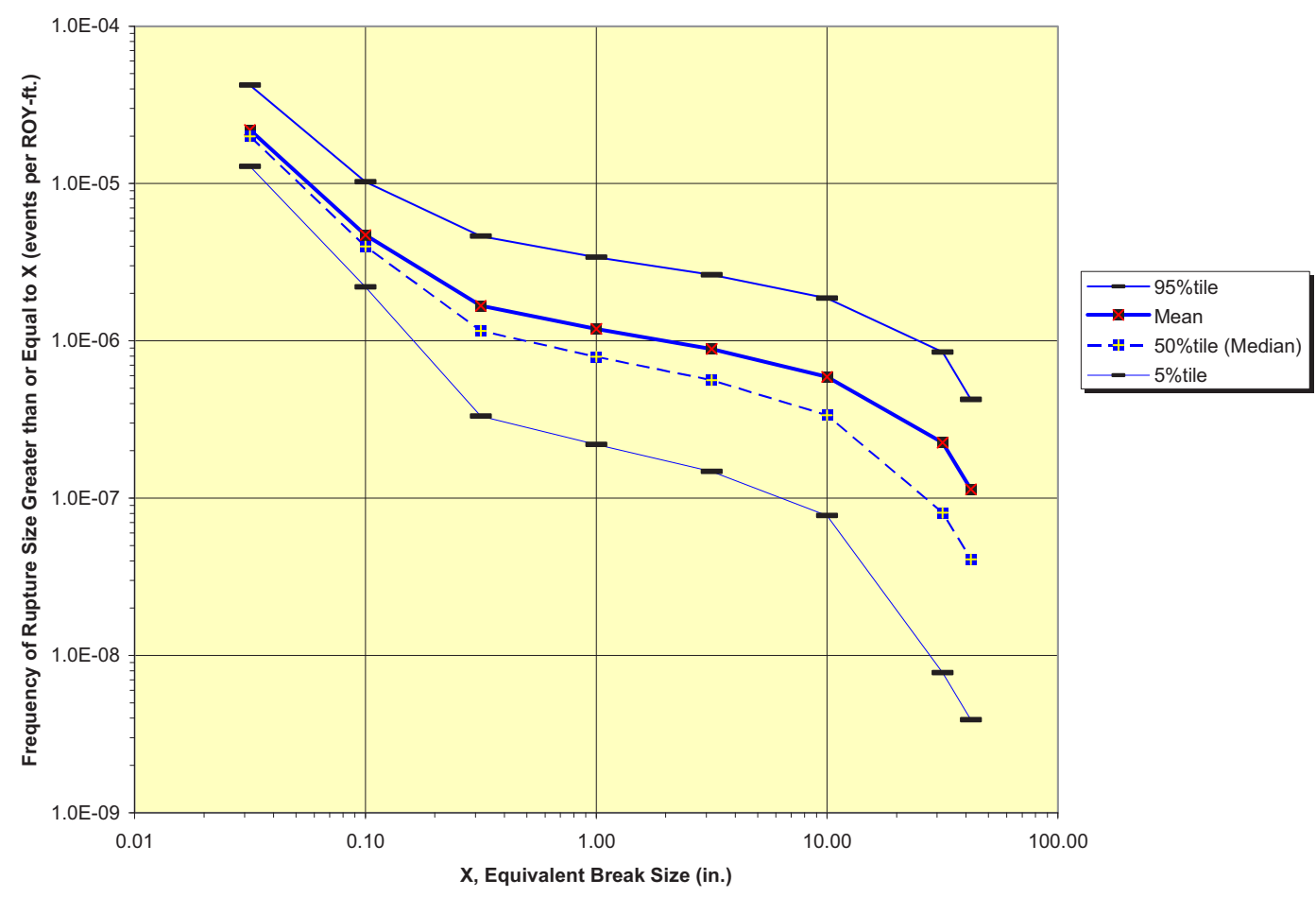

Figure B-59 Cumulative Rupture Frequency for NPS > 10" HPS Pipe Table B-30 Failure Rates and Cumulative Rupture Frequencies for NPS > 10" HPS System

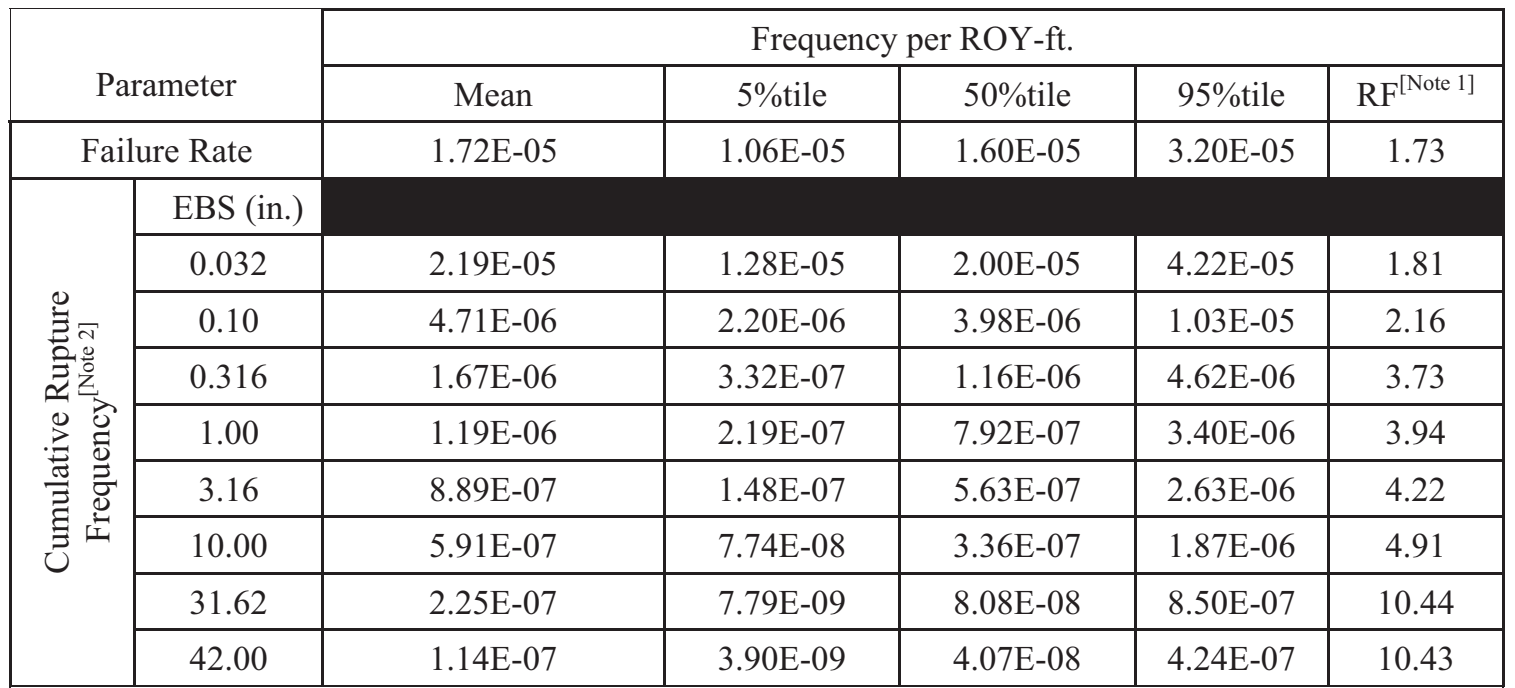

Note $1 . \mathrm{RF}=(95 \% \text { tile/5\%tile })^{0.5}$; These distributions can be approximated as lognormal distributions with the indicated mean and the calculated range factor $(\mathrm{RF})$

Note 2. Frequency of pipe rupture with EBS equal to or greater than indicated EBS value; use 42.0in. values for frequency of rupture with pipe whip potential. 


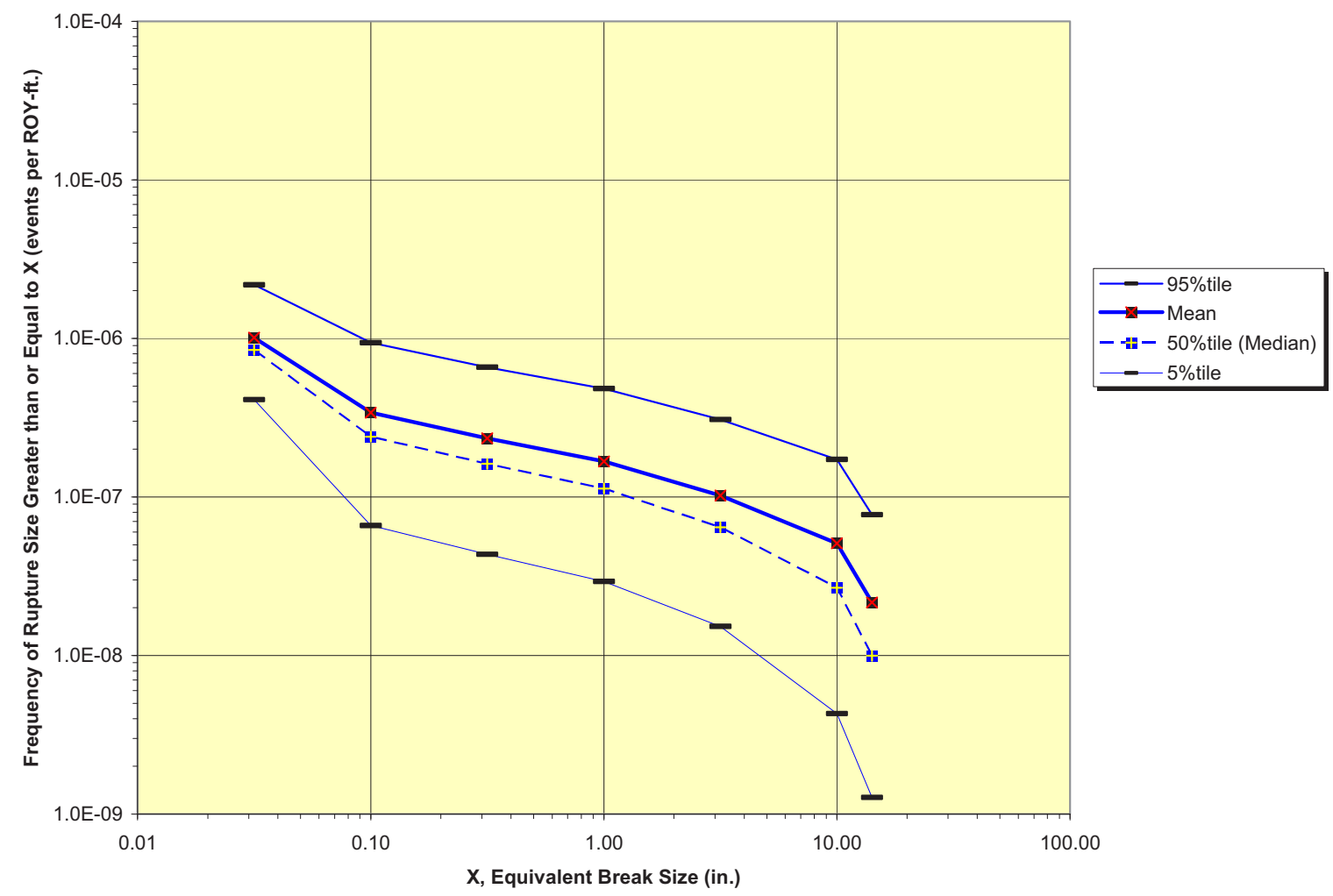

Figure B-60 Cumulative Rupture Frequency for EXT-ST $\leq 10$ " EXS Pipe

Table B-31 Failure Rates and Cumulative Rupture Frequencies for NPS $\leq 10$ " EXS System

\begin{tabular}{|c|c|c|c|c|c|c|}
\hline \multirow{2}{*}{\multicolumn{2}{|c|}{ Parameter }} & \multicolumn{5}{|c|}{ Frequency per ROY-ft. } \\
\hline & & Mean & $5 \%$ tile & $50 \%$ tile & $95 \%$ tile & $\mathrm{RF}^{[\text {Note 1] }}$ \\
\hline \multicolumn{2}{|c|}{ Failure Rate } & $3.79 \mathrm{E}-06$ & $1.98 \mathrm{E}-06$ & $3.44 \mathrm{E}-06$ & $6.98 \mathrm{E}-06$ & 1.88 \\
\hline \multirow{8}{*}{ 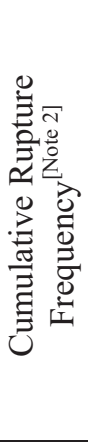 } & EBS (in.) & & & & & \\
\hline & 0.032 & $1.01 \mathrm{E}-06$ & $4.11 \mathrm{E}-07$ & $8.46 \mathrm{E}-07$ & $2.17 \mathrm{E}-06$ & 2.30 \\
\hline & 0.10 & $3.40 \mathrm{E}-07$ & $6.59 \mathrm{E}-08$ & $2.40 \mathrm{E}-07$ & $9.39 \mathrm{E}-07$ & 3.77 \\
\hline & 0.316 & $2.34 \mathrm{E}-07$ & 4.34E- 08 & $1.62 \mathrm{E}-07$ & $6.57 \mathrm{E}-07$ & 3.89 \\
\hline & 1.00 & $1.68 \mathrm{E}-07$ & 2.93E-08 & $1.13 \mathrm{E}-07$ & 4.82E-07 & 4.05 \\
\hline & 3.16 & $1.02 \mathrm{E}-07$ & $1.53 \mathrm{E}-08$ & $6.45 \mathrm{E}-08$ & 3.07E-07 & 4.49 \\
\hline & 10.00 & $5.10 \mathrm{E}-08$ & 4.30E-09 & $2.68 \mathrm{E}-08$ & $1.73 \mathrm{E}-07$ & 6.34 \\
\hline & 14.14 & $2.16 \mathrm{E}-08$ & $1.27 \mathrm{E}-09$ & $9.95 \mathrm{E}-09$ & $7.73 \mathrm{E}-08$ & 7.79 \\
\hline
\end{tabular}

Note $1 . \mathrm{RF}=(95 \% \text { tile/5\%tile })^{0.5}$; These distributions can be approximated as lognormal distributions with the indicated mean and the calculated range factor (RF)

Note 2. Frequency of pipe rupture with EBS equal to or greater than indicated EBS value; use 14.14in. values for frequency of rupture with pipe whip potential. 


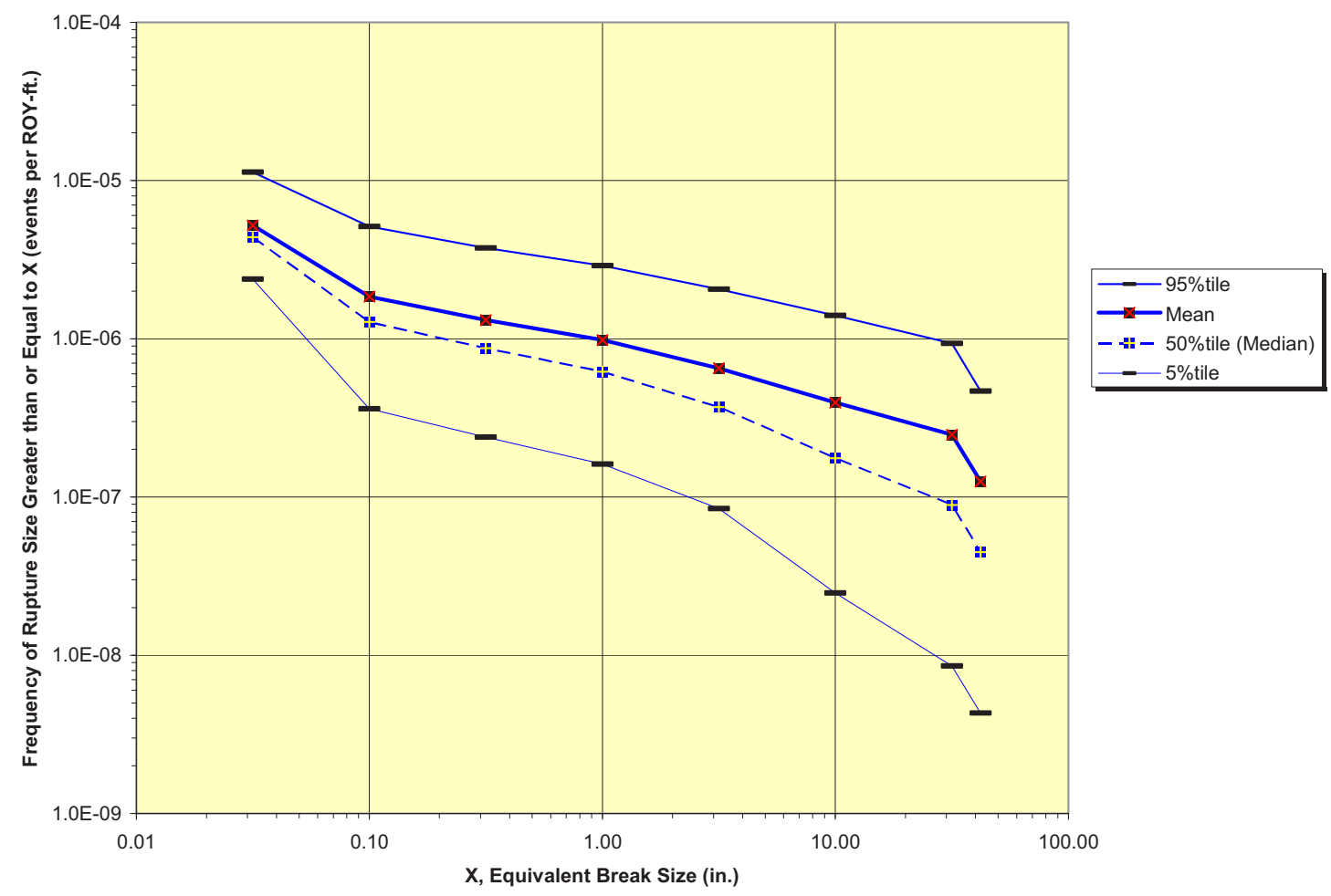

Figure B-61 Cumulative Rupture Frequency for NPS > 10" EXS Pipe

Table B-32 Failure Rates and Cumulative Rupture Frequencies for NPS > 10" EXS System

\begin{tabular}{|c|c|c|c|c|c|c|}
\hline \multirow{2}{*}{\multicolumn{2}{|c|}{ Parameter }} & \multicolumn{5}{|c|}{ Frequency per ROY-ft. } \\
\hline & & Mean & $5 \%$ tile & $50 \%$ tile & 95\%tile & $\mathrm{RF}^{[\text {Note 1] }}$ \\
\hline \multicolumn{2}{|c|}{ Failure Rate } & $1.90 \mathrm{E}-05$ & $1.16 \mathrm{E}-05$ & $1.76 \mathrm{E}-05$ & $3.51 \mathrm{E}-05$ & 1.74 \\
\hline \multirow{9}{*}{ 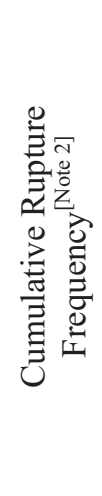 } & EBS (in.) & & & & & \\
\hline & 0.032 & $5.20 \mathrm{E}-06$ & 2.38E-06 & 4.38E-06 & $1.13 \mathrm{E}-05$ & 2.18 \\
\hline & 0.10 & $1.85 \mathrm{E}-06$ & $3.61 \mathrm{E}-07$ & $1.28 \mathrm{E}-06$ & $5.12 \mathrm{E}-06$ & 3.77 \\
\hline & 0.316 & $1.31 \mathrm{E}-06$ & $2.39 \mathrm{E}-07$ & $8.73 \mathrm{E}-07$ & $3.75 \mathrm{E}-06$ & 3.96 \\
\hline & 1.00 & $9.81 \mathrm{E}-07$ & $1.61 \mathrm{E}-07$ & $6.20 \mathrm{E}-07$ & $2.90 \mathrm{E}-06$ & 4.24 \\
\hline & 3.16 & $6.52 \mathrm{E}-07$ & $8.45 \mathrm{E}-08$ & $3.70 \mathrm{E}-07$ & $2.06 \mathrm{E}-06$ & 4.94 \\
\hline & 10.00 & $3.95 \mathrm{E}-07$ & $2.47 \mathrm{E}-08$ & $1.76 \mathrm{E}-07$ & $1.40 \mathrm{E}-06$ & 7.53 \\
\hline & 31.62 & $2.48 \mathrm{E}-07$ & 8.56E-09 & 8.92E-08 & $9.36 \mathrm{E}-07$ & 10.46 \\
\hline & 42.00 & $1.25 \mathrm{E}-07$ & $4.31 \mathrm{E}-09$ & $4.49 \mathrm{E}-08$ & 4.67E-07 & 10.41 \\
\hline
\end{tabular}

Note $1 . \mathrm{RF}=(95 \% \text { tile } / 5 \% \text { tile })^{0.5}$; These distributions can be approximated as lognormal distributions with the indicated mean and the calculated range factor (RF)

Note 2. Frequency of pipe rupture with EBS equal to or greater than indicated EBS value; use 42.0in. values for frequency of rupture with pipe whip potential. 


\subsubsection{Evaluation of Temporal Trends in Failure Rates for FAC Susceptible Systems}

To investigate the impact of industry efforts to address the FAC issue, a separate failure development was performed that considered only the service data prior to 1988 . This

by applying the failure rate history and the reactor years exposure data listed in

Table 4-8 and Table 4-9 together with the same conditional rupture model as in the previous analysis to obtain a new set of failure rate parameters. This update showed that the failure rates for the smaller pipes did not change very much, but the failure rates for the larger pipes changed quite significantly. As seen in the bar chart in Figure 4-9 below, there were quite dramatic reductions in failure rates after 1988 in the Feedwater and Condensate, Extraction Steam, and Low Pressure Steam piping with no significant change in the HP Steam piping. These changes correlate well with what is known about the susceptibility of piping to this failure mechanism. HP steam is dry and is largely confined to large straight pipe runs upstream of the main turbine and hence these pipes have a relatively low susceptibility to FAC. Extraction Steam on the other hand has the highest susceptibility to FAC as evidenced in the pipe rupture data. It is also interesting to note that while the trend in the failure data did indeed show a rapid decline starting in 1988, where failures include all events involving repair and replacement, the trend in the large pipe rupture data as shown in Figure 4-10 does not show a significant decrease until about 1997 or 9 years later.

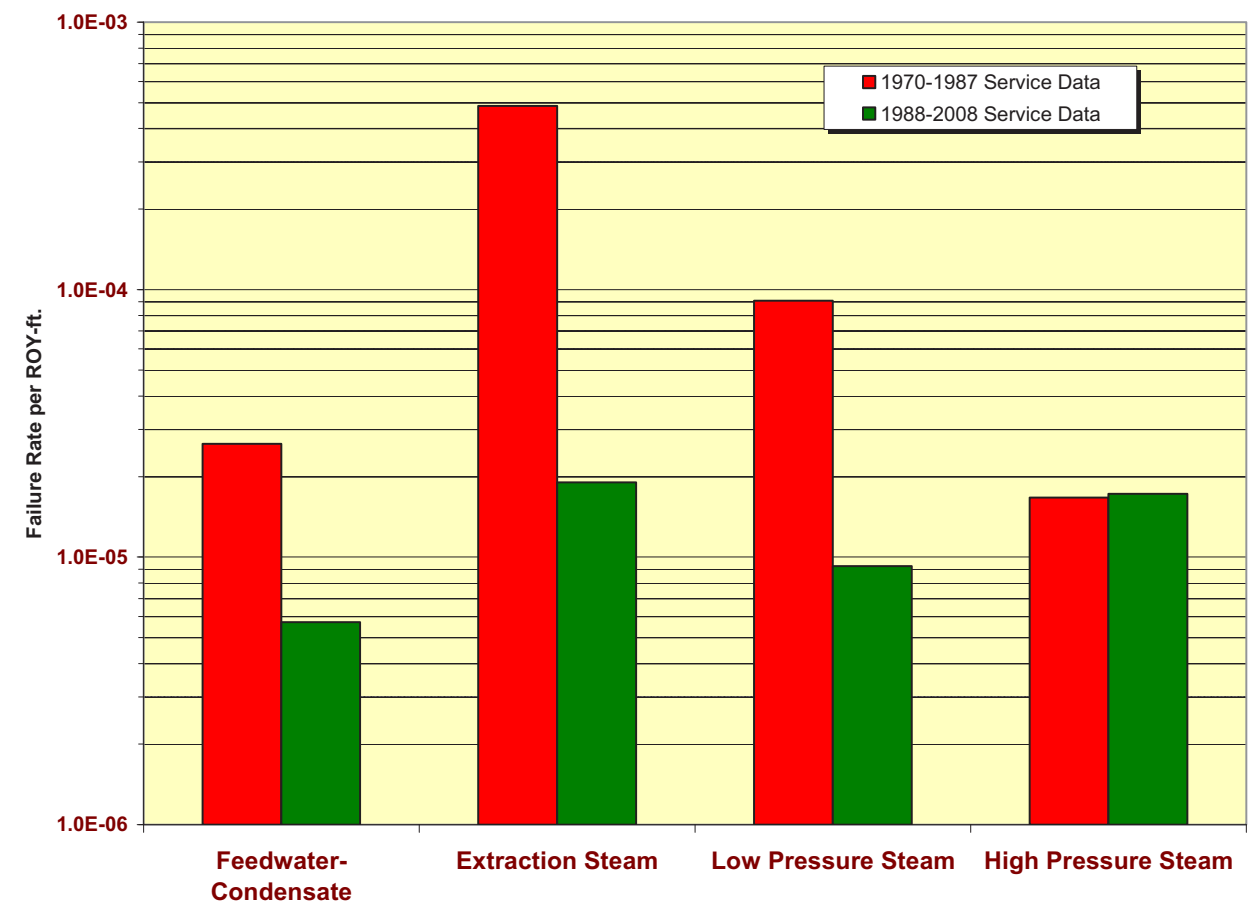

Figure B-62 Comparison of Pipe Failure Rates in Large (>6") FAC Susceptible Piping Based on Service Experience Before and After 1988 


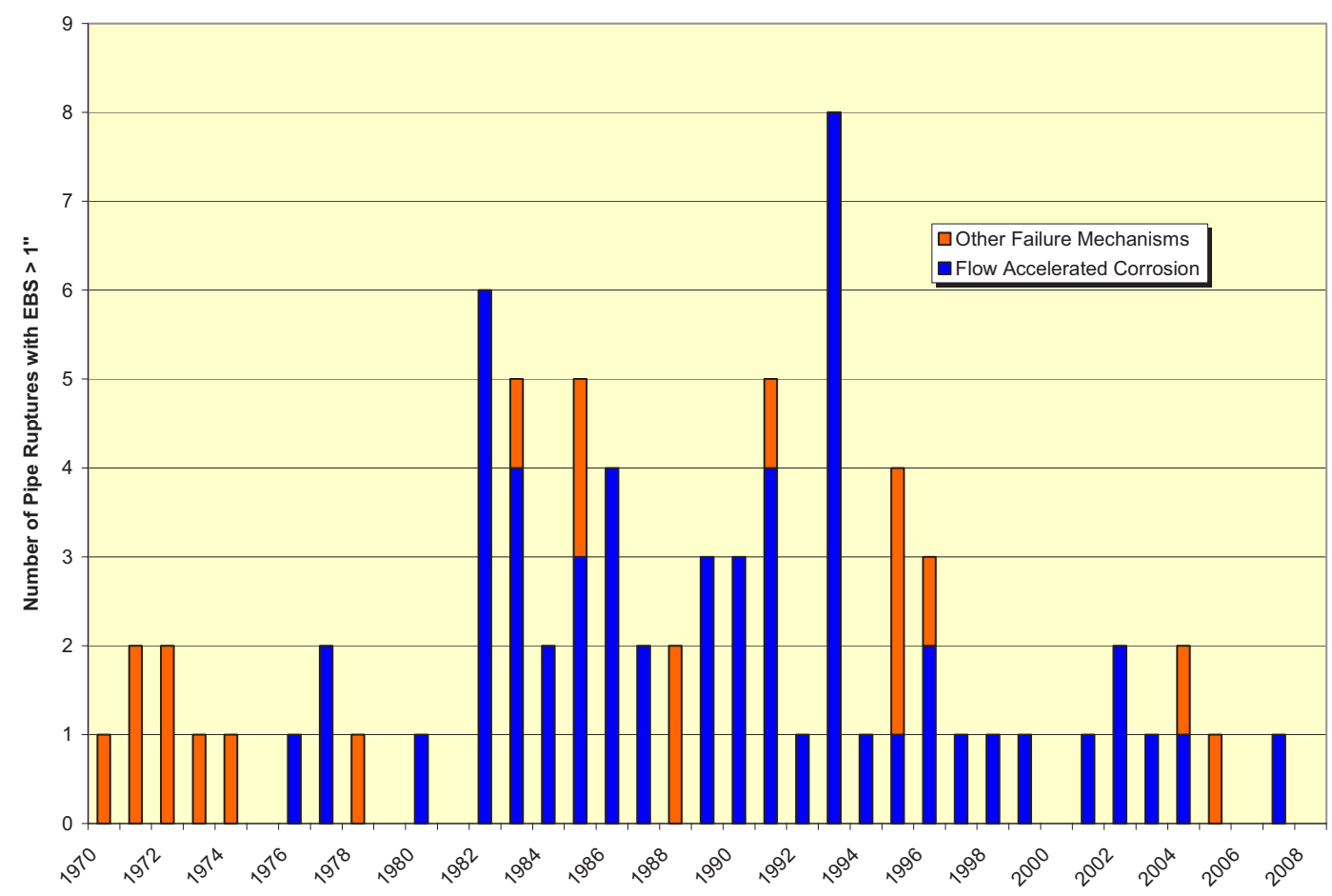

Figure B-63 Temporal Trends in the Frequency of Large Pipe Breaks in FAC Susceptible Systems

10.2.6 Impact of Alternative Inspection and Surveillance Strategies on FWC Piping

The impact of alternative inspection strategies to reduce the frequency of pipe rupture evaluated using the Markov Model and selected results are shown in Table 4-4, 
Treatment of Passive Component Reliability in Risk-Informed Safety Margin Characterization

Table 4-5, and 
Treatment of Passive Component Reliability in

Risk-Informed Safety Margin Characterization

Table 4-6. Table 4-4 and 
Table 4-5 show how varying the frequency of leak testing with and without additional NDE and a fixed $90 \%$ POD for both strategies change the Integrity Management factor. 
Table 4-6 shows how alternative POD with fixed frequencies of NDE (every 10 years) and leak testing (every quarter) impact the Integrity Management factor. These Integrity Management Factors are evaluated for the plant age of 32 years which corresponds to the average age of the plants in the service data. The baseline integrity management program assumed in these calculations is based on $25 \%$ of the pipe being subjected to an augmented FAC inspection program with NDE @90\% every 3 years, 75\% not subjected to NDE and 100\% being subjected to a leak inspection @90\% once every 1.5 years.

Table B-60 Impact of Alternative Leak Detection Strategies to Reduce FeedwaterCondensate System Pipe Rupture Frequencies

\begin{tabular}{|c|c|c|c|c|}
\hline \multirow{2}{*}{$\begin{array}{c}\text { Equivalent } \\
\text { Break Size } \\
\text { (in.) }\end{array}$} & \multicolumn{3}{|c|}{ No NDE with Variable Leak Testing Frequency } \\
\cline { 2 - 5 } & Base Rate & \multicolumn{2}{|c|}{$\begin{array}{c}\text { Factor Reduction in Base Rate for } \\
\text { per ROY-ft. }\end{array}$} & \multicolumn{2}{|c|}{ Periodic Leak Test @ 90\% POD } \\
\cline { 2 - 5 } & & Yearly & Quarterly & Weekly \\
\hline 0.032 & $1.56 \mathrm{E}-06$ & $1.29 \mathrm{E}+00$ & $1.26 \mathrm{E}+00$ & $1.25 \mathrm{E}+00$ \\
\hline 0.10 & $5.54 \mathrm{E}-07$ & $1.29 \mathrm{E}+00$ & $1.20 \mathrm{E}+00$ & $1.19 \mathrm{E}+00$ \\
\hline 0.32 & $3.95 \mathrm{E}-07$ & $1.29 \mathrm{E}+00$ & $1.17 \mathrm{E}+00$ & $1.15 \mathrm{E}+00$ \\
\hline 1.0 & $2.95 \mathrm{E}-07$ & $1.29 \mathrm{E}+00$ & $1.14 \mathrm{E}+00$ & $1.12 \mathrm{E}+00$ \\
\hline 3.2 & $1.96 \mathrm{E}-07$ & $1.29 \mathrm{E}+00$ & $1.08 \mathrm{E}+00$ & $1.03 \mathrm{E}+00$ \\
\hline 10 & $1.19 \mathrm{E}-07$ & $1.29 \mathrm{E}+00$ & $9.86 \mathrm{E}-01$ & $9.31 \mathrm{E}-01$ \\
\hline 31.6 & $7.46 \mathrm{E}-08$ & $1.29 \mathrm{E}+00$ & $8.77 \mathrm{E}-01$ & $5.82 \mathrm{E}-01$ \\
\hline 34 & $3.77 \mathrm{E}-08$ & $1.29 \mathrm{E}+00$ & $7.02 \mathrm{E}-01$ & $5.82 \mathrm{E}-01$ \\
\hline
\end{tabular}

Table B-61 Impact of NDE and Alternative Leak Detection Strategies to Reduce Fire Feedwater-Condensate System Pipe Rupture Frequencies

\begin{tabular}{|c|c|c|c|c|c|}
\hline \multirow{2}{*}{$\begin{array}{c}\text { Equivalent } \\
\text { Break Size } \\
\text { (in.) }\end{array}$} & \multicolumn{5}{|c|}{ NDE every 10 years at 90\% POD with Variable Leak Testing } \\
\cline { 2 - 6 } & $\begin{array}{c}\text { Base Rate } \\
\text { per ROY-ft. }\end{array}$ & \multicolumn{2}{|c|}{ Factor Reduction in Base Rate for Periodic Leak } \\
\cline { 2 - 6 } & & None & Yearly & Quarterly & Weekly \\
\hline 0.032 & $1.56 \mathrm{E}-06$ & $1.65 \mathrm{E}-01$ & $1.35 \mathrm{E}-01$ & $1.32 \mathrm{E}-01$ & $1.31 \mathrm{E}-01$ \\
\hline 0.10 & $5.54 \mathrm{E}-07$ & $2.13 \mathrm{E}-01$ & $1.36 \mathrm{E}-01$ & $1.26 \mathrm{E}-01$ & $1.25 \mathrm{E}-01$ \\
\hline 0.32 & $3.95 \mathrm{E}-07$ & $2.42 \mathrm{E}-01$ & $1.36 \mathrm{E}-01$ & $1.23 \mathrm{E}-01$ & $1.21 \mathrm{E}-01$ \\
\hline 1.0 & $2.95 \mathrm{E}-07$ & $3.01 \mathrm{E}-01$ & $1.36 \mathrm{E}-01$ & $1.20 \mathrm{E}-01$ & $1.17 \mathrm{E}-01$ \\
\hline 3.2 & $1.96 \mathrm{E}-07$ & $3.52 \mathrm{E}-01$ & $1.37 \mathrm{E}-01$ & $1.14 \mathrm{E}-01$ & $1.10 \mathrm{E}-01$ \\
\hline 10 & $1.19 \mathrm{E}-07$ & $4.09 \mathrm{E}-01$ & $1.37 \mathrm{E}-01$ & $1.04 \mathrm{E}-01$ & $9.71 \mathrm{E}-02$ \\
\hline
\end{tabular}


Treatment of Passive Component Reliability in Risk-Informed Safety Margin Characterization

\begin{tabular}{|c|c|r|r|r|r|}
\hline 31.6 & $7.46 \mathrm{E}-08$ & $4.99 \mathrm{E}-01$ & $1.38 \mathrm{E}-01$ & $9.22 \mathrm{E}-02$ & $8.36 \mathrm{E}-02$ \\
\hline 34 & $3.77 \mathrm{E}-08$ & $7.65 \mathrm{E}-01$ & $1.39 \mathrm{E}-01$ & $7.38 \mathrm{E}-02$ & $6.14 \mathrm{E}-02$ \\
\hline
\end{tabular}


Table B-62 Integrity Management Factors for Various Combinations of NDE and Leak Inspections for Feedwater-Condensate System

\begin{tabular}{|c|c|c|c|c|c|c|c|}
\hline \multicolumn{8}{|c|}{ NO NDE with Quarterly Leak Testing and Variable Leak Testing POD } \\
\hline EBS & $\begin{array}{l}\text { No Leak } \\
\text { Test }\end{array}$ & $\mathrm{POD}=.50$ & $\mathrm{POD}=.60$ & $\mathrm{POD}=.70$ & $\mathrm{POD}=.80$ & $\mathrm{POD}=.90$ & $\mathrm{POD}=1.00$ \\
\hline 0.03 & $1.57 \mathrm{E}+00$ & $1.26 \mathrm{E}+00$ & $1.26 \mathrm{E}+00$ & $1.26 \mathrm{E}+00$ & $1.26 \mathrm{E}+00$ & $1.26 \mathrm{E}+00$ & $1.26 \mathrm{E}+00$ \\
\hline 0.10 & $2.02 \mathrm{E}+00$ & $1.22 \mathrm{E}+00$ & $1.21 \mathrm{E}+00$ & $1.21 \mathrm{E}+00$ & $1.21 \mathrm{E}+00$ & $1.20 E+00$ & $1.20 \mathrm{E}+00$ \\
\hline 0.32 & $2.29 \mathrm{E}+00$ & $1.20 \mathrm{E}+00$ & $1.19 \mathrm{E}+00$ & $1.18 \mathrm{E}+00$ & $1.18 \mathrm{E}+00$ & $1.17 \mathrm{E}+00$ & $1.17 \mathrm{E}+00$ \\
\hline 1.00 & $2.85 \mathrm{E}+00$ & $1.17 \mathrm{E}+00$ & $1.16 \mathrm{E}+00$ & $1.15 E+00$ & $1.15 E+00$ & $1.14 \mathrm{E}+00$ & $1.14 \mathrm{E}+00$ \\
\hline 3.20 & $3.32 \mathrm{E}+00$ & $1.12 \mathrm{E}+00$ & $1.11 \mathrm{E}+00$ & $1.09 E+00$ & $1.09 E+00$ & $1.08 \mathrm{E}+00$ & $1.08 \mathrm{E}+00$ \\
\hline 10.00 & $3.84 \mathrm{E}+00$ & $1.04 \mathrm{E}+00$ & $1.02 \mathrm{E}+00$ & $1.01 E+00$ & 9.95E-01 & 9.86E-01 & 9.79E-01 \\
\hline 31.60 & $4.65 \mathrm{E}+00$ & 9.53E-01 & $9.25 E-01$ & 9.05E-01 & 8.89E-01 & 8.77E-01 & 8.68E-01 \\
\hline 34.00 & $7.07 \mathrm{E}+00$ & $8.10 \mathrm{E}-01$ & 7.70E-01 & 7.41E-01 & 7.19E-01 & 7.02E-01 & 6.88E-01 \\
\hline \multicolumn{8}{|c|}{ 10yr. NDE with $50 \%$ POD with Quarterly Leak Testing with Variable Leak Testing POD } \\
\hline EBS & \begin{tabular}{|l|} 
No Leak \\
Test \\
\end{tabular} & $\mathrm{POD}=.50$ & $\mathrm{POD}=.60$ & $\mathrm{POD}=.70$ & $\mathrm{POD}=.80$ & $\mathrm{POD}=.90$ & $\mathrm{POD}=1.00$ \\
\hline 0.03 & 2.96E-01 & 2.37E-01 & 2.37E-01 & 2.37E-01 & 2.36E-01 & 2.36E-01 & 2.36E-01 \\
\hline 0.10 & 3.80E-01 & 2.29E-01 & 2.28E-01 & 2.28E-01 & 2.27E-01 & 2.26E-01 & 2.26E-01 \\
\hline 0.32 & 4.31E-01 & 2.25E-01 & 2.23E-01 & $2.22 \mathrm{E}-01$ & $2.21 \mathrm{E}-01$ & $2.21 \mathrm{E}-01$ & 2.20E-01 \\
\hline 1.00 & 5.36E-01 & 2.20E-01 & 2.18E-01 & 2.16E-01 & $2.15 \mathrm{E}-01$ & 2.15E-01 & 2.14E-01 \\
\hline 3.20 & $6.25 \mathrm{E}-01$ & 2.11E-01 & 2.08E-01 & 2.06E-01 & 2.04E-01 & 2.03E-01 & 2.02E-01 \\
\hline 10.00 & 7.23E-01 & 1.96E-01 & $1.92 \mathrm{E}-01$ & 1.89E-01 & 1.87E-01 & 1.85E-01 & $1.84 \mathrm{E}-01$ \\
\hline 31.60 & 8.78E-01 & 1.80E-01 & 1.74E-01 & 1.70E-01 & 1.67E-01 & 1.65E-01 & 1.63E-01 \\
\hline 34.00 & $1.34 \mathrm{E}+00$ & $1.53 \mathrm{E}-01$ & $1.45 \mathrm{E}-01$ & $1.40 \mathrm{E}-01$ & 1.35E-01 & 1.32E-01 & 1.30E-01 \\
\hline \multicolumn{8}{|c|}{ 10yr. NDE with $90 \%$ POD with Quarterly Leak Testing with Variable Leak Testing POD } \\
\hline EBS & $\begin{array}{l}\text { No Leak } \\
\text { Test }\end{array}$ & $\mathrm{POD}=.50$ & $\mathrm{POD}=.60$ & $\mathrm{POD}=.70$ & $\mathrm{POD}=.80$ & $\mathrm{POD}=.90$ & $\mathrm{POD}=1.00$ \\
\hline 0.03 & $1.65 \mathrm{E}-01$ & 1.33E-01 & $1.32 \mathrm{E}-01$ & 1.32E-01 & $1.32 \mathrm{E}-01$ & $1.32 \mathrm{E}-01$ & $1.32 \mathrm{E}-01$ \\
\hline 0.10 & 2.12E-01 & $1.28 \mathrm{E}-01$ & 1.27E-01 & 1.27E-01 & 1.27E-01 & 1.26E-01 & 1.26E-01 \\
\hline 0.32 & 2.41E-01 & $1.26 \mathrm{E}-01$ & $1.25 \mathrm{E}-01$ & $1.24 \mathrm{E}-01$ & $1.24 \mathrm{E}-01$ & 1.23E-01 & 1.23E-01 \\
\hline 1.00 & 2.99E-01 & 1.23E-01 & 1.22E-01 & 1.21E-01 & $1.20 \mathrm{E}-01$ & $1.20 \mathrm{E}-01$ & 1.19E-01 \\
\hline 3.20 & 3.49E-01 & $1.18 \mathrm{E}-01$ & 1.16E-01 & 1.15E-01 & 1.14E-01 & 1.14E-01 & 1.13E-01 \\
\hline 10.00 & 4.04E-01 & 1.10E-01 & 1.07E-01 & 1.06E-01 & $1.05 \mathrm{E}-01$ & $1.04 \mathrm{E}-01$ & 1.03E-01 \\
\hline 31.60 & 4.90E-01 & $1.00 \mathrm{E}-01$ & 9.73E-02 & 9.51E-02 & 9.35E-02 & $9.22 \mathrm{E}-02$ & $9.12 \mathrm{E}-02$ \\
\hline 34.00 & 7.46E-01 & 8.55E-02 & $8.11 \mathrm{E}-02$ & 7.80E-02 & 7.57E-02 & 7.38E-02 & 7.24E-02 \\
\hline
\end{tabular}

In the above tables, factors above 1.0 indicate an assumed integrity management program less effective than what is assumed in the baseline, and factors less than 1 indicate a more effective program. 


\subsubsection{Impact of Plant Age on Estimated Failure Rates for FAC Susceptible Systems}

As was done for the FP piping, the Markov model was used to calculate aging factors to adjust the baseline failure rates, derived from service data with average plant age of 32 years, to account for aging at $40 \mathrm{yrs}, 60 \mathrm{yrs}$, and $80 \mathrm{yrs}$.

\section{Table B-63 Factors To Account for Aging Effects on NPS 24" FWC Pipe}

\begin{tabular}{|c|c|c|c|c|c|}
\hline \multirow{2}{*}{\multicolumn{2}{|c|}{ Pipe Failure Mode }} & \multirow{2}{*}{$\begin{array}{l}\text { Base } \\
\text { Rates } \\
\text { (mean) }\end{array}$} & \multicolumn{3}{|c|}{$\begin{array}{l}I_{T} \text {, Factor Increase to Account } \\
\text { for Aging at Time T }\end{array}$} \\
\hline & & & $\begin{array}{l}40 \\
\text { Years }\end{array}$ & $\begin{array}{c}60 \\
\text { Years }\end{array}$ & 80 Years \\
\hline \multicolumn{2}{|c|}{ All Failure Modes } & 5.72E-06 & 1.3 & 2.1 & 3.0 \\
\hline \multirow{8}{*}{ EBS (in.) } & 0.032 & $1.56 \mathrm{E}-06$ & 1.3 & 2.1 & 3.0 \\
\hline & 0.10 & $5.54 \mathrm{E}-07$ & 1.4 & 2.4 & 3.5 \\
\hline & 0.32 & 3.95E-07 & 1.4 & 2.5 & 3.7 \\
\hline & 1.0 & 2.95E-07 & 1.4 & 2.4 & 3.6 \\
\hline & 3.2 & 1.96E-07 & 1.4 & 2.5 & 3.9 \\
\hline & 10 & 1.19E-07 & 1.5 & 2.9 & 4.5 \\
\hline & 31.6 & 7.46E-08 & 1.5 & 3.0 & 4.8 \\
\hline & 34 & 3.77E-08 & 1.5 & 3.0 & 4.8 \\
\hline
\end{tabular}

\subsection{Investigation of Aging via Direct Estimation of Failure Rates and Rupture Frequencies}

In the previous sections, estimates of the possible growth in failure rates and rupture frequencies due to aging in the Fire Protection and Feedwater and Condensate Systems were made based on the time dependent growth in the hazard rate evaluated at the end of 40 years design life and 60 years extended life in comparison to the average age of the plants in the service data which happens to be 32 years. A more direct estimation of the possible trends in failure rates due to aging can be made simply by comparing the estimates made at different snapshots in time. The estimates of pipe failure rates in the previous sections were made based on nuclear power plant service experience through 2010. For Fire Protection the data start date was 1970 and for the current estimates for FWC the start date is 1989 so that the experience prior to full implementation of the FAC programs was screened out. In Reference [1] there were estimates made for both of these systems based on the service data up through 2005. By comparing and decomposing these estimates it is possible to provide a direct estimation of the changes in failure rate behavior in the last 5 years since 2005.

As seen in this figure, failure rates for spray and flood modes in FP piping over the last 5 years has increased by more than an order of magnitude relative to that estimated over the time 
period from 1970 though 2005. The failure rate for major flooding (flood rates exceeding $2,000 \mathrm{gpm}$ ) has increased by somewhat less than an order of magnitude. This trend suggests that failure rates are on the rise and aging is a candidate explanation.

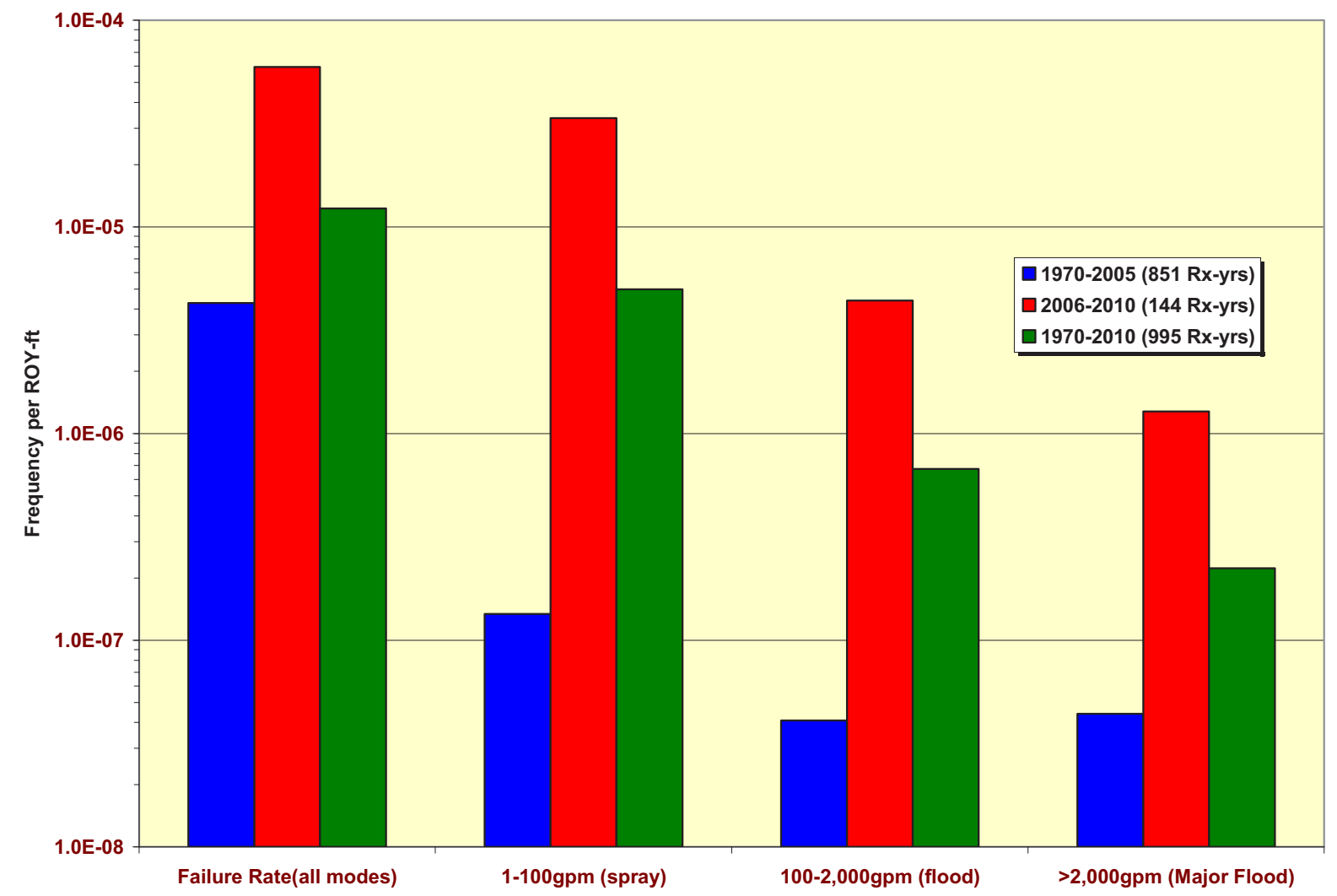

Figure B-64 Comparison of Fire Protection System Failure Rates Over Different Time Periods

Another example of this type of direct estimate can be made with respect to PWR feedwater and condensate piping by comparing estimates that were made at different snapshots in time. In this case the current results are compared to the results of an earlier study that was performed for the Prairie Island nuclear power plant. The time frames of this comparison are 1988 through 2004 and 2005 through 2008. In this case only the total failure rate is compared as shown in Figure 4-12. As seen in this figure there is more modest evidence of pipe aging in the larger pipe sizes for this system that is subjected to FAC. In this case there appears to be an increase in the failure rate of large FWC pipes on the order of a factor of 5 compared to the estimate derived in Reference [2] for the time period 1988 through 2004. It is noted that the most recent time period estimates are subjected to larger uncertainties (unquantified here) as only 400 reactor years are available in this data set. 


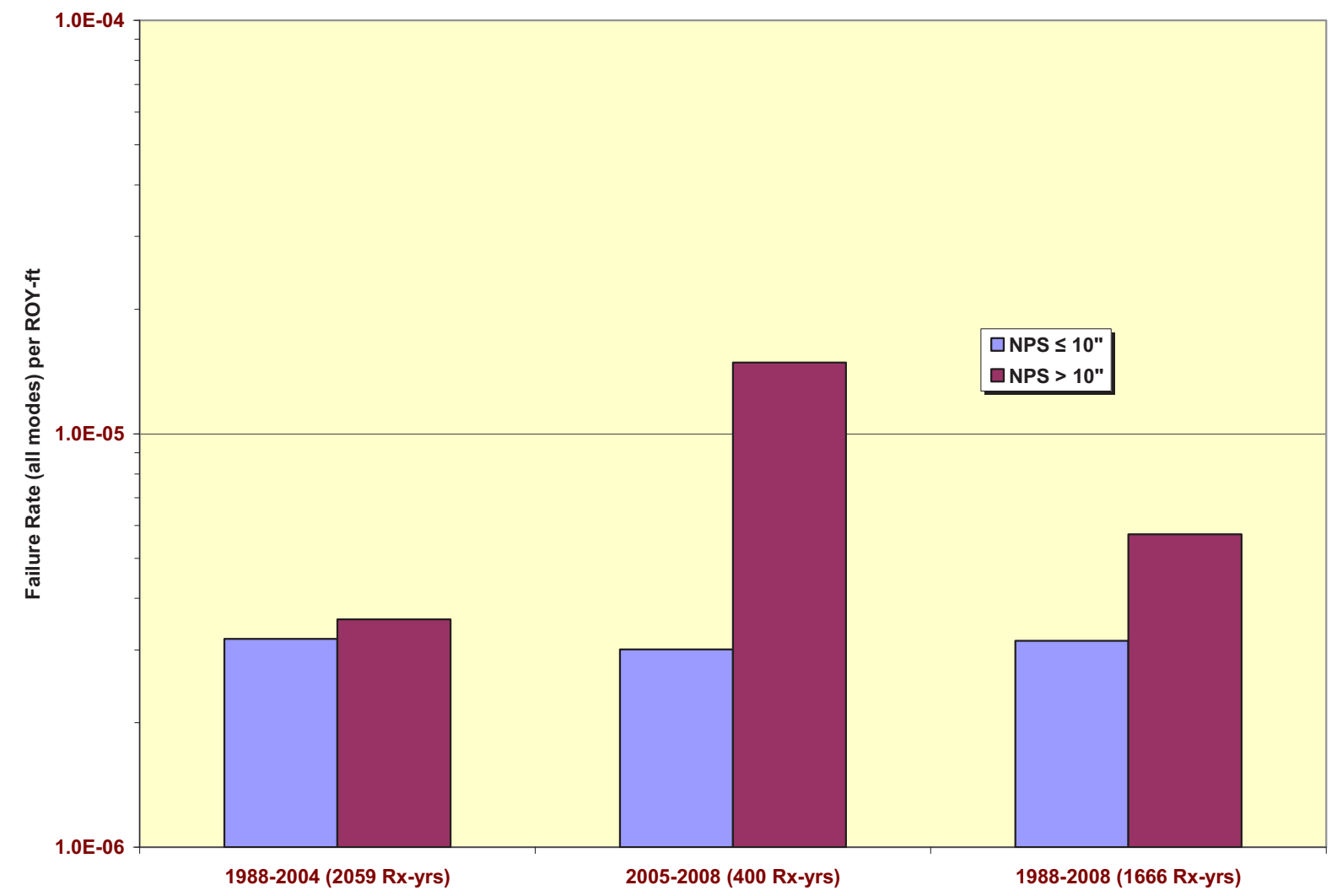

Figure B-65 Comparison of PWR FWC Failure Rate Estimates for Different Time Periods

\subsubsection{0pen Issues with FAC Susceptible Systems}

Some of the key assumptions made in the current estimation of failure rates and rupture frequencies include the following:

- Assumption that all pipe failures are precursors to pipe ruptures

- Assumption that classification of piping into FWC, HP Steam, LP Steam and Extraction Steam captures the important variabilities in FAC susceptibility and is adequate for pooling data for this application

- Assumption that modeling uncertainty on pipe exposure captures this uncertainty

- Assumption that the failure data are complete

- Uncertainty in the classification of pipe ruptures

- Uncertainty in the modeling of conditional pipe break probabilities vs. break size

- Uncertainty in the assumed prior distributions for pipe failure rates and conditional rupture probabilities

- Assumption that Markov model transition rates are time independent

- Assumption that discrete inspections can be modeled as continuous processes

- Uncertainties in assumptions regarding flaw to leak ratios

- Assumption that transition rates for leaks and ruptures can be estimated based on estimated average failure rates from service data 
- Assumption that time dependent growth in hazard rate can be used to forecast aging. 


\subsection{REFERENCES}

[44] Fleming, K.N. and B.O.Y. Lydell, "Pipe Rupture Frequencies for Internal Flooding PRAs, Revision 1", prepared by Karl N. Fleming Consulting Services LLC for EPRI, EPRI Report No. 1013141, March 2006

[45] Fleming, K.N. and B.O.Y. Lydell, " High Energy Line Break Pipe Failure Rates for the Prairie Island PRA", Prepared by KNF Consulting Services LLC for Xcel Energy, April 2009

[46] Fleming, K.N. and B.O.Y. Lydell, " High Energy Line Break Initiating Event Frequencies for the Kewaunee PRA", prepared by Karl N. Fleming Consulting Services for Dominion Energy, October 2005

[47] Fleming, K.N. and B.O.Y. Lydell, "Pipe Failure Rates for the Columbia Generating Station PRA”, Prepared by KNF Consulting Services LLC for Energy Northwest, June 2009

[48] Fleming, K. N., "Markov Models for Evaluating Risk Informed In-Service Inspection Strategies for Nuclear Power Plant Piping Systems", Reliability Engineering and System Safety, Vol. 83, No. 1 pp.:27-45, 2004.

[49] American Society of Mechanical Engineers and American Nuclear Society, RA-S-2008, "Standard for Level 1/Large Early Release Frequency PRA for Nuclear Power Plant Applications" December 2008

[50] Karl Fleming, " PBMR Passive Component Reliability - Application of Markov Model to Evaluate Alternative Integrity Management Strategies", Prepared by Technology Insights for PBMR Pty., Final Report, June 2007

[51] Poloski, J.P. et al, Rates of Initiating Events at U.S. Nuclear Power Plants, NUREG/CR5750, U.S. Nuclear Regulatory Commission, Washington (DC), 1999.

[52] Tregoning, R., L. Abramson and P. Scott, Estimating Loss-of-Coolant Accident (LOCA) Frequencies Through the Elicitation Process, Draft Report for Comment, NUREG-1829, U.S. Nuclear Regulatory Commission, Washington (DC), June 2005.

[53] Lydell, B.O.Y., "PIPExp/PIPE-2008: Monthly Summary of Database Content (Status as of 31-Dec-2008)", RSA-R-2004-01.07, RSA Technologies, Fallbrook (CA). Monthly summary reports have been issued since January 1999.

[54] Fleming, K.N. et al, "Piping System Reliability and Failure Rate Estimation Models for Use in Risk-Informed In-Service Inspection Applications", TR-110161 (EPRI Licensed Material), EPRI, Palo Alto (CA), 1998.

[55] U.S. Nuclear Regulatory Commission, Safety Evaluation Report Related to 'Revised RiskInformed In-service Inspection Evaluation Procedure (EPRI TR-112657, Rev. B, July 1999, Washington (DC), 1999.

[56] H. Martz, TSA-1/99-164: "Final (Revised) Review of the EPRI-Proposed Markov Modeling/Bayesian Updating Methodology for Use in Risk-Informed Inservice Inspection of Piping in Commercial Nuclear Power Plants,", Los Alamos National Labaratory, June 1999

[57] Simonen, F.A., Gosselin, S.R., Lydell, B.O.Y., Rudland, D.L. and Wilkowski, G.M., Probabilistic Fracture Mechanics Evaluation of Selected Passive Components, Letter Report PNNL-16625, Pacific Northwest National Laboratory, Richland (WA), May 2007.

[58] Gosselin, S.R., Simonen, F.A., Pilli, S.P. and Lydell, B.O.Y., Probabilities of Failure and Uncertainty Estimates for Passive Components - A Literature Survey, NUREG/CR-6936, U.S. Nuclear Regulatory Commission, Washington (DC), May 2007. 
[59] Fleming, K.N., Mikschl, T.J., "Piping System Failure Rates and Rupture Frequencies for Use in Risk Informed In-service Inspection Applications”, EPRI Report No. TR-111880 (EPRI Licensed Material), EPRI, Palo Alto (CA), 1999.

[60] Fleming, K.N. and B.O.Y. Lydell, "Database Development and Uncertainty Treatment for Estimating Pipe Failure Rates and Rupture Frequencies," Reliability Engineering and System Safety, 86:227-246, 2004

[61] Bush, S. et al, "Piping Failures in the US Nuclear Power Plants 1961-1995," SKI Report 96:20, Swedish Nuclear Power Inspectorate, Stockholm (Sweden), January 1996

[62] Fleming, K.N., and B.O.Y. Lydell, Guidelines for Performance of Internal Flooding Probabilistic Risk Assessment (IFPRA), Prepared by KNF Consulting Services LLC for EPRI, EPRI Report No. 1019194, December 2009 


\section{APPENDIX C}

Numerical Methods for Solving the Benchmark Problem

Section 1. SDB-O: Service Data Based Model using OpenBUGS Computational Approach

Section 2. SDB-FT and SDB-FB: Service Data Based Model using Flowgraph Computational Approach for triangular and beta distribution priors 


\section{Appendix C Section 1}

\section{C.1 Benchmark Problem 1 Using OpenBUGS Based Computational Approach}

The Service Data Based using OpenBUGS analysis (SDB-O) implemented the Markov model described in Section 5. This section describes that implementation, along with a check on the numerical solution by OpenBUGS of the ordinary differential equations that characterize the Markov model.

\section{C.1.1 Aleatory Models}

The occurrences of failures as a result of stress corrosion cracking (SC) and design and construction defects (DC) were assumed to be described by independent Poisson processes, with rates $\lambda_{\mathrm{SC}}$ and $\lambda_{\mathrm{DC}}$, respectively, consistent with the treatment in Section 5 . The occurrence of failures overall is then described by a Poisson process with rate $\lambda=\lambda_{\mathrm{SC}}+\lambda_{\mathrm{DC}}$. Data consist of the number of SC and DC failures, $n_{S C}$ and $n_{D C}$, observed over specified exposure times as described in Section 5.

The Section 5 analysis accounted for uncertainty in the exposure times via a discrete distribution, with nine components for SC, and three for DC. Lognormal priors for $\lambda_{\mathrm{SC}}$ and $\lambda_{\mathrm{DC}}$ were updated with $n_{S C}=8$ and $n_{D C}=4$, with the exposure times and weights given in Section 5 of the main report. A common set of input parameters was identified so that differences could be attributed to differences in the computational methodologies.

The posterior distributions for $\lambda_{\mathrm{SC}}$ and $\lambda_{\mathrm{DC}}$ are obtained by averaging over the weights used in Section 5 . The overall failure rate, $\lambda$, is then found by summing $\lambda_{\mathrm{SC}}$ and $\lambda_{\mathrm{DC}}$. The posterior distribution for $\lambda$ is multimodal. Again these formulations are consistent with the analysis in Section 5.

Following the development in Section 5, occurrences of ruptures conditional upon failures were described by a binomial distribution with parameters $P\left(R_{I}\right)$ and 12 (sum of $n_{S C}$ and $n_{D C}$ ). Each $P\left(R_{l}\right)$ has a lognormal prior distribution, as given in Table 5-2 of Section 5.2 in the main report.

The frequency of pipe rupture of a given size is found by multiplying $\lambda$ by $P(R I)$.

\section{C.1.2 Other Markov Model Parameters}

Uncertainties for the other parameters were represented as described in Section 5.1 and 5.2, with the exception of $P_{F D}$ and $P_{L D}$, for which Service Data Based Analytical approach (SDB-A) used a triangular distribution. Because the triangular distribution is not implemented in OpenBUGS, a beta distribution was used over the range in SDB-O, with a mean value approximately equal to the mode of the triangular distribution. This change should have no discernible impact on the results.

\section{C.1.3 Markov System Equations}

The Markov model is described by a set of four coupled linear first-order ordinary differential equations (ODEs). The equations give the rate of change of the four components of the state probability vector in terms of the Markov parameters and the state probability vector components, which are time-dependent. The initial condition necessary for the solution of the vector equation is $P(0)=(1,0,0,0)^{\top}$. 


\section{C.1.4 Exact Solution}

The system of ODEs can be written more compactly as:

$$
\frac{d P}{d t}=A P
$$

where $P=\left(P_{1}, P_{2}, P_{3}, P_{4}\right)^{\top}$ and $A$ is given by:

$$
A=\left(\begin{array}{cccc}
-\phi & \omega & \mu & 0 \\
\phi & -\left(\lambda_{F}+\rho_{F}+\omega\right) & 0 & 0 \\
0 & \lambda_{F} & -\left(\rho_{L}+\mu\right) & 0 \\
0 & \rho_{F} & \rho_{L} & 0
\end{array}\right)
$$

The general solution is given by:

$$
P(t)=\sum_{i=1}^{4} C_{i} E_{i} \exp \left(z_{i} t\right)
$$

where $z_{i}$ and $E_{i}$ are the eigenvalues and eigenvectors of $A$, and the coefficients, $C_{i}$, are determined from the initial condition $P(0)=(1,0,0,0)^{\top}$. This solution can be written more compactly as:

$$
P(t)=E e^{Z t} E^{-1} P(0)
$$

Where:

$$
e^{Z t}=\left(\begin{array}{cccc}
e^{z_{1} t} & 0 & 0 & 0 \\
0 & e^{z_{2} t} & 0 & 0 \\
0 & 0 & e^{z_{3} t} & 0 \\
0 & 0 & 0 & e^{z_{4} t}
\end{array}\right)
$$

With rupture (state 4) defined as failure for the system, the system hazard rate is given by:

$$
\begin{aligned}
h(t) & =\frac{f(t)}{1-F(t)}=-\frac{1}{r(t)} \frac{d r}{d t} \\
& =\frac{\rho_{F} P_{2}(t)+\rho_{L} P_{3}(t)}{\sum_{i=1}^{3} P_{i}(t)}
\end{aligned}
$$

The R package was used to find the eigenvalues and eigenvectors of $A$. The vector of coefficients is then found by solving:

$$
E C=\left(\begin{array}{l}
1 \\
0 \\
0 \\
0
\end{array}\right)
$$

where $E$ is the matrix of eigenvectors and $C=\left(C_{1}, C_{2}, C_{3}, C_{4}\right)^{\top}$. Alternatively, Eq. C1-6 can be used to find $P(t)$ more directly. Again, the R package was used to solve these equations. Note that when propagating uncertainties in the Markov parameters through the exact solution, new 
eigenvalues, eigenvectors, and coefficients must be found at each iteration, as the components of $A$ change with each iteration.

\section{C.1.5 Numerical Solution}

In OpenBUGS, a numerical ODE solver is used instead of the exact solution. The results of this numerical solution SDB-O for a 10-inch rupture were compared with the exact solution by iterating one step at a time through the uncertainty propagation (following burn-in), and comparing the results of the exact (from R) and numerical solutions (from OpenBUGS) at each step. The results generally agree extremely well, as shown in Table C1-1, so we have confidence in the numerical ODE solution in OpenBUGS.

Table C1-1 Comparison of SDB-O (top) and exact (bottom) solutions for hazard rate for 10 -inch rupture at times 10,40 , and 100 years for given parameter values sampled at each iteration

\begin{tabular}{|c|c|c|c|c|c|c|c|c|c|}
\hline Iteration & $\phi$ & $\omega$ & $\mu$ & $\lambda_{\mathrm{F}}$ & $\rho_{\mathrm{F}}$ & $\rho_{\mathrm{L}}$ & $h_{10}(10)$ & $h_{10}(40)$ & $h_{10}(100)$ \\
\hline 1 & $5.38 \mathrm{E}-3$ & $4.48 \mathrm{E}-3$ & $4.54 \mathrm{E}-3$ & $1.87 \mathrm{E}-3$ & $2.95 \mathrm{E}-6$ & $1.13 \mathrm{E}-2$ & $\begin{array}{l}5.78 \mathrm{E}-6 \\
5.38 \mathrm{E}-6\end{array}$ & $\begin{array}{l}6.9 \mathrm{E}-5 \\
6.4 \mathrm{E}-5\end{array}$ & $\begin{array}{l}2.58 \mathrm{E}-4 \\
2.42 \mathrm{E}-4\end{array}$ \\
\hline 2 & $1.80 \mathrm{E}-3$ & $4.55 \mathrm{E}-3$ & $4.58 \mathrm{E}-3$ & $1.70 \mathrm{E}-4$ & $7.48 \mathrm{E}-7$ & $3.51 \mathrm{E}-3$ & $\begin{array}{l}6.43 \mathrm{E}-8 \\
6.42 \mathrm{E}-8\end{array}$ & $\begin{array}{l}7.58 \mathrm{E}-7 \\
7.56 \mathrm{E}-7\end{array}$ & $\begin{array}{l}3.46 \mathrm{E}-6 \\
3.45 \mathrm{E}-6\end{array}$ \\
\hline 3 & $1.83 \mathrm{E}-4$ & $4.58 \mathrm{E}-3$ & $4.68 \mathrm{E}-3$ & $2.14 \mathrm{E}-5$ & $7.57 \mathrm{E}-8$ & $7.02 \mathrm{E}-3$ & $\begin{array}{l}1.43 \mathrm{E}-9 \\
1.44 \mathrm{E}-9 \\
\end{array}$ & $\begin{array}{l}1.82 \mathrm{E}-8 \\
1.82 \mathrm{E}-8\end{array}$ & $\begin{array}{l}8.25 \mathrm{E}-8 \\
8.27 \mathrm{E}-8\end{array}$ \\
\hline 4 & $7.98 \mathrm{E}-4$ & $4.11 \mathrm{E}-3$ & $4.48 \mathrm{E}-3$ & $2.14 \mathrm{E}-5$ & $2.81 \mathrm{E}-8$ & $8.63 \mathrm{E}-3$ & $\begin{array}{l}7.14 \mathrm{E}-9 \\
7.16 \mathrm{E}-9\end{array}$ & $\begin{array}{l}9.38 \mathrm{E}-8 \\
9.40 \mathrm{E}-8\end{array}$ & $\begin{array}{l}4.19 \mathrm{E}-7 \\
4.20 \mathrm{E}-7\end{array}$ \\
\hline 5 & $6.94 \mathrm{E}-5$ & $4.47 \mathrm{E}-3$ & $4.43 \mathrm{E}-3$ & $3.14 \mathrm{E}-6$ & $3.11 \mathrm{E}-9$ & $2.13 \mathrm{E}-2$ & $\begin{array}{l}2.1 \mathrm{E}-10 \\
2.1 \mathrm{E}-10\end{array}$ & $\begin{array}{l}2.55 \mathrm{E}-9 \\
2.55 \mathrm{E}-9\end{array}$ & $\begin{array}{l}9.75 \mathrm{E}-9 \\
9.76 \mathrm{E}-9\end{array}$ \\
\hline
\end{tabular}

A larger scale comparison was done by dumping output parameter files from OpenBUGS in CODA format, and importing these into $\mathrm{R}$ using the CODA package [1]. This allows the exact solution to be calculated for each iteration, and summary statistics can be computed for comparison with the OpenBUGS numerical results. The results, which are compared in Table C1-10, for the last 5,000 of 50,000 iterations (following 1,000 burn-in iterations), show excellent agreement between the numerical and exact solutions.

Table C1-2 Uncertainty Summaries for System Hazard Rate For 10-Inch Rupture From SDB-O (Top) And Exact Solution (Bottom) For Last 5,000 Of 50,000 Iterations

\begin{tabular}{|l|l|l|l|l|}
\hline & $5^{\text {th }}$ & $50^{\text {th }}$ & Mean & 95 th \\
\hline$h((1,10)$ & $4.09 \mathrm{E}-12$ & $3.86 \mathrm{E}-10$ & $3.11 \mathrm{E}-8$ & $5.49 \mathrm{E}-8$ \\
& $4.09 \mathrm{E}-12$ & $3.85 \mathrm{E}-10$ & $3.11 \mathrm{E}-8$ & $5.41 \mathrm{E}-8$ \\
\hline$h((10,10)$ & $2.88 \mathrm{E}-10$ & $2.86 \mathrm{E}-8$ & $1.77 \mathrm{E}-6$ & $4.38 \mathrm{E}-6$ \\
& $2.88 \mathrm{E}-10$ & $2.85 \mathrm{E}-8$ & $1.77 \mathrm{E}-6$ & $4.32 \mathrm{E}-6$ \\
\hline$h((40,10)$ & $3.39 \mathrm{E}-9$ & $3.36 \mathrm{E}-7$ & $1.56 \mathrm{E}-5$ & $4.79 \mathrm{E}-5$ \\
& $3.39 \mathrm{E}-9$ & $3.35 \mathrm{E}-7$ & $1.56 \mathrm{E}-5$ & $4.74 \mathrm{E}-5$ \\
\hline$h((100,10)$ & $1.36 \mathrm{E}-8$ & $1.32 \mathrm{E}-6$ & $4.33 \mathrm{E}-5$ & $1.60 \mathrm{E}-4$ \\
& $1.36 \mathrm{E}-8$ & $1.32 \mathrm{E}-6$ & $4.33 \mathrm{E}-5$ & $1.59 \mathrm{E}-4$ \\
\hline
\end{tabular}




\section{C.1.6 Results}

The OpenBUGS model is shown below. The model converged quickly, but for conservatism the first 1,000 iterations were discarded for burn-in. Parameter estimates are based on 50,000 iterations after burn-in, resulting in a Monte Carlo error of $1 \%$ or less of the overall standard deviation for each parameter.

Posterior summaries for the input parameters to the ODEs are shown in Table C1-5 and C1-6. The hazard rate results for 0.1 and 10-inch ruptures are plotted in Figure C1-1 and C1-2, and tabulated in Table C1-8 below.

\section{SDB-O OpenBUGS Script for Benchmark Problem}

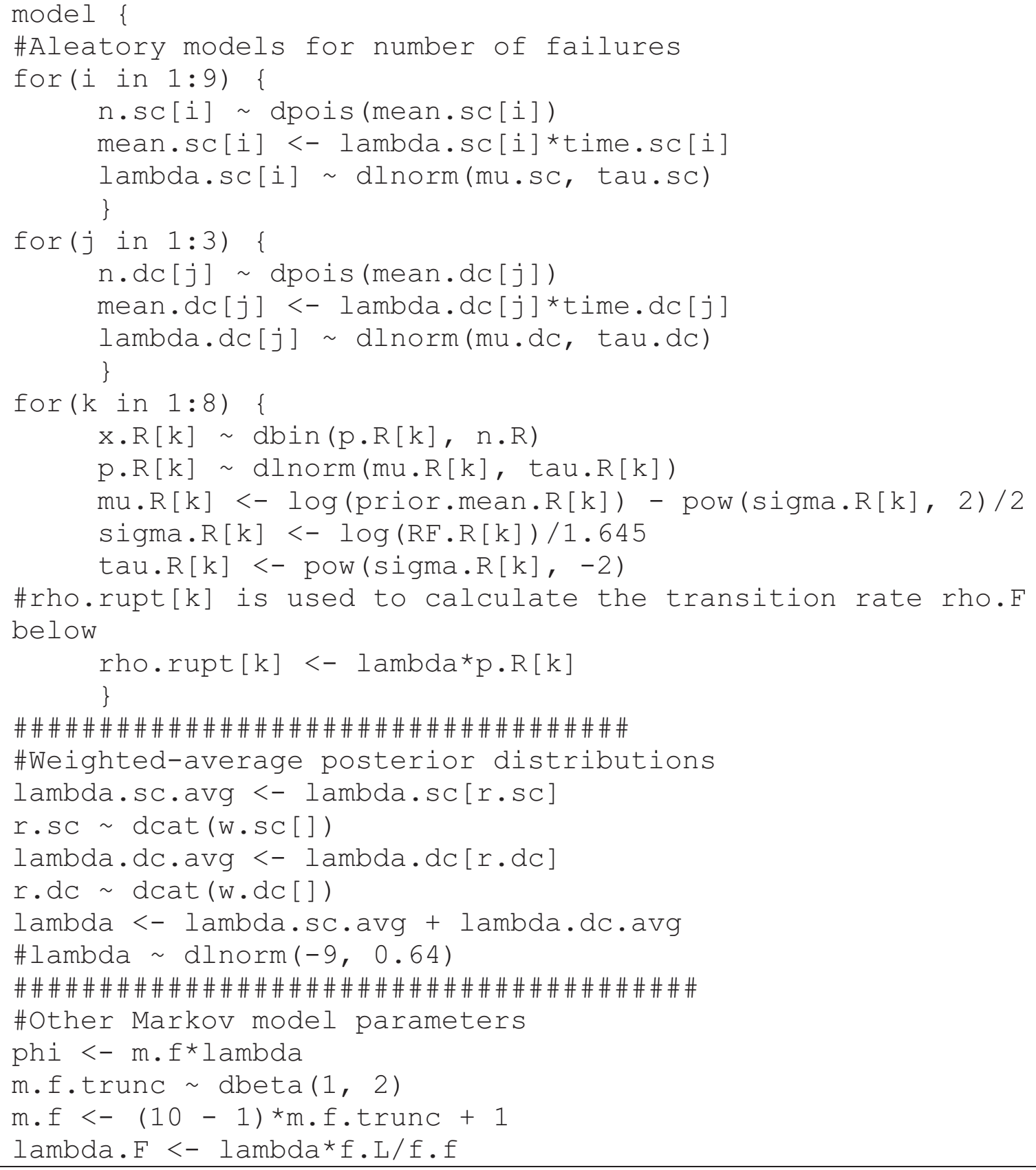




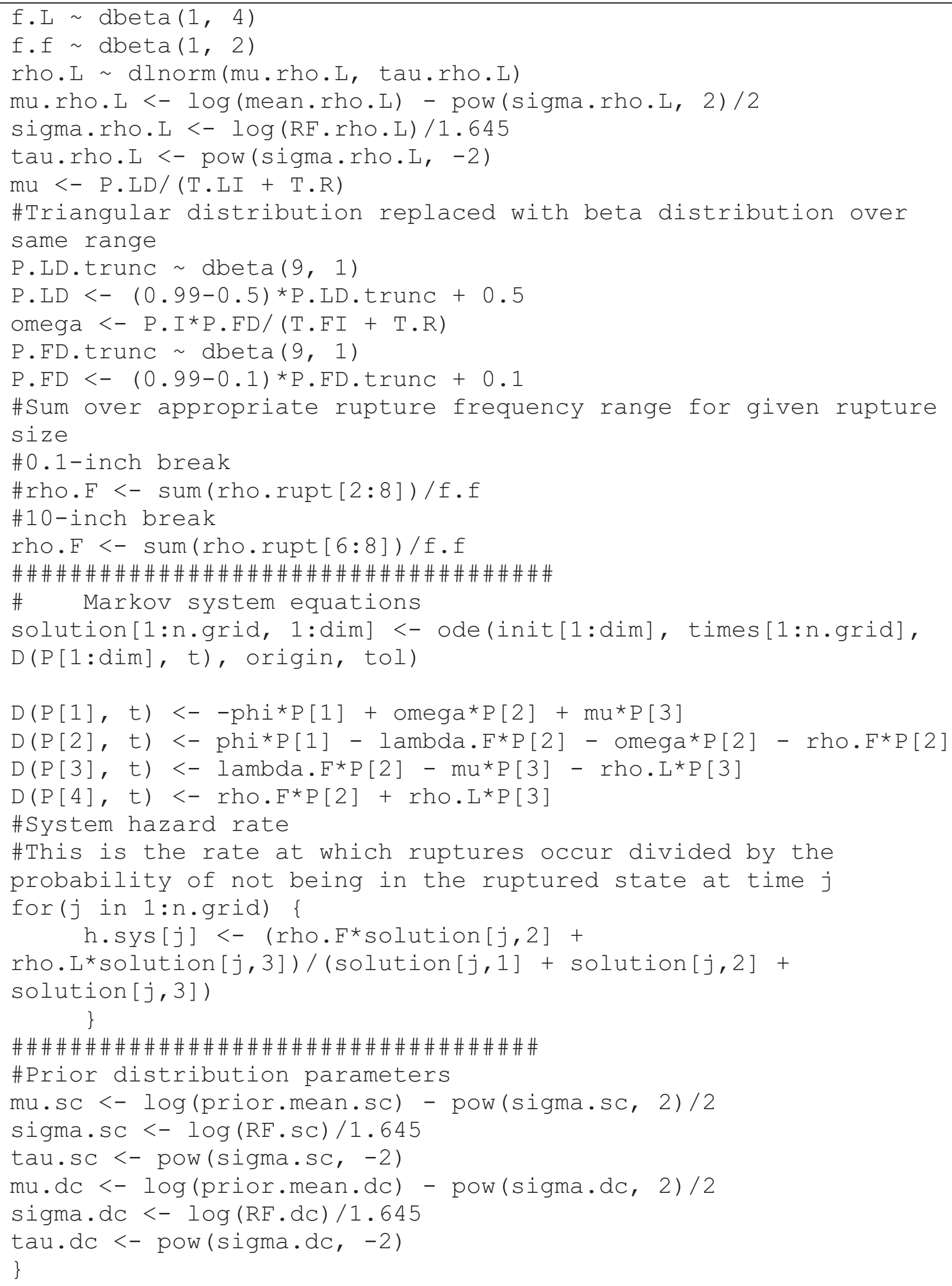




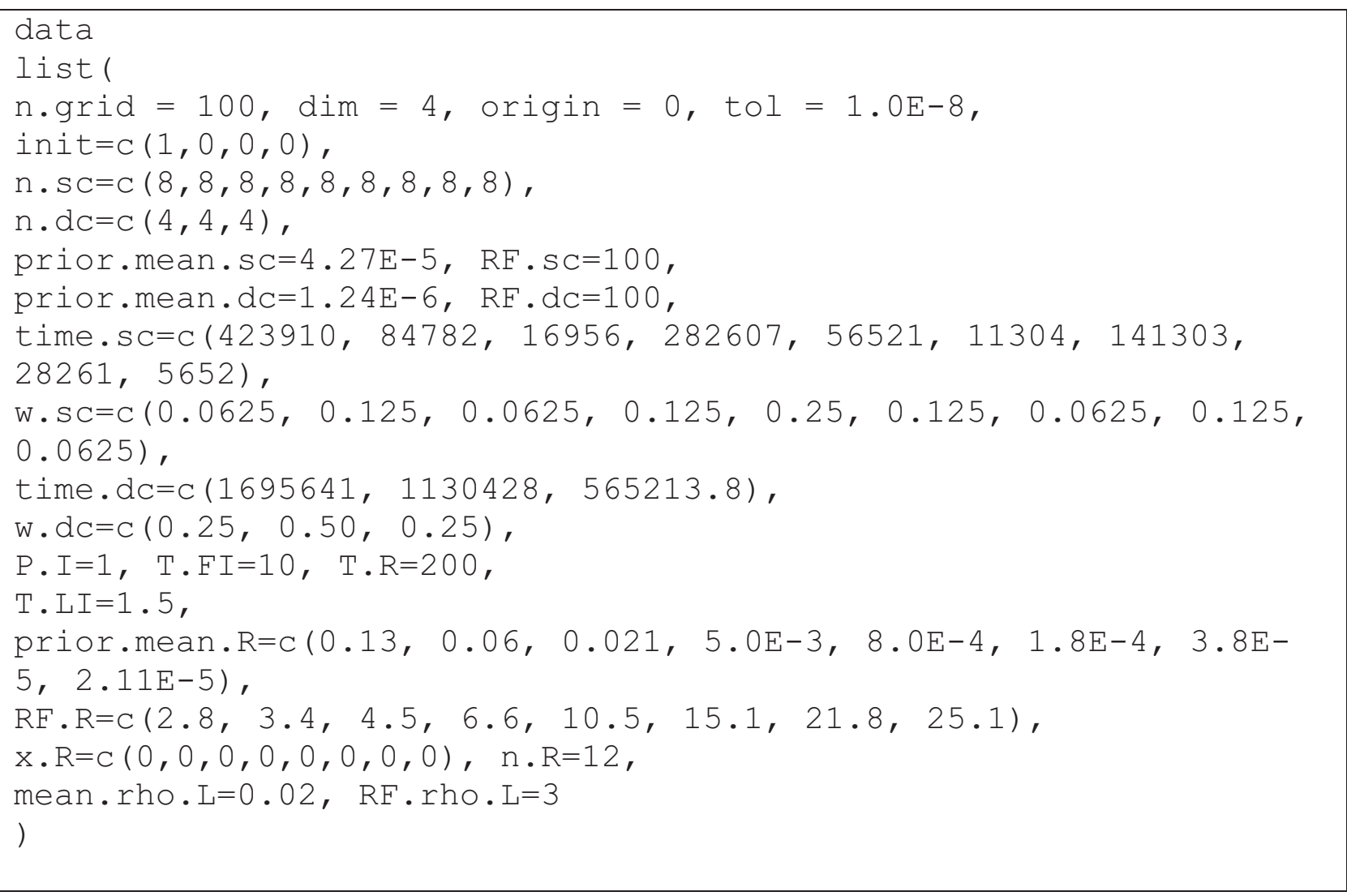

Table C1-3 Posterior Summaries of Rate Parameters in Markov Model

\begin{tabular}{|l|l|l|l|l|}
\hline & $5^{\text {th }}$ & $50^{\text {th }}$ & Mean & $95^{\text {th }}$ \\
\hline$\lambda_{\mathrm{SC}}$ & $1.7 \mathrm{E}-5$ & $1.3 \mathrm{E}-4$ & $2.7 \mathrm{E}-4$ & $1.0 \mathrm{E}-3$ \\
\hline$\lambda_{\mathrm{DC}}$ & $8.7 \mathrm{E}-7$ & $2.8 \mathrm{E}-6$ & $3.5 \mathrm{E}-6$ & $8.5 \mathrm{E}-6$ \\
\hline$\lambda=\lambda_{\mathrm{SC}}+\lambda_{\mathrm{DC}}$ & $2.0 \mathrm{E}-5$ & $1.3 \mathrm{E}-4$ & $2.7 \mathrm{E}-4$ & $1.0 \mathrm{E}-3$ \\
\hline$\lambda_{\mathrm{F}}=\lambda f_{L} / f_{f}^{4}$ & $2.9 \mathrm{E}-6$ & $7.5 \mathrm{E}-5$ & $3.5 \mathrm{E}-3$ & $2.0 \mathrm{E}-3$ \\
\hline
\end{tabular}

Table C1-4 Posterior summaries of conditional rupture probabilities based on updating lognormal priors with 0 ruptures in 12 trials

\begin{tabular}{|l|l|l|l|l|}
\hline Rupture size (in.) & $5^{\text {th }}$ & $50^{\text {th }}$ & Mean & $95^{\text {th }}$ \\
\hline 0.032 & 0.03 & 0.07 & 0.08 & 0.16 \\
\hline 0.10 & 0.01 & 0.03 & 0.04 & 0.10 \\
\hline 0.32 & $2.8 \mathrm{E}-3$ & 0.01 & 0.02 & 0.05 \\
\hline 1.00 & $3.8 \mathrm{E}-4$ & $2.4 \mathrm{E}-3$ & $4.3 \mathrm{E}-3$ & 0.01 \\
\hline 3.16 & $2.7 \mathrm{E}-5$ & $2.8 \mathrm{E}-4$ & $7.9 \mathrm{E}-4$ & $2.9 \mathrm{E}-3$ \\
\hline 10.0 & $3.1 \mathrm{E}-6$ & $4.7 \mathrm{E}-5$ & $1.8 \mathrm{E}-4$ & $6.9 \mathrm{E}-4$ \\
\hline 31.62 & $3.1 \mathrm{E}-7$ & $6.7 \mathrm{E}-6$ & $3.6 \mathrm{E}-5$ & $1.4 \mathrm{E}-4$ \\
\hline 42.4 & $1.2 \mathrm{E}-7$ & $3.1 \mathrm{E}-6$ & $2.5 \mathrm{E}-5$ & $8.0 \mathrm{E}-5$ \\
\hline
\end{tabular}

\footnotetext{
${ }^{4}$ Note the extremely skewed distribution of $\lambda_{\mathrm{F}}$. The mean is greater than the $95^{\text {th }}$ percentile.
} 


\section{Table C1-5 Posterior summaries of rupture frequencies ( $\lambda$ times conditional rupture probabilities from Table 3)}

\begin{tabular}{|l|l|l|l|l|}
\hline Rupture size (in.) & 5 th & 50 th & Mean & 95 th \\
\hline 0.032 & $1.2 \mathrm{E}-6$ & $9.4 \mathrm{E}-6$ & $2.1 \mathrm{E}-5$ & $8.4 \mathrm{E}-5$ \\
\hline 0.10 & $5.1 \mathrm{E}-7$ & $4.6 \mathrm{E}-6$ & $1.1 \mathrm{E}-5$ & $4.5 \mathrm{E}-5$ \\
\hline 0.32 & $1.5 \mathrm{E}-7$ & $1.6 \mathrm{E}-6$ & $4.4 \mathrm{E}-6$ & $1.8 \mathrm{E}-5$ \\
\hline 1.00 & $2.3 \mathrm{E}-8$ & $3.3 \mathrm{E}-7$ & $1.2 \mathrm{E}-6$ & $4.8 \mathrm{E}-6$ \\
\hline 3.16 & $1.9 \mathrm{E}-9$ & $3.9 \mathrm{E}-8$ & $2.1 \mathrm{E}-7$ & $8.1 \mathrm{E}-7$ \\
\hline 10.0 & $2.3 \mathrm{E}-10$ & $6.3 \mathrm{E}-9$ & $4.7 \mathrm{E}-8$ & $1.8 \mathrm{E}-7$ \\
\hline 31.62 & $2.4 \mathrm{E}-11$ & $9.0 \mathrm{E}-10$ & $9.3 \mathrm{E}-9$ & $3.5 \mathrm{E}-8$ \\
\hline 42.4 & $9.8 \mathrm{E}-12$ & $4.2 \mathrm{E}-10$ & $7.0 \mathrm{E}-9$ & $2.0 \mathrm{E}-8$ \\
\hline
\end{tabular}

Table C1-6 Posterior summaries of remaining Markov parameters

\begin{tabular}{|l|l|l|l|l|}
\hline & $5^{\text {th }}$ & $50^{\text {th }}$ & Mean & $95^{\text {th }}$ \\
\hline$\phi=m_{f} \lambda$ & $5.4 \mathrm{E}-5$ & $4.65 \mathrm{E}-4$ & $1.1 \mathrm{E}-3$ & $4.3 \mathrm{E}-3$ \\
\hline$\mu^{5}$ & $4.2 \mathrm{E}-3$ & $4.7 \mathrm{E}-3$ & $4.7 \mathrm{E}-3$ & $4.9 \mathrm{E}-3$ \\
\hline$\omega$ & $3.5 \mathrm{E}-3$ & $4.4 \mathrm{E}-3$ & $4.3 \mathrm{E}-3$ & $4.7 \mathrm{E}-3$ \\
\hline$\rho_{\mathrm{L}}{ }^{6}$ & $5.3 \mathrm{E}-3$ & $1.6 \mathrm{E}-2$ & $2.0 \mathrm{E}-2$ & $4.8 \mathrm{E}-2$ \\
\hline$\rho_{\mathrm{F}}(0.1-\text { in. })^{7}$ & $2.6 \mathrm{E}-6$ & $3.1 \mathrm{E}-5$ & $8.1 \mathrm{E}-4$ & $6.5 \mathrm{E}-4$ \\
\hline$\rho_{\mathrm{F}}(10-$-in. $)$ & $2.2 \mathrm{E}-9$ & $5.2 \mathrm{E}-8$ & $2.0 \mathrm{E}-6$ & $2.0 \mathrm{E}-6$ \\
\hline
\end{tabular}

\footnotetext{
${ }^{5}$ Note that the posterior distributions of $\mu$ and $\omega$ are negatively skewed.

${ }^{6}$ This is actually the input distribution, as no updating was done for $\rho_{\mathrm{L}}$.

${ }^{7}$ The parameter $\rho_{\mathrm{F}}$ for a particular rupture size is found by summing the rupture frequencies summarized in Table C from the break size of interest to the maximum break size, and dividing the result by $f_{f}$.
} 


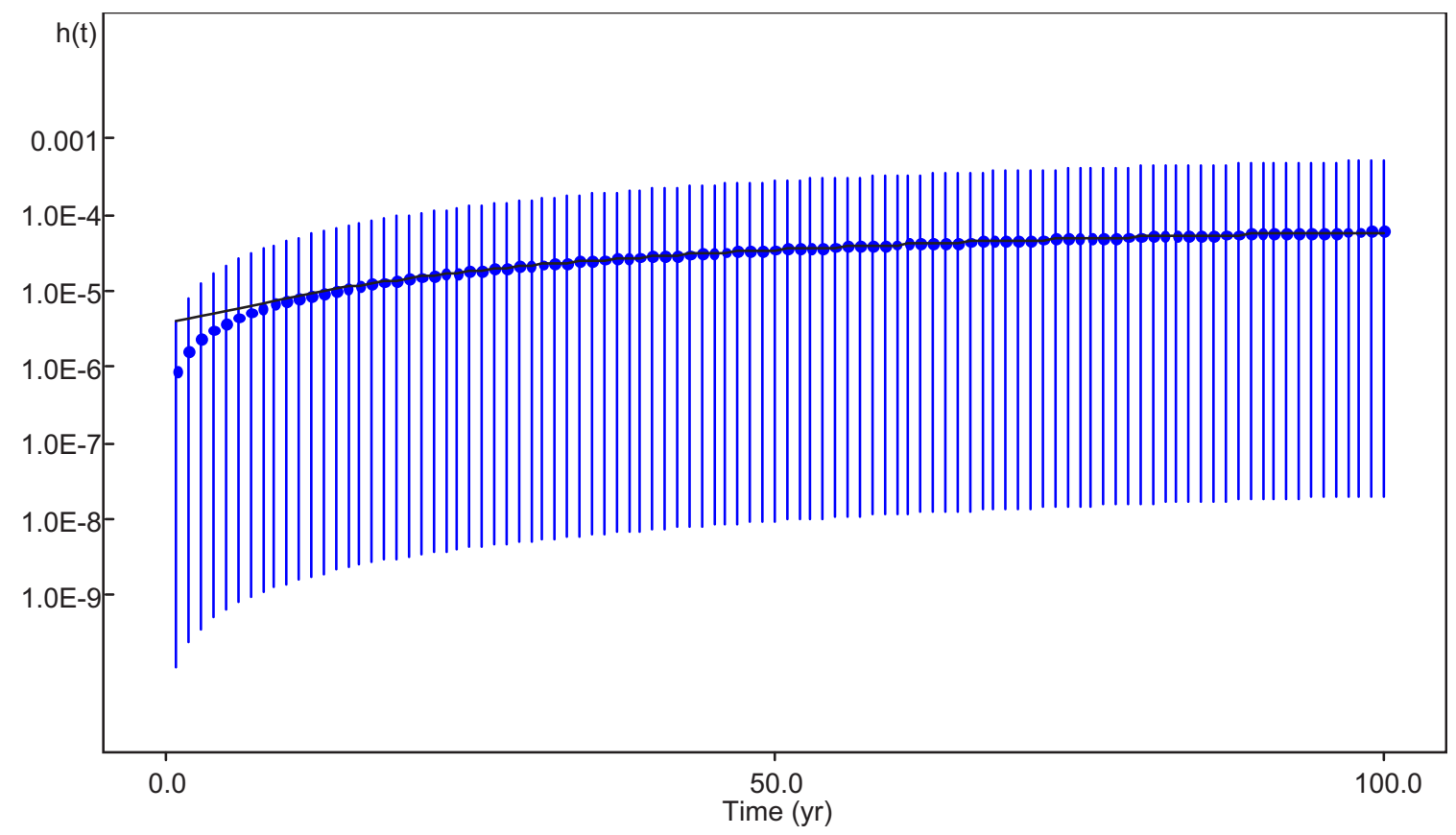

Figure C1-2 System Hazard Rate As A Function Of Time For 0.1-Inch Rupture. Line Is Posterior Mean And Bars Illustrate 95\% Credible Intervals

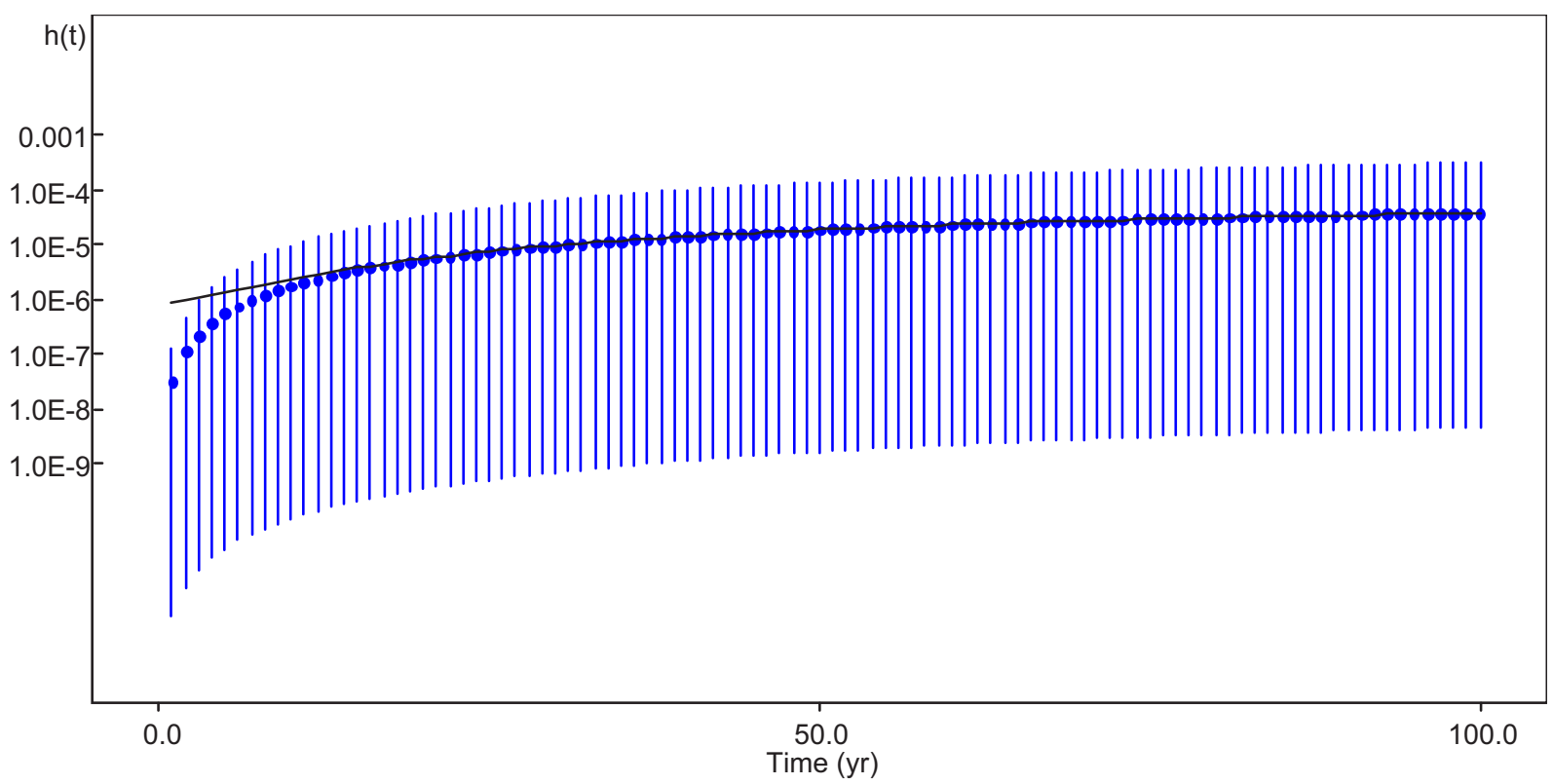

Figure C1-3 System Hazard Rate as A Function Of Time For 10-Inch Rupture. Line Is Posterior Mean and Bars Illustrate $95 \%$ Credible Intervals 
Table C1-7 Results for System Hazard Rate $\left(\mathrm{Yr}^{-1}\right)$

\begin{tabular}{|l|l|l|l|l|}
\hline $\mathrm{h}(\mathrm{t}$, size $)$ & $5^{\text {th }}$ & Median & Mean & $95^{\text {th }}$ \\
\hline$h(1,0.1)$ & $2.1 \mathrm{E}-10$ & $1.5 \mathrm{E}-8$ & $8.7 \mathrm{E}-7$ & $1.6 \mathrm{E}-6$ \\
\hline$h((10,0.1)$ & $2.6 \mathrm{E}-9$ & $1.9 \mathrm{E}-7$ & $7.4 \mathrm{E}-6$ & $1.9 \mathrm{E}-5$ \\
\hline$h((40,0.1)$ & $1.3 \mathrm{E}-8$ & $1.0 \mathrm{E}-6$ & $2.8 \mathrm{E}-5$ & $9.9 \mathrm{E}-5$ \\
\hline$h((100,0.1)$ & $3.8 \mathrm{E}-8$ & $2.8 \mathrm{E}-6$ & $6.0 \mathrm{E}-5$ & $2.5 \mathrm{E}-4$ \\
\hline$h((1,10)$ & $3.6 \mathrm{E}-12$ & $3.6 \mathrm{E}-10$ & $3.2 \mathrm{E}-8$ & $4.9 \mathrm{E}-8$ \\
\hline$h((10,10)$ & $2.3 \mathrm{E}-10$ & $2.7 \mathrm{E}-8$ & $1.8 \mathrm{E}-6$ & $3.9 \mathrm{E}-6$ \\
\hline$h((40,10)$ & $2.7 \mathrm{E}-9$ & $3.2 \mathrm{E}-7$ & $1.4 \mathrm{E}-5$ & $4.3 \mathrm{E}-5$ \\
\hline$h((100,10)$ & $1.1 \mathrm{E}-8$ & $1.3 \mathrm{E}-6$ & $3.9 \mathrm{E}-5$ & $1.5 \mathrm{E}-4$ \\
\hline
\end{tabular}

A calculation was run in which the uncertainty in $f_{f}$ was represented by a beta $(1,2)$ distribution over the interval $[0.01,1]$. This is expected to eliminate the very small samples, which make the distribution of $\lambda_{F}$ so highly skewed. This change affects $\lambda_{F}, \rho_{F}$, and the system hazard rate. The revised results are shown in Table C1-8 and Table C1-9.

Table C1-8 Posterior summaries of rate parameters with restricted beta distribution for $\boldsymbol{f}_{f}$

\begin{tabular}{|l|l|l|l|l|}
\hline & 5 th & 50 th & Mean & 95 th \\
\hline$\lambda_{\mathrm{F}}=\lambda f_{L} / f_{f}$ & $2.8 \mathrm{E}-6$ & $7.4 \mathrm{E}-5$ & $4.2 \mathrm{E}-4$ & $1.6 \mathrm{E}-3$ \\
\hline$\rho_{\mathrm{F}}(0.1-$ in. $)$ & $2.6 \mathrm{E}-6$ & $3.0 \mathrm{E}-5$ & $1.3 \mathrm{E}-4$ & $5.1 \mathrm{E}-4$ \\
\hline$\rho_{\mathrm{F}}(10$-in. $)$ & $2.3 \mathrm{E}-9$ & $5.1 \mathrm{E}-8$ & $4.85 \mathrm{E}-7$ & $1.6 \mathrm{E}-6$ \\
\hline
\end{tabular}

Table C1-9 Results for system hazard rate $\left(\mathrm{yr}^{-1}\right)$ with restricted beta distribution for $f_{f}$

\begin{tabular}{|l|l|l|l|l|}
\hline $\mathrm{h}(\mathrm{t}$, size $)$ & $5^{\text {th }}$ & Median & Mean & $9^{\text {th }}$ \\
\hline$h(1,0.1)$ & $2.1 \mathrm{E}-10$ & $1.4 \mathrm{E}-8$ & $4.0 \mathrm{E}-7$ & $1.4 \mathrm{E}-6$ \\
\hline$h((10,0.1)$ & $2.5 \mathrm{E}-9$ & $1.8 \mathrm{E}-7$ & $4.6 \mathrm{E}-6$ & $1.6 \mathrm{E}-5$ \\
\hline$h((40,0.1)$ & $1.3 \mathrm{E}-8$ & $9.5 \mathrm{E}-7$ & $2.1 \mathrm{E}-5$ & $8.3 \mathrm{E}-5$ \\
\hline$h((100,0.1)$ & $3.7 \mathrm{E}-8$ & $2.7 \mathrm{E}-6$ & $5.0 \mathrm{E}-5$ & $2.1 \mathrm{E}-4$ \\
\hline$h((1,10)$ & $3.4 \mathrm{E}-12$ & $3.4 \mathrm{E}-10$ & $1.4 \mathrm{E}-8$ & $4.2 \mathrm{E}-8$ \\
\hline$h((10,10)$ & $2.2 \mathrm{E}-10$ & $2.55 \mathrm{E}-8$ & $1.0 \mathrm{E}-6$ & $3.3 \mathrm{E}-6$ \\
\hline$h((40,10)$ & $2.7 \mathrm{E}-9$ & $3.0 \mathrm{E}-7$ & $1.0 \mathrm{E}-5$ & $3.7 \mathrm{E}-5$ \\
\hline$h((100,10)$ & $1.1 \mathrm{E}-8$ & $1.2 \mathrm{E}-6$ & $3.1 \mathrm{E}-5$ & $1.3 \mathrm{E}-4$ \\
\hline
\end{tabular}

\section{C.1.7 Comparison of Results of Analytical Approach and OpenBugs Method}

When the SDB-O analysis started developing results using OpenBugs for the same problem that was solved in Section 5.2, differences were successfully indentified and resolved. Good agreement in the uncertainty distribution results for all the parameters up to and including the parameters that are input to the Markov model were achieved. In addition, when running point 
estimates through the ODEs both solution approaches provided excellent agreement in the calculated hazard rates. However, good agreement was not reached in the Monte Carlo results of most of the hazard rate parameters which are dependent on the solutions to the ODEs and the calculation of the hazard rates, even though the point estimates for these solutions compared very well.

The following steps were taken to achieve better agreement in the Monte Carlo using the traditional analytical approach SDB-A described in Section 2 and implemented in Section 5.2.

- Modified the distribution of the flaw fraction parameter $f_{F}$ so that Equations 5.5 and 5.6 in Section 5.2 were not dividing by numbers sampled from the distribution that approached zero. When this change was made good agreement on the parameters defined in these two equations.

- Both initial conditions and conditions at $t \rightarrow \infty$ were used to resolve coefficients (see Appendix A) so that they are only determined from the conditions at $t=0$. Somewhat different looking algebraic expressions were obtained. Three of the four coefficients $\left(C_{0}\right.$, $\mathrm{C}_{1}, \mathrm{C}_{3}$ ) were checked with sample data and found to have the same values as calculated using the previous solution, but $\mathrm{C}_{2}$ had significantly different results. This change turned out not to have a significant impact on the point estimate or Monte Carlo results except that this change eliminated a problem with the previous solution that some combinations of input parameters were producing negative values for the hazard rates.

- Recalculated the hazard rate equation and found that previous excel spreadsheets had omitted some terms.

- The previous ODE solution was based on the discriminant: $q^{3}+r^{2}<0$, where these parameters are defined in the solution to the ODEs found in my Markov model paper. Output parameters were verified in Crystal Ball model but found that none of the 100,000 samples were violated.

- Despite this effort, the significant differences between the SDB-A2 and SDB-O results for the hazard rate distributions were not significantly changed and in fact got slightly worse as shown in Table 5-4. More research is required.

The following trends are observed in the comparison:

- $\quad$ For the $\lambda_{F}$ and $\rho_{F}$ parameters that are input to the Markov model SDB-A (Section 5.2) means run from $3 \%$ to $8 \%$ below the corresponding SDB-O (Appendix C) values. The $95 \%$ percentile upper tails also track consistently lower in the SDB-A results. These small changes may be significantly amplified in the hazard rate solutions.

- For hazard rates at 1 year there is fairly close agreement especially for the smaller break size; but the differences appear to grow with increasing time.

- For the 100 year 10inch case, the difference in the means is a factor of 50 .

- The latest SDB-A results show a slight increase in the separation from the SDB-O results. 
Table C1-10 Comparison of Current Benchmark Results by SDB-O and SDB-A

\begin{tabular}{|c|c|c|c|c|c|c|c|c|}
\hline \multirow[b]{2}{*}{ Parameter } & \multirow[b]{2}{*}{ Version\# } & \multicolumn{7}{|c|}{ Monte Carlo Results } \\
\hline & & 5th & 50th & Mean & 95th & $\begin{array}{c}\text { RF- } \\
\text { low** }\end{array}$ & $\begin{array}{c}\text { RF- } \\
\text { high*** }\end{array}$ & $\begin{array}{l}\text { Mean Ratio } \\
\text { Comparison } \\
\text { with SDB-O }\end{array}$ \\
\hline \multirow[t]{2}{*}{$\lambda_{\mathrm{F}}=\lambda f_{L} / f_{f}$} & SDB-O & $2.80 \mathrm{E}-06$ & 7.40E-05 & $4.20 \mathrm{E}-04$ & $1.60 \mathrm{E}-03$ & $2.64 \mathrm{E}+01$ & $2.16 \mathrm{E}+01$ & \\
\hline & SDB-A & $2.92 \mathrm{E}-06$ & $7.46 \mathrm{E}-05$ & $4.00 \mathrm{E}-04$ & $1.55 \mathrm{E}-03$ & $2.56 \mathrm{E}+01$ & $2.08 \mathrm{E}+01$ & 0.952 \\
\hline \multirow{2}{*}{$\rho_{\mathrm{F}}(0.1-\mathrm{in})}$. & SDB-O & $2.60 \mathrm{E}-06$ & $3.00 \mathrm{E}-05$ & $1.30 \mathrm{E}-04$ & $5.10 \mathrm{E}-04$ & $1.15 \mathrm{E}+01$ & $1.70 \mathrm{E}+01$ & \\
\hline & SDB-A & $2.62 \mathrm{E}-06$ & $3.03 \mathrm{E}-05$ & $1.27 \mathrm{E}-04$ & $4.86 \mathrm{E}-04$ & $1.16 \mathrm{E}+01$ & $1.60 \mathrm{E}+01$ & 0.976 \\
\hline \multirow[t]{2}{*}{$\rho_{\mathrm{F}}(10$-in. $)$} & SDB-O & $2.30 \mathrm{E}-09$ & $5.10 \mathrm{E}-08$ & $4.85 \mathrm{E}-07$ & $1.60 \mathrm{E}-06$ & $2.22 \mathrm{E}+01$ & $3.14 \mathrm{E}+01$ & \\
\hline & SDB-A & $2.26 \mathrm{E}-09$ & $5.02 \mathrm{E}-08$ & $4.48 \mathrm{E}-07$ & $1.54 \mathrm{E}-06$ & $2.22 \mathrm{E}+01$ & $3.06 \mathrm{E}+01$ & 0.923 \\
\hline \multirow[t]{2}{*}{$\mathrm{h}(1,0.1)^{*}$} & SDB-O & $2.10 \mathrm{E}-10$ & $1.40 \mathrm{E}-08$ & $4.00 \mathrm{E}-07$ & $1.40 \mathrm{E}-06$ & $6.67 \mathrm{E}+01$ & $1.00 \mathrm{E}+02$ & \\
\hline & SDB-A & $2.06 \mathrm{E}-10$ & $1.46 \mathrm{E}-08$ & $3.66 \mathrm{E}-07$ & $1.28 \mathrm{E}-06$ & $7.07 E+01$ & $8.79 E+01$ & 0.914 \\
\hline \multirow[t]{2}{*}{$\mathrm{h}((10,0.1)$} & SDB-O & $2.50 \mathrm{E}-09$ & $1.80 \mathrm{E}-07$ & $4.60 \mathrm{E}-06$ & $1.60 \mathrm{E}-05$ & $7.20 \mathrm{E}+01$ & $8.89 \mathrm{E}+01$ & \\
\hline & SDB-A & $1.69 \mathrm{E}-09$ & $1.19 \mathrm{E}-07$ & $2.81 \mathrm{E}-06$ & $1.01 \mathrm{E}-05$ & $7.02 E+01$ & $8.49 E+01$ & 0.610 \\
\hline \multirow[t]{2}{*}{$\mathrm{h}(40,0.1)$} & SDB-O & $1.30 \mathrm{E}-08$ & $9.50 \mathrm{E}-07$ & $2.10 \mathrm{E}-05$ & $8.30 \mathrm{E}-05$ & $7.31 \mathrm{E}+01$ & $8.74 \mathrm{E}+01$ & \\
\hline & SDB-A & $3.28 \mathrm{E}-09$ & $2.35 \mathrm{E}-07$ & $5.18 \mathrm{E}-06$ & $1.94 \mathrm{E}-05$ & $7.16 \mathrm{E}+01$ & $8.24 \mathrm{E}+01$ & 0.247 \\
\hline \multirow[t]{2}{*}{$\mathrm{h}(100,0.1)$} & SDB-O & $3.70 \mathrm{E}-08$ & $2.70 \mathrm{E}-06$ & $5.00 \mathrm{E}-05$ & $2.10 \mathrm{E}-04$ & $7.30 \mathrm{E}+01$ & $7.78 \mathrm{E}+01$ & \\
\hline & SDB-A & $3.58 \mathrm{E}-09$ & $2.61 \mathrm{E}-07$ & $5.66 \mathrm{E}-06$ & $2.15 \mathrm{E}-05$ & $7.28 \mathrm{E}+01$ & $8.26 \mathrm{E}+01$ & 0.113 \\
\hline \multirow[t]{2}{*}{$\mathrm{h}(1,10)$} & SDB-O & $3.40 \mathrm{E}-12$ & $3.40 \mathrm{E}-10$ & $1.40 \mathrm{E}-08$ & $4.20 \mathrm{E}-08$ & $1.00 \mathrm{E}+02$ & $1.24 \mathrm{E}+02$ & \\
\hline & SDB-A & $3.09 \mathrm{E}-12$ & $2.95 \mathrm{E}-10$ & $1.02 \mathrm{E}-08$ & $3.33 \mathrm{E}-08$ & $9.52 \mathrm{E}+01$ & $1.13 \mathrm{E}+02$ & 0.731 \\
\hline \multirow[t]{2}{*}{$\mathrm{h}(10,10)$} & SDB-O & $2.20 \mathrm{E}-10$ & $2.55 \mathrm{E}-08$ & $1.00 \mathrm{E}-06$ & $3.30 \mathrm{E}-06$ & $1.16 \mathrm{E}+02$ & $1.29 \mathrm{E}+02$ & \\
\hline & SDB-A & $6.68 \mathrm{E}-11$ & 7.03E-09 & $2.58 \mathrm{E}-07$ & $8.27 \mathrm{E}-07$ & $1.05 \mathrm{E}+02$ & $1.18 \mathrm{E}+02$ & 0.258 \\
\hline \multirow[t]{2}{*}{$\mathrm{h}(40,10)$} & SDB-O & $2.70 \mathrm{E}-09$ & $3.00 \mathrm{E}-07$ & $1.00 \mathrm{E}-05$ & $3.70 \mathrm{E}-05$ & $1.11 \mathrm{E}+02$ & $1.23 \mathrm{E}+02$ & \\
\hline & SDB-A & $1.46 \mathrm{E}-10$ & $1.57 \mathrm{E}-08$ & $5.36 \mathrm{E}-07$ & $1.83 \mathrm{E}-06$ & $1.07 \mathrm{E}+02$ & $1.16 \mathrm{E}+02$ & 0.054 \\
\hline \multirow[t]{2}{*}{$\mathrm{h}(100,10)$} & SDB-O & $1.10 \mathrm{E}-08$ & $1.20 \mathrm{E}-06$ & $3.10 \mathrm{E}-05$ & $1.30 \mathrm{E}-04$ & $1.09 \mathrm{E}+02$ & $1.08 \mathrm{E}+02$ & \\
\hline & SDB-A & $1.62 \mathrm{E}-10$ & $1.76 \mathrm{E}-08$ & 5.89E-07 & $2.03 \mathrm{E}-06$ & $1.09 \mathrm{E}+02$ & $1.15 \mathrm{E}+02$ & 0.019 \\
\hline
\end{tabular}

${ }^{* * *}$ RF-Low $=95$ th $/ 50$ th

No conclusions for the differences in the Monte Carlo results between numerical solutions with service data SDB-O and updated analytical SDB-A results. All the possible issues with the original analytical solutions to the ODEs were addressed and found to be insignificant. More time will be required to resolve this numerical issue. The SDB-A results use Excel to calculate all the ODE solutions and the numerical precision of these calculations is not as good as that provided by the SDB-O method. There may be some differences in the way Crystal Ball generates random numbers from a distribution compared to the SDB-O method. Resolution of this question is left for further research on this topic.

\section{C.1.8 References}

[1] Plummer Martyn [et al.] CODA: Output analysis and diagnostics for MCMC. R package version 0.13-5. - 2010. 


\section{Appendix C Section 2}

\section{C.2 Benchmark Problem 1 Using Flowgraph Method}

\section{C.2.1 Introduction}

We describe an analysis of the RISMC Markov benchmark problem 1 using statistical flowgraphs. The state transition diagram, based on Figure 2 in reference [4], is shown in Figure C2-1 below. For notational convenience, we have numbered the states; the state names used in $(\mathrm{S}, \mathrm{F}, \mathrm{L}$, and $\mathrm{R})$ are shown below the diagram. Edges of the graph are labeled with the transition rates, which are considered to be constant (consistent with the fact that this is modeled as a Markov process). Rates are subject to uncertainty, however, which is accounted for by using Bayesian techniques.

Figure C2-1 Transition Diagram

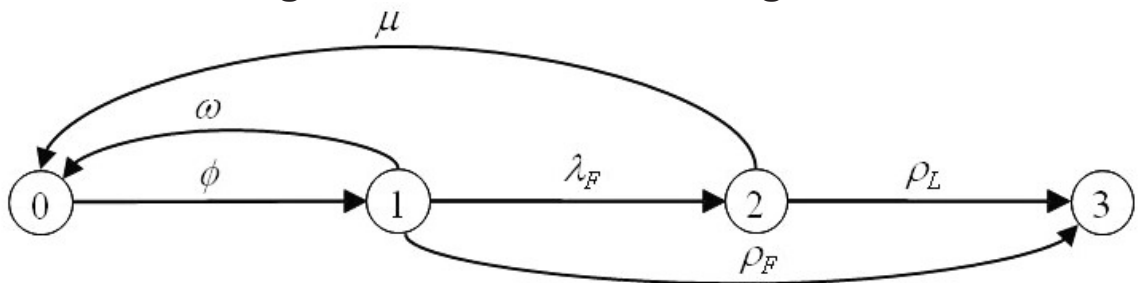

No detectable damage (S)
Detectable Flaw (F)
Detectable Leak (L)
Rupture

(R)

The benchmark problem itself, and the method of deriving Bayesian posterior distributions for the rate parameters, are described in detail in the benchmark papers described in Section 5.1 and 5.2 of the main report and SDB-O of Appendix $C$ and will not be repeated here. For leak and flaw detection probabilities ( $\mathrm{P}_{\mathrm{LD}}$ and $\left.\mathrm{P}_{\mathrm{FD}}\right)$, the analysis was performed with both SDB-A's triangular distribution and SDB-O's beta distribution; results are compared in Table C1-10 of Appendix $C$ to this paper. All symbolic and numerical calculations were done with Mathematica [4].

\section{C.2.2 Background on statistical flowgraphs}

The statistical flowgraph modeling framework is a body of theory and computational algorithms that has proven successful for modeling complex multistate systems in engineering applications ranging from aircraft maintenance scheduling to reliability of cellular telephone networks [3]. Systems are modeled as semi-Markov processes, a general class that includes many stochastic process models used in applications, such as Markov chains, continuous-time Markov processes, and Poisson processes. Typically flowgraph states represent conditions of degraded operation, and transitions represent repairs or failures. Usually we are interested in the progression from a fully operational state to an absorbing terminal state representing complete failure; however, flowgraph methods can be used to determine the time distribution for first passage between any pair of states, or the time-dependent probability of occupying a given transient state.

A statistical flowgraph is represented as a graph in which the edge labeling reflects the probabilities and time distributions for transitions between states. For computation, the holding 
time distribution for transitions from state $\mathrm{i}$ to $\mathrm{j}$ is represented by an integral transform of the probability density (pdf) fij (t), e.g., the Laplace transform Lij (s). An algebraic computation then yields the transform for the first passage distribution between states of interest, which is inverted analytically or numerically to give the first passage pdf (see the next section for an example). By placing priors on the transition densities, the computation can be carried out in a fully Bayesian way, giving the posterior predictive density (ppd) for the first passage distribution.

\section{C.2.3 Flowgraph analysis of the benchmark problem}

Since the benchmark problem is a Markov process, the transition rates labeling the edges of the graph in Figure C2-1 completely determine the transition probabilities and time distributions:

$$
\begin{array}{ll}
p_{01}=1, & p_{10}=\frac{\omega}{\omega+\lambda_{F}+\rho_{F}}, \quad p_{12}=\frac{\lambda_{F}}{\omega+\lambda_{F}+\rho_{F}}, \quad p_{13}=\frac{\rho_{F}}{\omega+\lambda_{F}+\rho_{F}} \\
p_{20}=\frac{\mu}{\mu+\rho_{L}}, & p_{23}=\frac{\rho_{L}}{\mu+\rho_{L}} ; \\
f_{01}(t)=\phi e^{-\phi t}, \quad f_{10}(t)=f_{12}(t)=f_{13}(t)=\left(\omega+\lambda_{F}+\rho_{F}\right) e^{-\left(\omega+\lambda_{F}+\rho_{F}\right) t}, \\
f_{20}(t)=f_{23}(t)=\left(\mu+\rho_{L}\right) e^{-\left(\mu+\rho_{L}\right) t} ; \\
L_{01}(s)=\frac{\phi}{\phi+s}, & L_{10}(s)=L_{12}(s)=L_{13}(s)=\frac{\omega+\lambda_{F}+\rho_{F}}{\omega+\lambda_{F}+\rho_{F}+s}, \\
& L_{20}(s)=L_{23}(s)=\frac{\mu+\rho_{L}+\rho_{F}}{\mu+\rho_{L}+\rho_{F}+s} .
\end{array}
$$

Solving the flowgraph for the first passage density $\mathrm{f}_{03^{*}}(\mathrm{t})$ (first passage from no detectable damage to rupture, regardless of the path) is based on these reduction rules:

1. The transmittance of each edge is the product of its transition probability and Laplace transform.

2. The transmittance of edges in parallel is the sum of the edge transmittances.

3. The transmittance of edges in series is the product of the edge transmittances.

4. Rules (1) and (2) are used recursively to determine the transmittance for transitions involving a feedback loop (e.g., the loop $0 \rightarrow 1 \rightarrow 0$ in Figure C2-1).

Repeated application of these rules yields the transmittance between the desired states, which is the Laplace transform of the first passage pdf. In this example, we have

$$
\begin{aligned}
L_{03^{*}}(s)= & L_{01}(s) p_{13} L_{13}(s)+L_{01}(s) p_{12} L_{12}(s) p_{23} L_{23}(s)+ \\
& L_{01}(s) p_{10} L_{10}(s) L_{03^{*}}(s)+L_{01}(s) p_{12} L_{12}(s) p_{20} L_{20}(s) L_{03^{*}}(s) \\
= & \frac{L_{01}(s)\left[p_{13} L_{13}(s)+p_{12} L_{12}(s) p_{23} L_{23}(s)\right]}{1-L_{01}(s)\left[p_{10} L_{10}(s)+p_{12} L_{12}(s) p_{20} L_{20}(s)\right]} .
\end{aligned}
$$

The recursive use of $\mathrm{L}_{03}{ }^{*}$ follows from the Markov property-after traversing the $0 \rightarrow 1$ loop or the $0 \rightarrow 1 \rightarrow 2 \rightarrow 0$ loop, the $0 \rightarrow 3$ passage time distribution has not changed. For more complex flowgraphs, an algorithm (Mason's rule) exists to determine the first passage transform. In some cases, the transform can be inverted analytically (e.g., by partial fractions and table lookup) to 
obtain the pdf; in addition, a fast, accurate algorithm exists for numerical inversion of any probability density transform [1]. The distribution function (CDF) can be derived by numeric integration of the density, or directly by inversion, using the fact that if $L i j(s)$ is the transform of the pdf fij $(t), s^{-1} L i j(s)$ is the transform of the CDF Fij $(t)$. The hazard rate function is $h i j(t)=f i j(t)$ / [1- Fij (t)].

\section{C.2.4 Bayesian flowgraph analysis}

For a Bayesian analysis of the flowgraph, repeated samples of the distribution parameters are taken (transition rates in this case), and the right-hand side of Equation C2-1 is computed for each sample; this provides a sample of Laplace transforms, which are inverted, and the inversions are averaged to yield a Bayes posterior predictive density, CDF, or hazard function for the first passage time. Credible intervals are derived using quantiles of the inversion points. For this exercise, 100,000 flowgraph solutions were used for numeric computations.

Selected hazard rates from this model are compared to SDB-O and SDB-A results in Table C21 below. Figures C2-2 and C2-3 below show log plots of the posterior hazard rates, with 95\% credible intervals, for $.1 "$ and $10 "$ ruptures. (these plots are based on samples with beta priors for repair rates $\mu$ and $\omega$ from SDB-O).

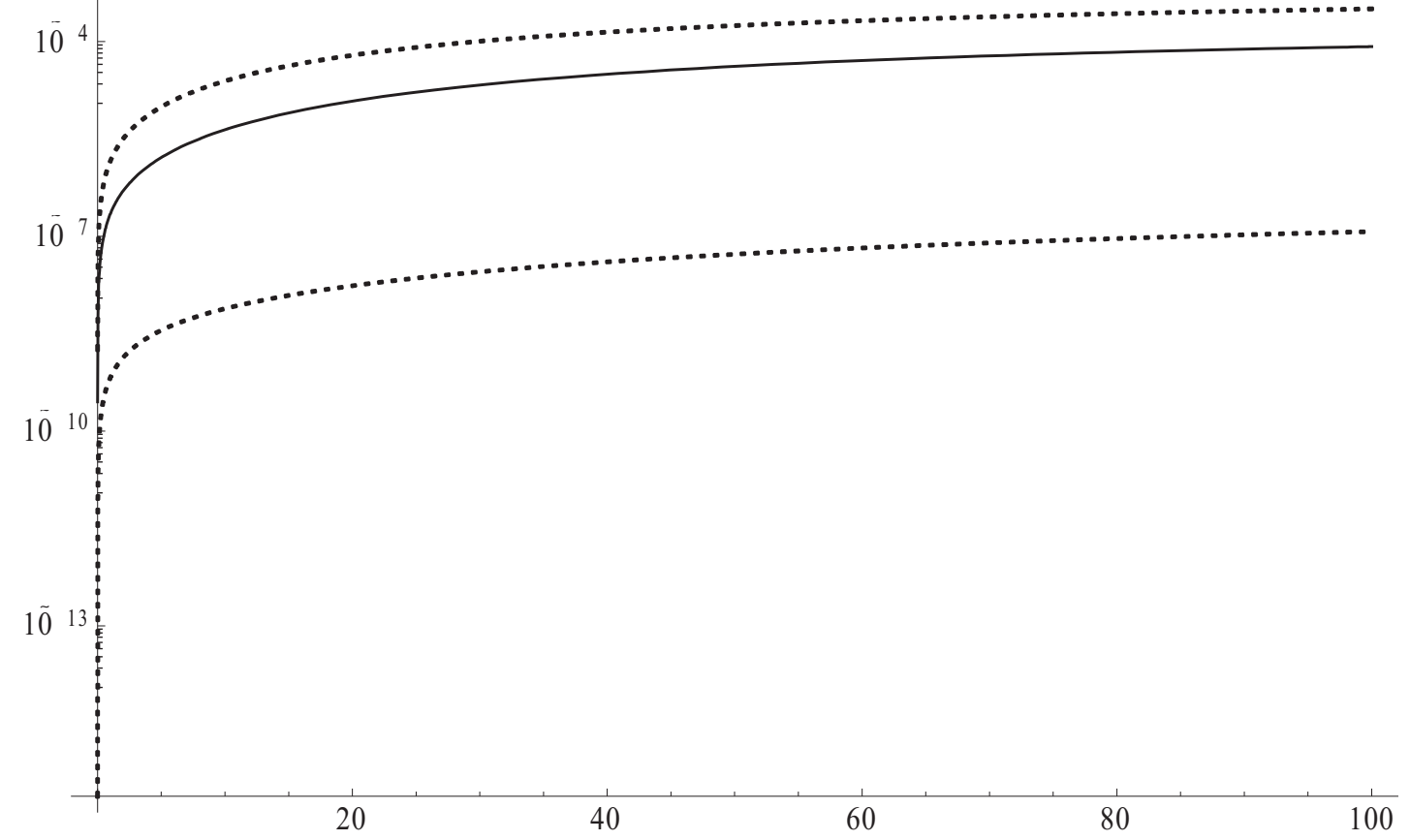

Figure C2-2 Log posterior mean hazard rate with $95 \%$ credible interval for 0.1 " rupture 


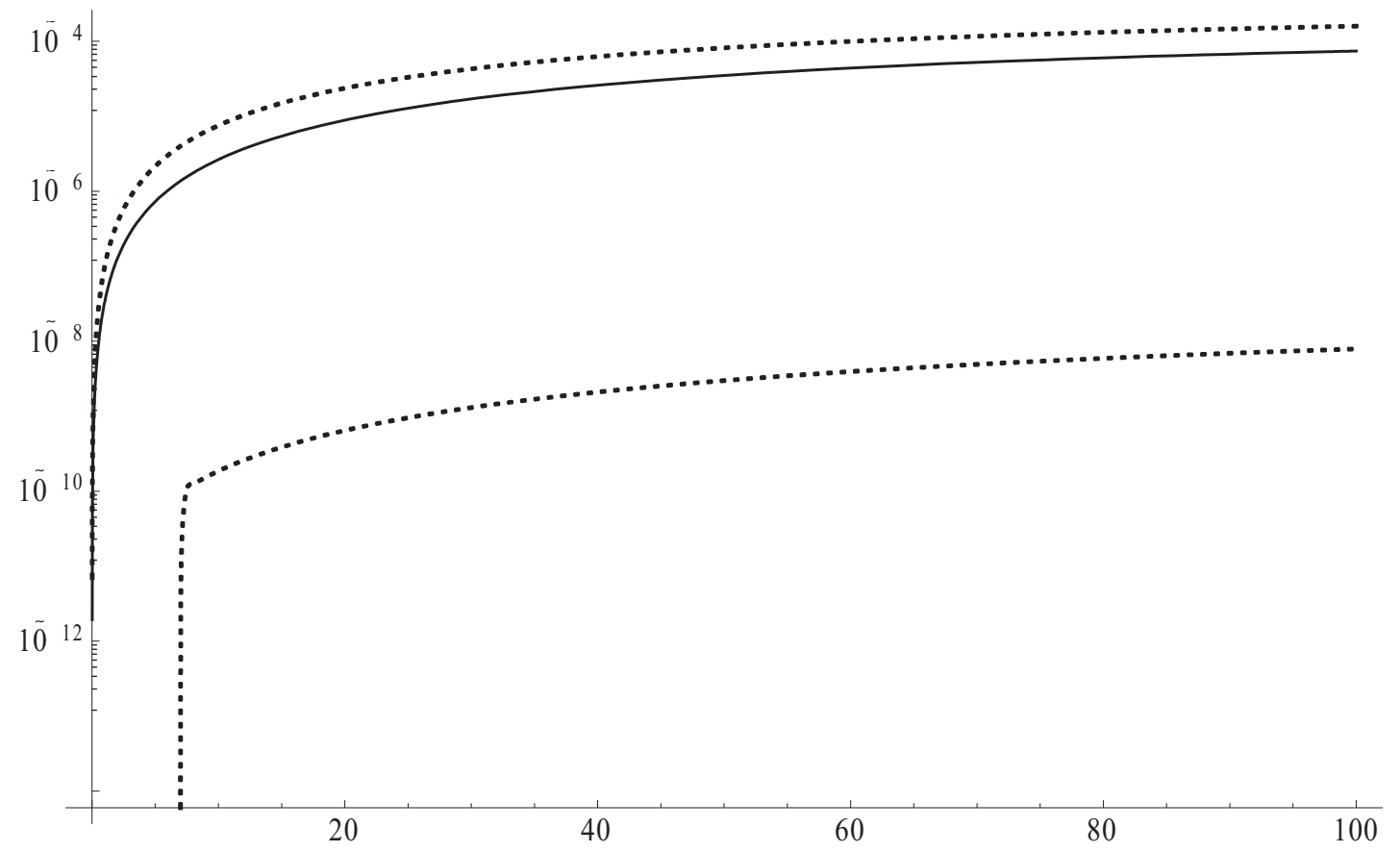

Figure C2-3 Log posterior mean hazard rate with $95 \%$ credible interval for 10 " rupture

\section{C.2.5 References}

[1] Abate J,, and Whitt, W. (1992), "The Fourier-series method for inverting transforms of probability distributions." Operations Research 10, 5-88.

[2] Fleming, K. N. (2004), "Markov models for evaluating risk-informed in-service inspection strategies for nuclear power plant piping systems." Reliability Engineering \& System Safety 83, $27-45$.

[3] Huzurbazar, A. V. (2005), Flowgraph Models for Multistate Time-to-Event Data. Hoboken, $\mathrm{NJ}$ : Wiley-Interscience.

[4] Wolfram, S. (2003), The Mathematica Book, Cambridge: Cambridge University Press. 
Table C2-1 Comparison of parameter values

For hazard rate points, we have added the results using both the triangular and beta distributions for $\mathrm{P}_{\mathrm{LD}}$ and $\mathrm{P}_{\mathrm{FD}}$

\begin{tabular}{|c|c|c|c|c|c|c|c|c|}
\hline \multirow[b]{2}{*}{ Parameter } & \multirow[b]{2}{*}{ Version\# } & \multicolumn{7}{|c|}{ Monte Carlo Results } \\
\hline & & 5th & 50th & Mean & 95th & $\begin{array}{c}\text { RF- } \\
\text { low** }\end{array}$ & $\begin{array}{c}\text { RF- } \\
\text { high }^{* * *}\end{array}$ & $\begin{array}{l}\text { Mean Ratio } \\
\text { Comparison } \\
\text { with SDB-O }\end{array}$ \\
\hline \multirow{3}{*}{$\lambda_{\mathrm{F}}=\lambda f_{L} / f_{f}$} & SDB-O & $2.80 \mathrm{E}-06$ & $7.40 \mathrm{E}-05$ & $4.20 \mathrm{E}-04$ & $1.60 \mathrm{E}-03$ & $2.64 E+01$ & $2.16 \mathrm{E}+01$ & \\
\hline & SDB-A & $2.92 \mathrm{E}-06$ & $7.46 \mathrm{E}-05$ & $4.00 \mathrm{E}-04$ & $1.55 \mathrm{E}-03$ & $2.56 \mathrm{E}+01$ & $2.08 \mathrm{E}+01$ & 0.952 \\
\hline & SDB-F & $2.91 \mathrm{E}-06$ & $7.30 \mathrm{E}-05$ & 4.03E-04 & $1.59 \mathrm{E}-03$ & $2.51 \mathrm{E}+01$ & $2.18 \mathrm{E}+01$ & 0.960 \\
\hline \multirow[t]{3}{*}{$\rho_{\mathrm{F}}(0.1-\mathrm{in})}$. & SDB-O & $2.60 \mathrm{E}-06$ & $3.00 \mathrm{E}-05$ & $1.30 \mathrm{E}-04$ & $5.10 \mathrm{E}-04$ & $1.15 \mathrm{E}+01$ & $1.70 \mathrm{E}+01$ & \\
\hline & SDB-A & $2.62 \mathrm{E}-06$ & $3.03 \mathrm{E}-05$ & $1.27 \mathrm{E}-04$ & $4.86 \mathrm{E}-04$ & $1.16 \mathrm{E}+01$ & $1.60 \mathrm{E}+01$ & 0.976 \\
\hline & SDB-F & $2.52 \mathrm{E}-06$ & 2.96E-05 & 1.26E-04 & $4.89 \mathrm{E}-04$ & $1.17 \mathrm{E}+01$ & $1.65 E+01$ & 0.969 \\
\hline \multirow{3}{*}{$\rho_{\mathrm{F}}(10-\mathrm{in})}$. & SDB-O & $2.30 \mathrm{E}-09$ & $5.10 \mathrm{E}-08$ & $4.85 \mathrm{E}-07$ & 1.60E-06 & $2.22 \mathrm{E}+01$ & $3.14 \mathrm{E}+01$ & \\
\hline & SDB-A & $2.26 \mathrm{E}-09$ & $5.02 \mathrm{E}-08$ & $4.48 \mathrm{E}-07$ & $1.54 \mathrm{E}-06$ & $2.22 \mathrm{E}+01$ & $3.06 \mathrm{E}+01$ & 0.923 \\
\hline & SDB-F & $2.16 \mathrm{E}-09$ & 4.94E-08 & $4.82 \mathrm{E}-07$ & $1.56 \mathrm{E}-06$ & $2.29 E+01$ & $3.16 \mathrm{E}+01$ & 0.994 \\
\hline \multirow{4}{*}{$\mathrm{h}(1,0.1)^{*}$} & SDB-O & $2.10 \mathrm{E}-10$ & $1.40 \mathrm{E}-08$ & $4.00 \mathrm{E}-07$ & $1.40 \mathrm{E}-06$ & $6.67 \mathrm{E}+01$ & $1.00 \mathrm{E}+02$ & \\
\hline & SDB-A & $2.06 \mathrm{E}-10$ & $1.46 \mathrm{E}-08$ & $3.66 \mathrm{E}-07$ & $1.28 \mathrm{E}-06$ & $7.07 \mathrm{E}+01$ & $8.79 \mathrm{E}+01$ & 0.914 \\
\hline & SDB-FT & $2.16 \mathrm{E}-10$ & 1.49E-08 & $3.78 \mathrm{E}-07$ & $1.38 \mathrm{E}-06$ & $6.90 \mathrm{E}+01$ & $9.26 \mathrm{E}+01$ & 0.945 \\
\hline & SDB-FB & $2.16 \mathrm{E}-10$ & 1.49E-08 & $3.78 \mathrm{E}-07$ & $1.38 \mathrm{E}-06$ & $6.90 \mathrm{E}+01$ & $9.26 \mathrm{E}+01$ & 0.945 \\
\hline \multirow{4}{*}{$\mathrm{h}((10,0.1)$} & SDB-O & $2.50 \mathrm{E}-09$ & $1.80 \mathrm{E}-07$ & $4.60 \mathrm{E}-06$ & $1.60 \mathrm{E}-05$ & $7.20 \mathrm{E}+01$ & $8.89 \mathrm{E}+01$ & \\
\hline & SDB-A & $1.69 \mathrm{E}-09$ & $1.19 \mathrm{E}-07$ & $2.81 \mathrm{E}-06$ & $1.01 \mathrm{E}-05$ & $7.02 \mathrm{E}+01$ & $8.49 \mathrm{E}+01$ & 0.610 \\
\hline & SDB-FT & $2.99 \mathrm{E}-09$ & $2.01 \mathrm{E}-07$ & $4.45 \mathrm{E}-06$ & $1.77 \mathrm{E}-05$ & $6.72 \mathrm{E}+01$ & $8.81 \mathrm{E}+01$ & 0.967 \\
\hline & SDB-FB & $2.98 \mathrm{E}-09$ & $2.00 \mathrm{E}-07$ & 4.43E-06 & 1.76E-05 & $6.71 \mathrm{E}+01$ & $8.80 \mathrm{E}+01$ & 0.963 \\
\hline \multirow{4}{*}{$\mathrm{h}(40,0.1)$} & SDB-O & $1.30 \mathrm{E}-08$ & $9.50 \mathrm{E}-07$ & $2.10 \mathrm{E}-05$ & $8.30 \mathrm{E}-05$ & $7.31 \mathrm{E}+01$ & $8.74 \mathrm{E}+01$ & \\
\hline & SDB-A & $3.28 \mathrm{E}-09$ & $2.35 \mathrm{E}-07$ & $5.18 \mathrm{E}-06$ & $1.94 \mathrm{E}-05$ & $7.16 \mathrm{E}+01$ & $8.24 \mathrm{E}+01$ & 0.247 \\
\hline & SDB-FT & 1.63E-08 & $1.12 \mathrm{E}-06$ & $2.18 \mathrm{E}-05$ & $9.23 \mathrm{E}-05$ & $6.87 \mathrm{E}+01$ & $8.24 \mathrm{E}+01$ & 1.038 \\
\hline & SDB-FB & $1.59 \mathrm{E}-08$ & $1.10 \mathrm{E}-06$ & $2.14 \mathrm{E}-05$ & $9.03 \mathrm{E}-05$ & $6.92 \mathrm{E}+01$ & $8.21 \mathrm{E}+01$ & 1.019 \\
\hline \multirow{4}{*}{$\mathrm{h}(100,0.1)$} & SDB-O & $3.70 \mathrm{E}-08$ & $2.70 \mathrm{E}-06$ & $5.00 \mathrm{E}-05$ & $2.10 \mathrm{E}-04$ & $7.30 \mathrm{E}+01$ & $7.78 \mathrm{E}+01$ & \\
\hline & SDB-A & $3.58 \mathrm{E}-09$ & $2.61 \mathrm{E}-07$ & $5.66 \mathrm{E}-06$ & $2.15 \mathrm{E}-05$ & $7.28 \mathrm{E}+01$ & $8.26 \mathrm{E}+01$ & 0.113 \\
\hline & SDB-FT & 4.76E-08 & $3.30 \mathrm{E}-06$ & $5.40 \mathrm{E}-05$ & 2.46E-04 & $6.93 E+01$ & $7.45 \mathrm{E}+01$ & 1.080 \\
\hline & SDB-FB & $4.51 \mathrm{E}-08$ & $3.12 \mathrm{E}-06$ & $5.13 \mathrm{E}-05$ & 2.34E-04 & $6.92 E+01$ & $7.50 \mathrm{E}+01$ & 1.026 \\
\hline \multirow{4}{*}{$\mathrm{h}(1,10)$} & SDB-O & $3.40 \mathrm{E}-12$ & $3.40 \mathrm{E}-10$ & $1.40 \mathrm{E}-08$ & $4.20 \mathrm{E}-08$ & $1.00 \mathrm{E}+02$ & $1.24 \mathrm{E}+02$ & \\
\hline & SDB-A & $3.09 \mathrm{E}-12$ & $2.95 \mathrm{E}-10$ & $1.02 \mathrm{E}-08$ & $3.33 \mathrm{E}-08$ & $9.52 \mathrm{E}+01$ & $1.13 \mathrm{E}+02$ & 0.731 \\
\hline & SDB-FT & $0.00 \mathrm{E}+00$ & $3.63 \mathrm{E}-10$ & $1.30 \mathrm{E}-08$ & $4.22 \mathrm{E}-08$ & & $1.16 \mathrm{E}+02$ & 0.929 \\
\hline & SDB-FB & $0.00 \mathrm{E}+00$ & $3.62 \mathrm{E}-10$ & $1.30 \mathrm{E}-08$ & 4.22E-08 & & $1.17 \mathrm{E}+02$ & 0.929 \\
\hline \multirow[t]{4}{*}{$\mathrm{h}(10,10)$} & SDB-O & $2.20 \mathrm{E}-10$ & $2.55 \mathrm{E}-08$ & $1.00 \mathrm{E}-06$ & $3.30 \mathrm{E}-06$ & $1.16 \mathrm{E}+02$ & $1.29 \mathrm{E}+02$ & \\
\hline & SDB-A & $6.68 \mathrm{E}-11$ & $7.03 \mathrm{E}-09$ & $2.58 \mathrm{E}-07$ & $8.27 \mathrm{E}-07$ & $1.05 E+02$ & $1.18 \mathrm{E}+02$ & 0.258 \\
\hline & SDB-FT & $2.41 \mathrm{E}-10$ & $2.60 \mathrm{E}-08$ & $1.01 \mathrm{E}-06$ & $3.27 \mathrm{E}-06$ & $1.08 \mathrm{E}+02$ & $1.26 \mathrm{E}+02$ & 1.010 \\
\hline & SDB-FB & $2.40 \mathrm{E}-10$ & $2.59 \mathrm{E}-08$ & $1.00 \mathrm{E}-06$ & 3.25E-06 & $1.08 \mathrm{E}+02$ & $1.25 E+02$ & 1.000 \\
\hline \multirow[t]{4}{*}{$\mathrm{h}(40,10)$} & SDB-O & $2.70 \mathrm{E}-09$ & $3.00 \mathrm{E}-07$ & $1.00 \mathrm{E}-05$ & $3.70 \mathrm{E}-05$ & $1.11 \mathrm{E}+02$ & $1.23 \mathrm{E}+02$ & \\
\hline & SDB-A & $1.46 \mathrm{E}-10$ & $1.57 \mathrm{E}-08$ & $5.36 \mathrm{E}-07$ & $1.83 \mathrm{E}-06$ & $1.07 \mathrm{E}+02$ & $1.16 \mathrm{E}+02$ & 0.054 \\
\hline & SDB-FT & 2.82E-09 & 3.10E-07 & $1.03 \mathrm{E}-05$ & $3.72 \mathrm{E}-05$ & $1.10 \mathrm{E}+02$ & $1.20 \mathrm{E}+02$ & 1.030 \\
\hline & SDB-FB & $2.76 \mathrm{E}-09$ & 3.02E-07 & $1.01 \mathrm{E}-05$ & 3.63E-05 & $1.09 E+02$ & $1.20 \mathrm{E}+02$ & 1.010 \\
\hline \multirow[t]{4}{*}{$\mathrm{h}(100,10)$} & SDB-O & 1.10E-08 & $1.20 \mathrm{E}-06$ & $3.10 \mathrm{E}-05$ & $1.30 \mathrm{E}-04$ & $1.09 \mathrm{E}+02$ & $1.08 \mathrm{E}+02$ & \\
\hline & SDB-A & $1.62 \mathrm{E}-10$ & $1.76 \mathrm{E}-08$ & $5.89 \mathrm{E}-07$ & $2.03 \mathrm{E}-06$ & $1.09 \mathrm{E}+02$ & $1.15 \mathrm{E}+02$ & 0.019 \\
\hline & SDB-FT & 1.71E-08 & 1.25E-06 & $3.25 \mathrm{E}-05$ & 1.32E-04 & $7.31 \mathrm{E}+01$ & $1.06 \mathrm{E}+02$ & 1.048 \\
\hline & SDB-FB & $1.10 \mathrm{E}-08$ & $1.18 \mathrm{E}-06$ & $3.08 \mathrm{E}-05$ & $1.26 \mathrm{E}-04$ & $1.07 E+02$ & $1.07 \mathrm{E}+02$ & 0.994 \\
\hline
\end{tabular}




\section{APPENDIX D}

Implementation of the Proportional Hazards Solution of the Physics Model

D - 1 


\section{D.1 Model Implementation Methodology}

This section describes the general form of the stochastic process that we are using to model the state of a dissimilar metal weld with SCC. It is hoped that this general form can accommodate any revisions we may need to make to the present model. A method for producing the numerical solution for the process is also given. In broad outline, the method is simple:

1. Convert the stochastic process to a Markov Process by enriching the state space.

2. Discretize the state space of the Markov Process so it becomes a Markov Chain. The Markov Chain will be an approximation to the Markov Process, with the approximation becoming more exact as the state space is discretized more finely.

3. Numerically calculate the state space probability vector, $U(t)$, for the Markov Chain.

\section{D.1.1 Proportional Hazards Model}

The term, Proportional Hazards Model (PHM) is used to identify the general stochastic process we are using to describe the state of a dissimilar metal weld. This term is used because the process is not Markov, and the process has some similarity to proportional hazards survival models used in statistics. There may be ultimately be a more appropriate name for the process.

Let $X(t)$ represent a stochastic process that describes the state of the weld of interest at time $t$. At time $t, X$ will take on one value from a discrete set of states denoted by $(S 1, S 2 \ldots S n)$. For example, our present model has six members in the state space: (S, M, C, R, D, L). The general stochastic process we will construct is defined by two inputs, 1) an initial state-space probability vector, $\mathrm{U}_{0}$, and 2) a transition function, $\Lambda(\mathrm{T})$.

The initial state-space vector defines the distribution on $\mathrm{X}(0)$. That is;

$$
U_{o}=(\operatorname{Pr}(X(0)=S 1), \operatorname{Pr}(X(0)=S 2) ; \ldots, \operatorname{Pr}(X(0)=S n))^{T}
$$

and the transition function describes the probability of transitions occurring in a small time interval $\delta . \Lambda(T)$ is actually matrix, with an element in $\Lambda$ denoted by $\lambda$ ij, or more specifically, $\lambda i j(T)$.

The argument in the function, $\mathrm{T}$, represents a time, but is different than $t$, which represents the time since the stochastic process was started. $\mathrm{T}$ is defined to be the time since the last transition in $X(t)$. Let us consider an example to clarify this definition. Suppose the stochastic process starts in state $S_{1}$ at time $t=0$, then transitions out of this state to $S_{5}$ at time $t=16$, and then transitions to state $S_{3}$ at $t=20$. Thus $\mathrm{T}=\mathrm{t}$ in the time interval $[0,16]$, and $\mathrm{T}=\mathrm{t}-16$ in the time interval $[16,20]$. As you might note from this example, we can't really refer to a value for $T$ without specifying an absolute time, $t$. A notation that would make this specific is to use $\mathrm{T}(\mathrm{t})$, which would represent the amount of time $X(t)$ has spent in its current state at time $t$. So here is a mathematical definition for $\mathrm{T}(\mathrm{t})$ :

$$
\tau(t)=t-\operatorname{Min}(z: z \leq t, X \text { is constant on }[z, t])
$$

The distribution of $X(t)$ is defined in terms of conditional distribution $\operatorname{Pr}(X(t+\delta) \mid X(t))$, which closely resembles the method used to define a Markov Process;

$$
\operatorname{Pr}(X(t+\delta)=S i \mid X(t)=S j)=\lambda i j(\tau(t)) \delta
$$


At this point, the reader may question whether or not this formula uniquely determines the distribution of $X(t)$; To calculate these conditional probabilities, one requires $T(t)$, but as one can see from its definition, $X(t)$ is required to determine $T(t)$. A little thought should convince us that all is well because at time $t$, we have defined $X(t)$ up to $t$ and hence can determine $T(t)$. From this equation, we can see that $X(t)$ only becomes a Markov Chain when $\Lambda(\mathrm{T})$ is constant (does not depend upon $\mathrm{T}$ ).

\section{D.1.2 State Space Enrichment}

Even though $\mathrm{X}(\mathrm{t})$ is not a Markov Process, it can be embedded into another stochastic process that is Markov. Before describing the new stochastic process, it is necessary to discuss what is meant by a stochastic process and a Markov process. A stochastic process $Y(t)$ may have a state space that is much more complicated than the discrete 6-state space we have defined for the dissimilar metal weld model. Specifically;

- $\quad Y$ may represent a vector of state variables $Y(t)=\left(Y_{1}(t) ; Y_{2}(t), \ldots Y_{m}(t)\right)$

- Some components $Y$ may be discrete, while others may represent continuous variables.

The important points about a stochastic process with a more complicated state space are these:

- A Markov Property can be defined for this sort of stochastic process. If the stochastic process obeys the Markov Property, it is called a Markov Process.

- If the Markov Property holds for $Y(t)$, then the distribution of $Y(t)$ is determined by the conditional probabilities $\operatorname{Pr}(Y(t+d) \mid Y(t))$.

- If the all the continuous variables in the state space of a Markov Process are discretized, then it becomes a Markov Chain, with a transition matrix defined by;

$$
\lambda i j \delta=\operatorname{Pr}(Y(t+\delta)=S i \mid Y(t)=S j)
$$

So let us construct the new stochastic process, $Y(t)$, from our original $X(t)$ that will be a Markov Process. The construction is quite simple. Define $Y(t)$ as:

$$
Y(t)=\left[\begin{array}{l}
Y 1(t) \\
Y 2(t)
\end{array}\right]=\left[\begin{array}{l}
X(t) \\
\tau(t)
\end{array}\right]
$$

To actually show that this is a Markov Process, one would have to show that it obeys the Markov Property. We will go through a sloppy version of this proof by writing down the formula for the conditional probability $\operatorname{Pr}(Y(t+\delta) \mid Y(t))$ for the discrete version of $Y(t)$ and observing that it relies only on $Y(t)$.

Discretize residence time into intervals of $\delta$ so that $\mathrm{T}$ can take on the values $\mathrm{T}_{\mathrm{k}}=\delta \mathrm{k}$, and the discretized state space of $Y$ can be represented by the ordered pair $\left(\mathrm{Si}, \mathrm{T}_{\mathrm{k}}\right)$. An element in the new transition matrix, $\gamma$, is given by:

$$
\gamma_{\mathrm{I}, \mathrm{k}, \mathrm{j}, \mathrm{k}}=\text { Probability of jumping from }\left(\mathrm{Sj}, \tau_{\mathrm{k}^{\prime}}\right) \text { to }\left(\mathrm{Si} ; \tau_{\mathrm{k}}\right)
$$

By applying Equations D-2 and D-3, one can show $Y(t)$ has the following non-zero transition probabilities; 


$$
\begin{gathered}
\gamma_{i, 0, j, k^{\prime}}=\operatorname{Pr}(X(t+\delta)=S i, \tau(t+\delta)=0 \mid X(t)=S j, ; \tau(t)=k) \\
=\lambda \mathrm{ij}(\delta \mathrm{k}) \delta
\end{gathered}
$$

for $\mathrm{i} \neq \mathrm{k}$ and,

$$
\begin{aligned}
\gamma_{j, k+1, j, k} & =\operatorname{Pr}\left(X(t+\delta)=S_{j,} \tau(t+\delta)=\delta(k+1) \mid X(t)=S_{j}, \tau(t)=\delta k\right) \\
& =1-\lambda_{\mathrm{jj}}(\delta \mathrm{k}) \delta
\end{aligned}
$$

All other transitions in $\gamma_{i, k, j, k}$ are zero.

\section{D.1.3 Definition of $\Lambda(\tau)$ for Current Problem}

For the current application, the transitions $\wedge$ relate to the parameters in the main report as follows:
$\lambda_{M, S}=\varphi_{1}$
$\lambda_{S, M}=\omega_{1}$
$\lambda_{C, M}=\varphi_{3}$
$\lambda_{D, M}=\varphi_{2}$
$\lambda_{S, C}=\omega_{3}$
$\lambda_{R, C}=\varphi_{6}$
$\lambda_{S, D}=\omega_{2}$
$\lambda_{L, D}=\varphi_{4}$
$\lambda_{S, L}=\omega_{4}$
$\lambda_{R, L}=\varphi_{5}$ 